Universidade de São Paulo

Instituto de Física

\title{
Estudos das propriedades estruturais e ópticas de vidros teluritos
}

\author{
Júlia Maria Giehl \\ Orientador: Prof. Dr. Walter Maigon Pontuschka \\ Tese de doutorado apresentada ao Instituto \\ de Física para a obtenção do título de Doutor \\ em Ciências
}

Banca Examinadora

Prof. Dr. Walter Maigon Pontuschka (IFUSP)

Profa. Dra. Rosangela Itri (IFUSP)

Profa. Dra. Ana Regina Blak (IFUSP)

Prof. Dr. Enver Fernandez Chillcce (UNICAMP)

Prof. Dr. Mauro Luciano Baesso (UEM) 
FICHA CATALOGRÁFICA

Preparada pelo Serviço de Biblioteca e Informação do Instituto de Física da Universidade de São Paulo

Giehl, Júlia Maria

Estudos das propriedades estruturais e ópticas de vidros teluritos - Sẫo Paulo, 2011.

Tese(Doutorado) - Universidade de Sẫo Paulo.

In stituto de Física - Departamento de Física Geral

Orientador. Prof ${ }^{\circ}$ Dr ${ }^{\circ}$ Walter Maigon Pontuschka

Área de Concentraçẫo: Física

Unitermos: 1.Física da Matéria Condensada;

2.Física Experimental; 3. Vidros Teluritos

4.Propriedades ópticas e estruturais de vidros

USP/IF/SBI-016/2011 
Dedico este longo trabalho aos meus pais, Júlio e Elena e ao meu marido Matheus; com amor, admiração e gratidão. 


\section{Agradecimentos}

Ao meu orientador Prof. Dr. Walter Maigon Pontuschka pelo trabalho em equipe, dedicação e paciência ao longo do desenvolvimento deste projeto.

Aos meus pais, Júlio e Elena, por mostrar que qualquer dificuldade pode ser vencida e ao meu irmão Luís Augusto.

Ao Matheus e ao Billy pelo apoio incondicional.

Ao Odilon, Zilah, Thiago, Lucas, Tati e agregados felinos por proporcionarem excelentes momentos e me receberem muito bem em sua família.

Aos grandes amigos Marcelo e Flávia por proporcionarem momentos agradáveis durante o intervalo de trabalho.

À Profa. Dra. Zélia, pelo apoio e colaboração no desenvolvimento deste projeto.

Ao Dr. Enver pela grande ajuda na produção de amostras e operação de alguns equipamentos.

À Profa. Dra. Shirley Schreier e a técnica Edilaine Linares pela utilização do equipamento de ressonância paramagnética eletrônica, do departamento de química.

Ao Prof. Dr. Niklaus Ursus Wetter pela utilização do sistema de lapidação e polimento.

Ao Prof. Dr. Luiz Carlos Barbosa por abrir as portas de seu laboratório e pela colaboração na realização deste projeto.

À Prfa. Dra. Ana Regina Blak por ceder o equipamento de correntes de despolarização termicamente estimulada e pelas valiosas discussões do assunto.

Ao Prof. Dr. Shigueo Watanabe pelo equipamento de absorção óptica e termoluminescência.

Ao engenheiro Carlos G. da Silveira e à engenheira Elizabeth S. Ribeiro do CTR-IPEN pela colaboração nas irradiações das amostras. 
Ao Prof. Dr. Mikiya Muramatsu e aos colegas do Laboratório de Óptica e Sistemas Amorfos.

À Profa. Dra. Sarah Alves e ao Dr. Diogo Soga pelo auxílio nas medidas de Varredura $Z$ e pelas valiosas discussões destes resultados.

Ao prof. Dr. Pedro Kyohara, do Laboratório de Microscopia Eletrônica de Transmissão do IFUSP, pelas medidas de Microscopia Eletrônica de Transmissão.

À Simone Perche de Toledo, do Laboratório de Microscopia Eletrônica de Transmissão, por realizar e analisar as medidas de Microscopia Eletrônica de Transmissão.

Ao desenhista Carlos Eduardo Franco de Siqueira, pelos excelentes desenhos que constam nesta tese.

As secretárias do departamento Dirce, Fátima e Silvana, pela grande colaboração e amizade ao longo da realização deste projeto.

À FAPESP pelo apoio financeiro.

Agradeço a todos que ajudaram de maneira direta ou indireta na realização deste trabalho. 
"Lançai na fornalha essa vil areia que pisais aos pés, deixai aí fundir-se a ferver, e tornar-se cristal esplêndido; é graças a ela que Galileu e Newton descobriram os astros."

Victor Hugo 


\section{Resumo}

Vidros teluritos são considerados fortes candidatos para aplicações em lasers e óptica não linear devido a importantes características, como o elevado índice de refração, baixa energia de fônons, baixa temperatura de transição vítrea e sua fácil preparação.

Neste trabalho foram produzidas amostras dos sistemas vítreos $\mathrm{TeO}_{2}$ $\mathrm{ZnO}-\mathrm{Na}_{2} \mathrm{O}, \mathrm{TeO}_{2}-\mathrm{Nb}_{2} \mathrm{O}_{5}-\mathrm{Na}_{2} \mathrm{O}$ e $\mathrm{Te}_{2} \mathrm{O}-\mathrm{Na}_{2} \mathrm{O}$ incluindo ou não dopagens de $\mathrm{AgNO}_{3}$ para estudos estruturais e ópticos.

As propriedades estruturais e os mecanismos de recombinação destes vidros foram estudados por meio das técnicas de ressonância paramagnética eletrônica, termoluminescência e correntes de despolarização termicamente estimuladas. Já as propriedades ópticas como o coeficiente de absorção linear, índice de refração linear e não linear foram estudadas por meio das técnicas de absorção óptica, acoplamento de prismas e varredura $Z$.

Foram ainda desenvolvidos estudos da precipitação de nanopartículas de prata para o sistema $\mathrm{TeO}_{2}-\mathrm{ZnO}-\mathrm{Na}_{2} \mathrm{O}$ com dopagens de $\mathrm{AgNO}_{3}$ com diferentes temperaturas de tratamento térmico. A caracterização das nanopartículas metálicas foi realizada por meio da técnica de absorção óptica auxiliada por microscopia eletrônica de transmissão e espectrometria de energia dispersiva.

Foram observadas por ressonância paramagnética eletrônica quatro respostas paramagnéticas dos vidros irradiados com raio $\mathrm{\gamma}$, sendo uma de natureza desconhecida e as outras três identificadas como $g_{1}, g_{2}$ e $g_{3}$ atribuídas respectivamente ao centro de buraco do telúrio e do oxigênio, centro de buraco do oxigênio terminal e centro de elétron do telúrio. Foi proposto ainda um modelo para explicar os mecanismos de formação destes centros. A partir dos resultados de termoluminescência observou-se que os processos de recombinação destes centros de defeitos são não radioativos.

Neste projeto foram estudados pela primeira vez na literatura os fenômenos de polarização e despolarização em vidros teluritos, com e sem irradiação gama, por meio da técnica de correntes de despolarização termicamente estimuladas.

Quanto às propriedades ópticas, foi investigada a influência da adição de prata dos sistemas vítreos $\mathrm{TeO}_{2}-\mathrm{ZnO}-\mathrm{Na}_{2} \mathrm{O}$ e $\mathrm{TeO}_{2}-\mathrm{Nb}_{2} \mathrm{O}_{5}-\mathrm{Na}_{2} \mathrm{O}$ em relação à 
energia do "gap", a cauda de Urbach, índice de refração linear e não linear. Nos resultados de varredura $Z$ do sistema vítreo $\mathrm{TeO}_{2}-\mathrm{Nb}_{2} \mathrm{O}_{5}-\mathrm{Na}_{2} \mathrm{O}$ foi observado o aumento da assimetria na curva com aumento da adição de $\mathrm{AgNO}_{3}$ Este fenômeno foi explicado por meio de uma adaptação do modelo de Sumi para processos não radiativos, responsáveis pelo aumento do caráter térmico do índice de refração não linear.

Por fim um modelo foi criado para explicar a precipitação de nanopartículas de prata na matriz vítrea $\mathrm{TeO}_{2}-\mathrm{ZnO}-\mathrm{Na}_{2} \mathrm{O}$ mediante tratamento térmico.

Palavras-chave: vidros teluritos, nanopartículas de prata, ressonância paramagnética eletrônica, centros de defeitos, correntes de despolarização termicamente estimuladas, varredura $Z$, índice de refração não linear, termoluminescência, absorção óptica, microscopia eletrônica de transmissão. 


\begin{abstract}
Tellurite glasses are considered powerful candidates for applications in lasers and nonlinear optics due to their important properties such as high refractive index, low phonon energy, relatively low glass transition temperature and easy glass production at room atmosphere.

In this work glass samples of the systems $\mathrm{ZnO}-\mathrm{Na}_{2} \mathrm{O}, \mathrm{TeO}_{2}-\mathrm{Nb}_{2} \mathrm{O}_{5}-\mathrm{Na}_{2} \mathrm{O}$ and $\mathrm{Te}_{2} \mathrm{O}-\mathrm{Na}_{2} \mathrm{O}$ were produced, including or not the $\mathrm{AgNO}_{3}$ doping for the structural and optical study purposes.

The structural properties and the recombination mechanisms of these glasses were studied by means of the techniques of electron paramagnetic resonance, thermoluminescence and thermally stimulated depolarization currents. The optical properties such as the optical linear absorption coefficient, linear and nonlinear refractive index were studied by means of the optical absorption techniques, prism coupling and Z-scan. Further studies were developed on the precipitation of silver nanoparticles embedded in the glass system $\mathrm{TeO}_{2}-\mathrm{ZnO}-\mathrm{Na}_{2} \mathrm{O}$ doped with $\mathrm{AgNO}_{3}$, by means of thermal treatments at different temperatures. The characterization of the metallic nanoparticles was carried out by optical absorption aided by transmission electron microscopy and dispersive energy spectroscopy.
\end{abstract}

Four paramagnetic responses were observed by electron paramagnetic resonance of the $y$-irradiated glasses, one not yet identified and the other three identified as $g_{0}, g_{1}$ and $g_{3}$ attributed respectively to the tellurium-oxygen hole center, non-bridging oxygen hole center and tellurium electron center. A model to explain the formation mechanisms of these centers was proposed. The thermoluminescence results indicated that the recombination processes of these centers are non-radiative.

This is the first study that deals with polarization and depolarization phenomena in tellurite glasses with and without gamma irradiation, by the technique of thermally stimulated depolarization currents.

In what regards the optical properties of the glass systems $\mathrm{TeO}_{2}-\mathrm{ZnO}-$ $\mathrm{Na}_{2} \mathrm{O}$ and $\mathrm{TeO}_{2}-\mathrm{Nb}_{2} \mathrm{O}_{5}-\mathrm{Na}_{2} \mathrm{O}$, the effect of the silver doping on the gap energy, Urbach tail, linear and nonlinear refractive indices were investigated. Through the Z-scan technique results of the glass system $\mathrm{TeO}_{2}-\mathrm{Nb}_{2} \mathrm{O}_{5}-\mathrm{Na}_{2} \mathrm{O}$, an 
increasing asymmetry of the curve, with increasing $\mathrm{AgNO}_{3}$ content was observed. This phenomenon was explained through an adaptation of Sumi's model for non-radiative processes, applied to a silver doped insulating glass, to explain the thermal character of the nonlinear refractive index.

Finally, a model was developed to explain the silver nanoparticles precipitation in the $\mathrm{TeO}_{2}-\mathrm{ZnO}-\mathrm{Na}_{2} \mathrm{O}$ glass matrix submitted to thermal treatment.

Keywords: tellurite glasses, silver nanoparticles, electron paramagnetic resonance, defect centers, thermally stimulated depolarization currents, Z-scan, nonlinear refractive index, thermoluminescence, optical absorption, transmission electron microscopy. 


\section{Lista de ilustrações}

Figura 1 - Unidades estruturais presentes nos vidros teluritos, dependendo da quantidade de oxigênio presente na sua composição química (Neov et al. [8]). Em (a) temos a bi-pirâmide trigonal, (b) $\mathrm{TeO}_{3+1}$ e em (c) pirâmide trigonal.

Figura 2 - a) Bi-pirâmide sendo a base sombreada a base comum às duas pirâmides, b) Bi-pirâmide $\mathrm{TeO}_{3+1}$ com um oxigênio se afastando dos demais e c) Pirâmide trigonal $\mathrm{TeO}_{3}$ com simetria $\mathrm{C}_{3 \mathrm{v}}$ 12

Figura 3 - Unidades estruturais presentes nos vidros teluritos com adição de $\mathrm{Li}_{2} \mathrm{O}[9]$. 13

Figura 4 - Gráfico das quantidades $\operatorname{Re}(n)-1$ e $\operatorname{Im}(n)$ em função da freqüência [2]. 24

Figura 5 - llustração dos poços de potencial de um material cristalino [3].......29 Figura 6 - llustração dos poços de potencial de um material amorfo [3] com flutuações de a) profundidade e b) largura.

Figura 7 - Esquema demonstrativo dos estados estendidos e localizados. A letra "A" representa regiões no qual o elétron é permitido e "P" uma região no qual ele é proibido. Para energias menores, "A" representa os estados localizados e a partir de $E_{c r}=E_{\mu}=E_{c}$ representa estados permitidos estendidos.

Figura 8 - Esquema demonstrativo da separação entre os limites $E_{v} e$ $\mathrm{E}_{\mathrm{c}}$ 31

Figura 9 - Esquema demonstrativo da banda de valência, da localização dos estados estendidos, localizados e da banda de condução. EF representa a energia de Fermi, $E_{o p t}^{i}$ a energia do gap de uma transição indireta, $E_{o p t}^{d}$ a energia do gap de uma transição direta e $E_{c r}=E_{\mu}=E_{c}$ representa o intervalo de energia no qual a mobilidade dos elétrons aumenta abruptamente. Para as energias $>E_{c r}$ observamos áreas localizadas proibidas (escuras) que diminuem gradualmente com o aumento da energia.

Figura 10 - Simulação realizada a partir dos dados experimentais obtidos das três regiões bem definidas. Neste esquema não foi incluída a correção $\mathrm{n}_{0} \mathrm{~h} v$ que leva em conta o caminho óptico a qual normalmente é desprezada na definição do $\alpha$. A linha cheia representa a variação do coeficiente de absorção 
ao longo de toda a cauda da banda de condução, assumindo $\mathrm{m}=\frac{1}{2}$ (região $\mathrm{A}$ representada por $\left.\alpha_{I_{d i r}}\right)$. No caso $m=2$ teríamos a linha cheia representada por $\mathrm{\alpha}_{\mathrm{I}_{\text {ind }}}$ nessa região.

Figura 11 - Exemplo da absorção óptica de um semicondutor de um filme fino de $\mathrm{Sb}_{2} \mathrm{~S}_{3}$ com as três regiões bem definidas para uma transição permitida [5].

Figura 12 - Ilustração da determinação do gap óptico pelo método de Jan Tauc, para uma transição permitida direta. Neste exemplo não foi incluída a correção $\mathrm{n}_{0} \mathrm{~h} v$ que leva em conta o caminho óptico que normalmente é desprezada na definição do coeficiente de absorção

Figura 13 - Modelo de bandas parabólicas de uma transição direta.

Figura 14 - Modelo de bandas parabólicas de uma transição indireta.

Figura 15 - Representação de um raio de luz apresenta uma trajetória curva, voltada para a região com o maior índice de refração [13]. 38

Figura 16 - Representação do efeito térmico que ocorre dentro da amostra..40 Figura 17 - Esquema do princípio básico de funcionamento da VZ no qual $D_{1} e$ $D_{2}$ são detectores e BS divisor de feixes [12] .40

Figura 18 - Esquema que representa a formação do vale-pico para $n_{2}>0 \ldots .41$

Figura 19 - Nanopartículas esféricas alongadas pela ação de uma tensão [8]. .48

Figura 20 - Nanopartículas de prata [11]. 48

Figura 21 - O gráfico acima representa picos de CDTE com diferentes concentrações de $\mathrm{Na}_{2} \mathrm{O}$. Curva A representa o vidro que contém (18 $\mathrm{Na}_{2} \mathrm{O}-82$ $\left.\mathrm{SiO}_{2}\right) \mathrm{mol} \%$, curva $\mathrm{B}$ representa o vidro $\left(4 \mathrm{Na}_{2} \mathrm{O}-96 \mathrm{SiO}_{2}\right) \mathrm{mol} \%$, curva $\mathrm{C} \mathrm{a}$ amostra $\left(10 \mathrm{Na}_{2} \mathrm{O}-90 \mathrm{SiO}_{2}\right)$ mol\% e a curva D (25 $\left.\mathrm{Na}_{2} \mathrm{O}-75 \mathrm{SiO}_{2}\right)$ mol\% [5].

Figura 22 - Espectro de CDTE do vidro $\left(25 \mathrm{Na}_{2} \mathrm{O}-75 \mathrm{SiO}_{2}\right)$ mol\% polarizado a $230 \mathrm{~K}$ por 10 minutos com $1,36 \times 10^{5} \frac{\mathrm{V}}{\mathrm{m}}$. Segue também a curva experimental do Teflon inserido entre o vidro e o eletrodo [6]. .54 
Figura 23 - Modelo dos sítios de íons alcalinos em vidros silicatos. Modelo de Agarwal e Day [6].

Figura 24 - Picos de CDTE com diferentes temperaturas de polarização [9].

Figura 25 - Picos antes e após a irradiação [9] .......................................56

Figura 26 - Diagrama da formação do par centro E' e OHC...........................60

Figura 27 - Formação do centro $E^{\prime}$ e do $\mathrm{OHC}^{\circ}$ em vidros silicatos, com o elétron aprisionado por um orbital vazio de uma vacância de oxigênio.

Figura 28 - Formação do centro $\mathrm{E}^{\prime}$ e do $\mathrm{OHC}^{\circ}$ por um cátion mais próximo modificador da rede vítrea

Figura 29 - Formação do E' e do SiOHC.

Figura 30 - Formação de centros de buracos de oxigênio [11]. a) Radical protonado do OHC "molhado" do NBO. b) Radical peroxil do $\mathrm{OHC}$ "seco"

Figura 31 - Espectro obtido por Prohaska [12].........................................64

Figura 32 - Almofariz e pilão de Ágata...................................................68

Figura 33 - Homogeneização da massa fundida com um bastão de quartzo. Ao lado do cadinho aparece o forno de radiofreqüência.....................................69

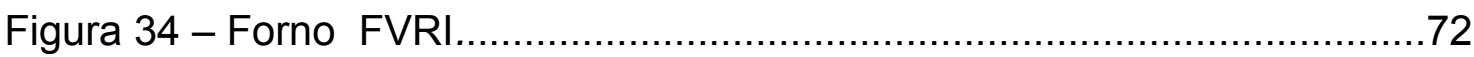

Figura 35 - Politriz Logitech, modelo Precision Lapping \& Machine PM

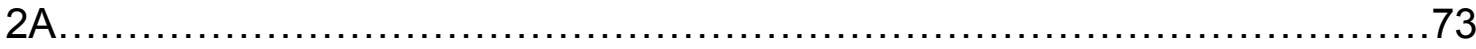

Figura 36 - Lapidadora (construída no IPEN)....................................... 74

Figura 37 - Amostras após o polimento................................................74

Figura 38 - Estudo dos efeitos do grão durante ATD do vidro TeZnLiBiCsCl [1] .76

Figura 39 - Estudo da influência do tamanho do grão no vidro TeWNaErCl e massa de $80 \mathrm{mg}[2]$ .77

Figura 40 - Estudo da influência da quantidade de massa nas medidas de ATD [2]. .77

Figura 41 - Efeito da sinterização do vidro telurito moído com grãos cujo tamanho é inferior a $62 \mu \mathrm{m}[2]$. .78

Figura 42 - Esquema simplificado de funcionamento do modelo Cary $500 \ldots . .79$

Figura 43 - Esquema simplificado de funcionamento do aparato experimental para as medidas de IRL 
Figura 44 - Equipamento utilizado para as medidas de IRL

Figura 45 - Esquema de montagem da VZ na escala de milissegundos: Ch chopper; L1-L3 lentes; Df - divisor de feixe; D1 e D2 - detectores; Ir - íris; O osciloscópio; Mc - microcomputador; A - amostra; Md - microdeslocador [3].

Figura 46 - Esquema experimental do equipamento de CDTE (esquerda). Representação do interior da câmara porta-amostra (direita)............................86

Figura 47 - Leitora do tipo Daybreak - 1100 Automated TL System...............88

Figura 48 - Esquema de funcionamento da leitora do tipo Daybreak - 1100

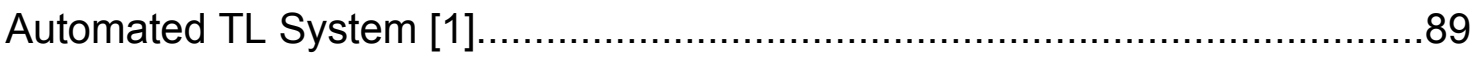

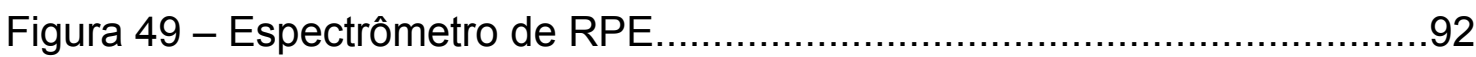

Figura 50 - Imagem real do sistema para medida da densidade usando o método baseado no princípio de Archimedes................................................93

Figura 51 - Foto do forno para polarização eletrotérmica................................95

Figura 52 - Foto do forno para polarização eletrotérmica onde aparece em detalhe o eletrodo inferior e a superfície onde é colocada a amostra...............96

Figura 53 - Foto do eletrodo superior fora do forno.........................................96

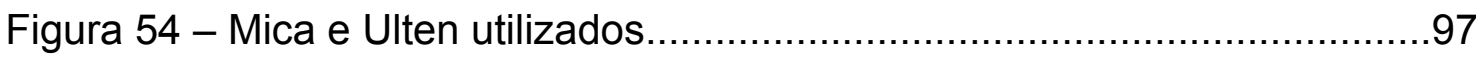

Figura 55 - Termograma ATD da amostra $A_{2}$ na forma monolítica...................98

Figura 56 - Termograma ATD da amostra $A_{2}$ em pó......................................99

Figura 57 - Espectro do coeficiente de absorção versus comprimento de onda das amostras $A_{2}, A_{3}, A_{4}$.e $A_{5}$. Todas as amostras foram recozidas a $320^{\circ} \mathrm{C}$ 101

Figura 58 - Espectro do coeficiente de absorção versus comprimento de onda das amostras $B_{2}, B_{3}$ e $B_{5}$ 102

Figura 59 - Espectro do coeficiente de absorção versus comprimento de onda da amostra $\mathrm{C}_{1}$ 102

Figura 60 - Espectro $(\alpha h v)^{1 / 2}$ versus hv para a determinação da energia do gap óptico para uma transição indireta permitida. 103

Figura 61 - Espectro do logaritmo natural do coeficiente de absorção da série de amostras A em função da energia. 105

Figura 62 - Espectro do logaritmo natural do coeficiente de absorção da amostra $A_{2}$ em função da energia para ilustrar a região $B$ 106 
Figura 63 - Espectro do coeficiente de absorção versus comprimento de onda das amostras $A_{3}$ e $A_{4}$, ambas tratadas a $400^{\circ} \mathrm{C}$ por duas horas. 108

Figura 64 - Espectro do coeficiente de absorção versus comprimento de onda da amostra $B_{2}$ (esquerda) e $B_{5}$ (direita) com diferentes tratamentos térmicos. 108

Figura 65 - Espectro do coeficiente de absorção versus comprimento de onda da amostra $\mathrm{B}_{5}$ tratada termicamente a $290^{\circ} \mathrm{C}$ por 2 horas e após com um polimento posterior. 109

Figura 66 - Modelo para formação de nanopartículas de prata 111

Figura 67 - Micrografias da amostra $B_{2}$ tratada a $270^{\circ} \mathrm{C}$ por duas horas (esquerda), a $290^{\circ} \mathrm{C}$ por duas horas (central) e a $310^{\circ} \mathrm{C}$ por duas horas (direita)

Figura 68 - Espectro de EDS da amostra $\mathrm{B}_{2}$ tratada a $270^{\circ} \mathrm{C}$ por 2 horas. 114

Figura 69 - Espectro de EDS da amostra $B_{2}$ tratada a $290^{\circ} \mathrm{C}$ por 2 horas

Figura 70 - Espectro de EDS da amostra $B_{2}$ tratada a $310^{\circ} \mathrm{C}$ por 2 horas. 115

Figura 71 - Micrografias da amostra $\mathrm{B}_{5}$ tratada a $270^{\circ} \mathrm{C}$ por duas horas (esquerda) e a $290^{\circ} \mathrm{C}$ por duas horas (direita). 116

Figura 72 - Espectro de EDS da amostra $\mathrm{B}_{5}$ tratada a $270^{\circ} \mathrm{C}$ por 2 horas.

Figura 73 - Espectro de EDS da amostra $B_{5}$ tratada a $270^{\circ} \mathrm{C}$ por 2 horas. 116

Figura 74 - Curvas VZ com ajuste por SB sem absorção, SB com absorção, LT e LT aberrante para a amostra $A_{2}$, contendo $0,5 \mathrm{~mol} \%$ de $\mathrm{AgNO}_{3}$ 125

Figura 75 - Curvas VZ com ajuste por SB sem absorção, SB com absorção, LT e LT aberrante para a amostra $A_{3}$, isenta de prata 126 Figura 76 - Curvas VZ com ajuste por SB sem absorção, SB com absorção, LT e LT aberrante para a amostra $\mathrm{A}_{4}$, contendo $2,0 \mathrm{~mol} \%$ de $\mathrm{AgNO}$ 126 
Figura 77 - Curvas VZ com ajuste por SB sem absorção, SB com absorção, LT e LT aberrante para a amostra $A_{5}$, contendo $5,0 \mathrm{~mol} \%$ de $\mathrm{AgNO}_{3}$ 127

Figura 78 - Curvas VZ com ajuste pelo método de Lara para a amostra $A_{5}$. 127

Figura 79 - Esquema que representa uma transição não-radiativa. 128

Figura 80 - Espectros de DRX das amostras dos vidros teluritos de nióbio sem tratamento térmico.

Figura 81 - Espectro de DRX das amostras $B_{2}, B_{3}$ e $B_{5}$ sem tratamento térmico e sem recozimento, respectivamente

Figura 82 - Espectro de DRX das amostras $C_{1}$ sem tratamento térmico e sem recozimento. 132

Figura 83 - Espectro de DRX das amostras $B_{2}$ tratada termicamente a $310^{\circ} \mathrm{C}$ por 2 horas 133

Figura 84 - Espectro de DRX da amostra $A_{3}$ com diferentes tratamentos térmicos. 134

Figura 85 - Espectro de DRX da amostra $A_{3}$ tratada termicamente a $550^{\circ} \mathrm{C}$ por 3 horas, com os precipitados identificados pelos índices $1=\mathrm{Nb}_{2} \mathrm{Te}_{4} \mathrm{O}_{13}, 2=\mathrm{TeO}_{2}$ e $3=\mathrm{Te}_{3} \mathrm{Nb}_{2} \mathrm{O}_{11}$ 134

Figura 86 - Espectro de $D R X$ da amostra $A_{3}$ com diferentes tratamentos térmicos, (cada tratamento com a duração de 3 horas), com os precipitados identificados pelos índices $1=\mathrm{Nb}_{2} \mathrm{Te}_{4} \mathrm{O}_{13}, 2=\mathrm{TeO}_{2}, 3=\mathrm{Te}_{3} \mathrm{Nb}_{2} \mathrm{O}_{11}$ e a= para indicar a diminuição acentuada de $\mathrm{TeO}_{2}$. 135

Figura 87 - Espectro de DRX da amostra $A_{3}$ com tratamento térmico de 3 horas a $550^{\circ} \mathrm{C}$ e a análise da estrutura cristalina constituinte por meio do programa Jade 135

Figura 88 - Espectro de CDTE da amostra $\mathrm{A}_{4}$ 137

Figura 89 - Espectro de CDTE da amostra $\mathrm{B}_{2}$ 138

Figura 90 - Espectro de CDTE da amostra $\mathrm{B}_{3}$ 138

Figura 91 - Espectro de CDTE da amostra $\mathrm{C}_{1}$ 141

Figura 92 - Espectro de CDTE da amostra $\mathrm{C}_{1}$ repetindo o valor da tensão com alteração da temperatura de aplicação da tensão para verificar o deslocamento do pico. 141 
Figura 93 - Espectro de CDTE do polietileno investigado por T. Hashimoto et al. [1]

Figura 94 - Espectro de CDTE da amostra $C_{1}$ sem aplicação de radiação e com a aplicação das doses de 25 e 50 kGy

Figura 95 - Espectro de CDTE da amostra $\mathrm{C}_{1}$ irradiada com 50 kGy 143

Figura 96 - Curva da correlação entre a intensidade média relativa de CDTE dos picos VS, o comportamento da intensidade pico a pico relativa intrínseca da amostra $\mathrm{C}_{1}$ não irradiada 144

Figura 97 - Curva TL da amostra $B_{3}$ irradiada com 1 kGy. 147

Figura 98 - Curva TL da amostra $\mathrm{C}_{1}$ irradiada com 1 kGy 147

Figura 99 - Curva TL da amostra $B_{2}$ irradiada com 1 kGy 148

Figura 100 - Curva TL da amostra $B_{5}$ irradiada com 1 kGy 148

Figura 101 - Curva TL comparativa da subida inicial de todas as amostras irradiada com 1 kGy 149

Figura 102 - Espectro de RPE da amostra $A_{5}$ irradiada com 15 kGy 150

Figura 103 - Espectros das amostras dos vidros teluritos básicos das série B e $\mathrm{C}$, irradiados com raios $\gamma$, com dose de $5 \mathrm{kGy}$, à temperatura ambiente: a) $\mathrm{B}_{3} \mathrm{e}$ b) $\mathrm{C}_{1}$. Resultado publicado por Giehl et al. [2] 151

Figura 104 - Espectros de RPE da amostra $B_{3}$ do vidro telurito medido após irradiação com raios $\gamma(5 \mathrm{kGy})$ e após armazenagem por durante 68 dias à temperatura ambiente.

Figura 105 - Espectros de RPE da amostra $B_{3}$ irradiado com doses de 1, 5 15, 25 e 50 kGy. Resultado publicado por Giehl et al. [2] 154

Figura 106 - Espectros de RPE da amostra $C_{1}$ irradiado com doses de 1, 515 , 25 e 50 kGy. Resultado publicado por Giehl et al. [2] 155

Figura 107 - Evolução das intensidades de RPE das ressonâncias $g_{1}, g_{2}$ e $g_{3}$ da amostra $B_{1}$, com a dose (kGy). Resultado publicado por Giehl et al. [2]. 156

Figura 108 - Evolução das intensidades de RPE das ressonâncias $g_{1}, g_{2}$ e $g_{3}$ da amostra $\mathrm{C}_{1}$, com a dose (kGy). Resultado publicado por Giehl et al. [2]. 156

Figura 109 - Espectros de RPE da amostra $B_{2}$ irradiado com doses de 1, 515 , 25 e 50 kGy. 
Figura 110 - Evolução das intensidades de RPE das ressonâncias $g_{1}, g_{2}$ e $g_{3}$ da amostra $B_{2}$, com a dose (kGy). 158

Figura 111 - Evolução das intensidades de RPE das ressonâncias $g_{1}, g_{2}$ e $g_{3}$ da amostra $B_{5}$, com a dose (kGy). 158

Figura 112 - Formação por meio da quebra de ligação, de um par de NBO's com as respectivas cargas compensadas pelos cátions $\mathrm{M}^{+}$; b) Reação parcial reversa, onde a molécula $\mathrm{M}_{2} \mathrm{O}$ é removida, deixando um par que se atrai mutuamente, $\mathrm{NBO}^{-}$e a vacância de oxigênio $\mathrm{V}_{\mathrm{o}}^{+}$; c) Efeito da radiação ionizante sobre o par $\left(\mathrm{NBO}^{-}, \mathrm{V}_{\mathrm{o}}^{+}\right)$, resultando o par eletricamente neutro (NBOHC, TeEC). Vale lembrar que a ligação axial é meramente ilustrativa. Resultado publicado por Giehl et al. [2]. 161

Figura 113 - Espectro de RPE da linha de TeOHC (linha pontilhada), após a subtração das ressonâncias $g_{1} e g_{2}$, da amostra $B_{3}$ irrradiada com dose de 5KGy. Resultado publicado por Giehl et al. [2] 163

Figura 114 - Modelo de formação do TeOHC. A notação das ligações é meramente ilustrativa. 164

Figura 115 - Representação esquemática do processo da diminuição da intensidade da ressonância $\mathrm{g}_{2}(\mathrm{NBOHC})$, resultando em uma vacância de oxigênio e um ânion $0^{-}$. A notação das ligações é meramente ilustrativa. Resultado publicado em Giehl et al. [2] 166

Figura 116 - Curva isócrona da amostra $B_{3}$ 167

Figura 117 - Curva isócrona da amostra $\mathrm{C}_{1}$. Figura 118 - Curva isócrona da amostra $\mathrm{B}_{2}$ 167

Figura 118 - Curva isócrona da amostra $B_{2}$ 169

Figura 119 - Curva isócrona da amostra $B_{5}$ 170

Figura 120 - Mecanismo de formação do TeEC-. A notação das ligações é meramente ilustrativa. 


\section{Lista de tabelas}

Tabela 1 - Matrizes vítreas versus densidade e energias do gap óptico [1].....14 Tabela 2 - Índice de refração linear com diferentes comprimentos de onda, número de Abbè e susceptibilidade não linear de terceira ordem [1]................15

Tabela 3 - Relação da Tg e energia do gap de vidros teluritos de nióbio..........15 Tabela 4 - Susceptibilidade não linear de terceira ordem medida em diversas composições $\chi^{(3)}[12]$. 16

Tabela 5 - Valores experimentais extraídos da literatura, com a respectiva amostra, sua temperatura de transição vítrea $(\mathrm{Tg})$, susceptibilidade não linear de terceira ordem $\left(\chi^{(3)}\right)$ e referências. 17

Tabela 6 - Valores do $\mathrm{n}_{2}$ eletrônico de vidros teluritos comparados aos de outros materiais, encontrados na literatura 18

Tabela 7 - Valores típicos de $\mathrm{n}_{2}$, escalas de tempo e origens físicas do efeito [18]. .44

Tabela 8 - Óxidos utilizados e suas respectivas purezas. 67

Tabela 9 - Composição das amostras (nominal)...........................................68

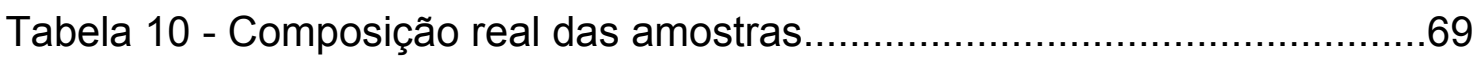

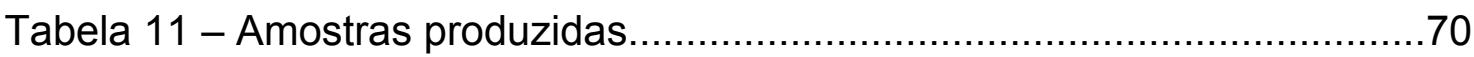

Tabela 12 - Dose de radiação gama aplicada nas amostras...........................90

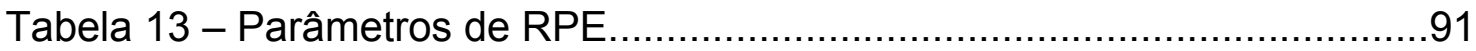

Tabela 14 - Massas das amostras medidas por RPE..................................92

Tabela 15 - Resultados das medidas de análise térmica diferencial.............100

Tabela 16 - Energias do gap óptico de cada amostra.................................105

Tabela 17 - Valores da largura a meia altura das amostras $B_{2}$ e $B_{3}$ tratadas com diferentes temperaturas.

Tabela 18 - Comprimento de onda versus índice de refração medido.

Tabela 19 - Comprimento de onda versus índice de refração medido.

Tabela 20 - Resultados do índice de refração linear calculados por meio da equação de Sellmeier...

Tabela 21 - Resultados do índice de refração linear calculados por meio da equação de Sellmeier 
Tabela 22 - Cálculo de $\mathrm{E}_{0}$ e $\mathrm{E}_{\mathrm{d}}$ utilizando o método de Wemple 120

Tabela 23 - Constante dielétrica e susceptibilidade linear.

Tabela 24 - Valores de $\mathrm{n}_{2}$ calculados a partir dos modelos de SB sem (SBSA) e com absorção (SBCA), LT e LT aberrante (LTA) 124

Tabela 25 - Parâmetros obtidos no ajuste Lara 124

Tabela 26 - Valores calculados do índice de refração não linear eletrônico $\mathrm{n}_{2}$ calculados. 129

Tabela 27 - Parâmetros experimentais utilizados nas curvas de CDTE. 136

Tabela 28 - Parâmetros experimentais utilizados nas curvas de CDTE

Tabela 29 - Parâmetros experimentais utilizados nas curvas de CDTE.......139

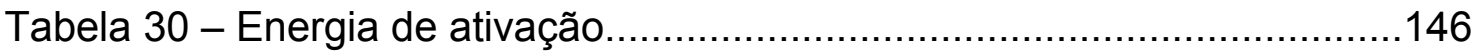

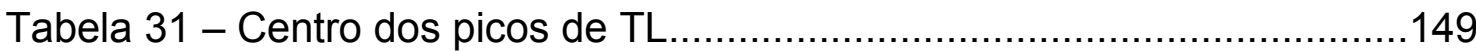

Tabela 32 - Resultados das medidas de densidade....................................172 


\section{LISTA DE ABREVIATURAS E SIGLAS}

$\mathrm{BO}$

Bridging Oxygen

NBO

Non Bridging Oxygen

MTO

Interferometria com Mistura de Três Ondas

IRT

Interferometria de Resolução Temporal

$\mathrm{AO}$

Absorção Óptica

UV

Ultravioleta

VIS

Visível

IR

Infravermelho

BV

Banda de Valência

$B C$

Banda de Condução

VZ

Varredura Z

PTE

Processos Termicamente Estimulados

CDTE

Correntes de Despolarização Termicamente Estimuladas

TL Termoluminescência

RPE

Ressonância Paramagnética Eletrônica

BEC

Centro de Elétron do Boro

$\mathrm{OHC}$

Centro de Buraco do Oxigênio

SiE'

Centro do Elétron do Silício

PEC

Centro de Elétron do Fósforo

$\mathrm{BOHC}$

Centro de Buraco do Boro e Oxigênio

$\mathrm{POHC}$

Centro de Buraco do Fósforo e Oxigênio

TeEC

Centro de Elétron do Telúrio

$\mathrm{TeOHC}$

Centro de Buraco do Telúrio e do Oxigênio

ICP-AES

Espectroscopia de Emissão Óptica com Acoplamento de Plasma

Induzido

FVRI

Forno Vertical de Radiofreqüência de Indução Elétrica

ATD

Análise Térmica Diferencial

MET

Microscopia Eletrônica de Transmissão

EDS

Espectroscopia de Fluorescência de Raio-X por Energia

Dispersiva

IRL

Índice de Refração Linear

Ch

Chopper 


$\begin{array}{ll}\text { Df } & \text { Divisor de Feixe } \\ \text { Ir } & \text { Íris } \\ \text { O } & \text { Osciloscópio } \\ \text { Mc } & \text { Microcomputador } \\ \text { A } & \text { Amostra } \\ \text { Md } & \text { Microdeslocador } \\ \text { DRX } & \text { Difração de Raio-X } \\ \text { CePOF } & \text { Centro de Pesquisas em Óptica e Fotônica } \\ \text { FPE } & \text { Forno de Polarização Eletrotérmica } \\ \text { PE } & \text { Polarização Eletro térmica } \\ \text { FWHM } & \text { Largura a Meia Altura } \\ \text { SBSA } & \text { Sheik-Bahae Sem Absorção } \\ \text { SBCA } & \text { Sheik-Bahae Com Absorção } \\ \text { LT } & \text { Lente Térmica } \\ \text { LTA } & \text { Lente Térmica Aberrante } \\ \text { TAT } & \text { Temperatura Aplicação da Tensão } \\ \text { TDT } & \text { Temperatura no Qual a Tensão Foi Desligada } \\ \text { IRR } & \text { Irradiada } \\ \text { TT } & \text { Tratamento Térmico } \\ \text { NBOHC } & \text { Centro de Buraco do Oxigênio Terminal } \\ \text { AEC } & \text { Centro de Elétron Alcalino } \\ \text { M } 20 & \text { Óxido Alcalino }\end{array}$




\section{LISTA DE SÍMBOLOS}

$\mathrm{T}_{\mathrm{g}} \quad$ Temperatura de Transição Vítrea

$v_{\mathrm{d}} \quad$ Número de Abbe

$\chi^{3} \quad$ Susceptibilidade Não Linear de Terceira Ordem

n I I lice de Refração Linear

$\lambda \quad$ Comprimento de Onda

$\mathrm{n}_{2} \quad$ Índice de Refração Não Linear

$\mathrm{n}_{\mathrm{f}} \quad$ Índice de Refração linear no Comprimento de Onda de 486,1 nm

$\mathrm{n}_{\mathrm{d}} \quad$ Índice de Refração linear no Comprimento de Onda de 587,6 nm

$\mathrm{n}_{\mathrm{c}} \quad$ Índice de Refração linear no Comprimento de Onda de 656,3 nm

$\mathrm{E}_{\mathrm{d} 1} \quad$ Área sob a Porção Eletrônica do Espectro da Componente

Complexa

$\mathrm{E}_{01} \quad$ Média de Todas as Excitações Eletrônicas

$\mathrm{n}_{\omega} \quad$ Índice de Refração linear em uma Determinada Freqüência

$\chi \quad$ Susceptibilidade Linear

$\varepsilon \quad$ Permissividade Elétrica em Materiais Isotrópicos

P Polarização Total do Meio

e Carga do Elétron

m Massa da Partícula

$\mathrm{N} \quad$ Número de Elétrons por Unidade de Volume

$\omega_{0} \quad$ Freqüência de Ressonância

$\omega \quad$ Freqüência

$\Gamma \quad$ Processos Dissipativos

$\eta \quad$ Índice de Refração Complexo

k Coeficiente de Extinção

$\mathrm{f}_{\mathrm{j}} \quad$ Força do Oscilador

$\mathrm{x}_{0 \mathrm{j}} \quad$ Elemento de matriz entre o Estado Excitado e o Fundamental da Coordenada do Dipolo 


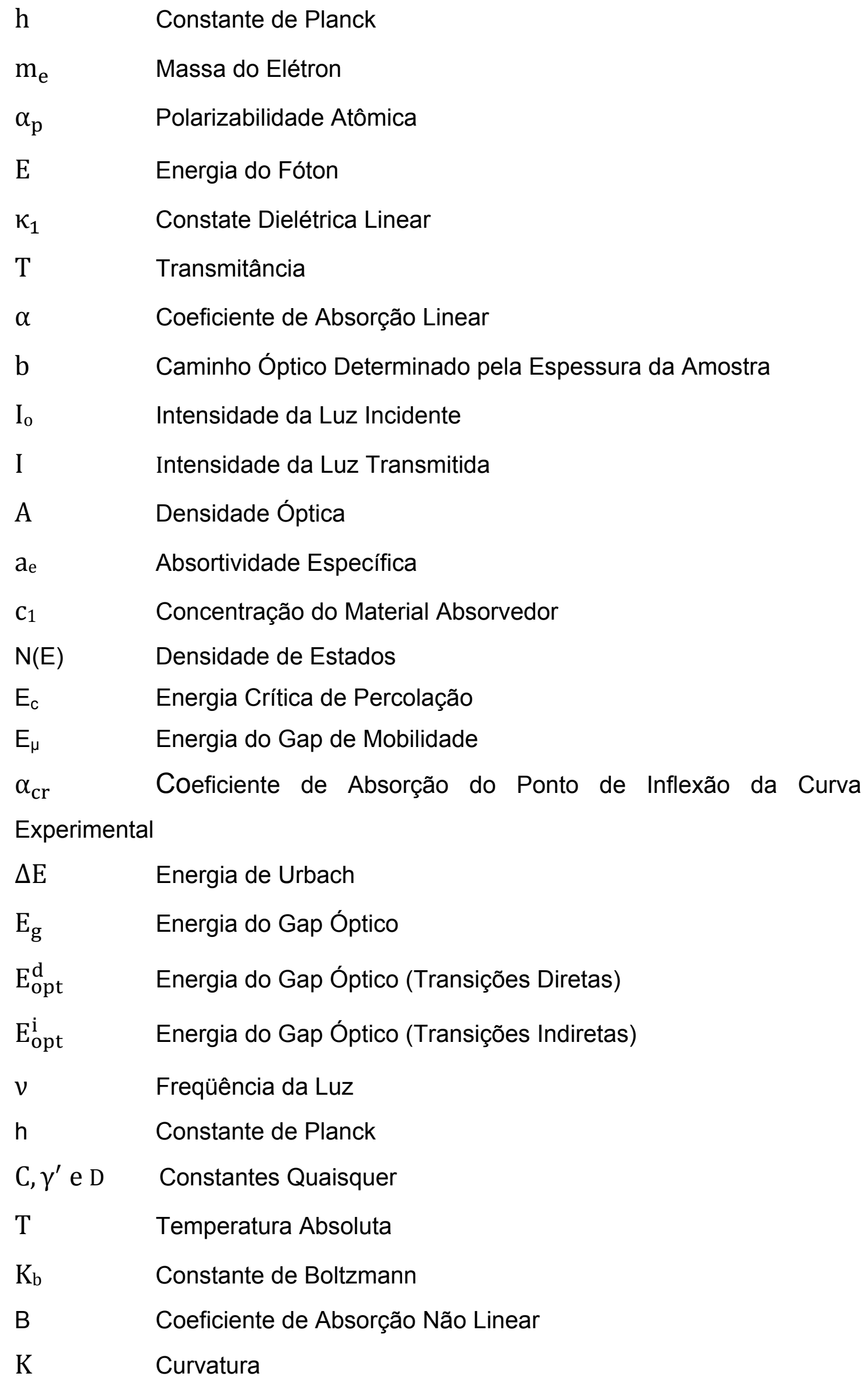




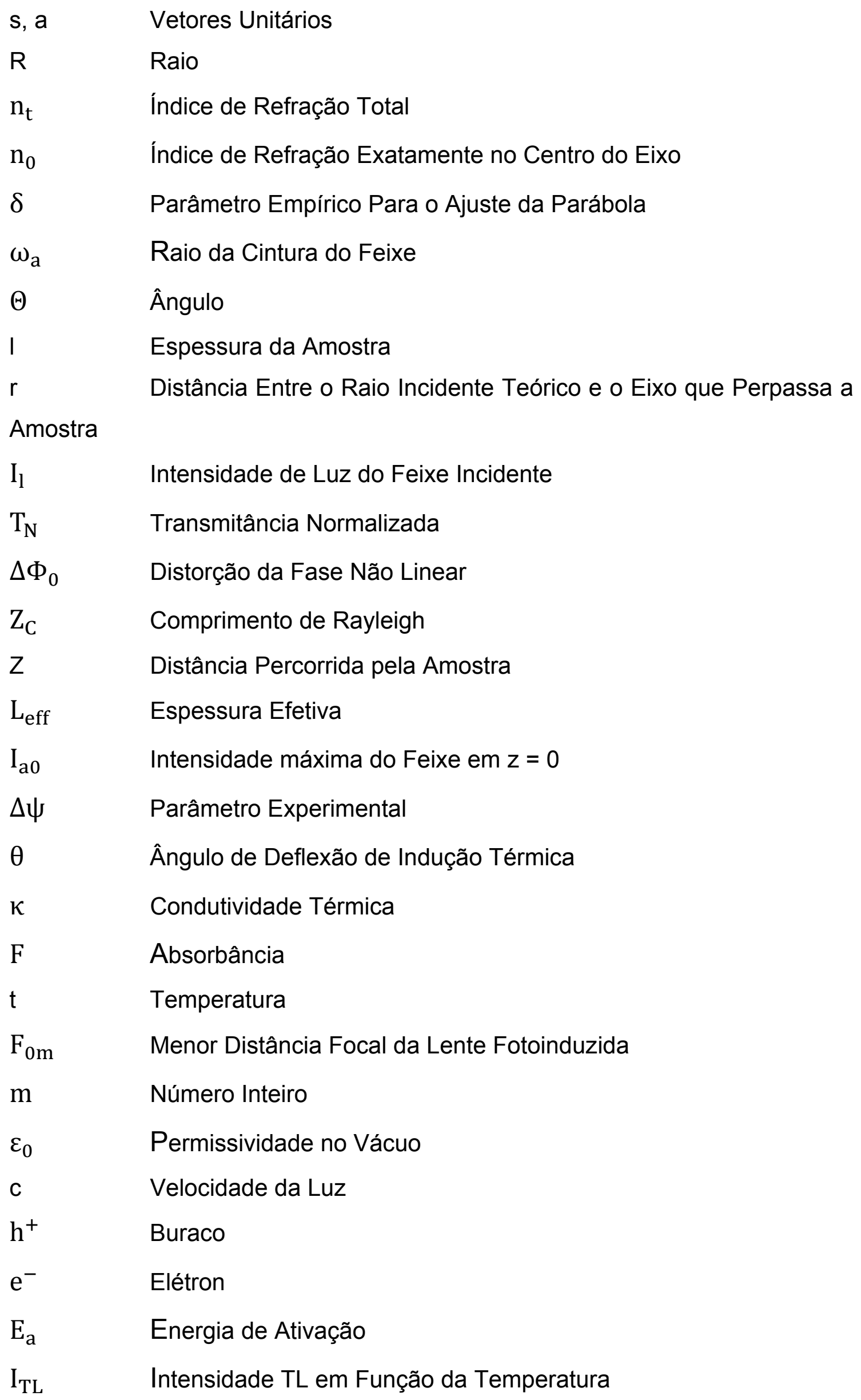


E' Centro de Elétron do Silício

$\mathrm{V}_{0} \quad$ Vacância de Oxigênio

$\beta_{1} \quad$ Magnéton de Bohr

$\mathrm{g}_{1}, \mathrm{~g}_{2}$ e $\mathrm{g}_{3}$ Fatores espectroscópicos

$\mathrm{S}_{1}, \mathrm{~S}_{2}$ e $\mathrm{S}_{3} \quad$ Números de Spin Eletrônico

$\mathrm{I}_{1}, \mathrm{I}_{2}$ e $\mathrm{I}_{3} \quad$ Números de Spin Nuclear

$A_{1}, A_{2}$ e $A_{3}$ Constantes de Interação Hiperfina

$V_{0}^{\prime} \quad$ Vacância de Oxigênio que Capturou um Elétron

$\mathrm{T}_{\mathrm{x}} \quad$ Temperatura de Cristalização

$\mathrm{T}_{\mathrm{f}} \quad$ Temperatura de Fusão

$\mathrm{K}_{\mathrm{H}} \quad$ Número de Hruby

$\theta_{\mathrm{i}} \quad$ Ângulo Incidente

$\mathrm{n}_{\mathrm{p}} \quad$ Índice de Refração Linear do Prisma

$\mathrm{n}_{\mathrm{v}} \quad$ Índice de Refração Linear da Amostra

L1-L3 Lentes

D1, D2 Detectores

$\mathrm{m}_{\mathrm{a}} \quad$ Massa da Amostra

$m_{\mathrm{ap}} \quad$ Massa Aparente da Amostra

$\rho_{\mathrm{a}} \quad$ Densidade da amostra

$\mathrm{E}_{\mathrm{e}} \quad$ Empuxo

$\rho_{1} \quad$ Densidade da Água

S Coeficiente de Sellmeier

M Coeficiente de Sellmeier

$\Delta \mathrm{H}_{\mathrm{pp}} \quad$ Largura de Linha

$\mathrm{F}_{\mathrm{r}} \quad$ Força Reativa

$\mathrm{F}_{\text {ext }} \quad$ Força Externa

V Velocidade da Partícula

$\tau_{\mathrm{c}} \quad$ Tempo Característico

$\mathrm{k}_{\mathrm{m}} \quad$ Coeficiente de Restituição

$\mathrm{E}_{\mathrm{c}} \quad$ Campo Elétrico 
Energia no Topo da Banda de Valência

$\mathrm{m}^{*} \quad$ Massa Reduzida do Elétron 


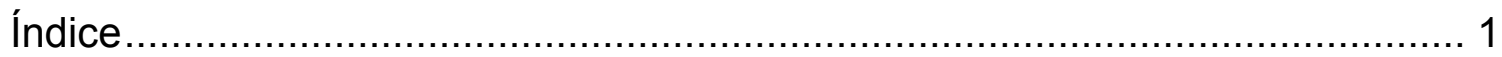

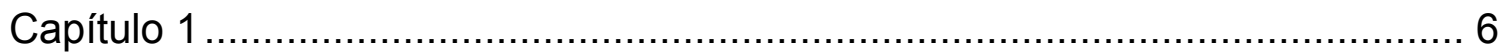

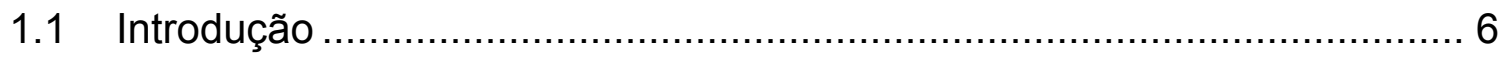

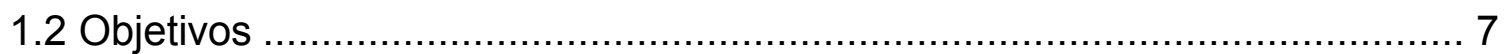

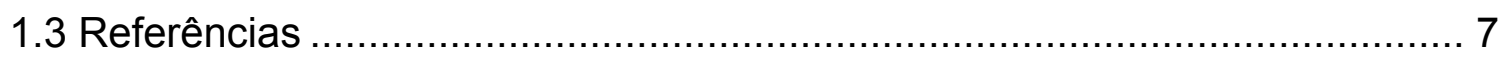

Capítulo 2 - Fundamentação teórica ………............................................. 9

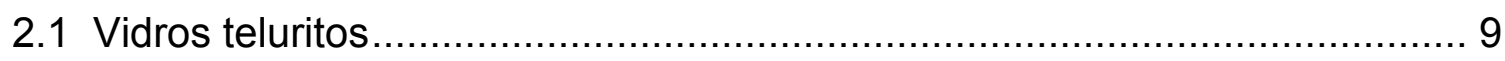

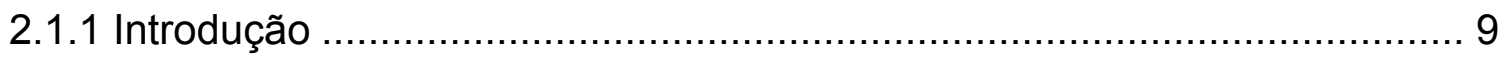

2.1.2 Estruturas dos vidros teluritos ……............................................... 9

2.1.3 Propriedades estruturais e ópticas de vidros teluritos de nióbio............... 13

2.1.4 Um breve histórico do progresso dos resultados da não linearidade de terceira ordem e do índice de refração não linear de segunda ordem utilizando

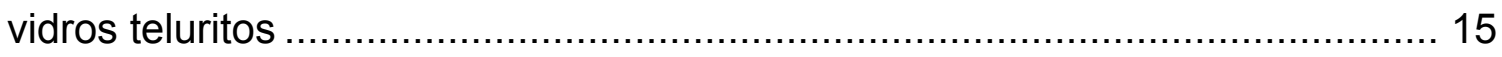

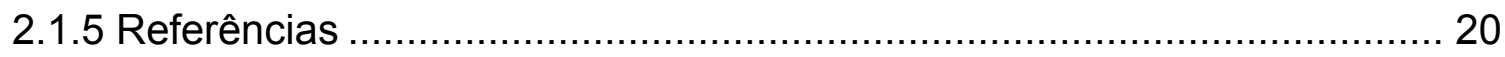

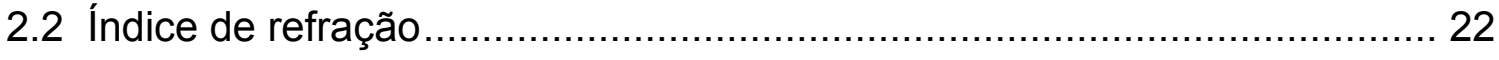

2.2.1 Uma breve revisão do comportamento do índice de refração real e complexo em um meio isotrópico e o método de Wemple ................................. 22

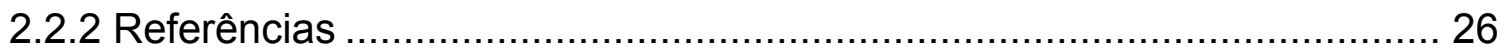

2.3 Técnicas ópticas

2.3.1 Estudo de absorção óptica (AO) na região do ultravioleta (UV), visível

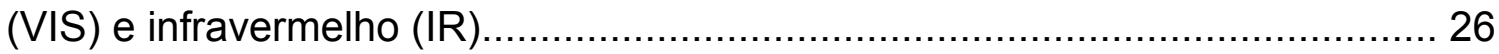

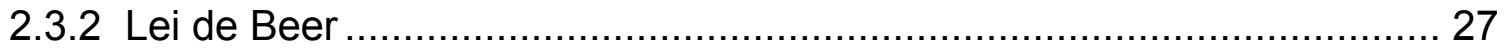

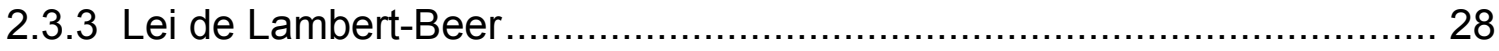

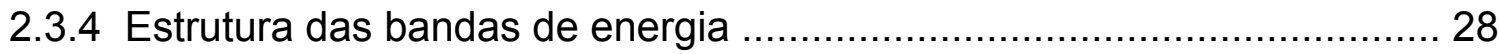

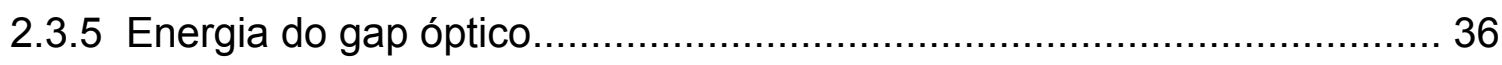


2.3.6 Varredura $Z(V Z)$ para a determinação do índice de refração não linear

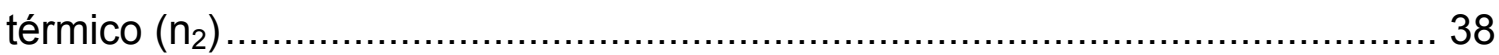

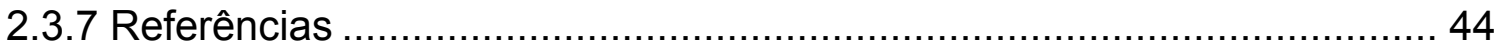

2.4 Nanopartículas de prata e ressonância de plasmons ............................. 46

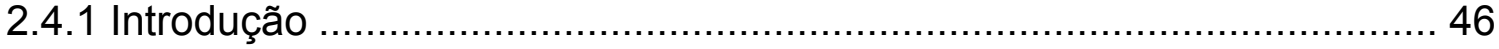

2.4 .2 Banda de plasmons ................................................................. 47

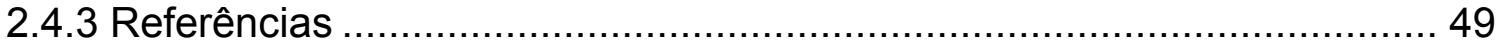

2.5. Processos Termicamente Estimulados (PTE) .................................... 50

2.5.1 Correntes de Despolarização Termicamente Estimuladas .................... 50

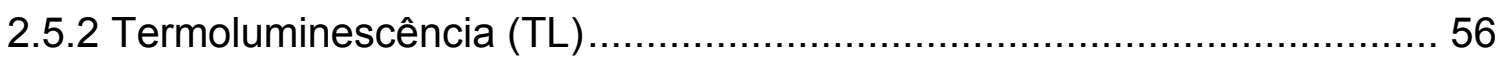

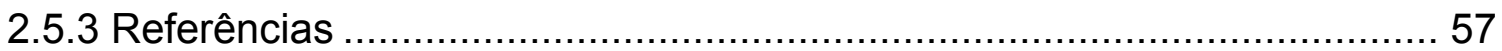

2.6 Ressonância paramagnética eletrônica (RPE) .................................. 59

2.6.1 Introdução aos defeitos em vidros óxidos (isolantes) .......................... 59

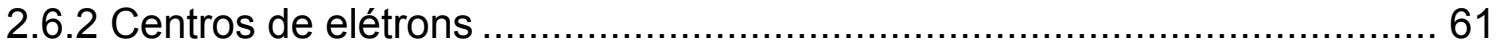

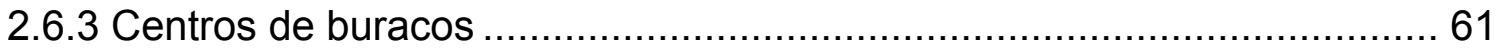

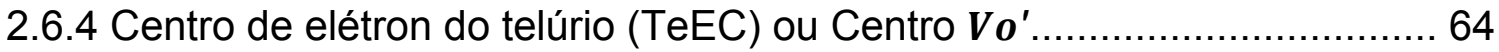

2.6.5 Centro de buraco do telúrio e oxigênio $(\mathrm{TeOHC})$................................ 64

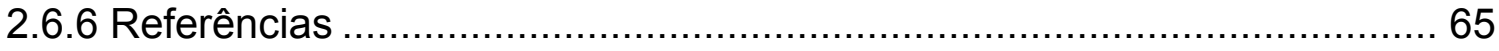

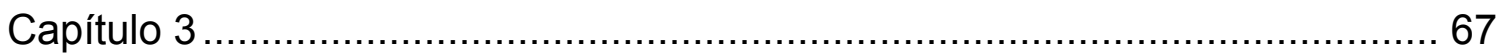

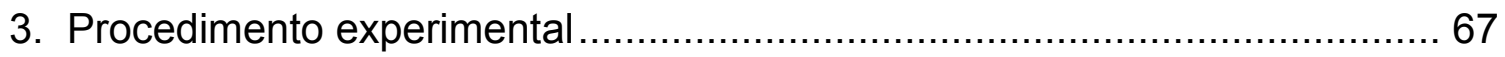

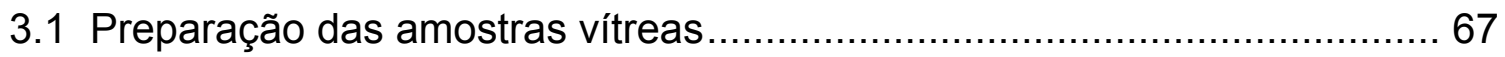

3.2 Forno vertical de radiofreqüência de indução elétrica (FVRI).................. 71

3.3 Equipamentos utilizados para desbastamento e polimento das amostras .. 72

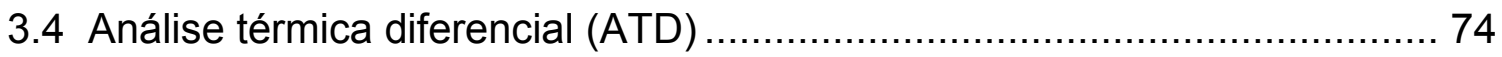

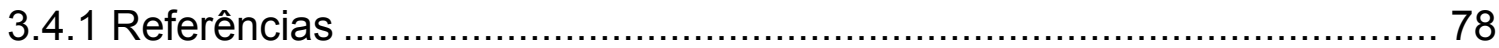

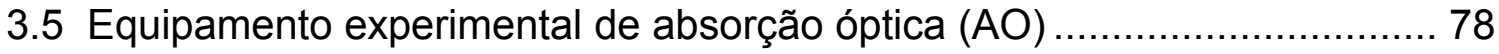


3.6 Microscopia eletrônica de transmissão (MET) e espectroscopia de fluorescência de raios-X por energia dispersiva (EDS) .................................... 80

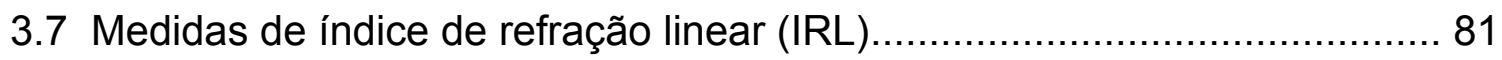

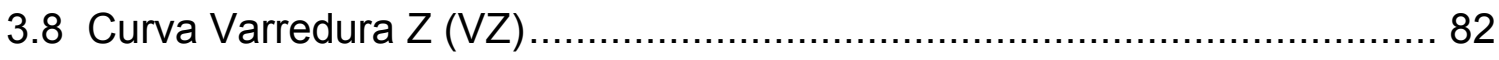

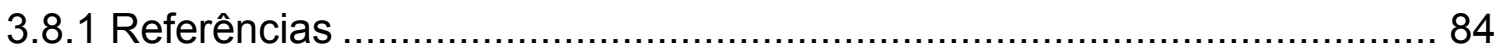

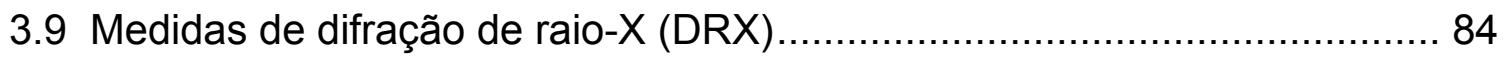

3.10 - Correntes de Despolarização Termicamente Estimuladas (CDTE) ........ 85

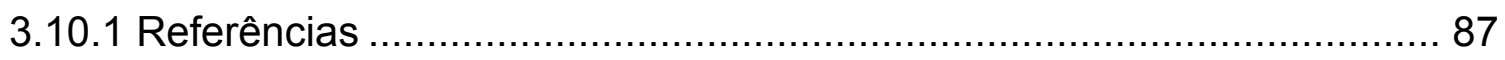

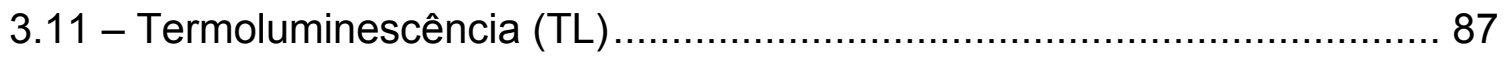

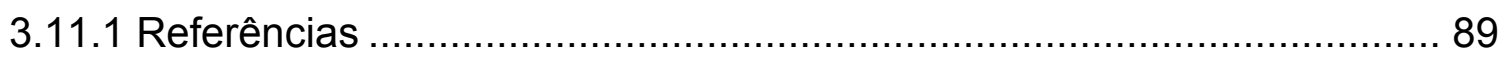

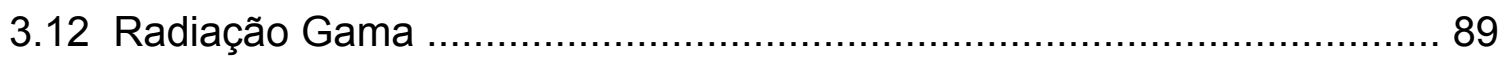

3.13 Ressonância Paramagnética Eletrônica (RPE) ……………………........ 90

3.14 Medidas de densidade utilizando método baseado no princípio de Arquimedes

3.15 Forno para polarização eletrotérmica (FPE) (montagem e procedimento)94

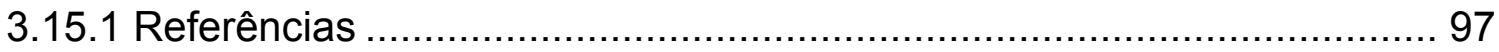

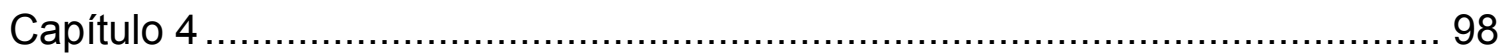

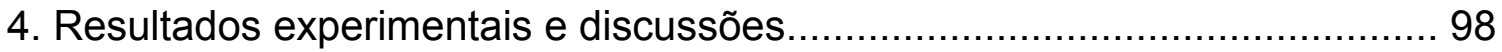

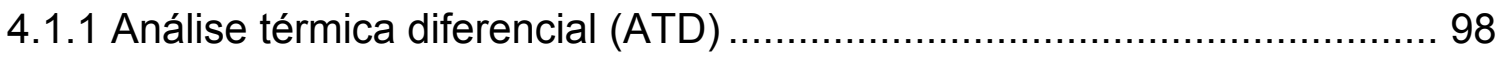

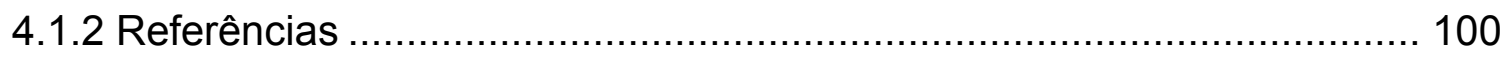

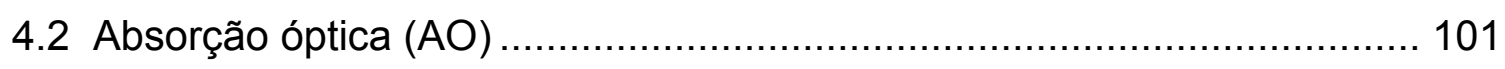

4.2.1 Absorção óptica (AO) sem tratamento térmico posterior ....................... 101

4.2.2 Absorção óptica (AO) das amostras sem recozimento e com posterior

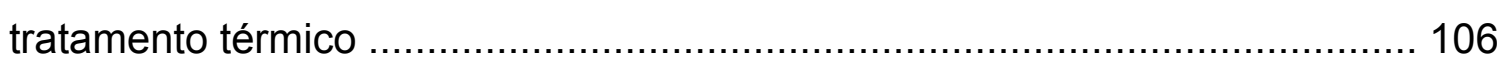

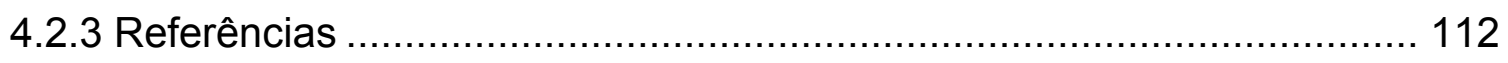

4.3 Microscopia eletrônica de transmissão (MET) e espectroscopia de fluorescência de raios-X por energia dispersiva (EDS) ............ 113_Toc287013807 
4.4 Índice de refração linear (IRL) experimentais e discussões dos cálculos obtidos a partir dos resultados .................................................... 117

4.4.1 Referências ......................................................................... 122

4.5 Índice de refração não linear experimental e calculado......................... 122

4.5.1 Índice de refração não linear obtido por meio da técnica de Varredura Z $(\mathrm{VZ})$

4.5.2 Índice de refração não linear $\mathbf{n}_{2}$ calculado ..................................... 128

4.5.3 Referências ......................................................................... 129

4.6 Difração de raios-X (DRX) ...................................................... 130

4.7 Medidas de Correntes de Despolarização Termicamente Estimuladas

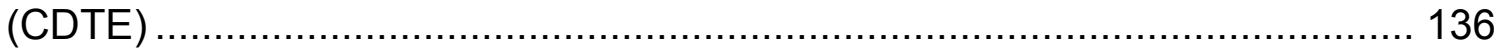

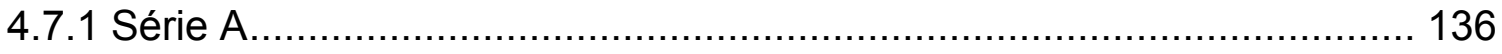

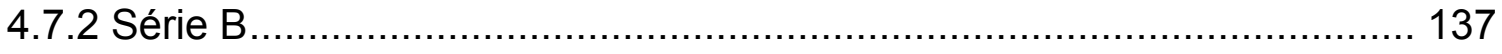

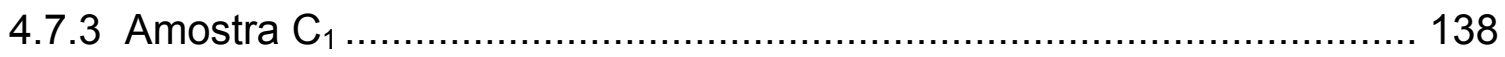

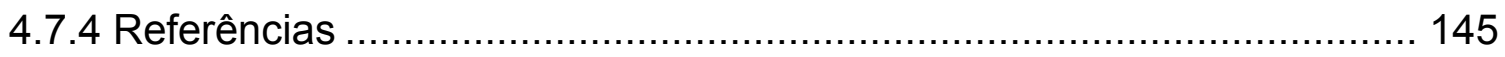

4.8 Medidas de Termoluminescência (TL) .......................................... 145

4.9 Medidas de ressonância paramagnética eletrônica (RPE) ..................... 149

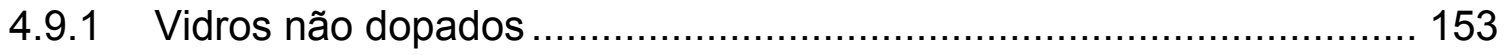

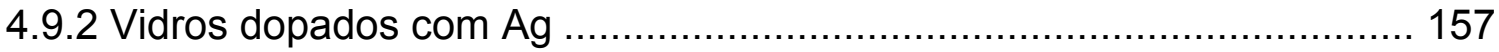

4.9.3 Centro de buraco do oxigênio não interligante (non-bridging oxygen hole

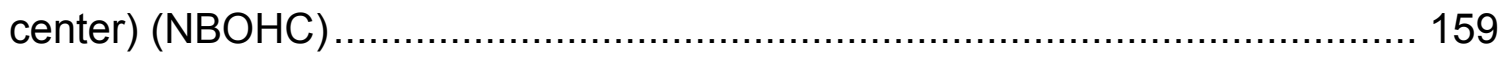

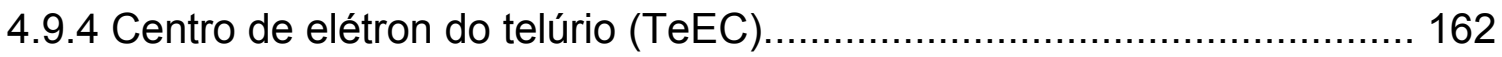

4.9.5 Centro de buraco de telúrio e oxigênio (TeOHC) ............................... 162

4.9.6 Evolução das intensidades das ressonâncias $\boldsymbol{g}_{1}, \boldsymbol{g}_{2}$ e $\boldsymbol{g}_{3}$ com a dose crescente de irradiação ............................................................................ 164

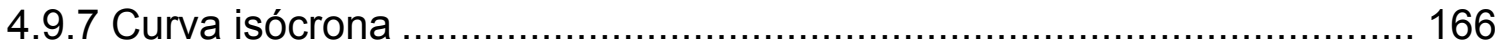

4.9.8 Referências ...................................................................... 171 
4.10 Medidas de densidade dos vidros

4.10.1 Referências

Capítulo 5

5. Sumário e conclusões

5.1 Sumário dos resultados de absorção óptica (AO) das amostras dopadas com prata, com posterior tratamento térmico e microscopia eletrônica de transmissão (TEM)

5.2 Sumário dos resultados ópticos

5.3 Sumário dos resultados de CDTE

5.4 Sumário dos resultados de TL 175

5.5 Sumário dos resultados de RPE 175

5.6 Conclusões finais 176

6. Projetos futuros 177

Anexo 1 - Uma breve revisão, do ponto de vista da eletrodinâmica clássica do comportamento do índice de refração real e complexo 178 Anexo 2 - Absorção óptica do fundo da banda de condução 181

A.2.1 Referências 183

Anexo 3 - Relações entre $n_{2}$ e $\chi^{(3)}$ em diferentes unidades 184

A.3.1 Referências 187

Anexo 4 Artigos publicados 187 


\section{Capítulo 1}

\subsection{Introdução}

J. E. Stanworth [1] foi o primeiro autor a reportar a produção de vidros teluritos. Em 1952 ele produziu duas matrizes vítreas: $\mathrm{BaO}-\mathrm{TeO}_{2}$ e $\mathrm{PbO}-\mathrm{TeO}_{2}$, tendo descoberto importantes propriedades físicas tais como: coeficiente de expansão térmica linear entre $10,2 \times 10^{-6}{ }^{\circ} \mathrm{C}^{-1}$ e $21,5 \times 10^{-6}{ }^{\circ} \mathrm{C}^{-1}$, temperatura de transição vítrea $\left(T_{g}\right)$ em torno de $300^{\circ} \mathrm{C}$, radicalmente diferente dos vidros até então estudados e índice de refração linear entre 1,82 e 2,21 no comprimento de onda de $578 \mathrm{~nm}$.

Vidros teluritos são considerados fortes candidatos para aplicações em lasers e óptica não linear devido a importantes características, como o elevado índice de refração situado entre 1,8 - 2,3 no comprimento de onda de $589,9 \mathrm{~nm}$; baixa energia de fônons $\hbar \omega\left(\mathrm{cm}^{-1}\right)$ entre $600-850$, inferior somente aos vidros fluoritos; possuem baixa $T_{g}$ e são facilmente obtidos à atmosfera ambiente [2,3].

Os vidros teluritos contendo nióbio oferecem um campo promissor de aplicações optoeletrônicas envolvendo interessantes fenômenos físicos para serem estudados, devido ao seu elevado índice de refração e alta transparência na região do espectro abrangendo a radiação visível e infravermelha, além do interessante fato dos vidros contendo nióbio a uma concentração abaixo de 15 mol\% constituírem o nióbio como elemento formador [4].

Neste trabalho são desenvolvidas basicamente duas linhas de pesquisa em vidros teluritos: os estudos estruturais que englobam as técnicas de: ressonância paramagnética eletrônica, correntes de despolarização termicamente estimuladas, termoluminescência, difração de raio-X e análise térmica diferencial; e os estudos ópticos compreendidos pelas técnicas de: acoplamento de prismas, absorção óptica, microscopia eletrônica de transmissão e Varredura $Z$.

Para o capítulo 2 procurou-se desenvolver: um estudo sobre as unidades estruturais dos vidros teluritos e pesquisas realizadas até o presente momento envolvendo estes vidros quanto à susceptibilidade não linear de termos ímpares bem como um apanhado de algumas propriedades físicas dos vidros teluritos de nióbio, uma breve revisão do comportamento do índice de refração real e complexo, 
um apanhado dos fundamentos teóricos e métodos de análise das técnicas de absorção óptica e varredura $Z$, os fenômenos de formação de nanopartículas de prata e ressonância de plasmons, processos termicamente estimulados e defeitos em vidros óxidos.

No capítulo 3 foram abordadas as técnicas de preparação das amostras vítreas, de polimento e de caracterização das amostras, além das providências e dificuldades encontradas na produção do forno para a polarização eletrotérmica.

Para caracterizar as amostras seguem-se no capítulo 4 os resultados e discussões de todas as técnicas empregadas, bem como a proposta de alguns modelos para elucidar os fenômenos envolvidos.

As conclusões deste trabalho seguem no capítulo 5 e no capítulo 6 são discutidas novas perspectivas para o futuro.

\subsection{Objetivos}

Esta tese tem por objetivos:

1. Produzir amostras vítreas ternárias e quaternárias à base de óxido de telúrio com qualidade óptica suficiente para medidas da variação do índice de refração linear e não-linear, com a possibilidade de aplicações;

2. Estudo da influência da adição de nitrato de prata sobre os vidros base e a possibilidade de criação de nanopartículas de prata;

3. Caracterizar os vidros teluritos por meio de técnicas espectroscópicas com a finalidade de compreender sua estrutura com ou sem a ação de raios gamma;

4. Estudo das correntes de despolarização objetivando compreender os processos envolvidos durante a polarização destas amostras;

5. Analisar qualitativa e quantitativamente os processos físicos envolvidos, levando em consideração as propriedades macroscópicas e microscópicas do material estudado, objetivando construir modelos que esclareçam o comportamento dos vidros teluritos estudados.

\subsection{Referências}


[1] Stanworth, J. E. Tellurite Glasses. Nature, v. 169, n. 4301, p. 581-582, 1952.

[2] Wang, J. S.; Vogel, E. M.; Snitzer, E. Tellurite glass: a new candidate for fiber devices. Opt. Materials, v. 3, n. 3, p. 187-203, 1994.

[3] Prakash, G. V.; Rao, D. N.; Bhatnagar, A. K. Linear optical properties of niobiumbased tellurite glasses. Solid State Comm., v. 119, p. 39-44, 2001 e referências citadas.

[4] Kim, V. M.; Reardon, D. E.; Bray, P. J. ESR studies of radiation-induced niobium centers in $\mathrm{Nb}_{2} \mathrm{O}_{5}-\mathrm{Na}_{2} \mathrm{O}-\mathrm{SiO}_{2}$ glasses. J. of Chem. Phys., v. 48, n. 8, p. 3396-3402, 1968. 


\section{Capítulo 2 - Fundamentação teórica}

\subsection{Vidros teluritos}

\subsubsection{Introdução}

Recentemente, vidros teluritos com a adição de óxidos de metais pesados, como $\circ \mathrm{Nb}, \mathrm{Pb}$ e $\mathrm{W}$, foram intensamente estudados devido às mudanças das propriedades físicas e ópticas que ocorrem nestes vidros [1]. Vidros óxidos de metais pesados e vidros teluritos são considerados promissores para aplicações em fotônica devido às suas excelentes propriedades ópticas lineares e não lineares [25].

Os vidros teluritos apresentam um grande potencial em aplicações no chaveamento óptico de grande velocidade, laser de luminescência não convencional, amplificadores de fibra óptica e fontes de luz para aplicações em telecomunicações de banda larga na região de 1,5 um [6-7].

\subsubsection{Estruturas dos vidros teluritos}

Espectroscopia Raman, Transmitância no Infravermelho e Difração de Nêutrons constituem técnicas muito úteis para estudar a estrutura dos vidros teluritos.

S. Neov e colaboradores [8] investigaram, por meio da técnica de difração de nêutrons, as ligações de curto alcance do vidro $\mathrm{TeO}_{2}-\mathrm{Li}_{2} \mathrm{O}$ e propuseram um modelo baseado na função de densidade atômica radial para determinar a configuração estrutural dos formadores Te ligados aos oxigênios vizinhos no vidro telurito. Este modelo leva em conta a influência do elemento modificador e do par de elétrons livres do átomo de Te no poliedro estrutural básico.

Nesses vidros, o telúrio encontra-se ligado aos átomos de oxigênio circunvizinhos com elevado grau de covalência, formando unidades estruturais (normalmente poliedros) que incluem átomos de telúrio com número de coordenação 4, 3+1 e 3 (figura 1), geralmente ligados entre si pelos vértices, dando origem a três tipos piramidais. Na figura 1a, temos uma bi-pirâmide trigonal e para que isto ocorra 
é necessário que a distância das ligações entre Te e O seja inferior a $2 \AA$. Na figura $1 \mathrm{~b}$ temos uma estrutura intermediária na qual um oxigênio com uma distância maior que 2,3 $\AA$ afasta-se gradualmente até a estrutura formar uma pirâmide trigonal (figura 1c).

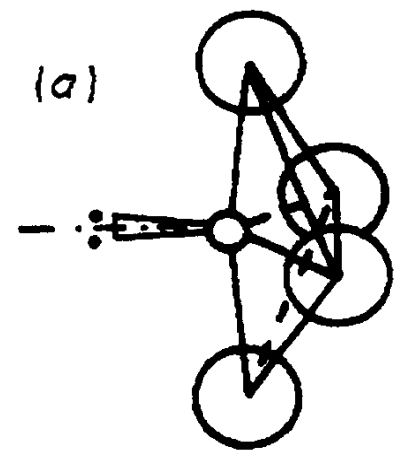

$\mathrm{TeO}_{4}$

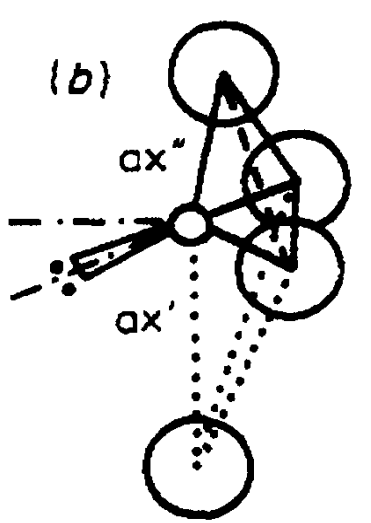

$R_{a X^{\prime}}>2 \cdot 30 \AA$

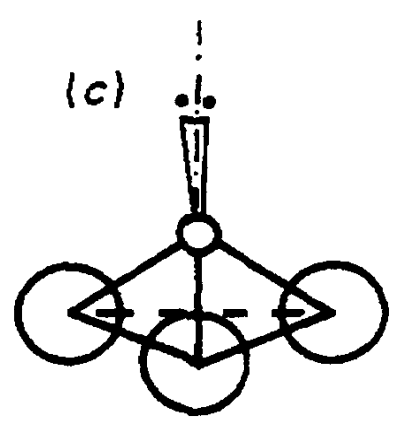

$\mathrm{TeO}_{3}$

Figura 1 - Unidades estruturais presentes nos vidros teluritos, dependendo da quantidade de oxigênio presente na sua composição química (Neov e colaboradores [8]). Em (a) temos bi-pirâmide trigonal, (b) $\mathrm{TeO}_{3+1}$ e em (c) pirâmide trigonal.

T. Sekiya e colaboradores [9] realizaram um estudo mais detalhado, utilizando espectroscopia Raman, da coexistência das unidades estruturais $\mathrm{TeO}_{4}$ (figura 2a), $\mathrm{TeO}_{3+1}$ ( figura $2 \mathrm{~b}$ ) e $\mathrm{TeO}_{3}$ (figura $2 \mathrm{c}$ ) em vidros binários do tipo $\mathrm{MO}_{1 / 2}-\mathrm{TeO}_{2}(\mathrm{M}=$ $\mathrm{Li}, \mathrm{Na}, \mathrm{K}, \mathrm{Rb}, \mathrm{Cs}$ and $\mathrm{Tl}$ ) e propôs que os vidros $\mathrm{TeO}_{2}$ têm uma cadeia de estruturas de bi-pirâmides trigonais $\mathrm{TeO}_{4}$ compostas de átomos conectados pelos vértices mediante ligações $\mathrm{Te}_{\mathrm{eq}}-\mathrm{O}_{\mathrm{ax}}-\mathrm{Te}$, onde eq = equatorial, $\mathrm{ax}=$ axial. Vidros com uma baixa concentração de óxidos alcalinos são compostos de estruturas poliédricas $\mathrm{TeO}_{4}$ e $\mathrm{TeO}_{3+1}$ conectadas pelos vértices. Em vidros com altas concentrações de óxidos alcalinos, a rede vítrea é formada de unidades estruturais isoladas dos íons $\mathrm{Te}_{2} \mathrm{O}_{5}{ }^{2-}$ e $\mathrm{TeO}_{3}{ }^{2-}$.

$\mathrm{Na}$ figura 3 segue-se o modelo proposto por T. Sekiya e colaboradores [9], no qual são representadas duas unidades estruturais bi-piramidais, assumindo que o oxigênio equatorial de uma estrutura bi-piramidal está ligado a um oxigênio axial da 
outra onde todos os oxigênios são inter-ligantes, do tipo BO (bridging oxygen). Com a adição do elemento modificador $\mathrm{Li}_{2} \mathrm{O}$ ocorre quebra de uma ligação na estrutura, com a formação de um oxigênio não inter-ligante NBO (non bridging oxygen) em uma extremidade da cadeia rompida e uma vacância de oxigênio na outra que recebe o oxigênio, proveniente do óxido alcalino adicionado. Portanto, haverá duas extremidades contendo oxigênio NBO, cada uma delas possuindo o excesso de uma carga negativa compensado pelo íon de lítio situado na região intermediária (figura $3 b)$.

Na figura 3c observamos que devido à presença do par de elétrons do orbital não ligante que exerce uma força de repulsão sobre os elétrons dos íons $\mathrm{O}^{2-}$ (tornando a unidade instável), haverá o enfraquecimento da ligação covalente mais fraca do oxigênio mais distante que acaba se separando da bi-pirâmide e tornandose uma pirâmide $\mathrm{TeO}_{3}$. 


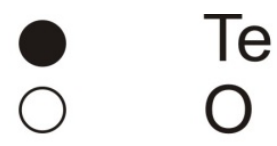

a)
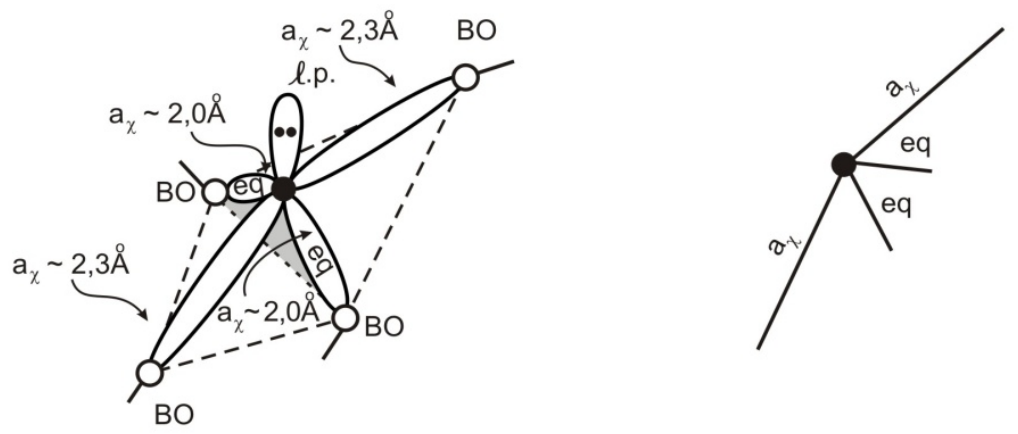

b)
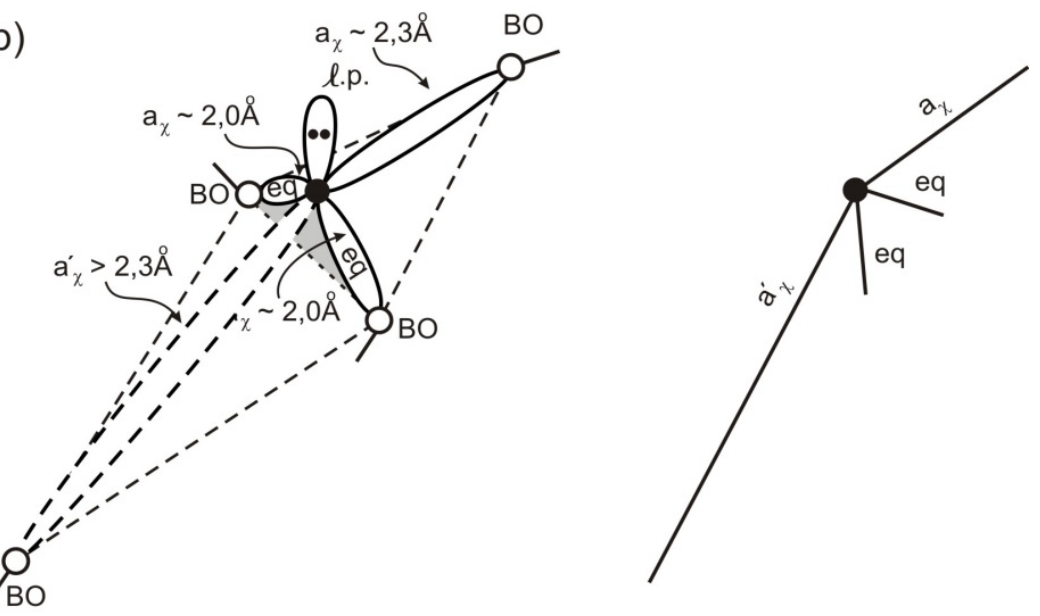

C)
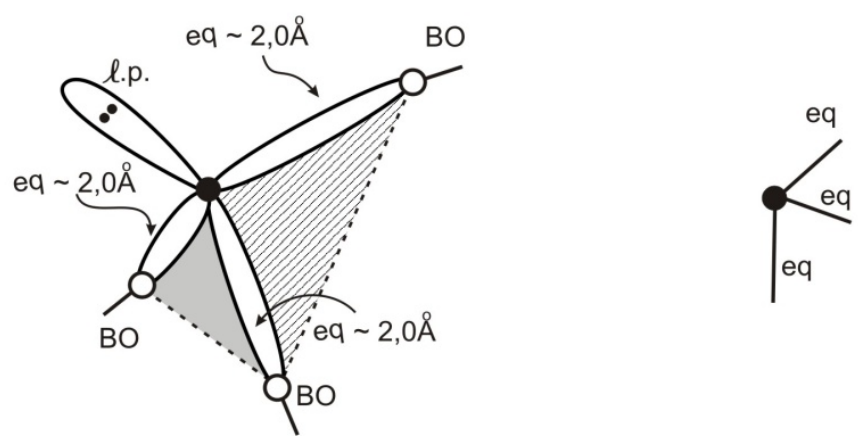

Figura 2 - a) Bi-pirâmide sendo a base sombreada a base comum as duas pirâmides, b) Bi-pirâmide $\mathrm{TeO}_{3+1} \mathrm{com}$ um oxigênio se afastando dos demais e c) Pirâmide trigonal $\mathrm{TeO}_{3} \mathrm{com}$ simetria $C_{3 \mathrm{v}}$. 
(a)

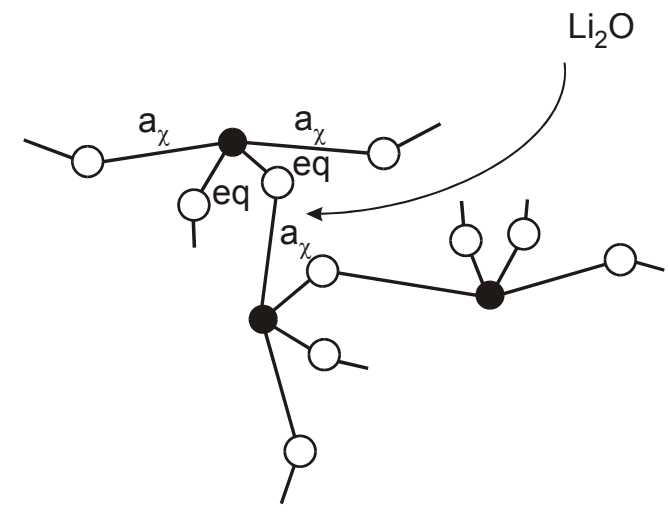

(b)
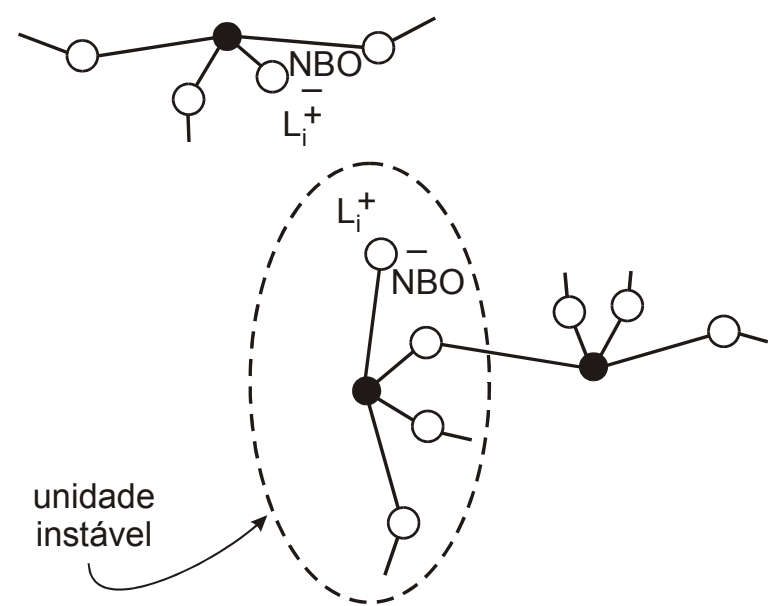

(c)
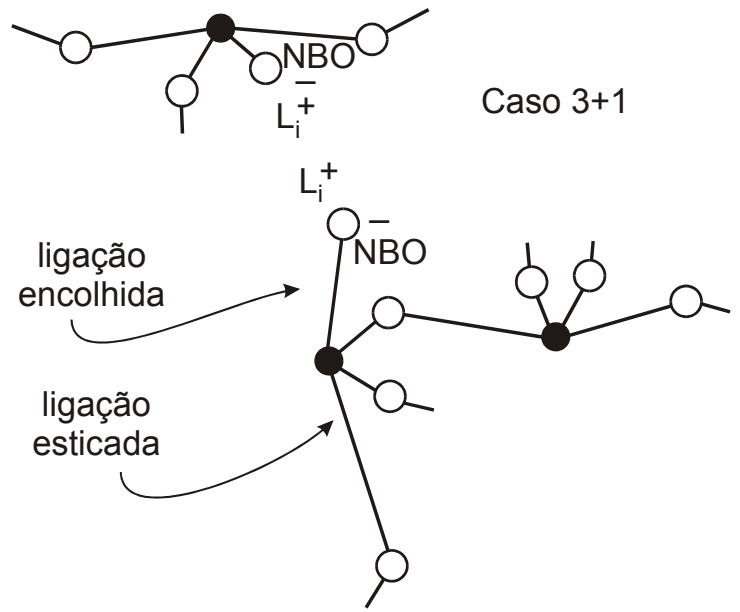

Figura 3 - Unidades estruturais presentes nos vidros teluritos com adição de $\mathrm{Li}_{2} \mathrm{O}$ [9].

2.1.3 Propriedades estruturais e ópticas de vidros teluritos de nióbio 
Segundo Lin e colaboradores [10] os vidros $\mathrm{TeO}_{2}-\mathrm{Nb}_{2} \mathrm{O}_{5}-\mathrm{ZnO}$ contêm íons $\mathrm{Nb}^{5+}$ que se encontram na rede em tetraedros $\mathrm{NbO}_{4}$ como elementos formadores, enquanto os íons restantes formam octaedros $\mathrm{NbO}_{6}$. Os íons $\mathrm{Zn}^{2+}$ ocupam posições intersticiais atuando como elementos modificadores da rede.

Prakash e colaboradores [1] produziram uma série de vidros teluritos de nióbio segundo a fórmula estequiométrica (10 $\left.\mathrm{Na}_{2} \mathrm{O}-\mathrm{xNb}_{2} \mathrm{O}_{5}-(90-\mathrm{x}) \mathrm{TeO}_{2}\right)$ mol\% com $x=0,5,10$ e 20. Para uma quantidade maior que 20 mol\% de $\mathrm{Nb}_{2} \mathrm{O}_{5}$ as amostras apresentaram-se opacas e parcialmente cristalizadas. Os vidros de Prakash e colaboradores [1] apresentaram uma ligeira coloração amarelada, com densidades que variam em torno de $4,91-5,4 \mathrm{mg} / \mathrm{cm}^{3}$. Na tabela 1 seguem as matrizes vítreas e suas respectivas densidades, envolvendo transições diretas do gap óptico (denominado $\mathrm{E}_{\mathrm{opt}}^{\mathrm{d}}$ ) e transições indiretas do gap óptico (denominado $\mathrm{E}_{\mathrm{opt}}^{\mathrm{i}}$ ). Os valores entre parênteses são os coeficientes obtidos pelo método da regressão linear.

Tabela 1 - Matrizes vítreas versus densidade e energias do gap óptico [1].

\begin{tabular}{|l|l|l|l|}
\hline Amostra & Densidade $\left(\mathrm{gm} / \mathrm{cm}^{3}\right)$ & $\mathrm{E}_{\mathrm{opt}}^{\mathrm{d}}(\mathrm{eV}) \pm 0,03$ & $\mathrm{E}_{\text {opt }}^{\mathrm{i}}(\mathrm{eV}) \pm 0,03$ \\
\hline $\mathrm{x}=0$ & 4,91 & $3,21(0,99)$ & $3,11(0,99)$ \\
\hline $\mathrm{x}=5$ & 5,41 & $3,16(0,92)$ & $3,02(0,92)$ \\
\hline $\mathrm{x}=10$ & 5,17 & $3,06(0,95)$ & $2,81(0,97)$ \\
\hline $\mathrm{x}=20$ & 5,11 & $2,96(0,99)$ & $2,70(0,99)$ \\
\hline $20 \mathrm{Na}_{2} \mathrm{O}-80 \mathrm{TeO}_{2}$ & 4,80 & - & - \\
\hline $6,5 \mathrm{~K}_{2} \mathrm{O}-93,5 \mathrm{TeO}_{2}$ & 5,27 & - & - \\
\hline $\mathrm{TeO}_{2}$ & 5,10 & 3,37 & - \\
\hline $15 \mathrm{~K}_{2} \mathrm{O}-15 \mathrm{Nb}_{2} \mathrm{O}_{5}-70 \mathrm{TeO}_{2}$ & 4,66 & - & - \\
\hline
\end{tabular}

Na tabela 2 segue o índice de refração linear em determinados comprimentos de onda medido por Prakash e colaboradores [1], bem como o número de Abbe $\left(v_{\mathrm{d}}\right)$ e a susceptibilidade não linear de terceira ordem $\left(\chi^{3}\right)$ calculada para suas amostras. 
Tabela 2 - Índice de refração linear com diferentes comprimentos de onda, número de Abbè e susceptibilidade não linear de terceira ordem [1].

\begin{tabular}{|l|l|l|l|l|l|}
\hline Amostra & \multicolumn{3}{|l|}{ Índice de refração linear com } & \multirow{2}{*}{$v_{\mathrm{d}}$} & $\chi^{3}$ (cal)10-12 esu \\
\cline { 2 - 5 } & \multicolumn{2}{|l|}{ diferentes comprimentos de onda } & & \\
\cline { 2 - 5 } & $486,1 \mathrm{~nm}$ & $587,6 \mathrm{~nm}$ & $656,3 \mathrm{~nm}$ & & \\
\hline $\mathrm{x}=0$ & 2,0216 & 1,9757 & 1,9577 & 15,20 & 2,8 \\
\hline$x=5$ & 2,2843 & 2,2474 & 2,2318 & 23,76 & 2,3 \\
\hline$x=10$ & 2,2829 & 2,2415 & 2,2245 & 21,26 & 2,7 \\
\hline$x=20$ & 2,3317 & 2,2769 & 2,2534 & 16,31 & 4,9 \\
\hline
\end{tabular}

Berthereau e colaboradores [11] estudaram uma série de vidros teluritos de nióbio em relação à sua $\mathrm{Tg}$ e em relação à energia do gap óptico. Estes resultados seguem na tabela 3 .

Tabela 3 - Relação da Tg e energia do gap de vidros teluritos de nióbio.

\begin{tabular}{|l|l|l|}
\hline Composição da amostra & $\mathrm{Tg}\left({ }^{\circ} \mathrm{C}\right)$ & Energia do gap (eV) \\
\hline$\left(92 \mathrm{TeO}_{2} .8 \mathrm{Nb}_{2} \mathrm{O}_{5}\right) \mathrm{mol} \%$ & 351 & 3,15 \\
\hline$\left(90 \mathrm{TeO}_{2} .10 \mathrm{Nb}_{2} \mathrm{O}_{5}\right) \mathrm{mol} \%$ & 357 & 3,14 \\
\hline$\left(85 \mathrm{TeO}_{2} .15 \mathrm{Nb}_{2} \mathrm{O}_{5}\right) \mathrm{mol} \%$ & 392 & 3,09 \\
\hline$\left(80 \mathrm{TeO}_{2} .2 \mathrm{NDb}_{2} \mathrm{O}_{5}\right) \mathrm{mol} \%$ & 427 & 3,06 \\
\hline $\mathrm{TeO}_{2}$ & - & 3,37 \\
\hline
\end{tabular}

\subsubsection{Um breve histórico do progresso dos resultados da não linearidade} de terceira ordem e do índice de refração não linear de segunda ordem utilizando vidros teluritos

Dutreilh-Colas e colaboradores [12] produziram várias amostras de vidros teluritos com espessura de 0,8 $\mu \mathrm{m}$ (amostras "a" da tabela 4) e 1,5 $\mu \mathrm{m}$ (amostras "b" da tabela 4) com diferentes quantidades de óxidos modificadores. A comparação da não linearidade de terceira ordem dessas amostras é complicada, pois o $\chi^{3}$ foi 
obtido por diferentes técnicas e em comprimentos de onda próximas da absorção fundamental, levando a discrepâncias entre os valores obtidos para o mesmo material. Mesmo assim ela é válida, pois a mudança do $\chi^{3}$ é claramente percebida com a utilização de amostras de vidro contendo diferentes óxidos modificadores. $\mathrm{Na}$ tabela 5 temos outros valores experimentais extraídos da literatura.

Hoje é bem conhecido que o aumento da concentração de óxidos modificadores na matriz vítrea de $\mathrm{TeO}_{2}$ conduz a uma progressiva despolimerização da rede devido à transformação das unidades estruturais $\mathrm{TeO}_{4}$ (simetria diesfenoidal) para $\mathrm{TeO}_{3}$ (pirâmides trigonais) passando por um poliedro intermediário $\mathrm{TeO}_{3+1}$, no qual um dos oxigênios de $\mathrm{TeO}_{4}$ se afasta gradualmente até a completa separação, exceto com a adição de $\mathrm{B}_{2} \mathrm{O}_{5}$ ou $\mathrm{TiO}_{2}$ que não provocam mudanças estruturais. Cálculos a partir de primeiros princípios, envolvendo as unidades estruturais $\left(\mathrm{TeO}_{4}\right)^{-4}$ e $\left(\mathrm{TeO}_{3}\right)^{-2}$, mostraram que a polarizabilidade dos di-esfenóides $\mathrm{TeO}_{4}$ é aproximadamente vinte vezes maior do que a dos grupos trigonais $\mathrm{TeO}_{3}$, mostrando que o aumento da concentração dos modificadores implica em uma redução das propriedades ópticas não-lineares [12].

Tabela 4 - Susceptibilidade não linear de terceira ordem medida em diversos composições $\chi^{3}$ [12].

\begin{tabular}{|c|c|c|}
\hline Amostra (mol\%) & $\chi^{(3)}\left(\frac{\mathrm{cm}^{2}}{\text { StatV }^{2}}\right) 10^{-12}( \pm 10 \%)$ & $\begin{array}{l}\text { Sinal de } \\
\text { ref. }\end{array}$ \\
\hline a) & & \\
\hline $56 \mathrm{TeO}_{2} .24 \mathrm{TIO}_{0-5 .} .20 \mathrm{PbO}$ & 5,10 & + \\
\hline $80 \mathrm{TeO}_{2} \cdot 10 \mathrm{TIO}_{0-5.10 \mathrm{PbO}}$ & 2,08 & + \\
\hline $70 \mathrm{TeO}_{2} .10 \mathrm{TIO}_{0-5} .20 \mathrm{PbO}$ & 2,88 & + \\
\hline $85 \mathrm{TeO}_{2 .} 10 \mathrm{TIO}_{0-5.5} \mathrm{PbO}$ & 3,29 & + \\
\hline $75 \mathrm{TeO}_{2} .10 \mathrm{TIO}_{0-5 .} .15 \mathrm{PbO}$ & 3,76 & + \\
\hline $57 \mathrm{TeO}_{2} .38 \mathrm{TIO}_{0-5.5} \mathrm{PbO}$ & 5,06 & + \\
\hline $66,5 \mathrm{TeO}_{2} .28,5 \mathrm{TIO}_{0-5} .5 \mathrm{PbO}$ & 5,22 & + \\
\hline $63 \mathrm{TeO}_{2} .27 \mathrm{TIO}_{0-5 .} .10 \mathrm{PbO}$ & 4,48 & + \\
\hline $59,5 \mathrm{TeO}_{2} .25,5 \mathrm{TIO}_{0-5.15 \mathrm{PbO}}$ & 4,26 & + \\
\hline
\end{tabular}




\begin{tabular}{|c|c|c|}
\hline $66,5 \mathrm{TeO}_{2} .28 \mathrm{TIO}_{0-5.5 \mathrm{PbO}}$ & 5,22 & + \\
\hline $51 \mathrm{TeO}_{2} .34 \mathrm{TIO}_{0-5} .15 \mathrm{PbO}$ & 4,59 & + \\
\hline $76 \mathrm{TeO}_{2 .} .19 \mathrm{TIO}_{0-5} .5 \mathrm{PbO}$ & 3,84 & + \\
\hline $72 \mathrm{TeO}_{2} .18 \mathrm{TIO}_{0-5.10 \mathrm{PbO}}$ & 3,51 & + \\
\hline $68 \mathrm{TeO}_{2} \cdot 17 \mathrm{TIO}_{0-5} .15 \mathrm{PbO}$ & 3,90 & + \\
\hline $64 \mathrm{TeO}_{2} .16 \mathrm{TIO}_{0-5.20 \mathrm{PbO}}$ & 3,90 & + \\
\hline $85 \mathrm{TeO}_{2 .} 15 \mathrm{PbO}\left(+1 \% \mathrm{~B}_{2} \mathrm{O}_{3}\right)$ & 3,13 & + \\
\hline $80 \mathrm{TeO}_{2} \cdot 20 \mathrm{PbO}\left(+1 \% \mathrm{~B}_{2} \mathrm{O}_{3}\right)$ & 3,33 & + \\
\hline $85 \mathrm{TeO}_{2} .15 \mathrm{~B}_{2} \mathrm{O}_{3}$ & 2,91 & - \\
\hline $85 \mathrm{TeO}_{2} .15 \mathrm{TiO}_{2}$ & 3,56 & - \\
\hline $90 \mathrm{TeO}_{2} .10 \mathrm{TiO}_{2}$ & 3,80 & - \\
\hline $85 \mathrm{TeO}_{2} .18 \mathrm{GaO}_{1-5}$ & 2,04 & - \\
\hline $75 \mathrm{TeO}_{2} .25 \mathrm{TIO}_{0-5}$ & 4,34 & + \\
\hline $60 \mathrm{TeO}_{2} .40 \mathrm{TIO}_{0-5}$ & 4,28 & + \\
\hline $50 \mathrm{TeO}_{2} .50 \mathrm{TIO}_{0-5}$ & 2,65 & + \\
\hline $85 \mathrm{TeO}_{2} .15 \mathrm{NbO}_{2-5}$ & 3,16 & + \\
\hline $58 \mathrm{TeO}_{2} .36 \mathrm{TIO}_{0-5.5 \mathrm{BiO}_{1-5}}$ & 5,69 & + \\
\hline $54 \mathrm{TeO}_{2} .36 \mathrm{TIO}_{0-5} .10 \mathrm{GaO}_{1-5}$ & 4,00 & + \\
\hline $58,5 \mathrm{TeO}_{2} .39 \mathrm{TIO}_{0-5} .2,5 \mathrm{GaO}_{1-5}$ & 3,24 & + \\
\hline \multicolumn{3}{|l|}{ b) } \\
\hline $54 \mathrm{TeO}_{2} \cdot 36 \mathrm{TIO}_{0-5} \cdot 10 \mathrm{GaO}_{1-5}$ & 1,33 & + \\
\hline $54 \mathrm{TeO}_{2} .36 \mathrm{TIO}_{0-5 .} .10 \mathrm{PbO}$ & 1,75 & + \\
\hline $59 \mathrm{TeO}_{2} .36 \mathrm{TIO}_{0-5} .5 \mathrm{BiO}_{1-5}$ & 1,75 & + \\
\hline
\end{tabular}

Alguns autores [18] e [19] mediram o índice de refração não linear $\mathrm{n}_{2}$ eletrônico por meio de diferentes técnicas, entre elas temos: interferometria com mistura de três ondas (MTO) e interferometria de resolução temporal (IRT). Na tabela 6 seguem os respectivos valores obtidos e calculados por estes autores com a respectiva técnica utilizada. 
Tabela 5 - Valores experimentais extraídos da literatura, com a respectiva amostra, sua temperatura de transição vítrea (Tg), susceptibilidade não linear de terceira ordem $\left(\chi^{(3)}\right)$ e referências.

\begin{tabular}{|l|l|l|l|}
\hline Amostra $\left(\mathrm{mol}^{\circ}\right)$ & $\begin{array}{l}\mathrm{Tg} \\
\left({ }^{\circ} \mathrm{C}\right)\end{array}$ & $\begin{array}{c}\chi^{(3)} \\
(\mathrm{esu})\end{array}$ & Ref. \\
\hline $30 \mathrm{ZnO} .70 \mathrm{TeO}_{2}$ & - & $9,9 \times 10^{-12}$ & {$[13]$} \\
\hline $30 \mathrm{NaO}_{1 / 2} .70 \mathrm{TeO}_{2}$ & 195 & - & {$[13]$} \\
\hline $20 \mathrm{WO}_{3} .80 \mathrm{TeO}_{2}$ & - & $1,48 \times 10^{-12}$ & {$[14,16]$} \\
\hline $70 \mathrm{TeO}_{2} .25 \mathrm{~Pb}\left(\mathrm{PO}_{3}\right)_{2} .5 \mathrm{Sb}_{2} \mathrm{O}_{3}$ & 380, & $2,2 \times 10^{-12}$ & {$[15]$} \\
& 450 & & \\
\hline $85 \mathrm{TeO}_{2} .15 \mathrm{Nb}_{2} \mathrm{O}_{5}$ & 380 & - & {$[17]$} \\
\hline
\end{tabular}

Tabela 6 - Valores do $n_{2}$ eletrônico de vidros teluritos comparados aos de outros materiais, encontrados na literatura.

\begin{tabular}{|c|c|c|c|c|c|}
\hline Amostras e $\lambda$ utilizado sobre a amostra & $n_{2}$ cal (esu) & $\begin{array}{ll}n_{2} & \text { med. } \\
\text { (esu) } & \end{array}$ & $\begin{array}{l}n \text { med. } \\
\text { e } \lambda(n m)\end{array}$ & $\begin{array}{l}\text { Téc- } \\
\text { nica }\end{array}$ & Ref. \\
\hline $\begin{array}{l}\left(79 \mathrm{TeO}_{2} \cdot 20 \mathrm{Na}_{2} \mathrm{O} .1 \mathrm{Nd}_{2} \mathrm{O}_{3}\right) \\
(\mathrm{NBS}) \mathrm{mol} \% ; \lambda_{1}=532 \mathrm{~nm}, \lambda_{2}=1071 \mathrm{~nm}, \\
\lambda_{3}=1057 \mathrm{~nm}\end{array}$ & $2,8 \times 10^{-12}$ & $2,3 \times 10^{-12}$ & 1,$99 ;-$ & MTO & [18] \\
\hline $\begin{array}{l}\left(88 \mathrm{TeO}_{2} \cdot 10,4 \mathrm{Nb}_{2} \mathrm{O}_{5} \cdot 1,6 \mathrm{Nd}_{2} \mathrm{O}_{3}\right) \\
\text { (Kigre) mol\%; } \lambda_{1}=532 \mathrm{~nm}, \quad \lambda_{2}= \\
1071 \mathrm{~nm}, \lambda_{3}=1057 \mathrm{~nm}\end{array}$ & $4,1 \times 10^{-12}$ & $2,4 \times 10^{-12}$ & $-;-$ & MTO & [18] \\
\hline$\left(95 \mathrm{TeO}_{2} .5 \mathrm{Nb}_{2} \mathrm{O}_{5}\right) \mathrm{mol} \%, \lambda=800 \mathrm{~nm}$ & - & $2,51 \times 10^{-12}$ & 2,$23 ; 840$ & - & [11] \\
\hline$\left(92 \mathrm{TeO}_{2} .8 \mathrm{Nb}_{2} \mathrm{O}_{5}\right) \mathrm{mol} \%, \lambda=800 \mathrm{~nm}$ & - & $2,33 \times 10^{-12}$ & 2,$25 ; 840$ & - & [11] \\
\hline$\left(90 \mathrm{TeO}_{2} .10 \mathrm{Nb}_{2} \mathrm{O}_{5}\right) \mathrm{mol} \%, \lambda=800 \mathrm{~nm}$ & - & $2,21 \times 10^{-12}$ & 2,$24 ; 840$ & - & [11] \\
\hline$\left(85 \mathrm{TeO}_{2} .15 \mathrm{Nb}_{2} \mathrm{O}_{5}\right) \mathrm{mol} \%, \lambda=800 \mathrm{~nm}$ & - & $2,16 \times 10^{-12}$ & 2,$22 ; 840$ & - & [11] \\
\hline$\left(80 \mathrm{TeO}_{2} .20 \mathrm{Nb}_{2} \mathrm{O}_{5}\right) \mathrm{mol} \%, \lambda=800 \mathrm{~nm}$ & - & $2,15 \times 10^{-12}$ & 2,$26 ; 840$ & - & [11] \\
\hline $\begin{array}{l}\left(60 \mathrm{~B}_{2} \mathrm{O}_{3} \cdot 30 \mathrm{BaO} \cdot 9,3 \mathrm{Al}_{2} \mathrm{O}_{3} \cdot 0,7 \mathrm{Nd}_{2} \mathrm{O}_{3}\right) \\
\text { (Kigre) } \mathrm{mol} \% ; \quad \lambda_{1}=532 \mathrm{~nm}, \quad \lambda_{2}= \\
1071 \mathrm{~nm}, \lambda_{3}=1057 \mathrm{~nm}\end{array}$ & $1,74 \times 10^{-13}$ & $1,88 \times 10^{-13}$ & & MTO & [18] \\
\hline $\begin{array}{l}\left(55 \mathrm{P}_{2} \mathrm{O}_{5} \cdot 40 \mathrm{SrO} \cdot 4,7 \mathrm{La}_{2} \mathrm{O}_{3} \cdot 0,3 \mathrm{Nd}_{2} \mathrm{O}_{3}\right) \\
(\mathrm{Hoya}) \mathrm{mol} \% ; \quad \lambda_{1}=532 \mathrm{~nm}, \quad \lambda_{2}= \\
1071 \mathrm{~nm}, \lambda_{3}=1057 \mathrm{~nm}\end{array}$ & $1,35 \times 10^{-13}$ & $1,56 \times 10^{-13}$ & & MTO & [18] \\
\hline
\end{tabular}


Segundo Adair e colaboradores [18] uma forma simplificada de estimar o valor do índice de refração não linear $\mathrm{n}_{2}$, e que possui boa concordância experimental para vários vidros e cristais de fluoreto, é dada pela fórmula de Boling e colaboradores:

$$
\mathrm{n}_{2}\left(10^{-13} \mathrm{esu}\right)=\frac{68\left(\mathrm{n}_{\mathrm{d}}-1\right)\left(\mathrm{n}_{\mathrm{d}}^{2}+2\right)^{2}}{v_{\mathrm{d}}\left[1,52+\frac{\left(\mathrm{n}_{\mathrm{d}}^{2}+2\right)\left(\mathrm{n}_{\mathrm{d}}+1\right)}{6 \mathrm{n}_{\mathrm{d}}}\right]^{\frac{1}{2}}},
$$

Em que $v_{d}$ é o número de Abbé e é dado pela expressão:

$$
v_{\mathrm{d}}=\frac{\left(\mathrm{n}_{\mathrm{d}}-1\right)}{\left(\mathrm{n}_{\mathrm{f}}-\mathrm{n}_{\mathrm{c}}\right)}
$$

em que $\mathrm{n}_{\mathrm{f}}, \mathrm{n}_{\mathrm{d}}, \mathrm{n}_{\mathrm{c}}$ representam o índice de refração da amostra nos comprimentos de onda de 486,1; 587,6 e 656,3 nm, respectivamente.

Segundo Kim e Yoko [16] existe quase uma relação linear entre o $\chi^{(3)}$ e o termo $\left(n_{\omega}^{2}+2\right) \cdot\left(n_{\omega}^{2}-1\right) \cdot \frac{E_{d 1}}{E_{01}^{2}}$, sendo $E_{d 1}$ a área sob a porção eletrônica do espectro da componente complexa da permissividade elétrica, $\mathrm{E}_{01}$ a média de todas as excitações eletrônicas representada por uma única transição em um modelo de dois níveis e $\mathrm{n}_{\omega}$ o índice de refração linear em uma determinada freqüência. Esta relação contém apenas três parâmetros mensuráveis sem contar com as espécies de orbitais moleculares que foram deduzidos com base na teoria desenvolvida por Lines. O valor de $\chi^{(3)}$ mais elevado obtido foi $1,69 \times 10^{-12}$ esu para o vidro (30 $\left.\mathrm{Nb}_{2} \mathrm{O}_{3} .70 \mathrm{TeO}_{2}\right)$ mol\% é aproximadamente 60 vezes maior do que o do vidro de sílica fundida pura. Já para o vidro $\left(20 \mathrm{Nb}_{2} \mathrm{O}_{3} .80 \mathrm{TeO}_{2}\right)$ mol\% temos o $\chi^{(3)}$ de $1,61 \times 10^{-12}$ esu. Esses autores efetuaram medidas sistemáticas para investigar a contribuição dos orbitais vazios catiônicos $3 d, 4 d$ e $5 d$ para a resposta óptica não linear.

Uma contribuição significativa da transição virtual entre os orbitais $p$ de valência e os orbitais vazios $5 \mathrm{~d}$ do átomo de telúrio foi sugerida pela primeira vez por Lines [20,21] baseada na teoria do orbital de ligação. É, portanto, de grande interesse esclarecer o papel dos orbitais d na resposta óptica não linear. 
Terashima e colaboradores [22] discutem algumas conclusões referentes a $\chi^{(3)}$ de vidros alcalinos binários $\mathrm{M}_{2} \mathrm{O}-\mathrm{B}_{2} \mathrm{O}_{3}(\mathrm{M}=\mathrm{Li}, \mathrm{Na}, \mathrm{K}, \mathrm{Rb}, \mathrm{Cs}$ e $\mathrm{Ag})$ nos quais sofre um aumento graças à presença de oxigênios terminais (NBO's) acima de 20 mol\% de $\mathrm{M}_{2} \mathrm{O}$ ( $\mathrm{M}=\mathrm{Li}, \mathrm{Na}, \mathrm{K}, \mathrm{Rb}$ e $\mathrm{Cs}$ ), introduzindo uma maior quantidade de oxigênios cuja polarizabilidade é muito maior que a do boro. Dentre os vidros alcalinos o vidro $\mathrm{Li}_{2} \mathrm{O}-\mathrm{B}_{2} \mathrm{O}_{3}$ foi o que apresentou melhor $\chi^{(3)}$ devido ao maior caráter covalente da ligação Li-O, em contrapartida à mudança das unidades estruturais de $\mathrm{BO}_{3}$ para $\mathrm{BO}_{4}$ não introduziu um aumento significativo. $\mathrm{O}$ vidro $A g_{2} \mathrm{O}-\mathrm{B}_{2} \mathrm{O}_{3}$ [23] apresentou o maior valor de $\chi^{(3)}$, em comparação com os demais, devido ao caráter covalente muito alto existente na ligação $\mathrm{Ag}-\mathrm{O}$ que consiste principalmente de estados de hibridização $\left(4 d_{z}^{2}+5 s+5 p\right)$. Estes estados ressaltam a força de oscilador da transição óptica devido ao grande alargamento da linha dos orbitais moleculares e também ao efeito de ressonância óptica.

\subsubsection{Referências}

[1] Prakash, G. V.; Rao, D. N.; Bhatnagnar, A. K. Linear optical properties of niobiumbased tellurite glasses. Solid State Comm., v. 119, p. 39-44, 2001 e referências contidas.

[2] Ohishi, Y.; Mori, A.; Yamada, M.; Ono, H.; Nishida, Y.; Oikawa, K. Gain characteristics of tellurite-based erbium-doped fiber amplifiers for $1.5-\mu \mathrm{m}$ broadband amplification. Opt. Lett., v. 23, p. 274-276, 1998.

[3] Hu, Y.; Jiang, S.; e colaboradores Numerical analyses of the population dynamics and determination of the upconversion coefficients in a new high erbium-doped tellurite glass. J. Opt. Soc. Am. B, v. 18, p. 1928-1934, 2001.

[4] Wang, J. S.; Snitzer, E.; Vogel E. M.; Sigel J. G. H. 1.47, 1.88 and $2.8 \mu \mathrm{m}$ emissions of $\mathrm{Tm}^{3+}$ and $\mathrm{Tm}^{3+}-\mathrm{Ho}^{3+}$-codoped tellurite glasses. J. Lumin., v.60/61, p. 145, 1994.

[5] Yano, T.; Watanabe A. Tellurite glass: A new acousto-optic material. J. of Applied Phys., v.42, n. 10, p. 3674, 1971.

[6] Tanabe, S. J. Of Alloys and Compounds, v. 675, p. 408-412, 2006. 
[7] Pontuschka, W. M.; Barbosa, L. C. Progress on oxide glasses Applications in photonics. In: G Lucovsky; M. A. Popescu (Org.). Non-Crystalline Materials for Optoelectronics. Bucharest, v. 13, p. 363-392, 2004.

[8] Neov, S.; Kozhukharov, V.; Gerasimova, I.; Krezhov, K.; Sidzhimov, B. A model for structural recombination in tellurite glasses. J. Phys. C: Solid State Phys., v. 12, p. 2475-2485, 1979.

[9] Sekiya, T.; Mochida, N.; Ohtsuka, A.; Tonokawa, M. Raman Spectra of $\mathrm{MO}_{1 / 2}-$ $\mathrm{TeO}_{2}(\mathrm{M}=\mathrm{Li}, \mathrm{Na}, \mathrm{K}, \mathrm{Rb}, \mathrm{Cs}$, and Ti) glasses. J. Non-Cryst. Solids, v. 144, p. 128-145, 1992.

[10] Lin, J.; Huang, W.; Sun, Z.; Ray, C. S.; Day, D. E. Structure and non-linear optical performance of TeO2-Nb2O5-ZnO glasses. J. of Non-Cryst. Solids, v. 336, p. 189-194, 2004.

[11] Berthereau, A.; Le Luyer, Y.; Olazcuaga, R.; Le Flem, G.; Couzi, M.; Canioni, L.; Segonds, P.; Sarger, L.; Ducasse, A. Nonlinear optical properties of some tellurium (IV) oxide glasses. Mat. Res. Bul., v. 29, n. 9, p. 933-941, 1994.

[12] Dutreilh-Colas, M.; Thomas, P.; Champarnaud-Mesjard, J. C. New $\mathrm{TeO}_{2}$ based glasses for nonlinear optical applications: study of the $\mathrm{Tl}_{2} \mathrm{O}-\mathrm{TeO}_{2}-\mathrm{Bi}_{2} \mathrm{O}_{3}, \mathrm{Tl}_{2} \mathrm{O}-$ $\mathrm{TeO}_{2}-\mathrm{PbO}$ and $\mathrm{Tl}_{2} \mathrm{O}-\mathrm{TeO}_{2}-\mathrm{Ga}_{2} \mathrm{O}_{3}$ systems. Phys. Chem. Glasses, v. 44, n. 5, p. 349-352, 2003.

[13] Narazaki, A.; Tanaka, K.; Hirao, K.; Soga, N. Induction and relaxation of optical second-order nonlinearity in tellurite glasses. J. Appl. Phys., v. 85 , n. 4, p. 20462051, 1999.

[14] Tanaka, K.; Narazaki, A.; Hirao, K. Large optical second-order nonlinearity of poled $\mathrm{WO}_{3}-\mathrm{TeO}_{2}$ glasses. Opt. Lett., v. 25, n. 4, p. 251-153, 2000.

[15] Ferreira, B.; Fargin, E.; Guillaume, B.; Flem, G. L.; Rodriguez, V.; Couzi, M.; e colaboradores Second harmonic generation in poled tellurite glass. J. Non-Cryst. Solids, v. 332, p. 207-218, 2003.

[16] Kim, S. H.; Yoko, T. Nonlinear optical properties of $\mathrm{TeO}_{2}$-based glasses: $\mathrm{MO}^{-}$ $\mathrm{TeO}_{2}(\mathrm{M}=\mathrm{Sc}, \mathrm{Ti}, \mathrm{V}, \mathrm{Nb}, \mathrm{Mo}, \mathrm{Ta}$, and $\mathrm{W}$ ) binary glasses. J. Am. Ceram. Soc., v. 78, n. 4, p.1061-1065, 1995. 
[17] Tanaka, K.; Narazaki, A.; Yonezaki, Y.; Hirao, K. Poling-induced structural change and second-order nonlinearity of $\mathrm{Na}^{+}$doped $\mathrm{Nb}_{2} \mathrm{O}_{5}-\mathrm{TeO}_{2}$ glass. J. Phys.: Condens. Matter., v. 12, n. 30, L513-518, 2000.

[18] Adair, R.; Chase, L. L.; Payne, S. A. Nonlinear refractive-index measurements of glasses using three-wave frequency mixing. J. Opt. Soc. Am. B, v. 4, n. 6, p. 875$881,1987$.

[19] Moran, M. J.; She, C. Y.; Carman, R. L. Interferometric measurements of the nonlinear refractive-index coefficient relative to CS, in laser-system-related materials. IEEE J. Quant. Electrom., v. 11, n. 6, p. 259-263, 1975.

[20] Lines, E. M. Bound orbital theory of linear na nonlinear electronic response in ionic crystals. II. Nonlinear response. Phys. Rev. B, v. 41, p. 3383-3390, 1990.

[21] Lines, E. M. Influence of d-orbitals on the nonlinear optical response of transparent transition-metal oxides. Phys. Rev. B, v. 43, p. 11978-11990, 1991.

[22] Terashima, K.; Kim, S. H.; Yoko, T. Nonlinear Optical Properties of $\mathrm{B}_{2} \mathrm{O}_{3}$-based glasses: $\mathrm{M}_{2} \mathrm{O}-\mathrm{B}_{2} \mathrm{O}_{3}(\mathrm{M}=\mathrm{Li}, \mathrm{Na}, \mathrm{K}, \mathrm{Rb}, \mathrm{Cs}$, and $\mathrm{Ag})$ binary borate glasses. J. Am. Ceram. Soc., v. 78, n. 6, p. 1601-1605, 1995.

[23] Terashima, K.; Hashimoto, T.; Yoko, T. Nonlinear optical properties of $\mathrm{B}_{2} \mathrm{O}_{3}$ based glasses: binary $\mathrm{Ag}_{2} \mathrm{O}-\mathrm{B}_{2} \mathrm{O}_{3}$ and ternary $\mathrm{AgX}-\mathrm{Ag}_{2} \mathrm{O}-\mathrm{B}_{2} \mathrm{O}_{3}(\mathrm{X}=\mathrm{Cl}, \mathrm{Br}$ and I) glasses. Phys. Chem. Glasses, v. 37,n. 4, p. 129-133, 1996.

\section{2 Índice de refração}

\subsubsection{Uma breve revisão do comportamento do índice de refração real e complexo em um meio isotrópico e o método de Wemple}

Vidros são materiais macroscopicamente isotrópicos, ou seja, a susceptibilidade elétrica linear (em unidades gaussianas) é dada por:

$$
\chi=\frac{\varepsilon-1}{4 \pi}
$$

em que $\varepsilon$ é a permissividade elétrica em materiais isotrópicos e $\chi$ possue o mesmo valor para qualquer direção do campo eletromagnético aplicado.

O índice de refração ordinário é dado por: 


$$
\mathrm{n}=\frac{\mathrm{c}}{\mathrm{v}}=\sqrt{\varepsilon},
$$

em meios não magnéticos $(\mu=1)$.

Considerando que o índice de refração depende da freqüência da onda eletromagnética aplicada e considerando que o átomo está ligado a outros átomos em um sistema massa-mola amortecido clássico, calculamos a polarização total no meio e substituímos a equação (A.1.16) na equação (A.1.18) para obter:

$$
\overrightarrow{\mathrm{P}}=\frac{\mathrm{e}^{2}}{\mathrm{~m}} \frac{\mathrm{N} \overrightarrow{\mathrm{E}}}{\left(\omega_{0}^{2}-\omega^{2}-\mathrm{i} \omega \Gamma\right)}
$$

O índice de refração de uma onda propagando-se em um meio material é:

$$
\eta=\mathrm{n}+\mathrm{ik}
$$

em que $\eta$ é o índice de refração complexo e k o coeficiente de extinção responsável pela absorção do material. Substituindo a equação (2.2.1.3) na equação (A.1.22) e igualando com a equação (2.2.1.4), teremos a parte real e imaginária do índice de refração:

$$
\begin{aligned}
& \mathrm{n}^{2}-\mathrm{k}^{2}=1+\frac{2 \pi N \mathrm{e}^{2}}{\mathrm{~m}}\left[\frac{\left(\omega_{0}^{2}-\omega^{2}\right)}{\left(\omega_{0}^{2}-\omega^{2}\right)^{2}+\Gamma^{2} \omega^{2}}\right] \\
& \mathrm{e} \quad 2 \mathrm{nk}=\frac{2 \pi N \mathrm{e}^{2}}{\mathrm{~m}}\left[\frac{\Gamma \omega}{\left(\omega_{0}^{2}-\omega^{2}\right)^{2}+\Gamma^{2} \omega^{2}}\right] .
\end{aligned}
$$

Os parâmetros ópticos $\mathrm{n}$ e $\mathrm{k}$ podem ser calculados por meio das equações abaixo:

$$
\begin{aligned}
\mathrm{n}(\omega) & =\sqrt{\frac{1}{2} \beta \pm \sqrt{\beta^{2}+4 \delta^{2}}} \\
\mathrm{e} \quad \mathrm{k}(\omega) & =\frac{\gamma \omega \tau}{2 \mathrm{n}}=\frac{2 \pi N e^{2}}{m}\left[\frac{\omega \Gamma}{\left(\omega_{0}^{2}-\omega^{2}\right)^{2}+\Gamma^{2} \omega^{2}}\right] \frac{1}{n(\omega)},
\end{aligned}
$$

onde $\beta=1+\frac{2 \pi N e^{2}}{m}\left[\frac{\left(\omega_{0}^{2}-\omega^{2}\right)}{\left(\omega_{0}^{2}-\omega^{2}\right)^{2}+\Gamma^{2} \omega^{2}}\right]$

e $\delta=\frac{2 \pi N e^{2}}{m}\left[\frac{\omega \Gamma}{\left(\omega_{0}^{2}-\omega^{2}\right)^{2}+\Gamma^{2} \omega^{2}}\right]$.

As equações (2.2.1.5) e (2.2.1.6) mostram que a parte real e imaginária do índice de refração depende da freqüência e conseqüentemente o meio será 
dispersivo. Na figura 4 temos um gráfico do comportamento da parte real e imaginária do índice de refração em função da freqüência sem o coeficiente de extinção. Neste gráfico temos três situações interessantes:

1. Se $\omega<\omega_{1}$ teremos uma dispersão normal, ou seja, a parte real do índice de refração aumenta com o aumento da freqüência;

2. Se $\omega>\omega_{2}$ temos o mesmo comportamento;

3. Já se $\omega_{1} \leq \omega \leq \omega_{2} \circ \operatorname{Re}(n)$ decresce à medida que a freqüência aumenta sendo chamado de região de dispersão anômala.

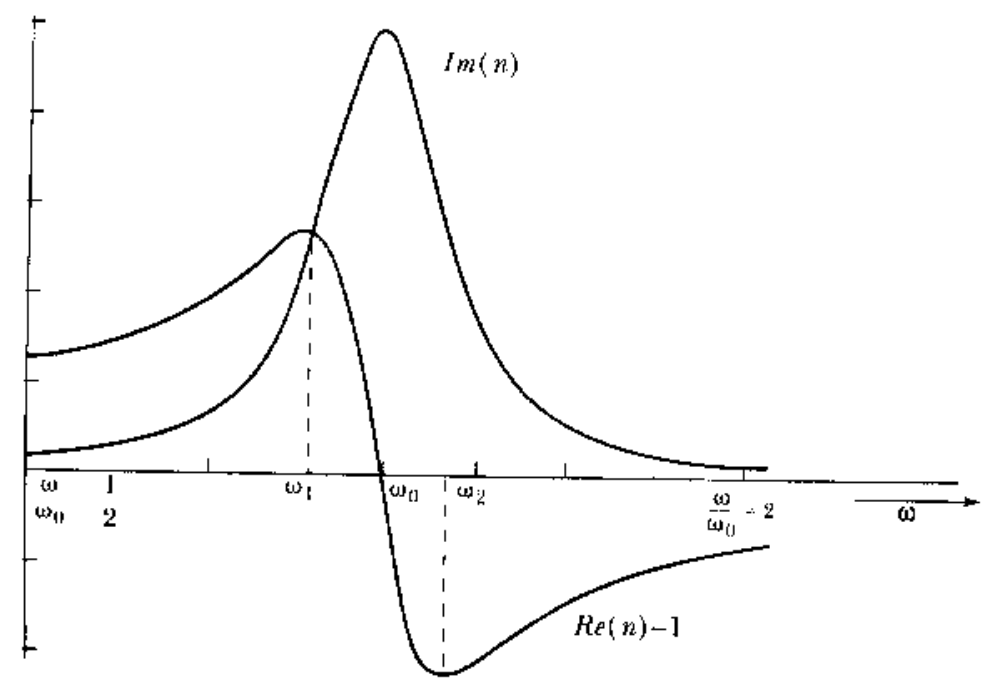

Figura 4 - Gráfico das quantidades $\operatorname{Re}(n)-1$ e $\operatorname{Im}(n)$ em função da freqüência [1].

Em materiais reais e com condutividade elétrica nula, os átomos muitas vezes vibram com diferentes freqüências de ressonância, de forma que o índice de refração complexo será dado pela expressão:

$$
\eta^{2}-\mathrm{k}=1+\frac{4 \pi \mathrm{e}^{2}}{\mathrm{~m}_{\mathrm{e}}} \sum_{\mathrm{j}} \frac{\mathrm{f}_{\mathrm{j}}}{\left(\omega_{\mathrm{j}}^{2}-\omega^{2}\right)-\mathrm{i} \Gamma_{\mathrm{j}} \omega} .
$$

$\operatorname{com} f_{j}=\frac{2 m_{e}}{\hbar^{2}} \hbar \omega_{j}\left|x_{0 j}\right|^{2}$

é a força do oscilador, $\mathrm{x}_{0 \mathrm{j}}$ representa o elemento de matriz entre o estado excitado e o fundamental da coordenada do dipolo, $\hbar=\frac{\mathrm{h}}{2 \pi}$, sendo $\mathrm{h}$ a constante de Planck e $\mathrm{m}_{\mathrm{e}}$ é a massa do elétron. 
Em materiais transparentes desconsideramos o termo de amortecimento e a parte real do índice de refração é dada pela expressão:

$$
\mathrm{n}^{2}=1+\frac{4 \pi \mathrm{e}^{2}}{\mathrm{~m}_{\mathrm{e}}} \sum_{\mathrm{j}} \frac{\mathrm{f}_{\mathrm{j}}}{\left(\omega_{\mathrm{j}}^{2}-\omega^{2}\right)}
$$

e a polarizabilidade atômica é dada pela expressão

$$
\alpha_{p}(\omega)=\frac{e^{2}}{m_{e}} \sum_{j} \frac{f_{j}}{\omega_{j}^{2}-\omega^{2}} .
$$

Segundo El-Mallawany [2] a equação de Clausius-Mossoti (2.2.1.15) indica que o índice de refração depende da composição da amostra e quanto mais polarizáveis os elétrons externos, maior será o índice de refração.

$$
\frac{\varepsilon-1}{\varepsilon+2}=\frac{n^{2}-1}{n^{2}+2}=\frac{4 \pi N \alpha}{3}=\frac{4 \pi N e^{2}}{3 m} \sum_{j} \frac{f_{j}}{\omega_{j}^{2}-\omega^{2}} .
$$

Wemple [3], em 1977, desenvolveu um método para calcular, a partir do índice de refração linear medido, a energia média do oscilador $E_{0}$ e a energia de dispersão $E_{d}$. A expressão que relaciona estas quantidades é:

$$
\frac{1}{n^{2}-1}=-\frac{E^{2}}{E_{0} E_{d}}+\frac{E_{0}}{E_{d}}
$$

Em que E é a energia de um fóton.

Para calcular $E_{0}$ e $E_{d}$ e verificar se os dados obedecem a um ajuste linear, reescrevemos a equação acima, como:

$$
\mathrm{Y}=-\mathrm{aX}+\mathrm{b}
$$

no qual a é o coeficiente angular obtido a partir da linearização dos dados experimentais e b o coeficiente linear.

Igualando a equação (2.2.1.16) e a equação (2.2.1.17), temos:

$$
\begin{aligned}
\mathrm{E}_{0} & =\sqrt{\frac{\mathrm{b}}{\mathrm{a}}} \\
\mathrm{E}_{\mathrm{d}} & =\sqrt{\frac{1}{\mathrm{ab}}} \\
\mathrm{e} \quad \mathrm{n}_{\mathrm{cal}} & =\sqrt{\frac{1}{\mathrm{Y}}+1}
\end{aligned}
$$

A constate dielétrica linear é dada pela equação: 


$$
\kappa_{1}=1+\frac{E_{d}}{E_{0}} .
$$

\subsubsection{Referências}

[1] Frenkel, J. Princípios de eletrodinâmica clássica. São Paulo, SP: Edusp, p. 344, 1996.

[2] El-Mallawany, R. The optical properties of tellurite glasses. J. Appl. Phys., v. 72, n. 5, p. 1774-1777, 1992.

[3] Wemple, S.H. Optical Oscillator Strengths and excitation energies in solids, liquids, and molecules. J. Chem. Phys., v. 67, p. 2151-2168, 1977.

\subsection{Técnicas ópticas}

Nesta secção serão exploradas as técnicas de absorção óptica e varredura Z.

\subsubsection{Estudo de absorção óptica (AO) na região do ultravioleta (UV), visível (VIS) e infravermelho (IR)}

A espectroscopia de absorção óptica (AO) é utilizada na investigação das transições eletrônicas entre o estado fundamental e os níveis de energia excitados de defeitos e impurezas presentes na região da banda proibida dos materiais isolantes e semicondutores e das características das bordas das bandas de valência e de condução, fornecendo informações sobre os estados de energia eletrônica dos átomos.

a) Espectroscopia de AO no ultravioleta (UV)

Para vidros teluritos a absorção no UV depende fundamentalmente do alcance das ligações Te-O e estas unidades estruturais seguem os mecanismos propostos por T. Sekiya e colaboradores [1], como descrito na seção 2.1.2.

b) Espectroscopia de AO no visível (VIS)

Nos vidros óxidos não dopados e não irradiados temos somente pequenas contribuições provenientes de traços de impurezas na região do visível, devido às energias das ligações destes vidros situarem-se fundamentalmente no UV distante. Desta forma, a absorção óptica nesta região possui interesse pela possibilidade de 
identificação de certas unidades estruturais moleculares irradiadas contendo centros atômicos de defeitos, bem como centros de cor associados a impurezas, envolvendo transições eletrônicas conhecidas e excitáveis.

Nanopartículas de prata, ouro, cobre, platina e outras são identificadas por meio de uma banda de plasmons na região do visível por meio da técnica de $A O$, maiores detalhes serão discutidos na secção 2.4 .

Os vidros teluritos apresentam cerca de $80 \%$ de transmitância na faixa de 470 a $2700 \mathrm{~nm}$. Pesquisas mostraram que estes vidros apresentam menor energia de fônons comparados aos vidros óxidos mais comuns [2].

c) Espectroscopia de AO no infravermelho (IR)

Certas terminações da rede vítrea como as hidroxilas e pontes de hidrogênio provenientes de impurezas decorrentes da incompleta eliminação da água possuem um certo número de modos de vibração característicos determinados pelas massas dos átomos constituintes, das forças interatômicas e da sua estrutura. Devido ao fato dessas vibrações situarem-se na região de freqüências do IR, a sua interação com ondas eletromagnéticas leva à produção de bandas de absorção, o que pode fornecer informações adicionais sobre a natureza de certas ligações covalentes envolvendo as estruturas mais específicas da rede vítrea. Um exemplo típico ocorre nos vidros contendo água hidrolizada que absorve fortemente a radiação IR na região espectral de 2700 a $4500 \mathrm{~nm}$.

Para uma análise quantitativa do fenômeno de AO utilizamos as duas leis abaixo.

\subsubsection{Lei de Beer}

Esta lei fornece a transmitância de uma placa transparente e suficientemente delgada que consiste na relação entre a luz transmitida através da amostra e a luz monocromática incidente. Esta relação, conhecida como lei de Beer, obedece à lei exponencial

$$
\mathrm{T}=\frac{\mathrm{I}}{\mathrm{I}_{0}}=\mathrm{e}^{-\alpha \mathrm{b}}
$$


onde T é a transmitância, $\alpha$ é o coeficiente de absorção linear, b comprimento óptico percorrido (espessura da amostra), $\mathrm{I}_{0}$ é a intensidade da luz incidente e I a intensidade da luz transmitida.

\subsubsection{Lei de Lambert-Beer}

A forma logarítmica de expressar a lei de Beer, definindo a densidade óptica A como

$$
A=\log _{10}\left(\frac{1}{T}\right)
$$

sendo $A=a_{e} b_{1}$

é conhecida como a lei de Lambert-Beer. Nos parâmetros acima $\mathrm{a}_{\mathrm{e}}$ é a absortividade característica da substância e depende da freqüência da luz e $c_{1}$ a concentração do material absorvedor.

Como as medidas de absorção óptica fornecem absorbância para um determinado comprimento de onda, pode-se calcular a concentração de impurezas da amostra com a equação (2.3.3.2).

\subsubsection{Estrutura das bandas de energia}

Assim como ocorre com as substâncias cristalinas, semicondutoras ou isolantes, também os materiais amorfos não metálicos possuem um intervalo de energia ("gap"), separando uma banda contínua de estados eletrônicos preenchidos denominada banda de valência (BV), de outra banda contínua de níveis desocupados distribuídos por um intervalo de energias mais altas, denominado banda de condução (BC).

As bordas das BV e BC são mais abruptas para os materiais cristalinos porque de acordo com o modelo de "tight-binding" o potencial cristalino pode ser aproximado por um conjunto de poços de potencial de mesma profundidade e regularmente distribuídos (figura 5). No caso dos materiais amorfos, as caudas das bandas são muito mais largas e avançam para o interior do gap, de modo que neste caso o mesmo passou a ser chamado de pseudogap. 
(a)

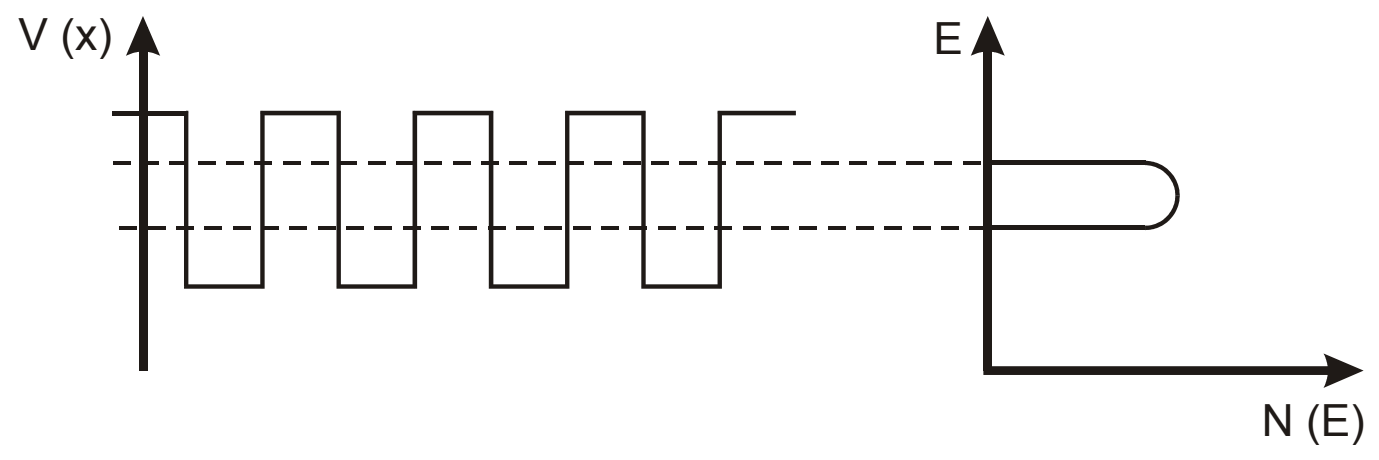

Figura 5 - llustração dos poços de potencial de um material cristalino [3].

O primeiro modelo desenvolvido para explicar o alargamento das caudas das bandas observado nos materiais não cristalinos foi proposto em 1958 por P. W. Anderson [3] que introduziu uma distribuição aleatória de profundidades e de posições dos poços de potencial, obtendo como resultado de cálculos teóricos uma banda alargada de densidade de estados $\mathrm{N}(\mathrm{E})$ para o estado amorfo (figura 6 ). Esta distribuição baseou-se no fato de que a própria desordem do vidro produz flutuações simultaneamente nas margens das bandas de condução e valência de onde resultam as variações de profundidades (figura 6a) e distribuição dos espaçamentos (figura 6b) dos poços de potencial.

Outro modelo básico foi proposto por N. F. Mott em 1967 [4] que efetuou uma extrapolação natural dos resultados coletados de cristais perfeitos e imperfeitos, definindo com precisão os limites das energias $E_{v}$ e $E_{c}$ que separam os estados localizados dos estados estendidos da BV e da BC, respectivamente. Entende-se por estado estendido ou percolado no qual existe uma probabilidade igual de se encontrar a partícula em qualquer parte do material. Em um estado estendido um elétron pode deslocar-se de uma extremidade a outra e dar, assim, uma contribuição não nula à condutividade do sistema (representado a partir de $E_{c r}=E_{\mu}=E_{c}$ na figura 7), em que $E_{c r}$ é a energia crítica de percolação que separa os estados localizados na cauda da $B C$ dos estados vazios estendidos em seu interior e $E_{\mu}$ é a energia do gap de mobilidade.

Em um estado localizado o elétron fica confinado a uma região finita no qual a amplitude da função de onda é diferente de zero (região $P$ da figura 7). A separação entre os limites $E_{v}$ e $E_{c}$ está representada nas figuras 8 e 9, onde $B V$ e $B C$ são 
separadas pelo pseudo gap com as respectivas caudas das bandas avançando para a região intermediária. Na figura 9 , as regiões em branco da BC representam os estados permitidos para serem ocupados pelos elétrons promovidos a partir da BV com energia hv correspondente ao nível deste particular estado. $A$ partir de $E_{c r}=E_{\mu}$ $=\mathrm{E}_{\mathrm{c}}$ temos a região de percolação que compreende os estados estendidos onde os elétrons podem se movimentar livremente (representada pela cor branca).

(a)

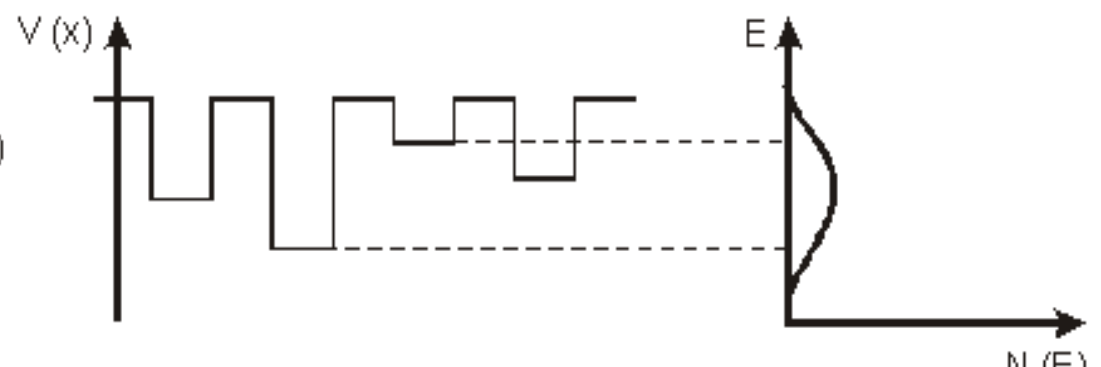

(b)

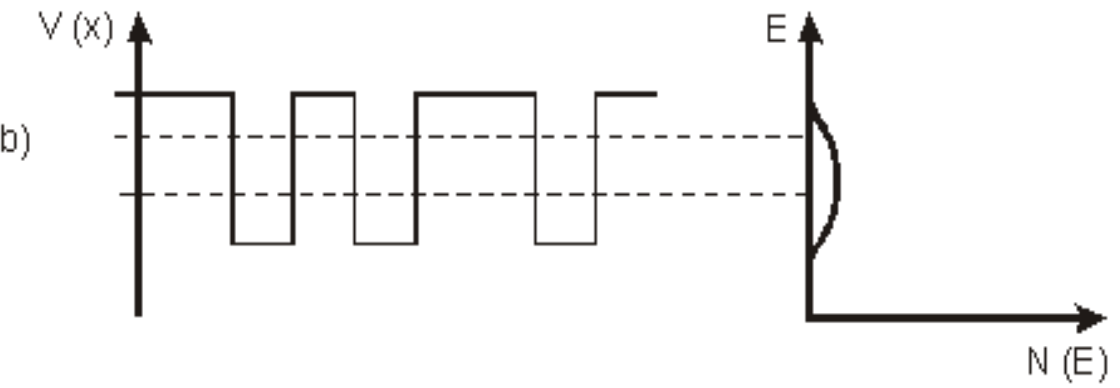

Figura 6 - Ilustração dos poços de potencial de um material amorfo [3] com flutuações de a) profundidade e b) largura. 


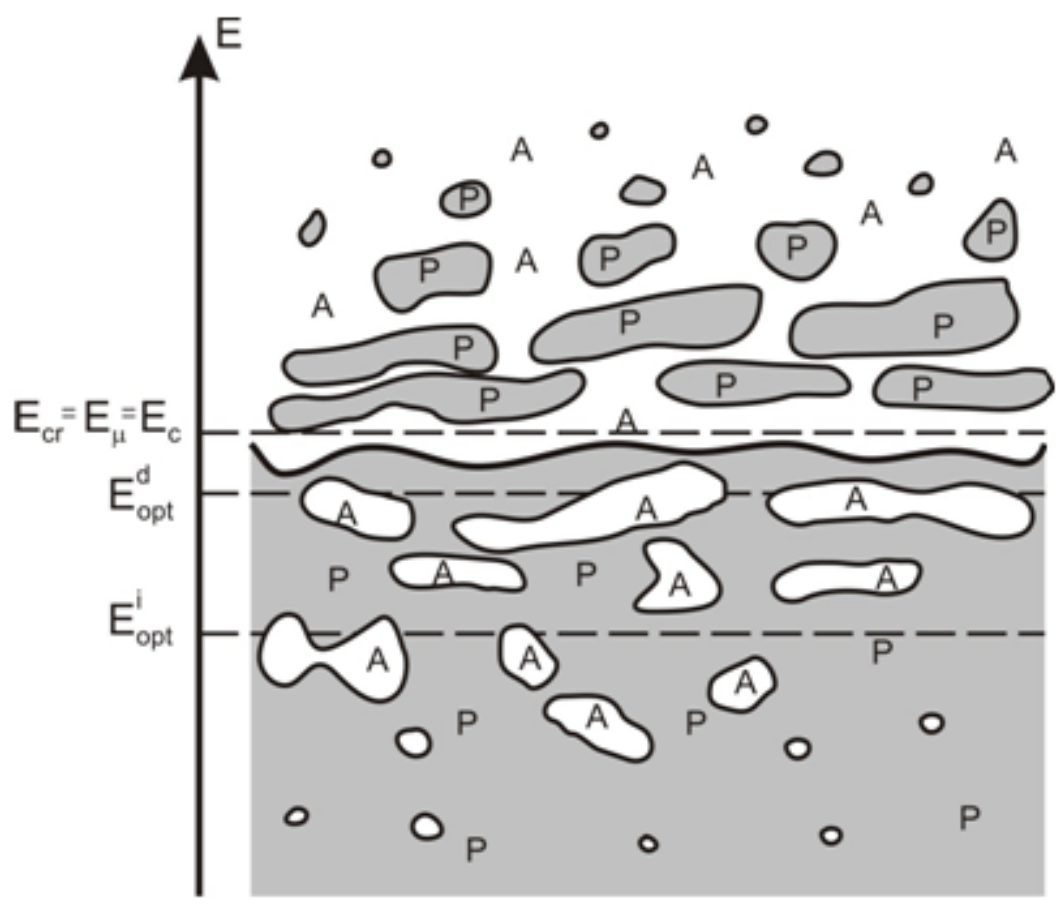

Figura 7 - Esquema demonstrativo dos estados estendidos e localizados. A letra " $A$ " representa regiões no qual o elétron é permitido e " $P$ " uma região no qual ele é proibido. Para energias menores, "A" representa os estados localizados e a partir de $\mathrm{E}_{\mathrm{cr}}=\mathrm{E}_{\mu}=\mathrm{E}_{\mathrm{c}}$ representa estados permitidos estendidos.

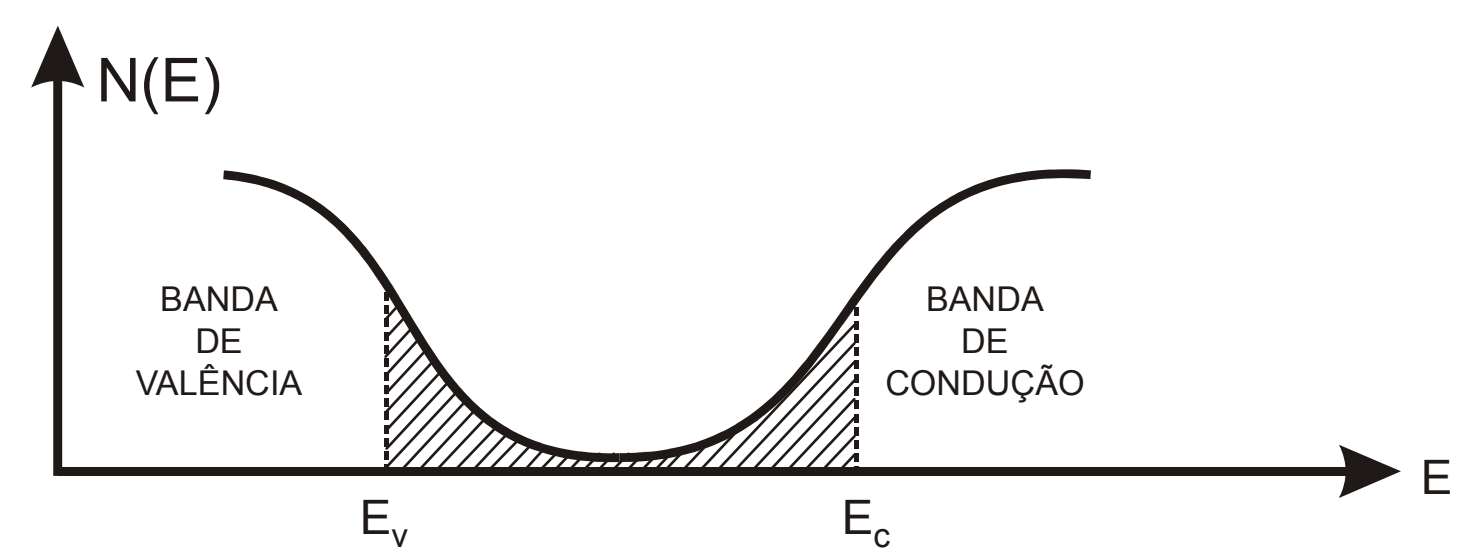

Figura 8 - Esquema demonstrativo da separação entre os limites $E_{v}$ e $E_{c}$.

Os modelos propostos permitiram calcular alguns parâmetros quantitativos deduzidos (Anexo 2) a partir de extrapolações das regiões especificas A, B e C da cauda da BC (figura 10 e 11).

Em que $\alpha_{\mathrm{I}}$ é dada pela função: 


$$
\alpha_{\mathrm{I}}=\frac{\alpha_{\mathrm{cr}}}{(\mathrm{m} \Delta \mathrm{E})^{\mathrm{m}}}\left(\mathrm{h} v-\mathrm{E}_{\mathrm{g}}\right)^{\mathrm{m}},
$$

$\left(\mathrm{h} v \geq \mathrm{E}_{\mathrm{g}}\right)$ com $\mathrm{m}=1 / 2\left(\alpha_{\mathrm{I}_{\text {dir }}}\right)$ para transição direta e $\mathrm{m}=2\left(\alpha_{\mathrm{I}_{\text {ind }}}\right)$ para transição indireta.

$\alpha_{\text {II }}$ é descrito pela equação:

$$
\alpha_{\text {II }}=\alpha_{c r} \mathrm{e}^{-\frac{1}{\Delta \mathrm{E}}\left(\mathrm{E}_{\mathrm{cr}}-\mathrm{h} v\right)},
$$

( $h v \leq \mathrm{E}_{\mathrm{cr}}$ ), no qual $\alpha_{\mathrm{cr}}$ é o coeficiente de absorção do ponto de inflexão da curva experimental, $\Delta \mathrm{E}$ é a energia de Urbach, $\mathrm{E}_{\mathrm{g}}$ é a energia da banda proibida ou energia do gap (neste caso referindo-se ao gap óptico), $v$ é a freqüência da luz monocromática incidente e h é a constante de Planck.

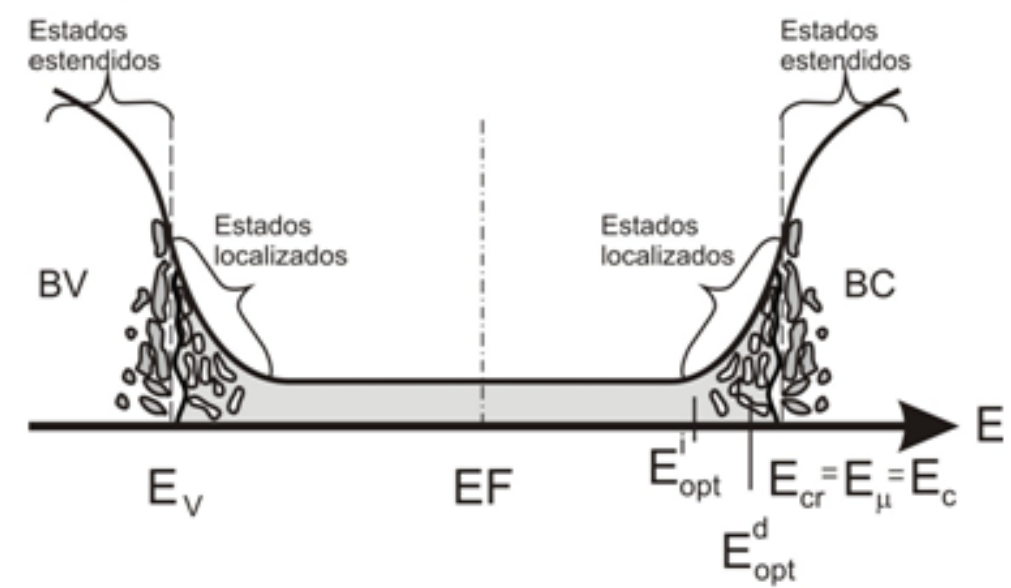

Figura 9 - Esquema demonstrativo da banda de valência, da localização dos estados estendidos, localizados e da banda de condução. EF representa a energia de Fermi, $E_{o p t}^{i}$ a energia do gap de uma transição indireta, $E_{\text {opt }}^{d}$ a energia do gap de uma transição direta e $\mathrm{E}_{\mathrm{cr}}=\mathrm{E}_{\mu}=\mathrm{E}_{\mathrm{c}}$ representa o intervalo de energia no qual a mobilidade dos elétrons aumenta abruptamente. Para as energias $>E_{c r}$ observamos áreas localizadas proibidas (escuras) que diminuem gradualmente com o aumento da energia.

De acordo com o modelo de Mott na região de alta absorção $A,\left(\alpha>10^{4} \mathrm{~cm}^{-}\right.$ 1) as transições ocorrem entre os estados estendidos da BV para os estados 
estendidos da BC. Considerando uma dependência parabólica do coeficiente de absorção em função da energia do fóton no qual $N(E) \propto E^{\frac{1}{2}}$, Jan Tauc propôs em 1970 um método hoje amplamente utilizado para a determinação da energia do gap óptico $\mathrm{E}_{\mathrm{g}}$ baseado na expressão (figura 12):

$$
\alpha \mathrm{n}_{0} \mathrm{hv}=\mathrm{C}\left(\mathrm{h} v-\mathrm{E}_{\mathrm{g}}\right)^{\frac{1}{2}}
$$

com hv $\geq E_{g}$, para uma transição permitida direta, em que C é uma constante.

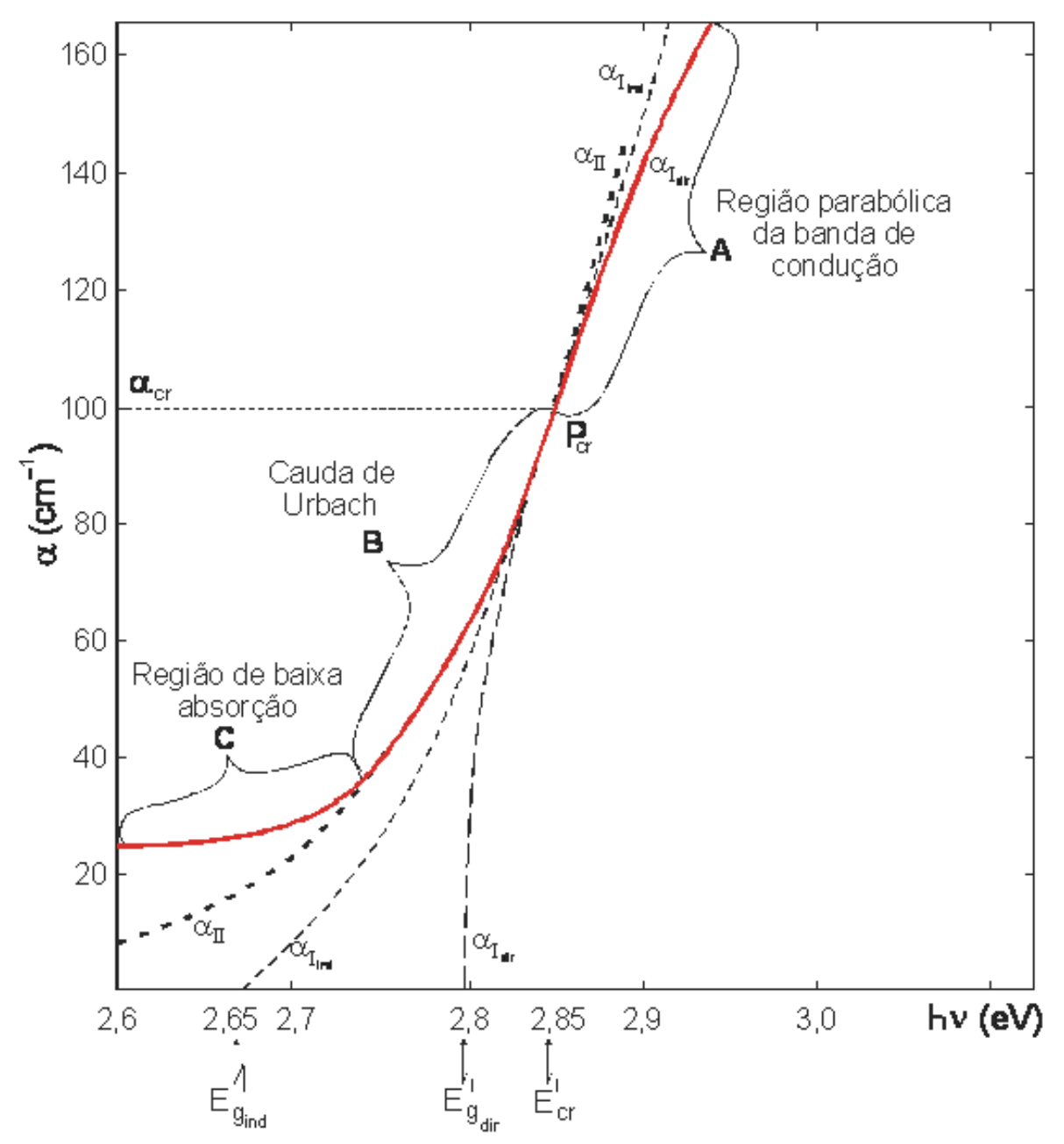

Figura 10 - Simulação realizada a partir dos dados experimentais obtidos das três regiões bem definidas. Neste esquema não foi incluída a correção $n_{0} h v$ que leva em conta o caminho óptico a qual normalmente é desprezada na definição do $\alpha$. A linha cheia representa a variação do coeficiente de absorção ao longo de toda a 
cauda da banda de condução, assumindo $m=\frac{1}{2}$ (região A representada por $\alpha_{\text {Idir }}$ ). No caso $m=2$ teríamos a linha cheia representada por $\alpha_{I_{\text {ind }}}$ nessa região.

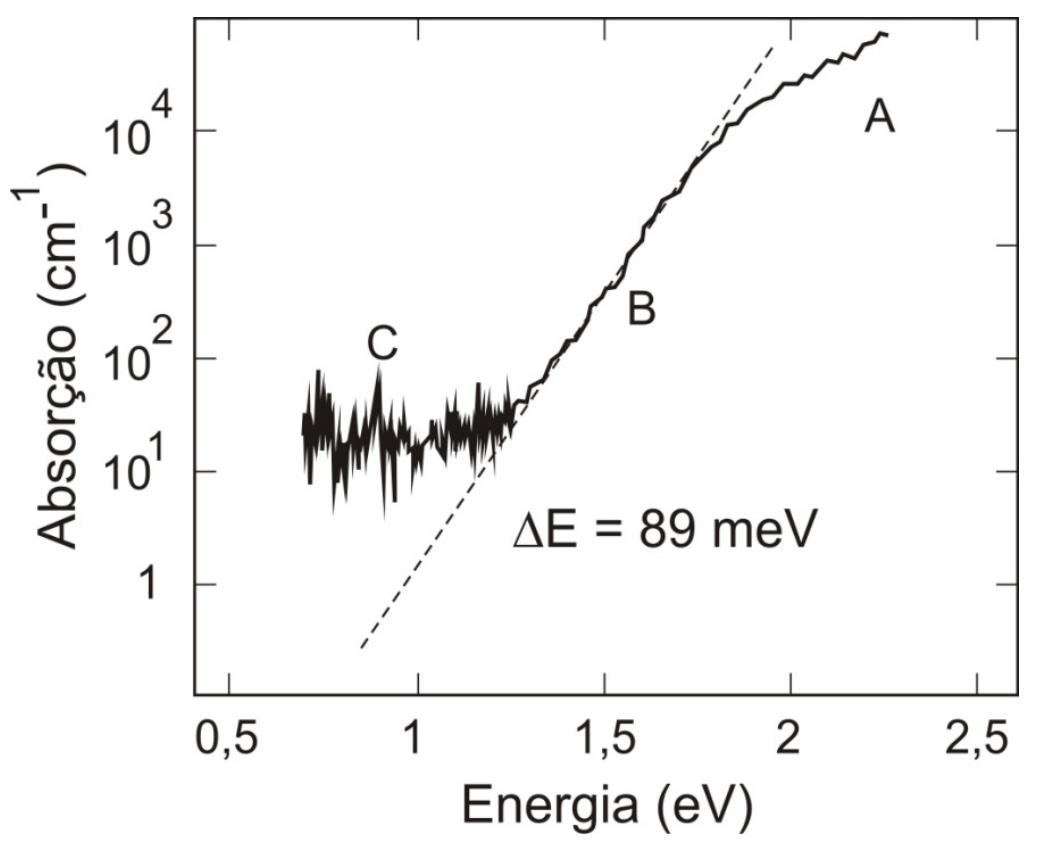

Figura 11 - Exemplo da absorção óptica de um semicondutor de um filme fino de $\mathrm{Sb}_{2} \mathrm{~S}_{3}$ com as três regiões bem definidas [5].

Posteriormente Mott e Davis [6] generalizaram a equação 2.3.4.1 sendo para $m=1 / 2$ uma transição permitida direta e para $m=2$ uma transição permitida indireta, no caso mais simples.

$A$ região $B$ que se estende para valores de energias inferiores ao ponto onde a reta começa a se afastar da curva é conhecida como a "cauda de Urbach" [7] que obedece ao decaimento exponencial decorrente de considerações das interações excitônicas entre elétrons e buracos, cuja mútua atração favorece o aparecimento de estados ligados, com energias menores do que de um par livre. Segundo Dexter \& Knox (1965) [8], a absorção óptica dessa região obedece à seguinte relação empírica:

$$
\alpha=\alpha_{0} \mathrm{e}^{-\frac{\gamma^{\prime}(\mathrm{Eg}-\mathrm{hv})}{\mathrm{K}_{\mathrm{b}} \mathrm{T}}}
$$


em que $\gamma^{\prime}$ é uma constante, T é a temperatura absoluta e $K_{b}$ é a constante de Boltzmann.

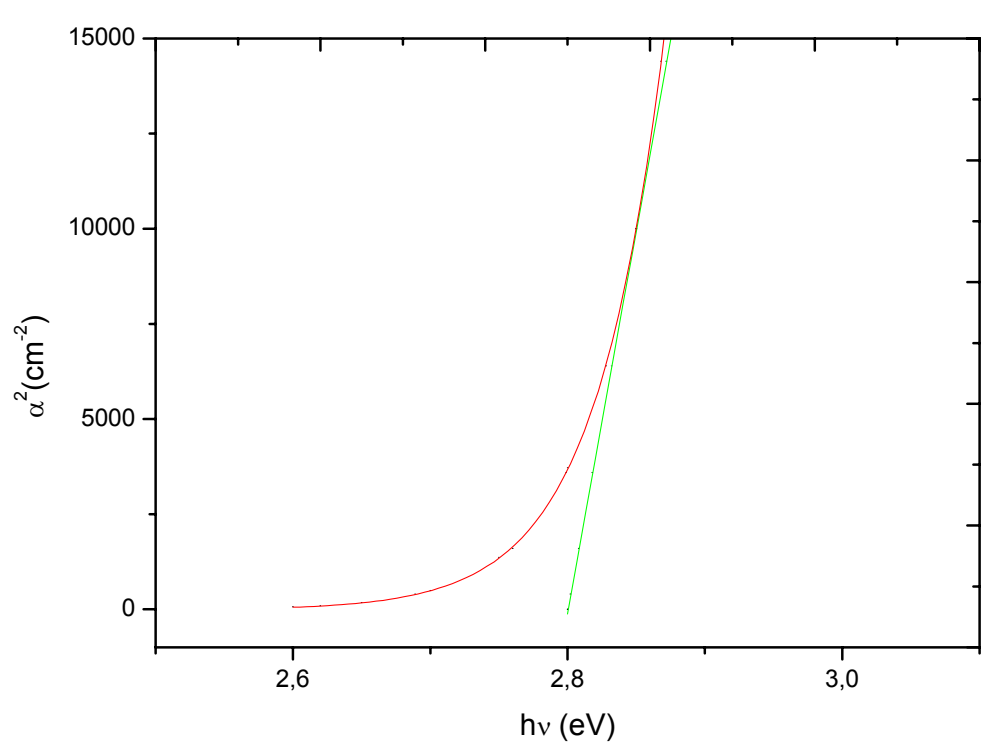

Figura 12 - Ilustração da determinação do gap óptico pelo método de Jan Tauc, para uma transição permitida direta. Neste exemplo não foi incluída a correção $n_{0} h v$ que leva em conta o caminho óptico que normalmente é desprezada na definição do coeficiente de absorção.

Os materiais amorfos apresentam uma simetria de curto alcance associada com o aparecimento de estados localizados nas caudas normalmente associados à banda de energia proibida [9]. Urbach e Martienssen reportaram a dependência da energia do fóton com a rampa de absorção [7] e [10]. A cauda exponencial da banda de condução, denominada energia de Urbach $(\Delta \mathrm{E})$, depende da temperatura, da desordem induzida, da desordem estática, das ligações iônicas fortes e sobre a média da energia dos fótons.

O coeficiente de absorção é dado por:

$$
\alpha(v)=\operatorname{De}^{\left(\frac{\mathrm{h} v}{\Delta \mathrm{E}}\right)}
$$

no qual $\mathrm{D}$ é uma constante.

A região $C$ é de baixa absorção e sua análise foge ao escopo deste projeto. 


\subsubsection{Energia do gap óptico}

Basicamente temos dois tipos básicos de transições ópticas que podem ocorrer para o fundo da banda de condução de cristais semicondutores e vidros, a transição direta (figura 13) na qual ocorre a absorção de um fóton e a transição indireta (figura 14) composta por uma transição direta acompanhada de uma interação com fônons. Ambas envolvem a interação da onda eletromagnética com um elétron na BV que se eleva através do gap para a BC. Entretanto, transição indireta também envolve relaxação (não radiativa) com emissão de fônons. Uma transição direta isolada ocorre no caso particular de uma transição ressonante, a qual resulta no espalhamento inelástico de Rayleigh onde ocorre a emissão quase simultânea de um fóton de mesma energia à do fóton absorvido.

As margens das bandas de absorção ( $\mathrm{BC}$ e $\mathrm{BV}$ ) correspondem à menor diferença de energia (vertical) hv entre as mesmas. No caso das bandas mais simples, em que as superfícies de freqüência constante podem ser aproximadas por elipsóides, vale a relação entre a densidade de estados e a diferença entre os níveis de energia

$$
N(E) \propto\left(E-E_{a}\right)^{\frac{1}{2}},
$$

onde $E_{a}$ não é necessariamente $E_{g}$, medido entre o topo da BV e o fundo da BC. Estes pontos podem não ser verticalmente situados no espaço de configuração $\mathrm{k}$, mas ainda assim é possível observar as transições ópticas correspondentes a $h v \approx E_{g}$, desde que ocorra simultaneamente uma emissão ou absorção de um fônon vibracional. Essas transições são conhecidas como transições indiretas ou assistidas por fônons.

Um exemplo de transição indireta é o efeito Raman, no caso ramo Stokes, em que ocorrem transições inelásticas: por exemplo, absorção de um fóton seguido de uma emissão de um fônon vibracional com posterior emissão de um fóton equivalente à energia do fóton absorvido menos a energia do fônon. 


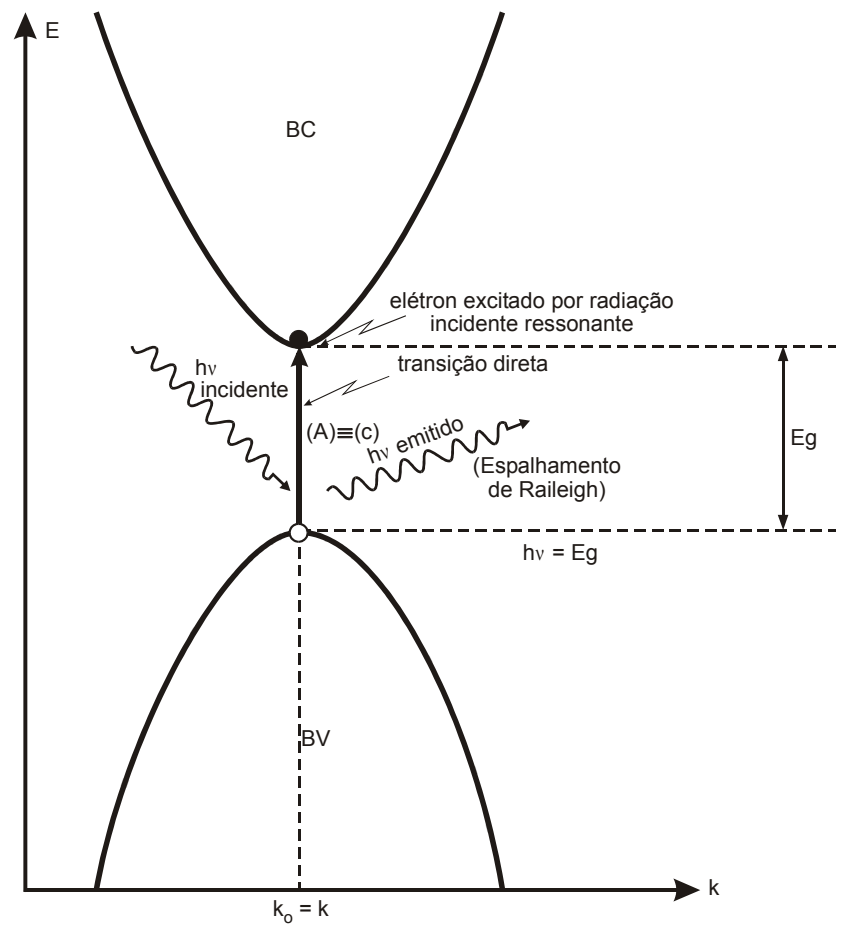

Figura 13 - Modelo de bandas parabólicas de uma transição direta.

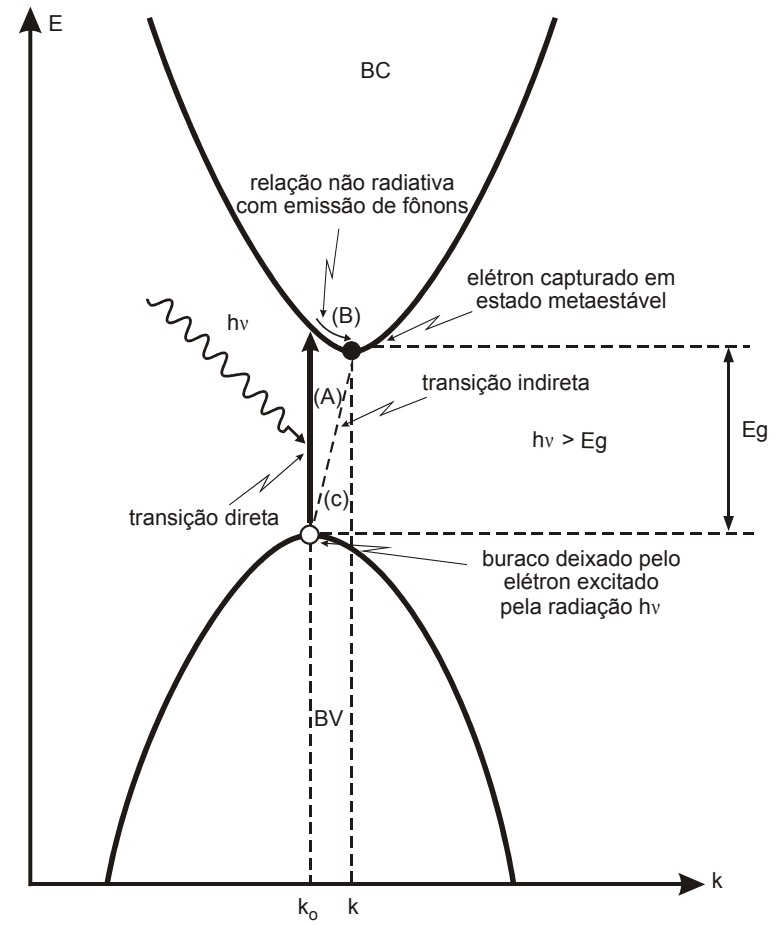

Figura 14 - Modelo de bandas parabólicas de uma transição indireta. 


\subsubsection{Varredura $Z$ (VZ) para a determinação do índice de refração não linear térmico $\left(\mathrm{n}_{2}\right)$}

A técnica de varredura Z (VZ) foi proposta por M. Sheik-Bahae, A. A. Said e E. W. Van Stryland [11, 12] para obter o índice de refração não linear $\left(\mathrm{n}_{2}\right)$ e o coeficiente de absorção não linear $(\beta)$ de um determinado material.

Quando o feixe de luz laser, de perfil gaussiano, atravessa a amostra, a variação transversal da intensidade da luz incidente gera um gradiente do índice de refração como conseqüência tanto de efeito térmico e / ou de indução de polarização eletrônica que pode ser linear ou não.

Nessas condições, um raio de luz apresenta uma trajetória curva, voltada para a região com o maior índice de refração (figura 15) [13]. Onde a curvatura $\overrightarrow{\mathrm{K}}$ é igual a:

$$
\overrightarrow{\mathrm{K}}=\frac{\mathrm{d} \overrightarrow{\mathrm{s}}}{\mathrm{ds}}=\frac{1}{\mathrm{R}} \overrightarrow{\mathrm{a}},
$$

Em que $\vec{s}$ é um vetor unitário da direção do feixe no ponto $P, \vec{a}$ é um vetor unitário na direção do centro da curvatura com raio $R$, sendo [13]:

$$
|\vec{K}|=\frac{1}{R}=\vec{a} \cdot \operatorname{grad} \log n_{t}=\vec{a} \cdot \frac{1}{n_{t}} \frac{d n_{t}}{d r} \frac{d \vec{r}}{d s}=\frac{1}{n_{t}} \frac{d n_{t}}{d r},
$$

pois $\frac{d \vec{r}}{d s}=\vec{a}$.

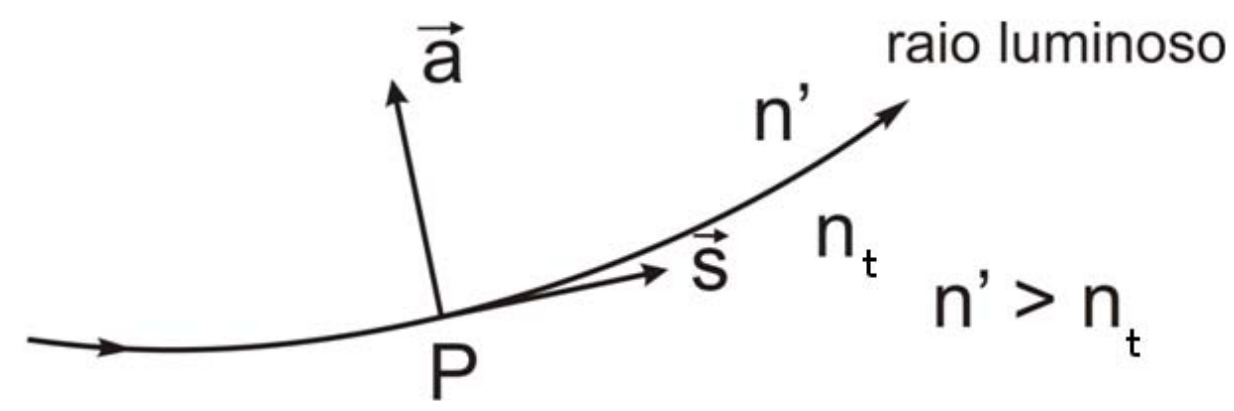

Figura 15 - Representação de um raio de luz apresenta uma trajetória curva, voltada para a região com o maior índice de refração [13]. 
Em um feixe gaussiano, na região mais próxima do eixo, a variação do índice de refração em função da distância ao eixo pode ser assumida aproximadamente como parabólica [14]:

$$
\mathrm{n}_{\mathrm{t}}(\mathrm{r})=\mathrm{n}_{0}\left[1+\delta\left(\frac{\mathrm{r}}{\omega_{\mathrm{a}}}\right)^{2}\right]
$$

de modo que:

$$
\frac{1}{\mathrm{R}}=\frac{1}{\mathrm{n}_{\mathrm{t}}} \frac{\mathrm{dn}_{\mathrm{t}}}{\mathrm{dr}}=\frac{1}{\mathrm{n}_{\mathrm{t}}} \cdot \mathrm{n}_{0} \delta \cdot \frac{2 \mathrm{r}}{\omega_{\mathrm{a}}^{2}} \sim \frac{2 \mathrm{r} \delta}{\omega_{\mathrm{a}}^{2}} .
$$

Em que $\mathrm{n}_{\mathrm{t}}, \mathrm{n}_{0}$, $\delta$ e $\omega_{\mathrm{a}}$ são respectivamente, o índice de refração total (proveniente de todas as contribuições citadas), o índice de refração exatamente no centro do eixo, um parâmetro empírico para o ajuste da parábola e o raio da cintura do feixe.

Para uma amostra delgada, a trajetória do raio de luz que a atravessa pode ser considerada circular, emergindo da face oposta formando um ângulo $\Theta$ com a direção do raio incidente (figura 16), de modo que ela passa a exercer a função de uma lente convergente ou divergente, introduzindo uma alteração no ponto focal $F$ para F' (vide figura 16).

$$
\operatorname{Como} \operatorname{sen} \Theta \approx \Theta \approx \frac{1}{\mathrm{R}}=\frac{2 \operatorname{lr} \delta}{\omega_{\mathrm{a}}^{2}}
$$

assumindo que o ângulo do raio incidente na amostra é muito menor do que $\Theta$, podemos definir o desvio F'F do ponto focal, como

$\mathrm{F}^{\prime} \mathrm{F} \approx \frac{\mathrm{r}}{\Theta}=\frac{\omega_{\mathrm{a}}^{2}}{2 \mathrm{l} \delta}$

Em que l e r são respectivamente, a espessura da amostra e a distância entre o raio incidente teórico e o eixo que perpassa a amostra.

O princípio básico de funcionamento da VZ (figura 17) é baseado no fato de que um feixe de perfil Gaussiano de um laser pulsado ou contínuo (que contém uma amostra em sua trajetória), ao ser focalizado por uma lente irá convergir para uma região de diâmetro mínimo, onde a intensidade do feixe é máxima (figura 18), a partir deste ponto passando a divergir. Com a amostra sendo deslocada ao longo do feixe na região próxima ao ponto focal da lente, é feita a medida da transmitância do feixe em função do deslocamento da amostra. Se a curva apresenta um vale seguido de um pico, teremos o efeito de auto-focalização com $\mathrm{n}_{2}>0$ (a amostra atua como se fosse uma lente delgada convergente), ou seja, antes do foco teremos uma 
diminuição da intensidade do feixe sobre o detector, seguida de um aumento. No caso inverso de $\mathrm{n}_{2}<0$ temos a auto-defocalização.

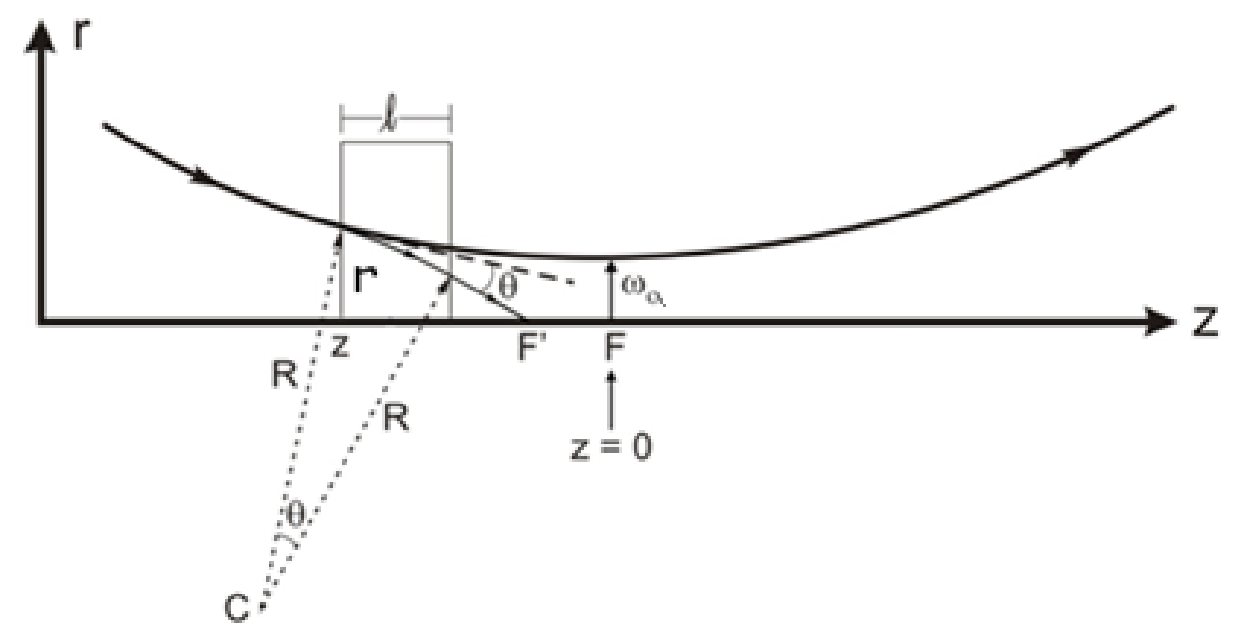

Figura 16 - Representação do efeito térmico que ocorre dentro da amostra.

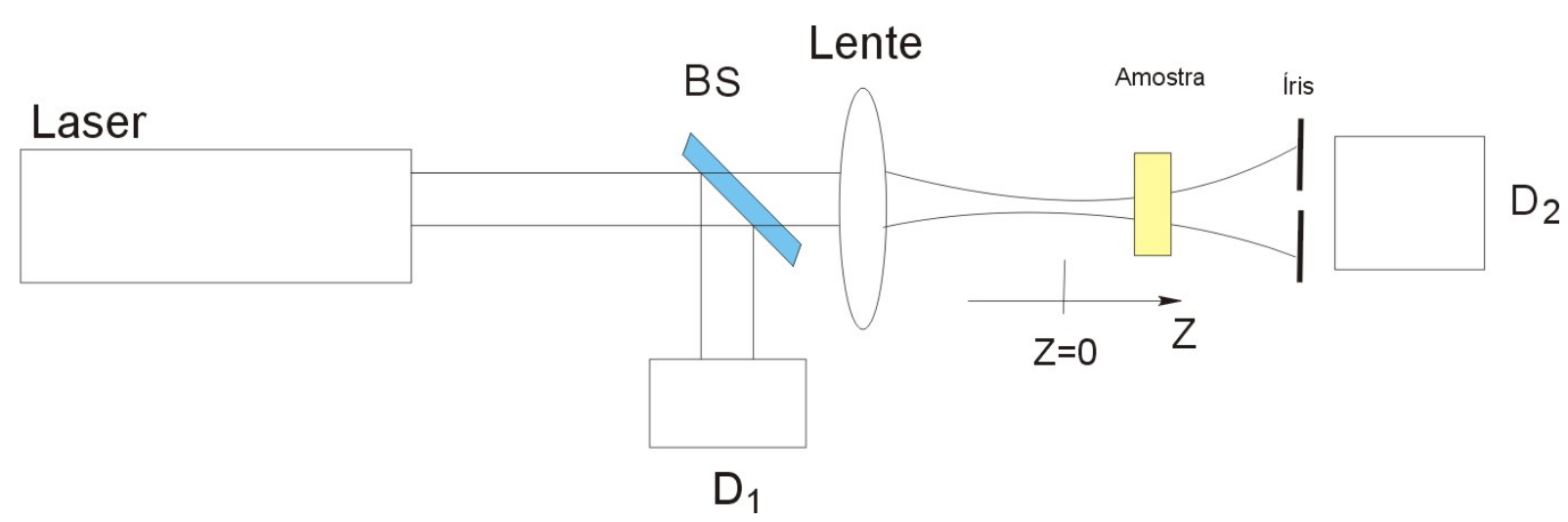

Figura 17 - Esquema do princípio básico de funcionamento do VZ, no qual $D_{1}$ e $D_{2}$ são detectores e BS divisor de feixes [12].

Atualmente existem alguns modelos para o tratamento dos dados obtidos por VZ em materiais, tais como: modelo de Sheik-Bahae [11, 12], da lente térmica [15], da lente térmica aberrante [15] e de Lara [16]. 


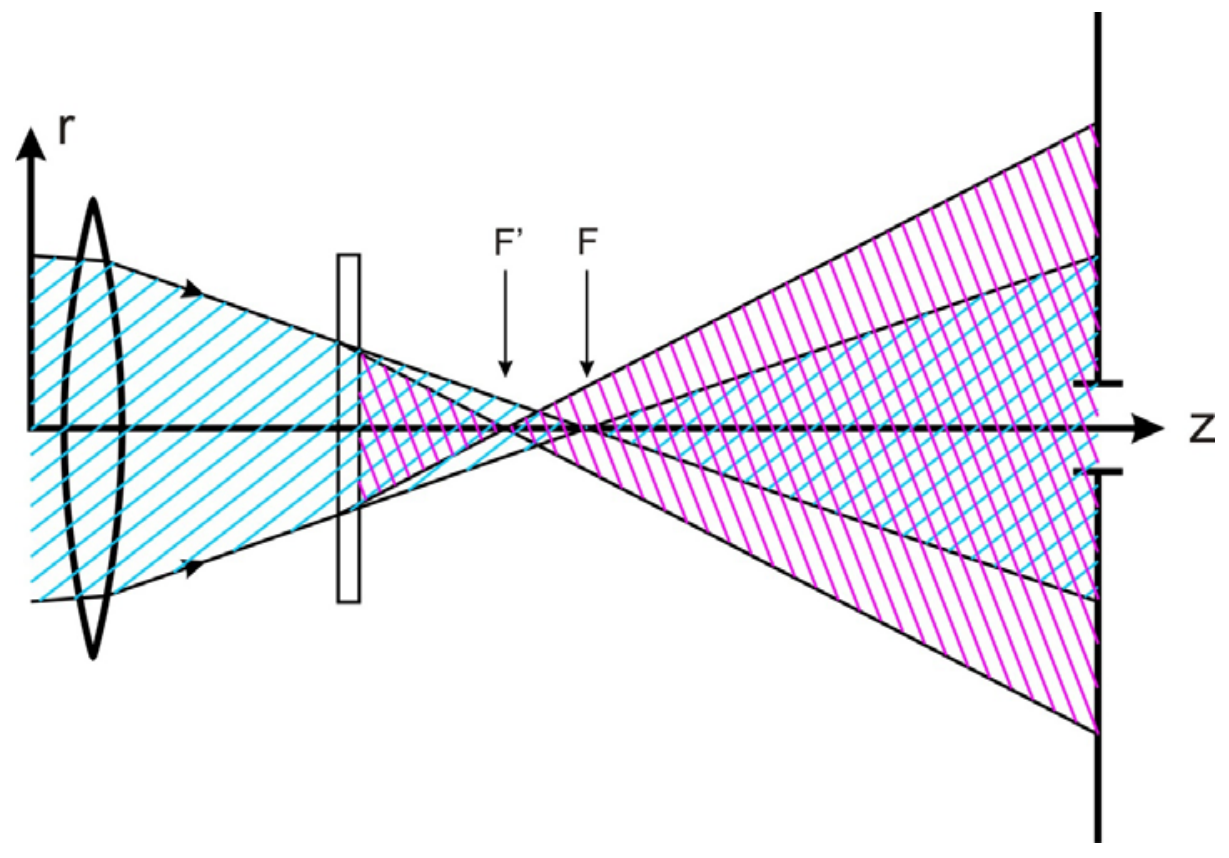

Figura 18 - Esquema que representa a formação do vale-pico para $\mathrm{n}_{2}>0$.

Considerando uma configuração com a íris fechada para um material sem linearidade de terceira ordem, o índice de refração total $n_{t}$ será dado por [11, 12]:

$$
\mathrm{n}_{\mathrm{t}}=\mathrm{n}+\Delta \mathrm{n}_{\mathrm{t}}=\mathrm{n}+\mathrm{n}_{2} \mathrm{I}_{\mathrm{l}}
$$

onde $\mathrm{I}_{1}$ é a intensidade de luz do feixe incidente.

Para esta configuração considerando a hipótese que não há $\beta$, a transmitância, para o modelo de Sheik-Bahae et.al. [11,12] é dada por:

$$
\begin{aligned}
& \mathrm{T}_{\mathrm{N}}(\mathrm{z})=1+\frac{4 \mathrm{x}}{\left(1+\mathrm{x}^{2}\right)\left(9+\mathrm{x}^{2}\right)} \Delta \Phi_{0}, \\
& \text { em que } \quad \mathrm{x}=\frac{\mathrm{z}}{\mathrm{Z}_{\mathrm{c}}}, \\
& \mathrm{Z}_{\mathrm{c}}=\frac{\pi \omega_{\mathrm{a}}^{2}}{\lambda}, \\
& \Delta \Phi_{0}=\frac{2 \pi \mathrm{n}_{2} \mathrm{I}_{\mathrm{a} 0} \mathrm{~L}_{\mathrm{eff}}}{\lambda}, \\
& \mathrm{L}_{\mathrm{eff}}=\frac{\left(1-\mathrm{e}^{-\alpha \mathrm{l}}\right)}{\alpha},
\end{aligned}
$$

em que $\Delta \Phi_{0}$ é a distorção da fase não linear, $\mathrm{Z}_{\mathrm{C}}$ é o comprimento de Rayleigh ao longo da propagação do feixe de laser de $z=0$ (cintura do feixe) até onde a área da secção transversal é o dobro do valor inicial, $Z$ é a distância percorrida pela amostra 
durante a medida, $\omega_{\mathrm{a}}$ é o raio da cintura do feixe, $\lambda$ do laser, $L_{\text {eff }}$ é a espessura efetiva e $\mathrm{I}_{\mathrm{a} 0}$ é a intensidade máxima do feixe em $\mathrm{z}=0$.

Yin e colaboradores [17] estenderam o modelo para sistemas que descrevem a transmitância normalizada considerando o $\mathrm{n}_{2}$ e $\beta$ simultaneamente:

$$
\begin{aligned}
& \mathrm{T}_{\mathrm{N}}(\mathrm{z})=1+\frac{4 \mathrm{x}}{\left(1+\mathrm{x}^{2}\right)\left(9+\mathrm{x}^{2}\right)} \Delta \Phi_{0}-\frac{2\left(\mathrm{x}^{2}+3\right)}{\left(1+\mathrm{x}^{2}\right)\left(9+\mathrm{x}^{2}\right)} \Delta \psi, \\
& \Delta \psi=\beta \mathrm{I}_{\mathrm{a} 0} \mathrm{~L}_{\mathrm{eff}},
\end{aligned}
$$

no qual $\Delta \psi$ é um parâmetro que pode ser medido a partir dos resultados de $V Z$, em que toda a luz transmitida é medida pelo detector.

O modelo da lente térmica [15] leva em consideração a baixa absorção da amostra, a conversão da energia absorvida em calor, o tempo de exposição da amostra ao feixe e a variação da distância focal da lente induzida pela propagação de calor. A equação da intensidade do feixe dependente da posição é descrita pela expressão:

$$
\frac{\mathrm{I}(0)-\mathrm{I}(\infty)}{\mathrm{I}(\infty)}=\theta\left(\frac{2 \gamma}{1+\gamma^{2}}\right)+\theta^{2}\left(\frac{1}{1+\gamma^{2}}\right)
$$

em que $\theta=2,303 \mathrm{P}\left(\frac{\mathrm{dn}}{\mathrm{dt}}\right) \frac{\mathrm{F}}{\lambda \kappa}$,

$$
\gamma=\frac{\mathrm{z}}{\mathrm{z}_{\mathrm{c}}}
$$

no qual $\theta$ é o ângulo de deflexão de indução térmica, $\kappa$ é a condutividade térmica, $\mathrm{F}$ é a absorbância, 2,303 PF representa a potência absorvida e $\frac{\mathrm{dn}}{\mathrm{dt}}$ é a variação do índice de refração em relação a temperatura ou coeficiente termo óptico, sendo t a temperatura.

Para o modelo de lente térmica aberrante [15] os termos de $\theta^{2}$ são mantidos, de acordo com a expressão abaixo:

$$
\begin{gathered}
\frac{\mathrm{I}(0)-\mathrm{I}(\infty)}{\mathrm{I}(\infty)}=-1+ \\
\left\{1-\theta \tan ^{-1}\left(\frac{2 \gamma}{3+\gamma^{2}}\right)+\left[\frac{\theta}{2} \tan ^{-1}\left(\frac{2 \gamma}{3+\gamma^{2}}\right)\right]^{2}+\left[\frac{\theta}{4} \ln \left(\frac{1+\gamma^{2}}{9+\gamma^{2}}\right)\right]^{2}\right\}^{-1}
\end{gathered}
$$


O modelo descrito por Lara et. al. [16] representa uma análise da propagação de feixes Gaussianos para lentes finas e com pequenas distorções, sendo a transmitância dada pela expressão:

$$
\mathrm{T}=\frac{1}{1-\frac{4 \mathrm{x}}{\left(1+\mathrm{x}^{2}\right)^{\frac{\mathrm{m}}{2}}}\left(\frac{\mathrm{Z}_{\mathrm{c}}}{2 \mathrm{~F}_{0 \mathrm{~m}}}\right)+\frac{4}{\left(1+\mathrm{x}^{2}\right)^{\mathrm{m}-1}\left(\frac{\mathrm{z}_{\mathrm{c}}}{2 \mathrm{~F}_{0 \mathrm{~m}}}\right)^{2}} .}
$$

Em que $\mathrm{F}_{0 \mathrm{~m}}$ é a menor distância focal da lente fotoinduzida e $\mathrm{m}$ é um número inteiro. Este modelo pode ser utilizado como primeira aproximação para explicar resultados experimentais no qual não é bem conhecido o tipo de lente foto induzida utilizada.

Sant'Anna Cuppo e colaboradores [18] relaciona os modelos de Sheik-Bahae, no qual a intensidade do campo sobre a posição da amostra depende da intensidade da não linearidade óptica, com o modelo de Lente Térmica que não apresenta uma dependência local e temporal, dada pela equação:

$$
\theta=\frac{2 \pi \mathrm{l}}{\lambda} \frac{\mathrm{n}_{2}}{\varepsilon_{0} \mathrm{cn}} \mathrm{I}_{\mathrm{a} 0}=\frac{\pi \alpha \omega_{\mathrm{a}}^{2} \mathrm{l}}{2 \lambda \kappa} \frac{\partial \mathrm{n}}{\partial \mathrm{t}} \mathrm{I}_{\mathrm{a} 0}
$$

no qual $\varepsilon_{0}$ é a permissividade no vácuo e c a velocidade da luz.

A diferença de montagem para obter distintamente $\mathrm{o} \mathrm{n}_{2}$ térmico e eletrônico reside principalmente no tempo de varredura utilizado, no espaçamento e largura dos pulsos do laser. A montagem para se obter $\mathrm{o} \mathrm{n}_{2}$ térmico consiste de um detector lento, com tempo de resposta $\leq 35 \mathrm{~ns}$, cuja finalidade é detectar os efeitos puramente térmicos do feixe de um laser contínuo provido de um modulador óptico (chopper).

O índice de refração não linear envolve processos, dependendo do material, tais como: efeitos térmicos, absorção atômica saturada, eletrostricção e transições eletrônicas. Diversos processos podem provocar mudanças no índice de refração, dependendo da intensidade do feixe incidente. Alguns desses processos envolvem efeitos rápidos, já outros ocorrem em escalas de tempo maiores (tabela 7) [19].

Trabalhos recentes vêm empregando a técnica de varredura $Z$ para a determinação do índice não linear de vidros teluritos normalmente acompanhados de íons de metais pesados que possam ser facilmente polarizados $\left(\mathrm{Pb}^{+}, \mathrm{Bi}^{3+}\right.$ e $\left.\mathrm{Ti}^{4+}\right)$ e íons de transição $\left(\mathrm{Ti}^{4+}, \mathrm{Nb}^{5+}\right.$ e $\left.\mathrm{W}^{6+}\right)[20,21]$. 
Tabela 7 - Valores típicos de $\mathrm{n}_{2}$, escalas de tempo e origens físicas do efeito [19].

\begin{tabular}{|l|l|l|l|}
\hline Mecanismo & $\mathrm{n}_{2}\left(\mathrm{~cm}^{2} / \mathrm{W}\right)$ & $\chi^{(3)} 1111(\mathrm{esu})$ & Tempo de resposta (s) \\
\hline Polarização eletrônica & $10^{-16}$ & $10^{-14}$ & $10^{-15}$ \\
\hline Reorientação molecular & $10^{-14}$ & $10^{-12}$ & $10^{-12}$ \\
\hline Eletrostricção & $10^{-14}$ & $10^{-12}$ & $10^{-9}$ \\
\hline Absorção atômica saturada & $10^{-10}$ & $10^{-8}$ & $10^{-8}$ \\
\hline Efeitos térmicos & $10^{-6}$ & $10^{-4}$ & $10^{-3}$ \\
\hline
\end{tabular}

\subsubsection{Referências}

[1] Sekiya, T.; Mochida, N.; Ohtsuka, A.; Tonokawa, M. Raman Spectra of $\mathrm{MO}_{1 / 2}$ $\mathrm{TeO}_{2}(\mathrm{M}=\mathrm{Li}, \mathrm{Na}, \mathrm{K}, \mathrm{Rb}, \mathrm{Cs}$, and Ti) glasses. J. Non-Cryst. Solids, v. 144, p. 128-145, 1992.

[2] Reisfeld, R.; Eckestein, Y. Intensities of electronics transitions and Quantum efficiencies of green luminescence of $\mathrm{Er}^{3+}$ in Tellurite glasses. Solid State Commun., v. 13, p. $741,1973$.

[3] Anderson, P.W. Absence of diffusion in certain rand on lattices. Phys. Rev., v. 109, p. 1492-1505, 1958.

[4] Mott, N. F. Electrons in disordered structures. Adv. In Phys., v. 16, n. 61, p. 49$144,1967$.

[5] Droichi, M. S.; Vaillant, F.; Bustarret, E. and Jousse, D. Study of localized states in amorphous chalcogenide $\mathrm{Sb}_{2} \mathrm{~S}_{3}$ films. J. Non-Cryst. Solids, v. 101, p. 151- 155, 1988.

[6] Mott, N. F.; Davis, E. A. In. Electronic processes in non-crystalline materials. Clarendon Press, Oxford, p. 273, 1979.

[7] Urbach, F. The long-wavelength edge of photographic sensitivity and of the electronic absorption of solids. Phys. Rev., v. 92, p. 1324, 1953.

[8] Dexter, D. L.; Knox, R. S. Excitons. New York: Wiley Interscience, 1967. 


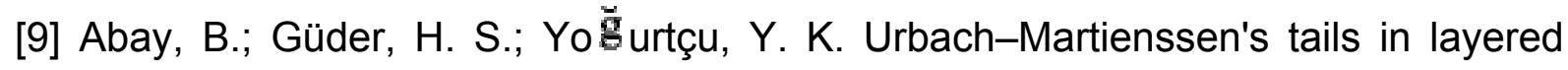
semiconductor GaSe, Solid State Commun., v. 112, p. 489-494, 1999.

[10] Martienssen, W. Über die excitonenbanden der alkalihalogenidkristalle. J. of Phys. and Chem. of Solids, v. 2, n. 4, p. 257-267, 1957.

[11] Sheik-Bahae, M.; Said, A. A.; Van Stryland, E. W. High-Sensitivity, single-beam $\mathrm{n}_{2}$ measurements. Opt. Lett., v. 14, p. 955-957, 1989.

[12] Sheik-Bahae, M.; Said, A. A.; Wei, T. H.; Van Stryland, E. W. Sensitive measurement of optical nonlinearities using a single beam. J. Quantum Electron., v. 26, p. 760-769, 1990.

[13] Born, M; Wolf, E. Principles of optics electromagnetic theory of propagation, interference and diffraction of light. Pergamon Press, $5^{\circ}$ edição, p. 124, 1975.

[14] Gordon, J. P.; Leite, R. C. C.; e colaboradores Long-transient effects in laser with inserted liquid samples. J. Appl. Phys., v. 36, n.1, p. 3-8, 1965.

[15] Carter, C. A.; Harris, J. M. Comparison of models describing the thermal lens effect. Applied Opt., v. 23, n. 3, p. 476-481, 1984.

[16] Lara, E. R.; Meza, Z. N.; Castillo, M. D. I.; Palacios, C. G. T. Influence of the photoinduced focal length of a thin nonlinear material in the Z-scan technique. Opt. Express, v.15, n.5, p. 2517-2529, 2007.

[17] Yin, M.; Li, H. P.; Tang, S. H.; Ji, W. Determination of nonlinear absorption and refraction by single Z-scan method. Applied Phys. B, v. 70, p. 587-591, 2000.

[18] Sant'Anna Cuppo, F. L.; Figueiredo Neto, A. M.; Goméz, S. L. Thermal-lens model compared with the Sheik-Bahae formalism in interpreting Z-scan experiments on lyotropic liquid crystals. J. Opt. Soc. Am. B, v. 19, n. 6, p. 1342-1348, 2002.

[19] Boyd, R. W. Nonlinear Optics. Academic Press, Inc., 1992.

[20] Chen, F; Xu, T.; Dai, S.; Nie, Q.; Shen, X.; Zhang, J.; Wang, X. Linear and nonlinear characteristics of tellurite glasses within $\mathrm{TeO}_{2}-\mathrm{Bi}_{2} \mathrm{O}_{3}-\mathrm{TiO}_{2}$ ternary system. Opt. Materials, v. 32, p. 868-872, 2010.

[21] Chen, Y.; Nie, Q.; Xu, T.; Dai, S.; Wang, X.; Shen, X. A study of nonlinear optical properties in $\mathrm{Bi}_{2} \mathrm{O}_{3}-\mathrm{WO}_{3}-\mathrm{TeO}_{2}$ glasses. J. Non-Cryst. Solids, v. 354, p. 3468-3472, 2008. 


\subsection{Nanopartículas de prata e ressonância de plasmons}

\subsubsection{Introdução}

Vidros óxidos de metais pesados e vidros teluritos são considerados vidros promissores para aplicações em fotônica devido às suas excelentes propriedades ópticas não lineares [1-4]. Os vidros teluritos apresentam um grande potencial em aplicações no chaveamento óptico de grande velocidade, laser de luminescência não convencional, amplificadores de fibra óptica e fontes de luz para aplicações em telecomunicações de banda larga na região de 1,5 $\mu \mathrm{m}$ [4-6]. Entretanto, em comparação com as melhores propriedades não lineares de cristais ópticos e polímeros, a não linearidade dos vidros teluritos convencionais ainda é insatisfatória e os seus mecanismos não são ainda suficientemente compreendidos. Constatou-se recentemente que vidros contendo nanopartículas metálicas melhoram consideravelmente as condições de não linearidade comparada a cristais maciços de mesma composição química.

As nanopartículas são resultantes da nucleação de fases cristalinas que tanto podem ser isolantes, semicondutoras ou metálicas. Neste trabalho estamos interessados em nanopartículas de prata obtidas por meio da dopagem com $\mathrm{AgNO}_{3}$.

O principal problema enfrentado em sua obtenção consiste em obter nanopartículas de mesmo tamanho, forma e distribuição homogênea, pois quanto menor a dispersão de tamanho, maior será a não linearidade de terceira ordem do material.

Atualmente na literatura são apresentados vários métodos para a produção de nanopartículas metálicas em vidros, tais como: método sol-gel, método de implantação iônica, troca iônica, método de sputtering e o método que concilia fusão e tratamento térmico. Este último método consiste em fundir os reagentes, a seguir resfriar o fundido rapidamente e tratar termicamente o material obtido. De um modo geral, as nanopartículas tendem, sem nenhum processo externo, a adquirir a forma esférica, que corresponde ao estado de menor energia. Para obter-se uma forma privilegiada de nanopartículas é necessário analisar duas propriedades inerentes aos nanoestruturados como: os defeitos cristalográficos e os plasmons superficiais. Em determinados materiais, como silicato de sódio e cálcio [7], o nitrato de prata é 
diluído em água e a seguir colocado sobre o vidro e levado a uma estufa a $80^{\circ} \mathrm{C}$ para formar um filme sobre a superfície do vidro. A seguir o vidro é colocado em uma atmosfera redutora de $\mathrm{H}_{2}$ ou $\mathrm{N}_{2}$ para que ocorra a formação das nanopartículas. $\mathrm{O}$ autor conseguiu obter nanopartículas metálicas com tratamentos térmicos com temperaturas superiores sem a necessidade de uma atmosfera redutora.

\subsubsection{Banda de plasmons}

Plasmons superficiais são oscilações quantizadas dos elétrons livres que interagem com ondas de luz que incidem sobre as nanoestruturas metálicas. Nesta interação, os elétrons acompanharam a variação do campo elétrico da luz, oscilando em ressonância. A interação ressonante entre a oscilação da carga superficial e o campo eletromagnético da luz dá origem ao plasmon superficial. Os comprimentos de onda específicos de absorção da luz que abrangem as oscilações plasmônicas são chamados de banda de plasmon, como podemos observar na figura 19 [8].

O primeiro autor a reportar a interação da luz com uma dispersão de partículas de ouro em 1908 foi Gustav Mie [9], em sua teoria ele assume que a partícula e o meio envolvente são homogêneos. Ele predisse ainda que as partículas não interagiam entre si. Isto é aplicável somente em partículas em suspensões coloidais.

Segundo Almeida Pinto [10] ao excitar os plasmons superficiais com luz de mesma freqüência da oscilação dos plamons, observa-se o aparecimento de uma intensa banda de absorção, devida à ressonância. Essa freqüência de ressonância dos plasmons superficiais depende de várias características:

- do tipo de material utilizado (prata, ouro, cobre, platina, etc);

- da distribuição de tamanho das nanopartículas;

- da forma das nanopartículas;

- do ambiente químico do hospedeiro;

- da janela de transmissão da matriz vítrea.

O tamanho e forma das nanopartículas criadas dependerá da energia de ativação do sistema, ou seja, do tempo e temperatura empregados no processo.

Segundo J. J. Mock [11] nanopartículas de prata esféricas apresentam uma banda de absorção entre 400 e 600 nm, centrada em 450 nm (figura 20), já as 
nanopartículas pentagonais apresentam-se centradas em $532 \mathrm{~nm}$ e as com formato de um prisma triangular em aproximadamente $675 \mathrm{~nm}$.

Nanopartículas também podem ser criadas por meio de irradiação de raios $X$ e laser na região do ultra-violeta.

Artigos recentes abordam a eficiência quântica introduzida por meio da troca de energia entre terras raras e nanopartículas de prata $[12,13]$.

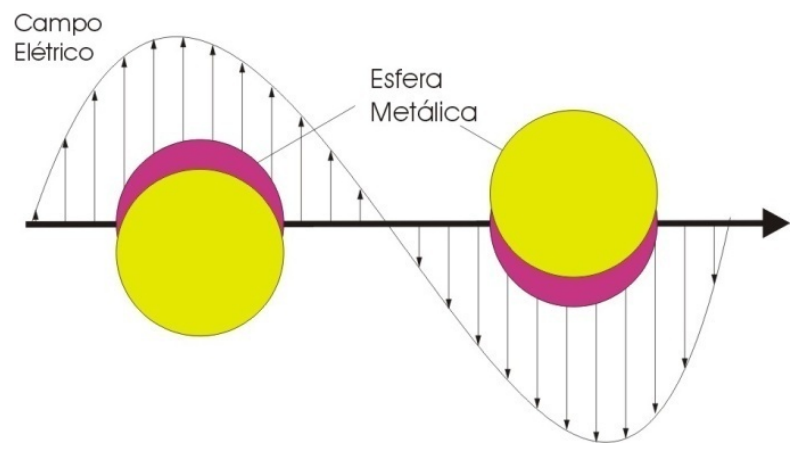

Figura 19 - Nanopartículas esféricas alongadas pela ação de uma tensão [8].

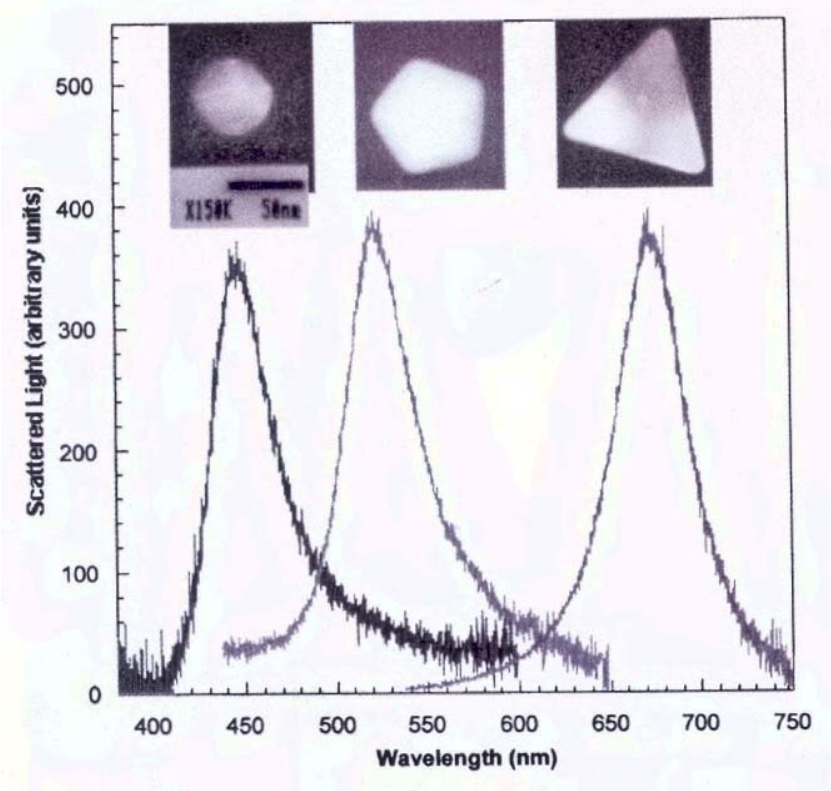

Figura 20 - Nanopartículas de prata [11]. 


\subsubsection{Referências}

[1] Ohishi, Y.; Mori, A.; Yamada, M.; Ono, H.; Nishida, Y.; Oikawa, K. Gain characteristics of tellurite-based erbium-doped fiber amplifiers for $1.5-\mu \mathrm{m}$ broadband amplification Opt. Lett., v. 23, p. 274-276, 1998.

[2] Hu, Y.; Jiang, S.; e colaboradores Numerical analyses of the population dynamics and determination of the upconversion coefficients in a new high erbium-doped tellurite glass. J. Opt. Soc. Am. B, v. 18, p. 1928-1934, 2001.

[3] Wang, J. S.; Snitzer, E.; Vogel E. M.; Sigel J. G. H. 1.47, 1.88 and $2.8 \mu \mathrm{m}$ emissions of $\mathrm{Tm}^{3+}$ and $\mathrm{Tm}^{3+}-\mathrm{Ho}^{3+}$-codoped tellurite glasses. J. Lumin., v.60/61, p. 145, 1994.

[4] Yano, T.; Watanabe A. Tellurite glass: A new. acousto-optic material. J. of Applied Phys., v.42, n. 10, p. 3674, 1971.

[5] Tanabe, S. J. Of Alloys and Compounds, v. 675, p. 408-412, 2006.

[6] Pontuschka, W. M.; Barbosa, L. C. Progress on oxide glasses Applications in photonics. In: G Lucovsky; M. A. Popescu (Org.). Non-Crystalline Materials for Optoelectronics. Bucharest, v. 13, p. 363-392, 2004.

[7] Hu, J.; Cai, W.; Li, Y.; Zeng, H. Oxygen-induced enhancement of surface Plasmon resonance of silver nanoparticles for silver-coated soda-lime glass. J. of Phys. Con. Matter, v. 17, p. 5349-5354, 2005.

[8] Lance Kelly, K.; Coronado, E.; Zhao, L. L.; Schatz, C. The properties of metal nanoparticles: the influence of size, shape, and dielectric environment. J. Phys. Chem. B, v. 107, p. 668-677, 2003.

[9] Mie G. Beiträge zur Optik trüber Medien, speziell kolloidaler Metallösungen. Annalen der Physik, n. 3, p. 377-445, 1908.

[10] Almeida Pinto, R. Síntese e caracterização de vidros telureto dopados com ions de $\mathrm{Eu}^{3+} \mathrm{e} \mathrm{Tb}^{3+}$ com nanopartículas metalícas. 2009. Dissertação (Mestrado) - Escola Politécnica da Universidade de São Paulo, São Paulo, São Paulo.

[11] Mock, J. J.; Barbic, M.; Smith, D. R.; Schultz, D. A.; Schultz, S. Shape effects in plasmon resonance of individual colloidal silver nanoparticles. J. Chem. Phys., v.116, n. 15, p. 6755-6659, 2002.

[12] Rai, V. K.; Menezes, L.S.; Araújo, C. B.; Kassab, L. R. P.; Da Silva, R. M.; Kobayashi, R. A. Surface-plasmon-enhanced frequency upconversion in $\mathrm{Pr}^{3+}$ doped 
tellurium-oxide glasses containing silver nanoparticles. J. Appl. Physics, v. 103, p. 093526-1 a 4, 2008.

[13] Kassab, L. R. P.; De Araújo, C. B.; Kobayashi, R. A.; Pinto, R. A.; Da Silva, D. M. Influence of silver nanoparticles in the luminescence efficiency of $\mathrm{Pr}^{3+}$ - doped tellurite glasses. J. Appl. Physics, v. 102, 103515-1 a 4, 2007.

\subsection{Processos Termicamente Estimulados (PTE)}

Entende-se por PTE qualquer fenômeno no qual uma amostra seja aquecida e certa grandeza física seja monitorada. De uma forma geral, a propriedade física a ser medida aparece somente com uma prévia excitação ou tratamento conveniente antes do aquecimento térmico. Nesta tese serão abordados dois processos: Correntes de Despolarização Termicamente Estimuladas (CDTE) e Termoluminescência (TL).

\subsubsection{Correntes de Despolarização Termicamente Estimuladas}

Em 1964 C. Bucci e R. Fieschi [1] propuseram um método denominado lonic Thermoconductivity para estudar isolantes. Seu principal interesse centrava-se em cristais iônicos que contivessem defeitos do tipo dipolo (apresentam momento dipolar intrínseco). Um exemplo de dipolo é composto de uma vacância de ânion ao lado de uma vacância de um cátion.

Em um meio dielétrico, o efeito de polarização poderá ser devido aos seguintes fatores microscópicos:

1. alinhamento de dipolos permanentes; no caso dos vidros, este dipolo é formado pelo $\mathrm{NBO}^{-}$e por um cátion modificador que se encontra em um sítio intersticial da rede vítrea compensando carga ou por uma vacância de oxigênio;

2. migração de cátions, como por exemplo $\circ \mathrm{Na}^{+}$, causando um acúmulo de carga espacial próximo aos eletrodos; 
3. movimento de elétrons e ou buracos em direção aos eletrodos com a captura dos mesmos;

4. deslocamento dos elétrons com relação aos íons e pequenos deslocamentos dos íons com relação às moléculas;

5. injeção de cargas (elétrons ou buracos) dos eletrodos na amostra;

6. polarização de interface, característica de sistemas que possuem heterogeneidades (materiais com excesso de impurezas ou vidros com separação de fases).

Segundo Hong e Day [2] a técnica de CDTE foi usada para estudar captura de cargas em vidros calcogenetos $\left(\mathrm{As}_{2} \mathrm{Se}_{3}\right)$, migração de polarização em vidros aluminoboratos e o movimento do $\mathrm{Na}^{+}$em filmes de vidros crescidos termicamente. A liberação de íons de $\mathrm{Na}^{+}$das interfaces de eletrodos de $\mathrm{Si}$ ou $\mathrm{Al}$ com filmes de $\mathrm{SiO}_{2}$ produziu picos de correntes iônicas termicamente estimuladas dos quais foram determinadas a profundidade das capturas e a mobilidade do $\mathrm{Na}^{+}$. Ainda segundo os autores antes de seu trabalho publicado em 1979 [2] a técnica de CDTE nunca havia sido aplicada a vidros óxidos contendo álcalis e as curvas de CDTE dependem da composição e condições de polarização do vidro. Eles utilizaram os seguintes vidros: $4 \mathrm{Na}_{2} \mathrm{O}-96 \mathrm{SiO}_{2}$ (mol\%), $25 \mathrm{Na}_{2} \mathrm{O}-75 \mathrm{SiO}_{2}$ (mol\%) e $30 \mathrm{PbO}-70 \mathrm{SiO}_{2}$ (mol\%). Para a amostra contendo $\mathrm{PbO}$ foi observado somente um pico de CDTE , já para as amostras que contêm sódio foram observados dois picos. Para a amostra $4 \mathrm{Na}_{2} \mathrm{O}-$ $96 \mathrm{SiO}_{2}$ (mol\%) o primeiro pico consiste na despolarização das orientações dos íons alcalinos em torno dos oxigênios NBO's, como proposto por Charles $[3,4]$ e segundo este autor, este processo ocorre de duas formas:

a) os íons alcalinos saltam de um NBO- para outro, por meio de um mecanismo ainda não totalmente conhecido, talvez por meio de uma combinação de vacância-interstício;

b) um íon alcalino supostamente salta para outros sítios próximos ao mesmo NBO-

Ainda para a amostra $4 \mathrm{Na}_{2} \mathrm{O}$ [2] o deslocamento geral dos íons de sódio torna-se apreciável aproximadamente à mesma temperatura onde se encontra o pico de CDTE. Isso fornece um excelente exemplo da utilidade da técnica, pois a polarização (movimento do álcali) associada com o pico de $373 \mathrm{~K}$ apresenta-se 
oculta pela manifestação da corrente de fundo à alta temperatura quando o vidro é aquecido com o campo aplicado (técnica de correntes de polarização termicamente estimuladas) e apenas se torna evidente quando o movimento de deslocamento geral dos íons alcalinos é eliminado com a remoção do campo aplicado (CDTE).

Nos vidros que possuem duas fases imiscíveis e que possuem diferentes características elétricas, tais como os vidros $30 \mathrm{PbO}$ e $4 \mathrm{Na}_{2} \mathrm{O}$ que têm ambas as fases separadas, algum tipo de polarização pode ser esperado na interface existente entre as fases imiscíveis. No caso do vidro $4 \mathrm{Na}_{2} \mathrm{O}$, o qual contém gotículas isoladas ricas em sódio ( $400 \AA$ de diâmetro) distribuídas em uma matriz pobre de sódio, a diferença de mobilidade do sódio pode ser imaginada como a causadora da polarização interfacial na fronteira de separação entre duas fases diferentes. Tentativamente, o pico de CDTE em $373 \mathrm{~K}$ no vidro $4 \mathrm{Na}_{2} \mathrm{O}$ é atribuído a uma polarização interfacial desse tipo, no qual a mobilidade maior dos íons de sódio nas gotículas resulta na sua polarização em relação à matriz.

Em um artigo posterior [5], Hong e Day atribuíram os dois picos de CDTE dos vidros silicatos de sódio ao movimento do íon de sódio em torno de um NBO-. Neste artigo os autores produziram vidros variando a concentração de $\mathrm{Na}_{2} \mathrm{O}$, os resultados seguem na figura 21.

Para o vidro (25 $\left.\mathrm{R}_{2} \mathrm{O}-75 \mathrm{SiO}_{2}\right)$ mol\%, sendo $\mathrm{R}=\mathrm{Li}, \mathrm{Na}, \mathrm{K}$ e $\mathrm{Rb}$ [6] foram observados dois picos de CDTE atribuídos ao movimento de álcalis, figura 22 . $\mathrm{O}$ primeiro pico $(222 \mathrm{~K}$ para $\mathrm{R}=\mathrm{Na}$ ) manteve-se estável e o segundo $(278 \mathrm{~K}$ para $\mathrm{R}=$ $\mathrm{Na}$ ), apresentou maior intensidade e variou com o tipo de álcali presente. Para temperaturas acima de $300 \mathrm{~K}$ os autores [6] detectaram uma corrente de fundo associada com a condutividade. Agarwal e Day [6] propuseram um modelo para os sítios de íons alcalinos na vizinhança dos NBO's assumiram a presença de um campo elétrico aplicado. Essencialmente, a profundidade dos poços de potencial foi distribuída entre três tipos (figura 23): os poços profundos $\left(E_{d c}\right)$ atribuídos à condutividade de corrente contínua, aos poços rasos $\left(E_{i}\right)$ atribuídos aos sítios intersticiais e o terceiro $E_{2}$ ligeiramente menores do que poços profundos que formam trajetórias de regiões de condução limitada. Segundo os autores $K_{\mathrm{l}}$ representa a probabilidade dos íons alcalinos de sair de um poço de potencial instável para um estável e $\mathrm{K}_{\mathrm{S}}$ de um potencial estável para um instável. Já $\mathrm{K}_{2}$ 
representa a probabilidade de saltar de um poço de região de condução limitada para outro. Em posterior trabalho Agarwal e Day [7] atribuíram os dois picos de CDTE ao movimento localizado e limitado de translação dos íons alcalinos nos vidros contendo apenas um tipo de álcali. Este artigo discute que a adição de $\mathrm{Li}_{2} \mathrm{O}$ segundo a fórmula estequiométrica $25\left[\mathrm{xLi}_{2} \mathrm{O}+(1-\mathrm{x}) \mathrm{Na}_{2} \mathrm{O}\right] .75 \mathrm{SiO}_{2} \mathrm{~mol} \%$ com $x=0,05$; a constatação foi de que o pico de maior temperatura diminui.

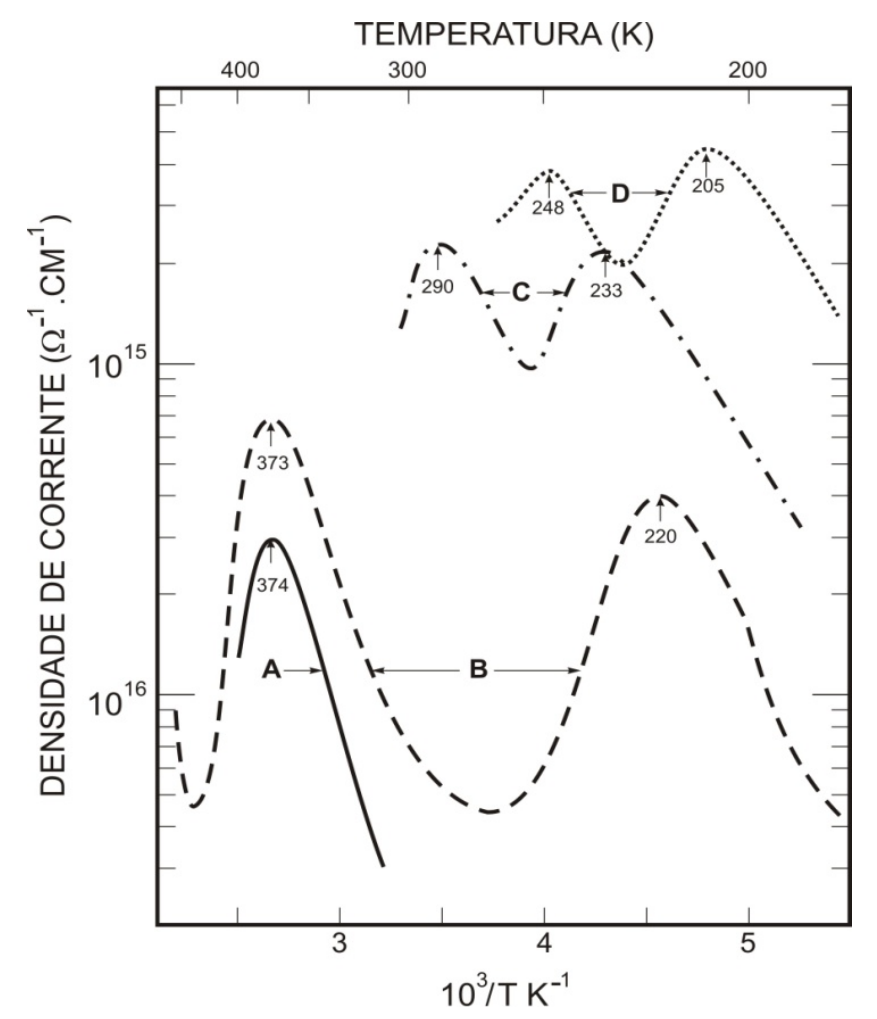

Figura 21 - O gráfico acima representa picos de CDTE com diferentes concentrações de $\mathrm{Na}_{2} \mathrm{O}$. Curva A representa o vidro que contém (18 $\mathrm{Na}_{2} \mathrm{O}-82$ $\left.\mathrm{SiO}_{2}\right) \mathrm{mol} \%$, curva $\mathrm{B}$ representa o vidro $\left(4 \mathrm{Na}_{2} \mathrm{O}-96 \mathrm{SiO}_{2}\right)$ mol\%, curva $\mathrm{C}$ a amostra (10 $\left.\mathrm{Na}_{2} \mathrm{O}-90 \mathrm{SiO}_{2}\right)$ mol\% e a curva $\mathrm{D}\left(25 \mathrm{Na}_{2} \mathrm{O}-75 \mathrm{SiO}_{2}\right) \mathrm{mol} \%$ [5].

Segundo Hong e colaboradores [8] a polarização pode ser criada devido à aplicação de um campo elétrico e a irradiação das amostras com raios gama. A liberação de cargas capturadas nos vidros irradiados produz um pico de corrente termicamente estimulada com a mesma energia de ativação que a do pico de corrente nos espécimes eletricamente polarizados. A irradiação produziu uma ruptura dielétrica e que está correlacionada com a quantidade de cargas capturadas 
e com o tempo de relaxação da liberação de carga, determinado por CDTE [8]. A ruptura induzida por irradiação não parece estar diretamente correlacionada com a condutividade maciça ou com a constante dielétrica. $\mathrm{O}$ fator determinante tem sido atribuído tentativamente à micro-estrutura do vidro e a separação de fase. Outros fatores também podem estar influindo, pois alguns vidros com separação de fase não apresentam ruptura [8]. Os autores concluíram que a radiação uniforme não polarizaria macroscopicamente o vidro e, portanto, não haveria picos de CDTE. Os vidros analisados foram silicatos de chumbo [8].

Alguns autores como Rocha et al [9] observaram três picos de CDTE localizados em; 105, 190,6 e $300 \mathrm{~K}$ em vidros aluminoboratos de bário com a seguinte fórmula estequiométrica $\left(14 \mathrm{Al}_{2} \mathrm{O}_{3}-72 \mathrm{~B}_{2} \mathrm{O}_{3}-14 \mathrm{BaO}\right.$ ) mol\%. Os autores atribuíram todos os picos a defeitos dipolares, sendo o primeiro e o último devido a vários dipolos e o segundo a um único defeito dipolar (figura 24). Os autores irradiaram a amostra com raios - X (300 KV - $5 \mathrm{~mA}$ por 2,5 horas) e obtiveram dois picos, em 140 e $240 \mathrm{~K}$, respectivamente. Outras pequenas mudanças foram observadas no espectro, mas segundo os autores, de difícil explicação (figura 25).

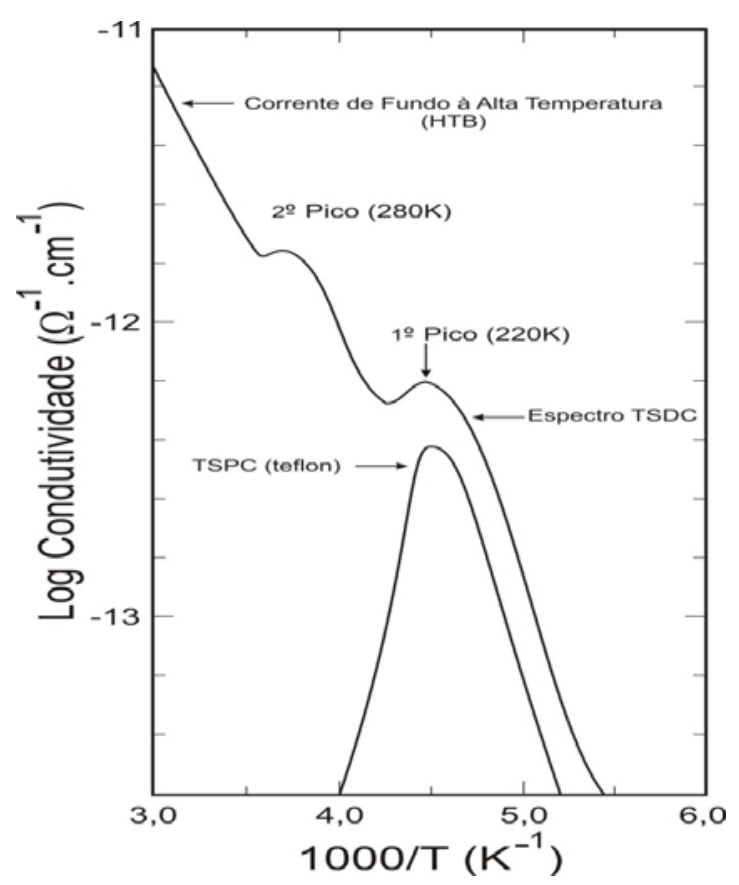

Figura 22 - Espectro de CDTE do vidro (25 $\left.\mathrm{Na}_{2} \mathrm{O}-75 \mathrm{SiO}_{2}\right)$ mol\% polarizado a $230 \mathrm{~K}$ por 10 minutos com $1,36 \times 10^{5} \frac{\mathrm{V}}{\mathrm{m}}$. Segue também a curva experimental do Teflon inserido entre o vidro e o eletrodo [6]. 


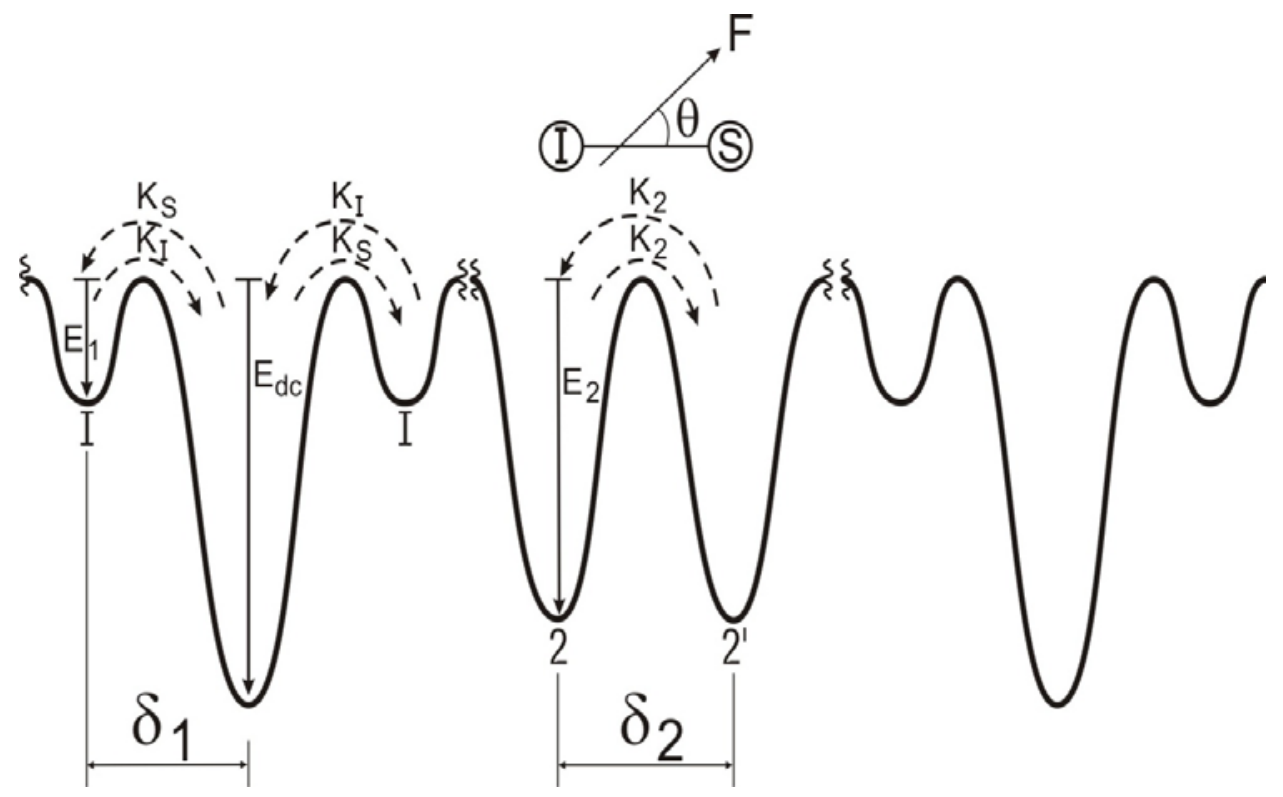

Figura 23 - Modelo dos sítios de íons alcalinos em vidros silicatos. Modelo de Agarwal e Day [6].

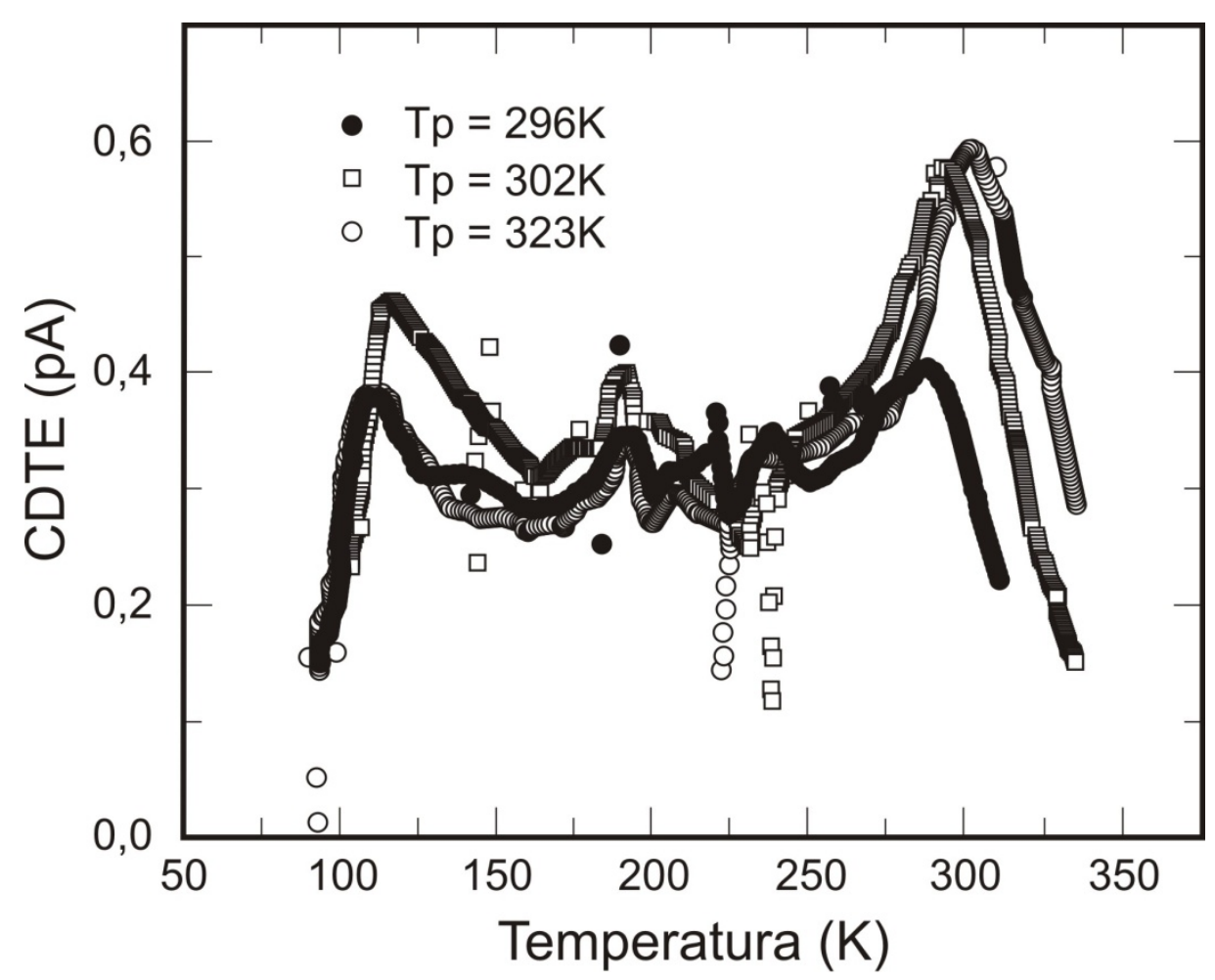

Figura 24 - Picos de CDTE com diferentes temperaturas de polarização [9]. 


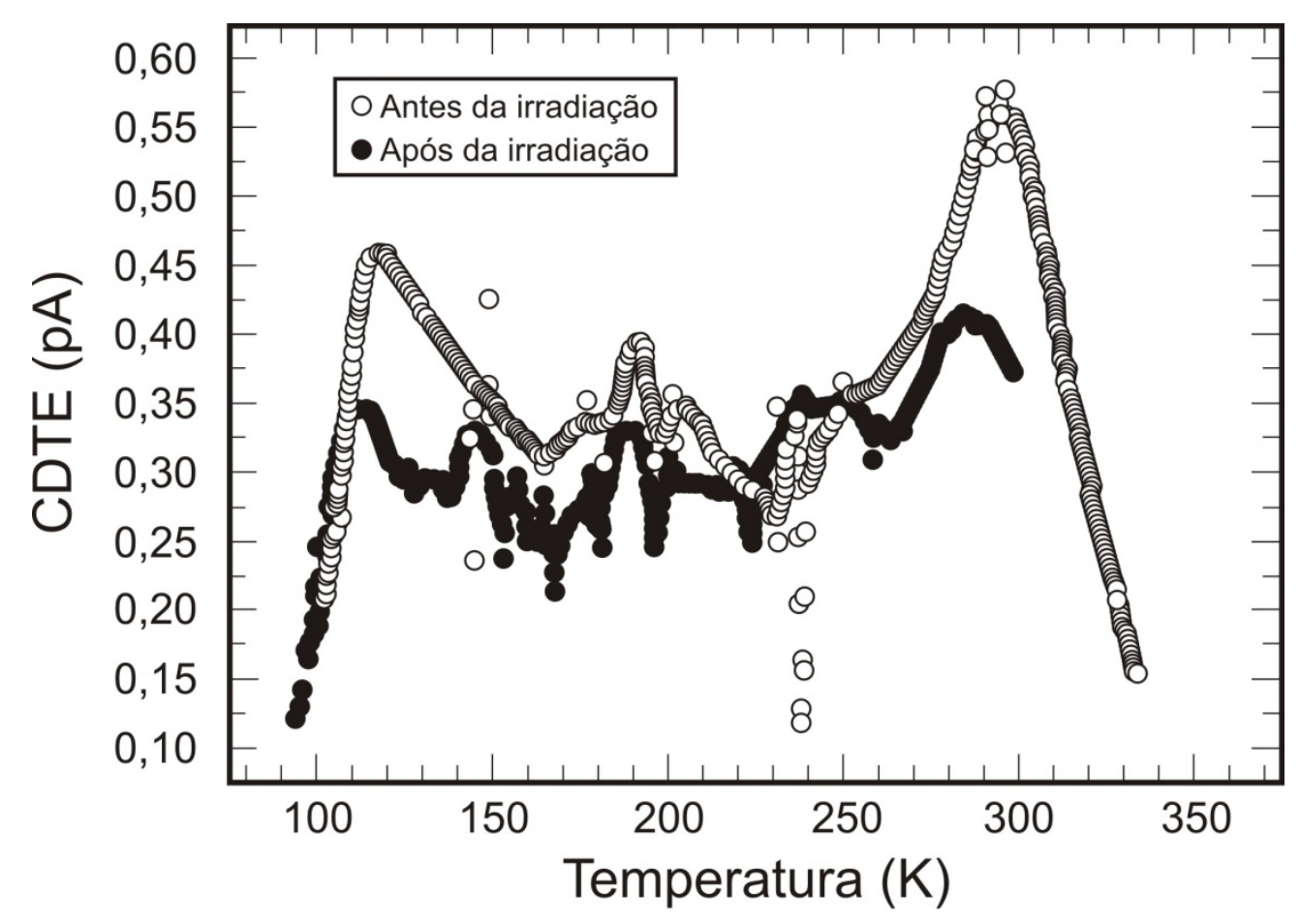

Figura 25 - Picos antes e após a irradiação [9].

\subsubsection{Termoluminescência ( $T L)$}

Para estudar a natureza de defeitos nos vidros por meio da técnica de termoluminescência (TL) é necessário promover a excitação prévia da amostra com a captura de elétrons e buracos pelos centros luminescentes e de recombinação, por meio da exposição a uma fonte de radiação ionizante (raios- $X, \mathrm{y}$, luz UV e laser). Nesse caso específico, o portador de carga capturado pelo centro luminescente situado a uma pequena profundidade da banda de condução (BC) no caso de ser um elétron é, ou da banda de valência (BV) no caso de um buraco $\mathrm{h}^{+}$onde existe uma infinidade de níveis de energia que permitem o deslocamento da carga até o centro de recombinação. A reação de recombinação consiste na mútua aniquilação de $\mathrm{e}^{-}-\mathrm{h}^{+}$com a emissão de um fóton da TL.

Pode ocorrer, também, o caso de o centro luminescente se encontrar muito próximo ao centro de recombinação de modo que a vibração térmica, a uma determinada temperatura, provocar a sucessão de múltiplas colisões entre os 
centros e a conseqüente recombinação entre o elétron e o respectivo buraco deixado no sítio de onde foi arrancado.

Existem vários modelos matemáticos da TL que dependem da maior ou menor complexidade das reações de recombinação entre os portadores de carga: processos de primeira ordem estudados Randall e Wilkins [10, 11], cinética de segunda ordem de Garlick e Gibson [12], cinética de ordem geral de May e Partridge [13] e aplicações mais recentes, entre outras, as de McKeever e colaboradores [14, 15].

Em alguns casos mais simples de processos de cinética de primeira e segunda ordem, a região de subida inicial do pico TL pode ser descrita como

$$
\mathrm{I}_{\mathrm{TL}}(\mathrm{t})=\mathrm{C} \mathrm{e}^{-\frac{\mathrm{E}_{\mathrm{a}}}{\mathrm{Kt}}}
$$

no qual $E_{a}$ é a energia de ativação da armadilha e $\mathrm{I}_{\mathrm{TL}}(\mathrm{t})$ é a intensidade $T L$ em função da temperatura. Melhorias e limitações deste método foram consideradas por Halperin et al [16]. Neste trabalho, vamos nos limitar a este método para determinar as energias de ativação a partir das curvas de TL.

\subsubsection{Referências}

[1] Bucci, C.; Fieschi, R. Ionic thermoconductivity. Method for the investigation of polarization in insulators. Phys. Rev. Lett., v. 12, p. 16-19, 1964.

[2] Hong, C.; Day, D. E. Thermally stimulated polarization and depolarization current (TSPC/ TSDC) techniques for studying ion motion in glass. J. of Mat., v. 14, p. 24932499, 1979.

[3] Charles, R. J. Polarization and diffusion in a silicate glass. J. Appl. Phys., v. 32, n. 6, p. 1115-1126, 1961.

[4] Charles, R. J. Structural state and diffusion in a silicate glass. J. Am. Ceram. Soc., v. 45, n. 3 , p. 105-113, 1962.

[5] Hong, C.; Day, D. E. Thermally stimulated currents in sodium silicate glasses. J. of the Am. Cer. Soc., v. 64, n. 2, p.61-68, 1981.

[6] Agarwal, A. K.; Day, D. E. Thermally stimulated currents and alkali-ion motion in silicate glasses. J. Am. Ceram. Soc., v. 65, n. 2, p. 111-117, 1981. 
[7] Agarwal, A. K.; Day, D. E. Polarization and conduction mechanism in mixed-alcali glasses. J. Am. Ceram. Soc., v. 65, n. 5, p. 231-237, 1981.

[8] Hong, C. M.; Day, D. E; Weeks, R. A.; Kinser, D. L. Charge trapping and release in electron and gamma irradiated lead silicate glasses. J. of Non-Cryst. Solids, v. 46, p. 389-404, 1981.

[9] Da Rocha, M. S. F.; Blak, A. R.; Pontuschka, W. M.; Carvalhaes, R. P. M.; Bergo, P. V. A. Depolarization currents and low-frequency measurements in X-ray irradiated barium aluminoborate glasses. Nuc. Inst. And Method. In Phys. Research B, v. 218, p. 183-188, 2004.

[10] Randal, J. T.; Wilkins, M. H. F. Phosphorescence and electron traps I. The study of traps distributions. In: Proceedings of the Royal Society of London. Series A, Mathematical and physical sciences, v. 184, p. 365-389, 1945.

[11] Randal, J. T.; Wilkins, M. H. F. Phosphorescence and electron traps II. The interpretation on long-period phosphorescence. In: Proceedings of the Royal Society of London. Series A, Mathematical and physical sciences, v. 184, p. 390-407, 1945.

[12] Garlich, G.; Gibson, A. F. The electron trap mechanism of luminescence in sulphide and silicate phosphors. In: Proceedings of the Royal Society of London. Series A, Mathematical and physical sciences, v. 60, p. 574-590, 1948.

[13] May, C. E.; Partridge, J. A. Thermoluminescent kinetics of alpha-irradiated alkali halides. J. Chem. Physics, v. 40, n. 5, p. 1401-1409, 1964.

[14] Mckeever, Stephen W. S. On the analysis of complex thermoluminescence glowcurves: resolution into individual peaks. Physica Status Solidi, v. 62, n. 1, p. 331-340, 1980.

[15] Mckeever, Stephen W. S.; Chen, C. Y.; Halliburton, L. E. Point defects and the pre-dose effect in natural quartz. Nuclear Traks and Rad. Meas., v. 10, n. 1, p. 489495, 1985.

[16] Halperin, A.; Braner, A. A. Evaluation of thermal activation energies from glow curves. Phys. Rev., v. 117, n. 2, p. 408-415, 1960. 


\subsection{Ressonância paramagnética eletrônica (RPE)}

\subsubsection{Introdução aos defeitos em vidros óxidos (isolantes)}

A ressonância paramagnética eletrônica (RPE) é uma técnica muito sensível, mas que é aplicável somente a materiais que contenham substâncias paramagnéticas. Entre a grande variedade de áreas de conhecimento, estamos especialmente interessados em esclarecer detalhes e mecanismos relacionados com as propriedades físicas, químicas e estruturais de defeitos e impurezas em vidros óxidos (isolantes). Como os vidros geralmente não são paramagnéticos assim que preparados, o estudo de EPR é geralmente efetuado com amostras irradiadas com a radiação ionizante de raios $\mathrm{X}, \gamma$ ou feixe de elétrons, exceto quando as amostras são dopadas com impurezas paramagnéticas.

A ionização nos vidros óxidos ocorre em um orbital de um átomo de oxigênio, de onde o fotoelétron é promovido da banda de valência (BV) para a banda de condução (BC), após transpor a banda proibida com intervalo de energia $E_{g}$, nesta região ele se movimentará livremente até ser aprisionado por uma armadilha de elétrons, como o caso particular do centro E' do silício (figura 26). Um buraco (OHC) é deixado em um nível na (BV) onde pode movimentar-se livremente até encontrar um poço de potencial situado um pouco acima da (BV), nos estados localizados descritos anteriormente.

No caso particular da formação do centro E', o elétron é aprisionado por um orbital vazio de uma vacância de oxigênio $\left(V_{O}\right)$ ou por um cátion mais próximo modificador da rede vítrea (figura 27 e 28). 


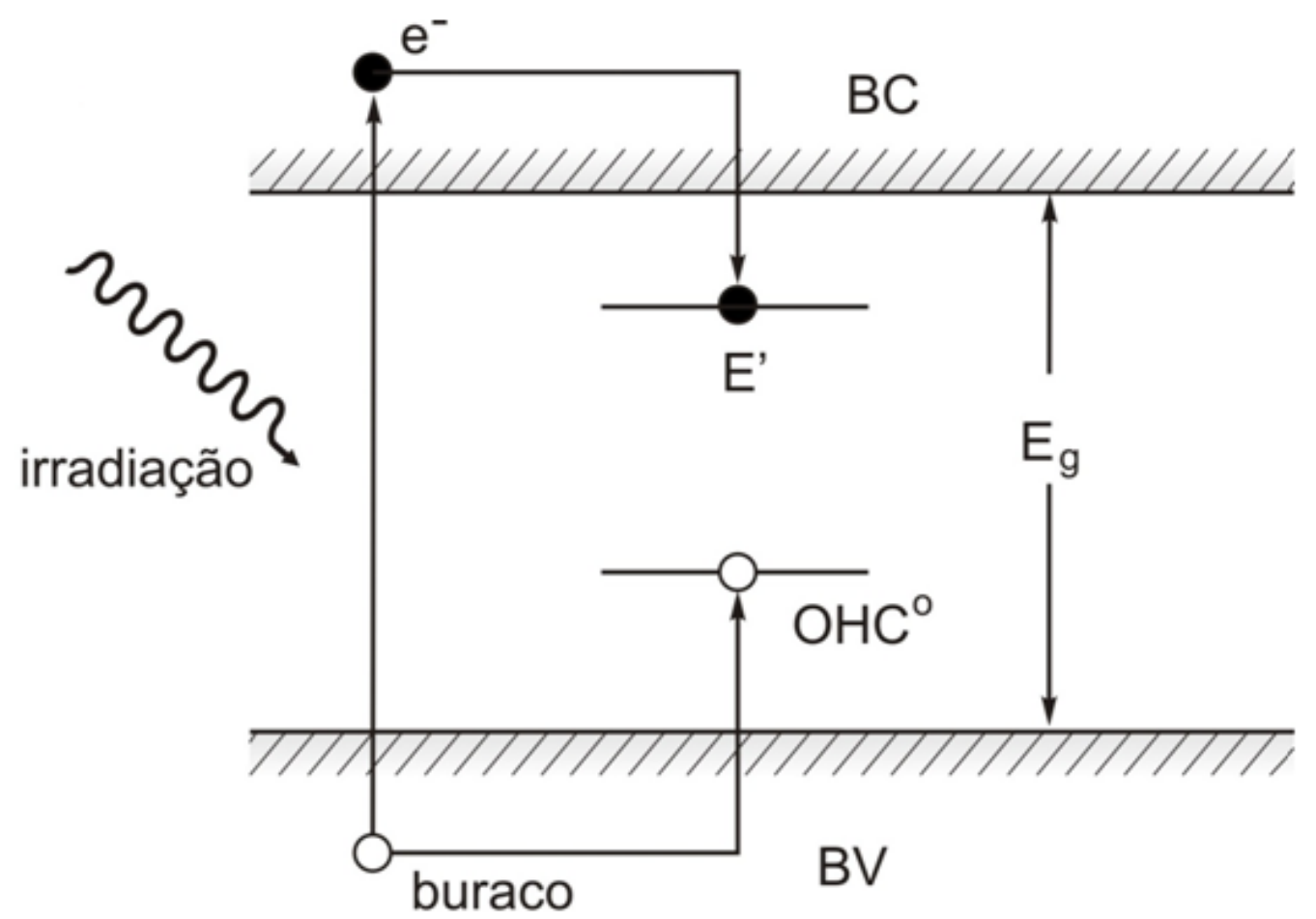

Figura 26 - Diagrama da formação do par centro E' e OHC.

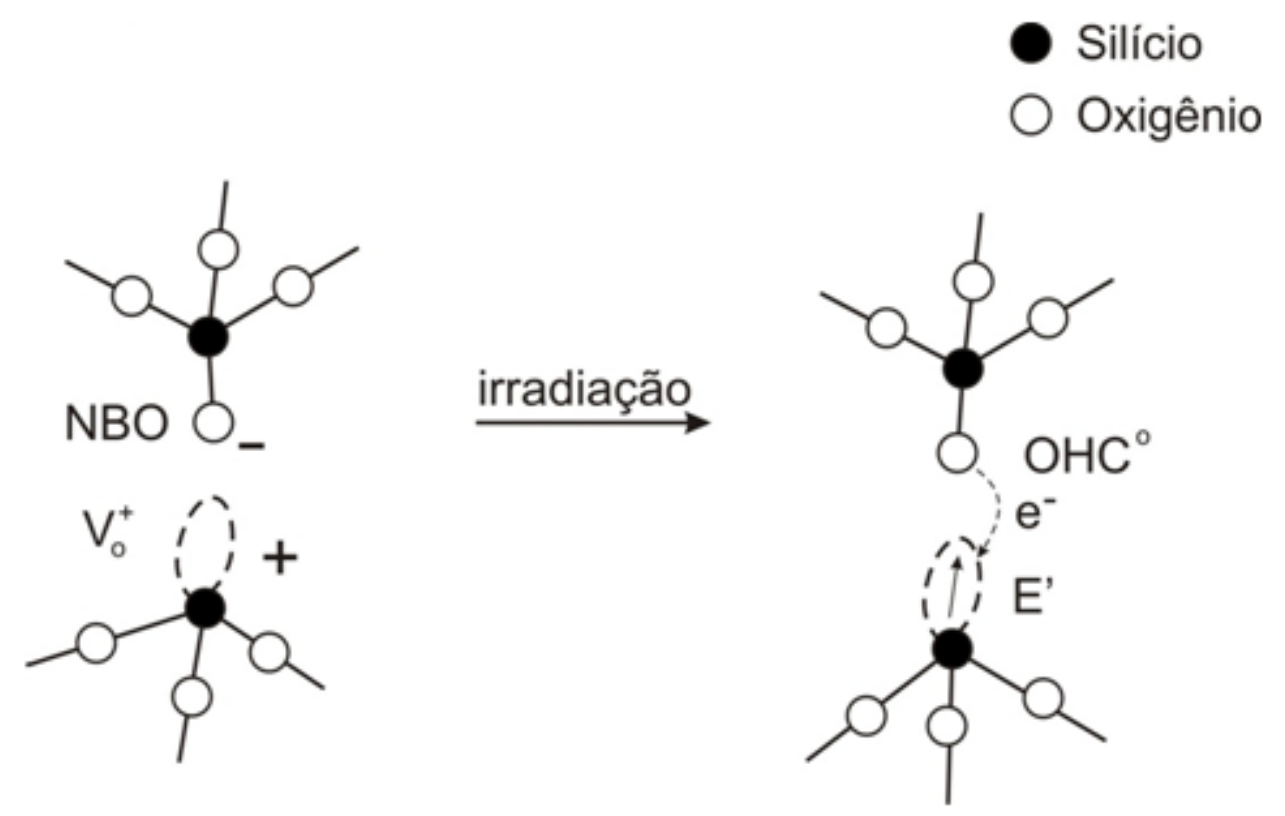

Figura 27 - Formação do centro $E^{\prime}$ e do $\mathrm{OHC}^{\circ}$ em vidros silicatos, com o elétron aprisionado por um orbital vazio de uma vacância de oxigênio. 


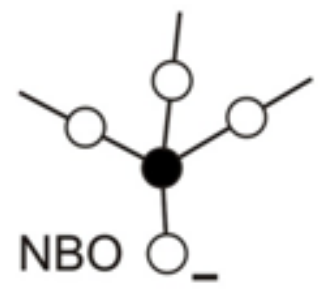

$\mathrm{M}^{+}$
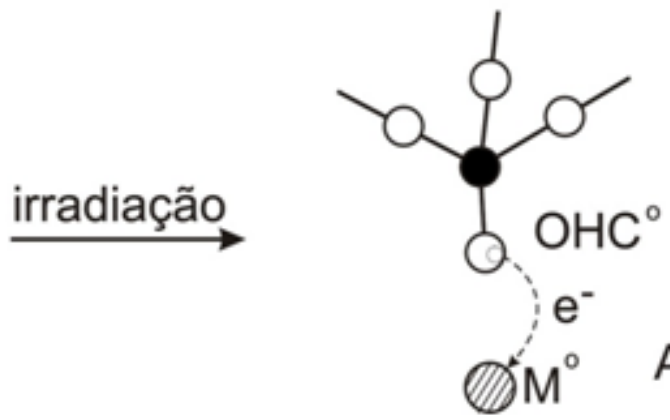

AEC

Figura 28 - Formação do centro de elétron capturado por um cátion modificador e do $\mathrm{OHC}^{\circ}$ por um cátion mais próximo modificador da rede vítrea.

\subsubsection{Centros de elétrons}

O centro de elétron do silício E' foi estudado pela primeira vez em 1956 por R. A. Weeks [1] no quartzo, tendo então utilizado o modelo de vacância de oxigênio em uma unidade estrutural $\mathrm{SiO}_{4}$ com um elétron capturado na ligação pendente que ficou no lugar do oxigênio removido. Outros modelos foram também propostos posteriormente para explicar a natureza do centro E' nos vidros silicatos [2-5].

Outro centro de elétron bem conhecido é o centro de elétron do boro (BEC), que foi estudado por D. L. Griscom em 1971 [6] em sistemas de vidros boratos de lítio, sódio e potássio, irradiados e medidos à temperatura do nitrogênio líquido. Assim como nos vidros boratos, os vidros fosfatos e em outros vidros óxidos foram encontrados centros de defeitos análogos, entre outros que não pretendemos citar aqui. No caso dos vidros fosfatos, o centro análogo ao SiE' (centro de elétron do Silício) ou ao BEC é o centro $\mathrm{P}_{1}[7,8]$ que também pode ser do fósforo PEC.

\subsubsection{Centros de buracos}

Durante a irradiação, o buraco deixado no orbital $p$ de energia mais alta na (BV) estará se deslocando livremente até encontrar um poço de potencial ao longo de sua trajetória no interior das ligações covalentes e ser auto-aprisionado, geralmente, no sítio de um oxigênio que forma ponte (BO) entre duas unidades 
estruturais consecutivas ou então, em um oxigênio terminal (NBO), cuja carga é compensada por um cátion modificador da rede vítrea (figura 29).

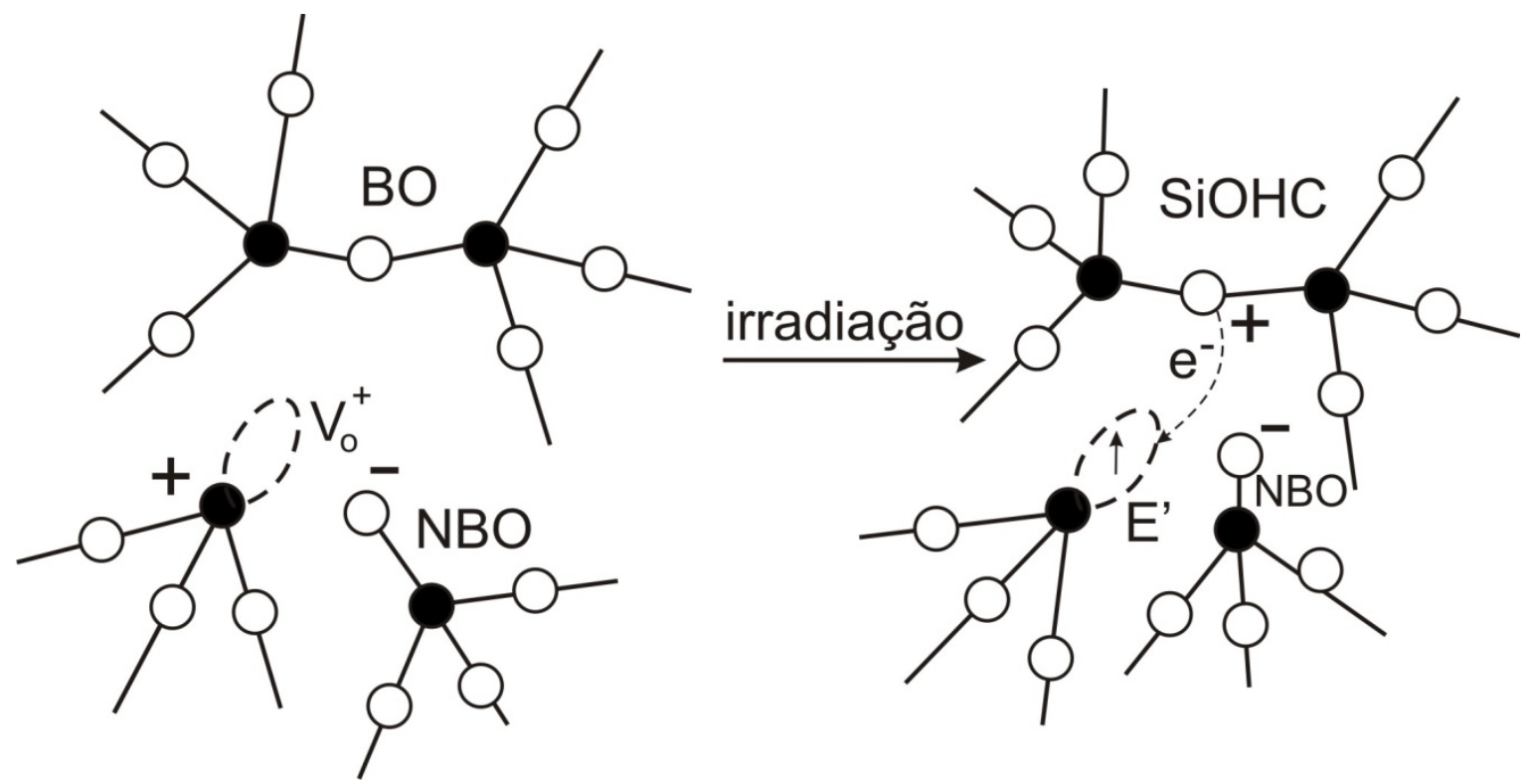

Figura 29 - Formação do E' e do SiOHC.

Griscom e colaboradores [9] desenvolveram um estudo de RPE de vidros boratos de lítio, irradiados com raios $\gamma$ a $77^{\circ} \mathrm{C}$, utilizando um Hamiltoniano de Spin do tipo:

$$
\begin{aligned}
& H=\beta_{1}\left(g_{1} S_{1} H_{1}+g_{2} S_{2} H_{2}+g_{3} S_{3} H_{3}\right)+ \\
& A_{1} S_{1} I_{1}+A_{2} S_{2} I_{2}+A_{3} S_{3} I_{3},
\end{aligned}
$$

no qual $\beta_{1}$ é o magnéton de Bohr; $g_{1}, g_{2}$ e $g_{3}$ são fatores espectroscópicos; $\mathrm{S}_{1}, \mathrm{~S}_{2}$ e $\mathrm{S}_{3}$ são números de spin eletrônico; $\mathrm{I}_{1}, \mathrm{I}_{2}$ e $\mathrm{I}_{3}$ são números de spin nuclear e $A_{1}, A_{2}$ e $A_{3}$ são constantes de interação hiperfina. Desenvolveram ainda uma simulação computacional levando em conta a natureza amorfa da matriz vítrea, fixando um valor para cada uma das grandezas $g_{1}$ e $g_{2}$ assumindo uma distribuição estatística para $g_{3}$. Para as constantes hiperfinas, entretanto, não foi possível estabelecer uma correspondência de um a um. Mesmo assim, os valores determinados pelo método de tentativas e erros produziram excelentes resultados.

Quanto aos centros de buracos induzidos por radiação nos vidros silicatos, foram identificados dois tipos distintos: o "molhado" que é o radical de NBO associado a uma hidroxila e o "seco", terminado por dois oxigênios consecutivos 
formando o radical peróxi. O primeiro foi caracterizado por RPE como sendo associado ao próton [10] ligado a um oxigênio terminal vizinho (figura 30.a). O segundo também foi descoberto por $\operatorname{RPE}[10,11]$ e atribuído ao radical peróxi, que se originou por meio da quebra de uma ligação entre um par de tetraedros de $\mathrm{SiO}_{4}$ entre os quais figuram dois oxigênios (figura 30.b).

(a)<smiles>CO[Sb]([O-])(OC)OCCOS(=O)(OC)(OC)OC</smiles>

(b)
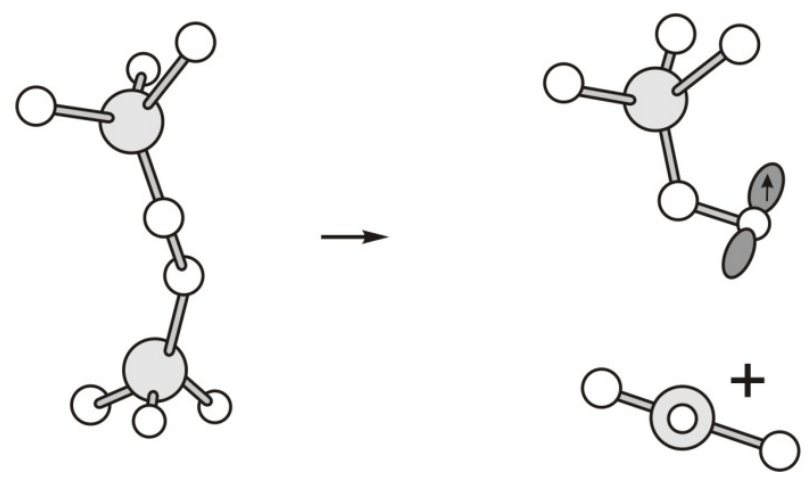

Figura 30 - Formação de centros de buracos de oxigênio [11]. a) Radical protonado do OHC "molhado" do NBO. b) Radical peroxil do OHC "seco".

Um centro correspondente ao centro de buraco do boro e oxigênio (BOHC), nos vidros fosfatos, é o centro de buraco do fósforo e oxigênio $(\mathrm{POHC})$ o qual consiste de uma unidade $\mathrm{PO}_{4}$ que possui dois NBO's e que capturou um buraco [7]. 


\subsubsection{Centro de elétron do telúrio (TeEC) ou Centro $V_{o}^{\prime}$}

A ressonância bem resolvida e estreita, identificada na figura 31 foi observada pela primeira vez por Prohaska [12], tendo sido atribuída a um centro do tipo $V_{0}^{\prime}$ (vacância de oxigênio que capturou um elétron) caracterizado por um elétron capturado numa vacância de $\mathrm{O}^{2-}$ em uma unidade estrutural de vidro de óxido de telúrio, neste trabalho denominado de TeEC. Esta denominação é baseada no trabalho de Weeks [1] sobre o quartzo e algumas amostras de vidro de sílica fundida. Em geral, nos vidros óxidos, esses centros consistem de elétrons capturados, abaixo da temperatura ambiente em níveis rasos, da ordem de $\sim 0,2 \mathrm{eV}$ [13] e durante o aquecimento até cerca de $300 \mathrm{~K}$ estes centros já se encontram quase completamente recombinados. Entretanto, nos vidros teluritos, este centro é bem caracterizado e é relativamente estável à temperatura ambiente, como foi reportado por Prohaska e confirmado pelo presente trabalho.

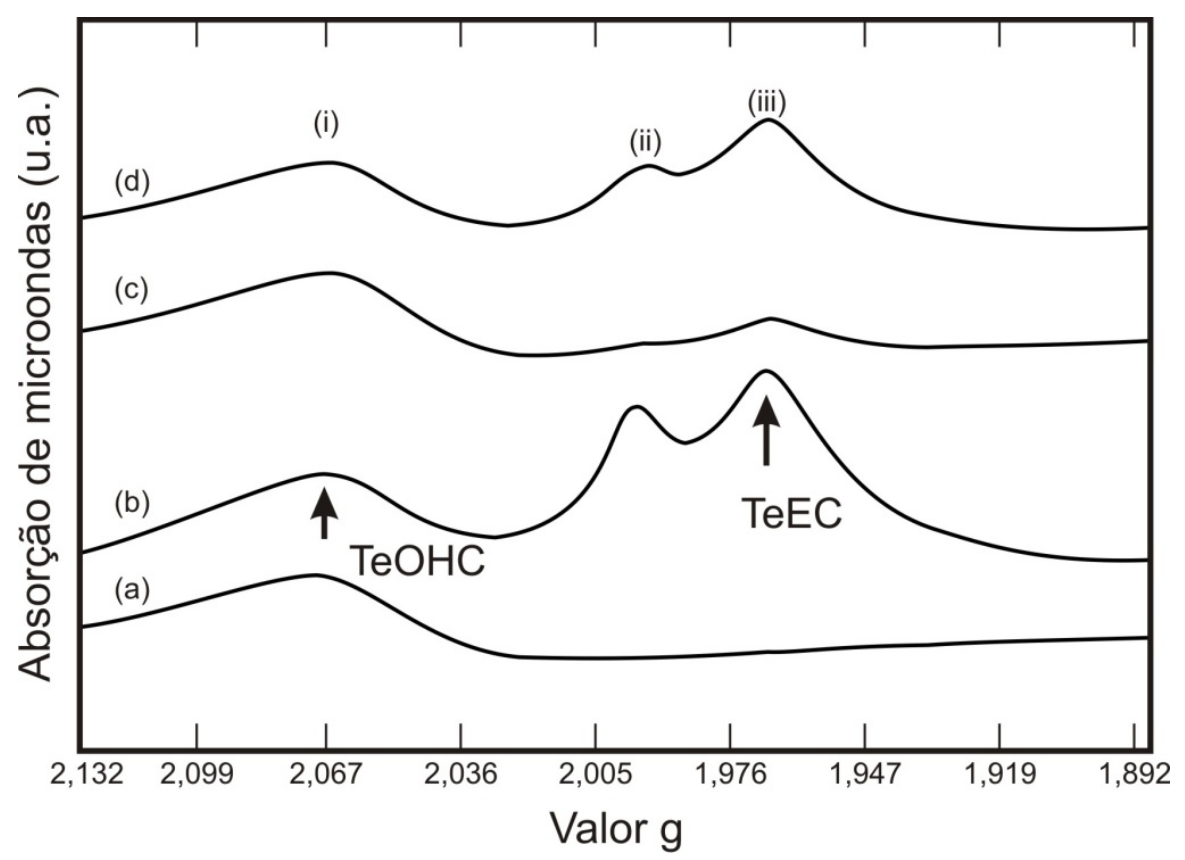

Figura 31 - Espectro obtido por Prohaska [12].

\subsubsection{Centro de buraco do telúrio e oxigênio (TeOHC)}


Este centro é caracterizado por um buraco criado pela retirada de um fotoelétron de um oxigênio qualquer da rede vítrea, o qual é auto-capturado no sítio de um oxigênio interligante ("bridging oxygen") (BO) conectando duas unidades estruturais unidas pelos vértices. Um modelo detalhado foi desenvolvido por $D$. L. Griscom et al [9] e confirmado por simulação computadorizada dos espectros de RPE, tendo assumido distribuições contínuas de valores anisotrópicos de g. Defeitos similares ocorrem regularmente também em outros vidros óxidos. Assumimos, portanto, que o $\mathrm{TeOHC}$ consiste de um buraco capturado no orbital molecular $p-\pi$ em um BO que ocupa um vértice comum de um par de unidades estruturais dos vidros teluritos.

Prohaska e colaboradores [12] atribuiu a linha $g=2,0747 \pm 0,0005$ ao $\mathrm{TeOHC}$, em vidros não irradiados, com a fórmula estequiométrica $\left(5 \mathrm{Na}_{2} \mathrm{O}-25 \mathrm{ZnO}\right.$ $\left.-70 \mathrm{TeO}_{2}\right) \mathrm{mol} \%$.

Kanth e colaboradores [14] afirmaram que a produção do centro de elétron do telúrio (TEC), centro de buraco do oxigênio terminal e centro de buraco de telúrio e oxigênio $(\mathrm{TOHC})$ é decorrente da irradiação dos vidros produzindo elétrons secundários dos sítios onde eles se encontravam em um estado estável possuindo um excesso de energia. Tais elétrons podem se deslocar através da rede vítrea dependendo da sua energia e composição do vidro até finalmente serem capturados formando então centros de cor (ou alternativamente formando éxcitons com estados de energia no interior da banda proibida).

\subsubsection{Referências}

[1] Weeks, R. A. Paramagnetic resonance of lattice defects in irradiated quartz. J. Appl. Phys., v. 27, n. 11, p. 1376-1381, 1956.

[2] Feigl, F. J.; Fowler, W. B.; Yip, K. L. Oxygen vacancy model for the $E_{1}^{\prime}$ center in $\mathrm{SiO}_{2}$. Solid St. Commun., v. 14, n. 3, p. 225-229, 1974.

[3] Yip, K. L.; Fowler, W. B. Electronic structure of the $E_{1}^{\prime}$ centers in $\mathrm{SiO}_{2}$. Phys. Rev. B, v. 11, n. 6, p. 2327-2338, 1975.

[4] Greaves, G. N. Colour centres in vitreous silica. Phil. Mag. B, vol. 37, p. 447-466, 1978. 
[5] Lucovsky, G. Paramagnetic centres associated with bonding defects in $\mathrm{v}-\mathrm{SiO}_{2}$. Phil. Mag. B, v. 41, p. 457-467, 1980.

[6] Griscom, D. L. ESR studies of an intrinsic trapped-electron center in X-irradiated alkali borate glasses. J. Chem. Phys., v. 55, n. 3, p. 1113-1122, 1971.

[7] Griscom, D. L.; Friebele, E. J.; Long, K. J. Fundamental defect centers in glass: electron spin resonance and optical absorption studies of irradiated phosphorusdoped silica glass and optical fibers. J. Appl. Phys., v. 54, n. 7, p. 3743-3762, 1983.

[8] Symons, M. C. R. EPR study of Phenacite: the $\mathrm{PO}_{4}^{4-}$ radical. J. Chem. Phys., v. 53, n. 2, p. 857-858, 1970.

[9] Griscom, D. L.; Taylor, P. C.; Ware, D. A.; Bray, P. J. ESR studies of lithium borate glasses and compounds $\gamma$ irradiated at $77^{\circ} \mathrm{K}$ : Evidence for a new interpretation of the trapped-hole centers associated with boron. J. Chem. Phys., v. 48, n. 11, p. 5158-5173, 1968.

[10] Stapelbroek, M.; Griscom, D. L.; Friebele, J. E.; Sigel, G. H. Oxygen associated trapped - hole centers in high - purity fused silicas. J. Non-Cryst. Solids, v. 32, p. 313-326, 1979.

[11] Friebele, E. J.; Griscom, D. L.; Stapelbroek, M.; Weeks, R. A. Fundamental defect centers in glass: the peroxy radical in irradiated, high-purity, fused silica. Phys. Rev. Lett., v. 42, n. 20, p. 1346-1349, 1979.

[12] Prohaska, J. D.; Wang, J. S.; Bartram, R. H. Eletron spin resonance observations of excimer-laser-induced paramagnetic centers in tellurite glasses. Appl. Phys. Lett., v. 67, n. 13, p. 1841-1843, 1995.

[13] Pontuschka, W. M.; Oliveira, M.I.T.; Del Nery, S. M. Luminescence quenching mechanisms for $\mathrm{Y}$-irradiated barium aluminoborate glasses doped with Fe. In "Borate Glasses, Crystals \& Melts, edited by A.C. Wright, S.A. Feller, A.C. Hannon, Alden Preess, Oxford, UK, p.392, 1996.

[14] Kanth, C. L.; Raghavaiah, B. V.; Appa Rao, B.; Veeraiah, N. Spectroscopic investigations on $\mathrm{ZnF}_{2}-\mathrm{MO}-\mathrm{TeO}_{2}(\mathrm{MO}=\mathrm{ZNO}, \mathrm{CdO}$ and $\mathrm{PbO})$ glasses doped with chromium ions. J. Quant. Spectrosc. Radiat. Trans., v. 90, p. 97-113, 2005. 


\section{Capítulo 3}

\section{Procedimento experimental}

\subsection{Preparação das amostras vítreas}

As amostras vítreas foram preparadas a partir da mistura de compostos de óxidos e de carbonatos de alta pureza. Os compostos usados e suas purezas seguem na tabela 8. A homogeneização dos reagentes foi realizada em um almofariz e pilão de ágata (figura 32).

A fusão de cada mistura foi efetuada em cadinho de platina previamente submetido a um processo de limpeza com ácido clorídrico ou fluorídrico. Um método de limpeza alternativo foi desenvolvido, evitando a necessidade do uso do ácido fluorídrico e que foi adotado durante as sucessivas fusões de vidros teluritos. Após o fundido de telurito ser vertido, procedeu-se uma fusão de vidro aluminoborato de bário no qual o resíduo de telurito ficou dissolvido. Após verter e descartar esta mistura, o resíduo foi facilmente eliminado, utilizando exclusivamente o ácido clorídrico.

Para que a amostra vítrea não fosse comprometida pelas estrias, a massa fundida foi homogeneizada com um bastão de quartzo com movimentos horários e anti-horários alternados (figura 33).

Tabela 8 - Óxidos utilizados e suas respectivas purezas.

\begin{tabular}{|l|l|}
\hline Elemento & Pureza \\
\hline $\mathrm{TeO}_{2}$ & $99,999 \%$ \\
\hline $\mathrm{Nb}_{2} \mathrm{O}_{5}$ & $99,998 \%$ \\
\hline $\mathrm{AgNO}_{3}$ & $99,9999 \%$ \\
\hline $\mathrm{Na}_{2} \mathrm{CO}_{3}$ & $99,995 \%$ \\
\hline $\mathrm{ZnO}$ & $99,99 \%$ \\
\hline
\end{tabular}




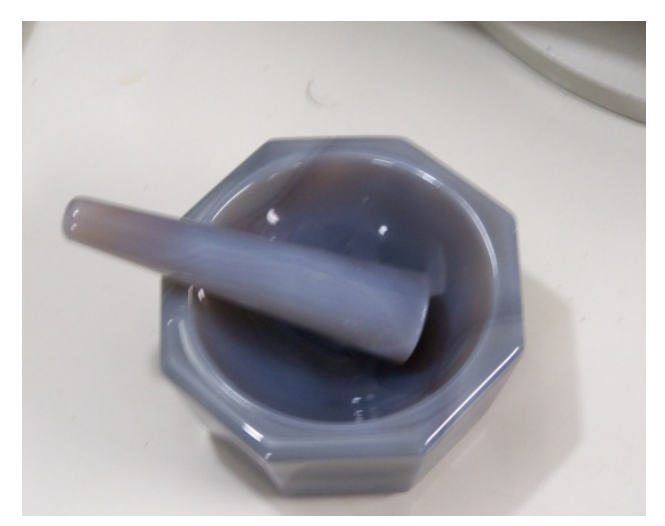

Figura 32 - Almofariz e pilão de ágata.

A tabela 9 mostra as composições químicas nominais das amostras produzidas que serão doravante identificadas pelas referidas siglas.

Tabela 9 - Composição das amostras (nominal).

\begin{tabular}{|c|c|c|}
\hline Amostra & Composição (mol\%) & Dopagem (mol \%) \\
\hline $\begin{array}{l}\text { Série A (fórmula } \\
\text { geral) }\end{array}$ & $\begin{array}{l}\mathrm{XAgO}_{1 / 2 \cdot}(100-\mathrm{x})\left(0,85 \mathrm{TeO}_{2}\right. \\
\left.0,12 \mathrm{Nb}_{2} \mathrm{O}_{5 \cdot} .0,03 \mathrm{Na}_{2} \mathrm{O}\right)\end{array}$ & $x$ \\
\hline $\mathrm{A}_{2}$ & & 0,5 \\
\hline$A_{3}$ & & Sem dopagem \\
\hline $\mathrm{A}_{4}$ & & 2,0 \\
\hline $\mathrm{A}_{5}$ & & 5,0 \\
\hline $\begin{array}{l}\text { Série B (fórmula } \\
\text { geral) }\end{array}$ & $\begin{array}{l}\mathrm{xAgO}_{1 / 2 \cdot} \cdot(100-\mathrm{x})\left(0,60 \mathrm{TeO}_{2} .\right. \\
\left.0,25 \mathrm{ZnO} \cdot 0,15 \mathrm{Na}_{2} \mathrm{O}\right)\end{array}$ & $x$ \\
\hline $\mathrm{B}_{2}$ & & 0,5 \\
\hline $\mathrm{B}_{3}$ & & Sem dopagem \\
\hline $\mathrm{B}_{5}$ & & 5,0 \\
\hline $\mathrm{C}_{1}$ & $\left(85 \mathrm{TeO}_{2} \cdot 15 \mathrm{Na}_{2} \mathrm{O}\right)$ & Sem dopagem \\
\hline
\end{tabular}




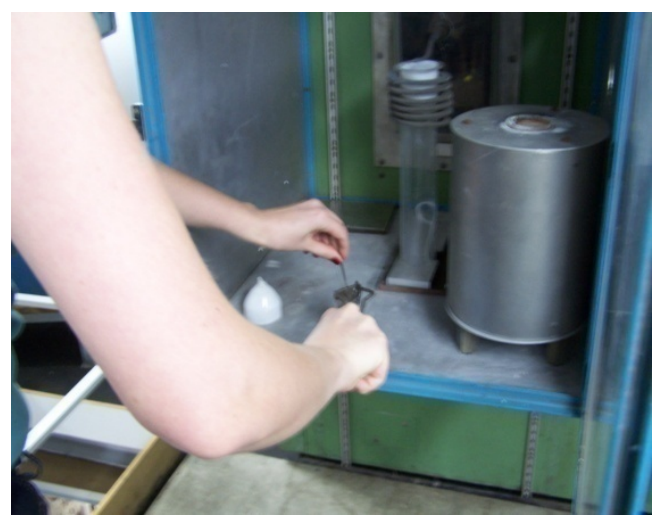

Figura 33 - Homogeneização da massa fundida com um bastão de quartzo. Ao lado do cadinho aparece o forno de radiofreqüência.

$\mathrm{Na}$ tabela 10 segue a composição real das amostras calculadas a partir dos resultados obtidos com a técnica de Espectroscopia de Emissão Óptica com Acoplamento de Plasma Induzido (ICP-AES), com o aparelho marca Spectro, modelo Spectro Arcos SOP - FHS12 analisadas pelo Instituto de Química da USP.

Tabela 10 - Composição real das amostras.

\begin{tabular}{|l|l|l|l|l|l|}
\hline Amostra & $\mathrm{TeO}_{2}(\mathrm{~mol} \%)$ & $\mathrm{Nb}_{2} \mathrm{O}_{5}(\mathrm{~mol} \%)$ & $\mathrm{Na}_{2} \mathrm{O}(\mathrm{mol} \%)$ & $\begin{array}{l}\mathrm{ZnO} \\
(\mathrm{mol} \%)\end{array}$ & $\begin{array}{l}\mathrm{AgO}_{1 / 2} \\
(\mathrm{~mol} \%)\end{array}$ \\
\hline $\mathrm{A}_{2}$ & $82 \pm 1$ & $11 \pm 1$ & $6 \pm 2$ & - & $0,35 \pm 0,05$ \\
\hline $\mathrm{A}_{3}$ & $82 \pm 1$ & $12,0 \pm 0,2$ & $6 \pm 2$ & - & - \\
\hline $\mathrm{A}_{4}$ & $82 \pm 1$ & $10 \pm 1$ & $6 \pm 2$ & - & $2,2 \pm 0,2$ \\
\hline $\mathrm{A}_{5}$ & $80,6 \pm 0,4$ & $10 \pm 1$ & $5 \pm 2$ & - & $4,4 \pm 0,3$ \\
\hline $\mathrm{B}_{2}$ & $64 \pm 2$ & - & $13,6 \pm 0,6$ & $22 \pm 1$ & $0,23 \pm 0,04$ \\
\hline $\mathrm{B}_{3}$ & $64 \pm 2$ & - & $13 \pm 2$ & $23 \pm 2$ & - \\
\hline $\mathrm{B}_{5}$ & $64 \pm 2$ & - & $10 \pm 1$ & $21 \pm 2$ & $4,5 \pm 0,5$ \\
\hline $\mathrm{C}_{1}$ & $90 \pm 2$ & - & $10 \pm 1$ & - & - \\
\hline
\end{tabular}

A escolha de cada elemento da composição acima está baseada nas propriedades ópticas lineares e não lineares, na possibilidade de investigação estrutural bem como uma possível compreensão do fenômeno de polarização eletro térmica destes vidros pelas técnicas de RPE e CDTE. 
Para a fusão dos vidros foi utilizado um forno vertical de radiofreqüência de indução elétrica (FVRI) pertencente ao Laboratório de Materiais Vítreos do Instituto Gleb Wataghin, UNICAMP; por dois motivos:

a) permite uma rápida fabricação das amostras e um baixo risco de contaminação, pois nenhum isolante térmico é necessário para evitar a dissipação do calor para o meio ambiente;

b) este forno possui um exaustor acoplado que permite a eliminação dos gases tóxicos provenientes do reagente óxido de telúrio.

Para evitar que ocorra alta evaporação de algum dos reagentes fixamos os parâmetros de corrente a intervalos de 10 minutos em 240 mA, 260 mA e 300 mA (cerca de $850{ }^{\circ} \mathrm{C}$ ), respectivamente. Para verificar a correspondência entre a corrente utilizada e a temperatura, fez-se um teste utilizando um termopar tipo $\mathrm{K}$, dentro do tubo de quartzo, com leituras de 5 em 5 minutos. As medidas foram executadas com o desligamento prévio da RF.

A tabela 11 mostra as amostras produzidas com a respectiva temperatura e tempo de recozimento. Este recozimento foi realizado para evitar que o vidro trinque por meio do choque térmico quando o vidro é derramado sobre uma forma de aço inox previamente aquecida.

Tabela 11 - Amostras produzidas.

\begin{tabular}{|c|c|c|c|}
\hline Amostra & Recozimento & Atmosfera do forno & $\begin{array}{c}\text { Resultado e } \\
\text { cor }\end{array}$ \\
\hline $\mathrm{A}_{2}$ & $(320 \pm 5)^{\circ} \mathrm{C}$ por $2 \mathrm{~h}$ & Ambiente & $\begin{array}{c}\text { Satisfatória } \\
\text { Amarela clara }\end{array}$ \\
\hline $\mathrm{A}_{3}$ & $(325 \pm 5)^{\circ} \mathrm{C}$ por $2 \mathrm{~h}$ & Ambiente & $\begin{array}{c}\text { Satisfatória } \\
\text { Amarela clara }\end{array}$ \\
\hline $\mathrm{A}_{4}$ & $(320 \pm 5)^{\circ} \mathrm{C}$ por $2 \mathrm{~h}$ & Ambiente & Satisfatória \\
& & & Amarela clara \\
\hline $\mathrm{A}_{5}$ & $(320 \pm 5)^{\circ} \mathrm{C}$ por $2 \mathrm{~h}$ & Ambiente & Satisfatória \\
& & & Amarela clara \\
\hline $\mathrm{B}_{2}$ & $(250 \pm 5)^{\circ} \mathrm{C}$ por $2 \mathrm{~h}$, & Ambiente & Satisfatória \\
\hline
\end{tabular}




\begin{tabular}{|c|c|c|c|}
\hline & $\begin{array}{c}\text { outra parte da amostra } \\
\text { sem recozimento }\end{array}$ & & $\begin{array}{c}\text { Amarela bastante } \\
\text { clara }\end{array}$ \\
\hline $\mathrm{B}_{3}$ & $\begin{array}{c}(250 \pm 5)^{\circ} \mathrm{C} \text { por } 2 \mathrm{~h}, \\
\text { outra parte da amostra } \\
\text { sem recozimento }\end{array}$ & Ambiente & $\begin{array}{l}\text { Satisfatória } \\
\text { Praticamente } \\
\text { transparente }\end{array}$ \\
\hline $\mathrm{B}_{5}$ & $\begin{array}{c}(220 \pm 5)^{\circ} \mathrm{C} \text { por } 1 \mathrm{~h} \\
\text { outra parte da amostra } \\
\text { sem recozimento }\end{array}$ & Ambiente & $\begin{array}{c}\text { Parcialmente } \\
\text { satisfatória, } \\
\text { Regiões que não } \\
\text { foram } \\
\text { rapidamente } \\
\text { resfriadas } \\
\text { apresentaram-se } \\
\text { cristalizadas }\end{array}$ \\
\hline $\mathrm{C}_{1}$ & $(220 \pm 5)^{\circ} \mathrm{C}$ por $1 \mathrm{~h}$ & Ambiente & $\begin{array}{c}\text { Satisfatória } \\
\text { Amarela clara }\end{array}$ \\
\hline
\end{tabular}

\subsection{Forno vertical de radiofreqüência de indução elétrica (FVRI)}

As amostras foram fundidas em um forno de FVRI (figura 34) durante um tempo entre 15 e 20 minutos para conseguir a fusão de um vidro quaternário, como $\circ \mathrm{A}_{2}$.

O funcionamento do forno FVRI é baseado na indução de corrente elétrica de alta freqüência $(5 \mathrm{MHz})$ no cadinho metálico de $\mathrm{Pt}$.

Uma vantagem deste forno é que a possibilidade de contaminação é menor, já que não é necessário nenhum isolante térmico para evitar a dissipação do calor para o meio ambiente.

A principal desvantagem é que não existe um controle exato da temperatura, somente da corrente elétrica. Para superar este problema, sem provocar a 
evaporação completa do fundido controlamos o tempo de fusão, a corrente elétrica e estipulamos o tempo máximo de fusão de 30 minutos.

A mistura passa para a fase líquida após 20 minutos do começo em qualquer dos casos da tabela 9.

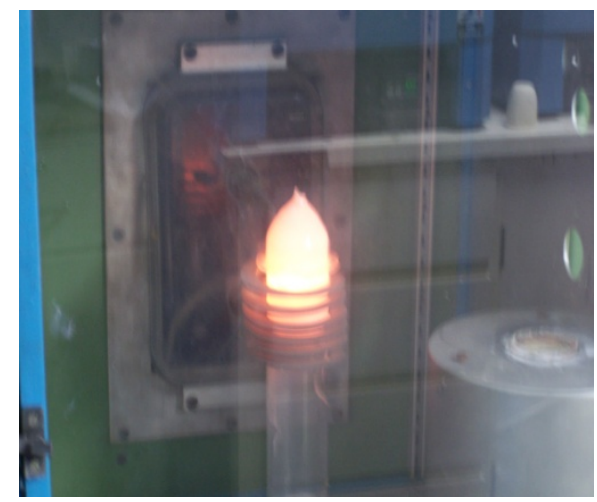

Figura 34 - Forno de FVRI.

\subsection{Equipamentos utilizados para desbastamento e polimento das amostras}

Para o polimento das amostras foi utilizada a politriz marca Logitech, modelo Precision Lapping \& Machine PM 2A juntamente com os abrasivos de Alumina com grãos de 0,5 $\mu \mathrm{m}$ e $1 \mu \mathrm{m}$. Este equipamento consiste de um suporte cilíndrico, no qual a amostra é fixada com cera de abelha, fixo em um suporte (Jig) que executa um movimento semicircular e apoiado sobre um disco de cera. Durante o movimento semicircular ocorre a liberação do abrasivo de um reservatório localizado na parte superior do sistema (figura 35).

Para o desbastamento das amostras, foi utilizada uma lapidadora mecânica construída no IPEN (figura 36) com o abrasivo ALO 2000 (produto à base de $\mathrm{Al}_{2} \mathrm{O}_{3}$ 2000 meshes e etileno glicol). Seu funcionamento é similar à politriz divergindo somente no material que compõe o disco de suporte e no que se refere ao abrasivo, já que este é jogado mecanicamente sobre o disco de alumínio.

O processo de desbastamento e polimento da amostra é constituído de várias etapas: 
a) inicialmente prende-se a amostra a um suporte circular com cera de abelha e a seguir conecta-se este ao Jig;

b) acopla-se o Jig à lapidadora mecânica e realiza-se o desbastamento;

c) realiza-se a limpeza do Jig com a amostra utilizando um Ultrasom modelo MaxiClean 1600 durante 5 minutos;

d) o próximo processo consiste na lapidação da amostra que dura em média 10 horas;

e) a seguir retira-se a amostra do sistema circular acoplado ao Jig e vira-se a amostra para trabalhar sobre a outra superfície;

f) para conseguir considerável paralelismo da amostra ajustamos o sistema de molas e parafusos do Jig utilizando um colimador;

g) para finalizar repete-se o processo descrito acima até o passo "d".

Na figura 37 segue-se a série A após o polimento.

Para as técnicas que não necessitam de polimentos com qualidade óptica como as técnicas de ressonância paramagnética eletrônica e correntes de despolarização termicamente estimuladas utilizamos lixas d' água com diferentes graduações para realizar o desbastamento e polimento.

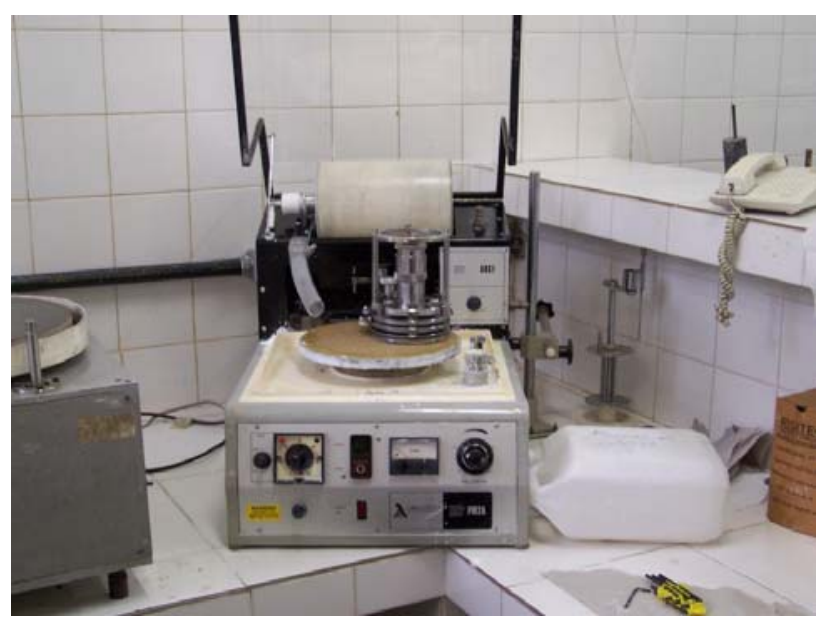

Figura 35 - Politriz Logitech, modelo Precision Lapping \& Machine PM 2A. 


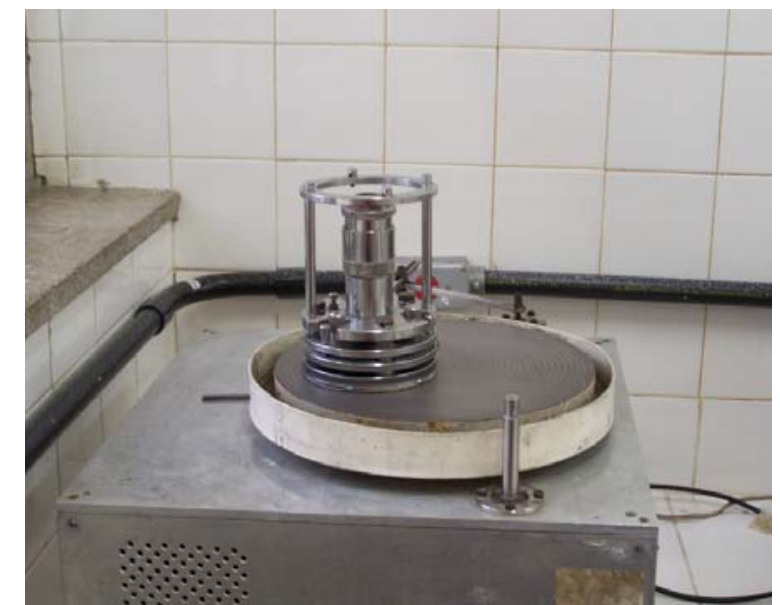

Figura 36 - Lapidadora (construída no IPEN.)

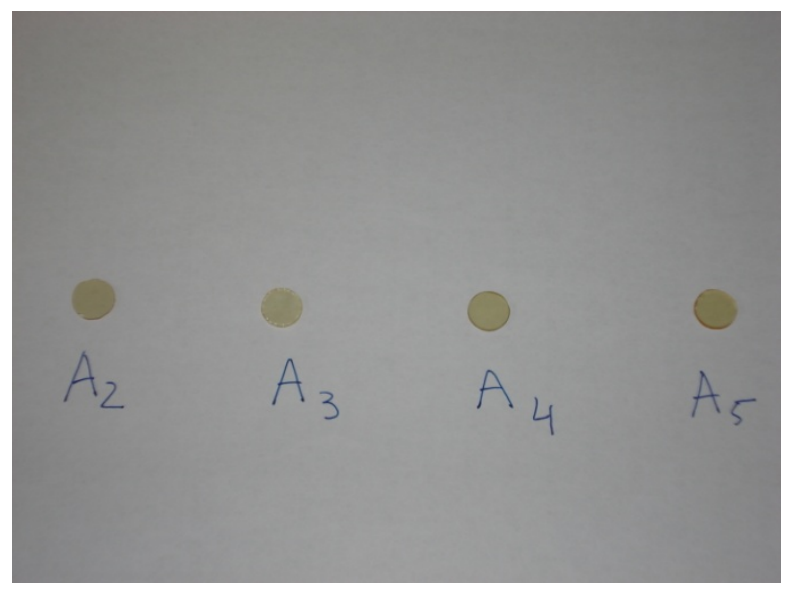

Figura 37 - Amostras após o polimento.

\subsection{Análise térmica diferencial (ATD)}

Os termogramas de análise térmica diferencial (ATD) foram feitos usando o equipamento modelo DTA-50 da Shimatzu pertencente ao Laboratório de Materiais Vítreos do Instituto Gleb Wataghin, UNICAMP. Foram utilizados dois cadinhos de platina, visando evitar contaminações, com as dimensões padrão de 5,6 mm de diâmetro e 2,5 mm de altura. Para a obtenção dos espectros de ATD são utilizados dois cadinhos, em atmosfera ambiente, sendo um cadinho de referência (vazio) e o outro com a amostra vítrea reduzida a pó de $75 \mu \mathrm{m}$, na forma monolítica (bulk), com massa de $40 \mathrm{mg}$ e taxa de aquecimento de $10 \frac{{ }^{\circ} \mathrm{C}}{\mathrm{S}}$. Este procedimento foi utilizado 
para obter a diferença de temperatura entre os cadinhos em função da temperatura de aquecimento e a temperatura ambiente. Com o espectro de ATD foram obtidas as temperaturas de transição vítrea $\left(T_{g}\right)$, do início da cristalização $\left(T_{x}\right)$ e de fusão $\left(T_{f}\right)$ para cada amostra. Isto foi feito a partir do método geométrico da intersecção do prolongamento de segmentos de retas tangentes do ponto de máxima inclinação da curva do termograma obtido, que mais se aproxima da "descontinuidade" pela qual passa o calor específico. Vale lembrar que este ponto depende ligeiramente da taxa de aquecimento.

Devido ao fato de que grande parte dos manuais recomenda o uso de pó para a realização do termograma de ATD, para melhor visualização da $T_{g}$, Gorvenia [1] e da $T_{x}$ Chillcce [2] estudaram a influência do fenômeno endotérmico da sinterização do pó nos resultados de ATD. Gorvenia [1] (figura 38) mostra que o evento endotérmico $\mathrm{T}_{\mathrm{g}}$ é igual para todas as amostras em $272^{\circ} \mathrm{C}$, o qual é melhor definido para as amostras de pó do que na forma monolítica. Para as amostras em pó ocorre o fenômeno da sinterização das partículas de vidro que pode ser confundido com o início da cristalização, o qual não é observado para tamanhos de grão superiores. Para a autora o evento exotérmico, conhecido como pico de cristalização é observado nos três casos, é mais intenso para tamanhos de grãos menores (da ordem de $62 \mu \mathrm{m})$.

Para Chillcce [2], o tamanho do grão e a quantidade de massa (figuras 39 e 40) utilizada para cada medida influenciam o resultado do termograma de ATD. Desta forma utilizamos as condições otimizadas para o tamanho do grão e para a quantidade de massa em vidros teluritos, que são: massa entre 40 e $50 \mathrm{mg}$ e tamanho do grão entre 62 e $150 \mu \mathrm{m}$. Para Chillcce grãos abaixo de $62 \mu \mathrm{m}$ se unem para formar um grão maior, formando pescoços (figura 41), numa faixa de temperatura que corresponde à queda do sinal de ATD. E para tamanho de grãos superiores a $1000 \mu \mathrm{m}$ não é possível observar o pico de cristalização, observa-se somente um pseudo-pico numa temperatura menor que a cristalização (figura 39). Para Chillcce [2] em relação à figura 39 a queda em $450{ }^{\circ} \mathrm{C}$ aumenta à medida que o tamanho do grão diminui, o que indica assim como o pseudo-pico tem uma relação direta com o processo de sinterização. À medida que o tamanho de grão diminui há maior efeito de sinterização que induz maior absorção de calor para unir os grãos, 
logo, libera energia reduzindo a energia final do sistema. O pseudo-pico aparece pela inércia do sistema em manter a temperatura de equilíbrio.

Um parâmetro que determina a qualidade de formação vítrea e está diretamente ligado à sua estabilidade térmica $\left(T_{x}-T_{g}\right)$ é o número de Hruby [3], dado pela equação abaixo:

$$
K_{H}=\frac{T_{x}-T_{g}}{T_{f}-T_{x}}
$$

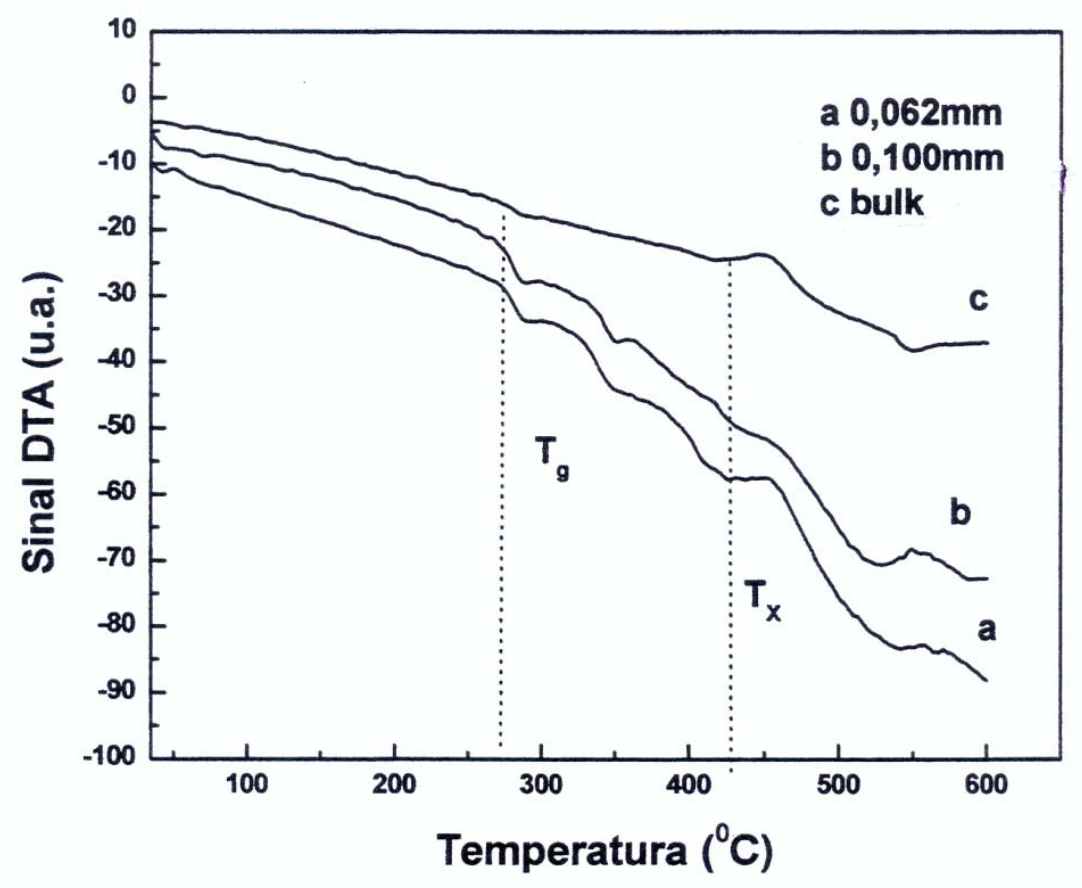

Figura 38 - Estudo dos efeitos do grão durante ATD do vidro TeZnLiBiCsCl [1]. 


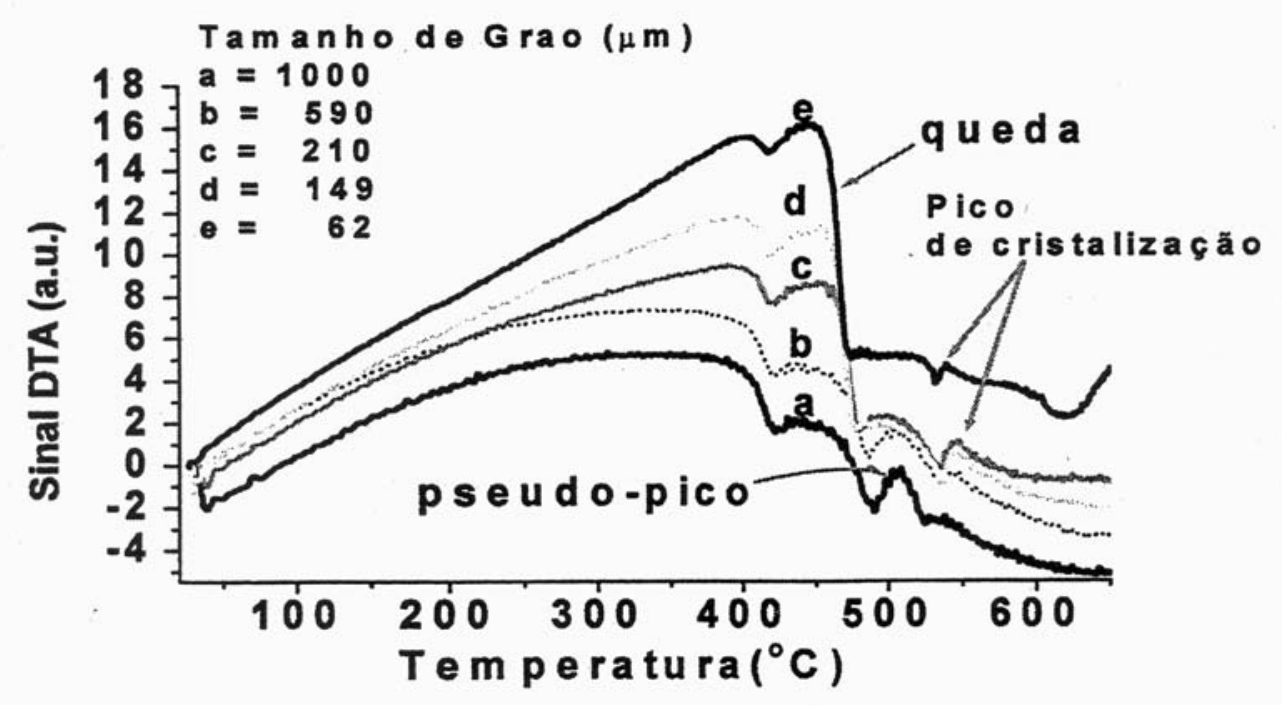

Figura 39 - Estudo da influência do tamanho do grão no vidro TeWNaErCl e massa de $80 \mathrm{mg}$ [2].

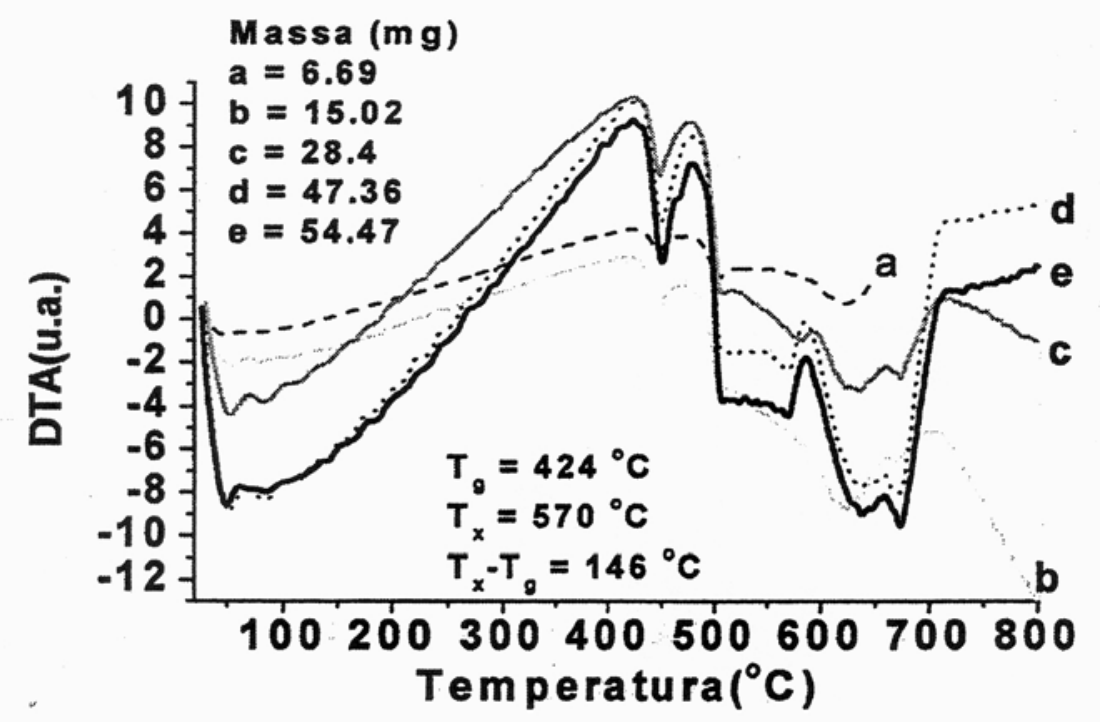

Figura 40 - Estudo da influência da quantidade de massa nas medidas de ATD [2]. 


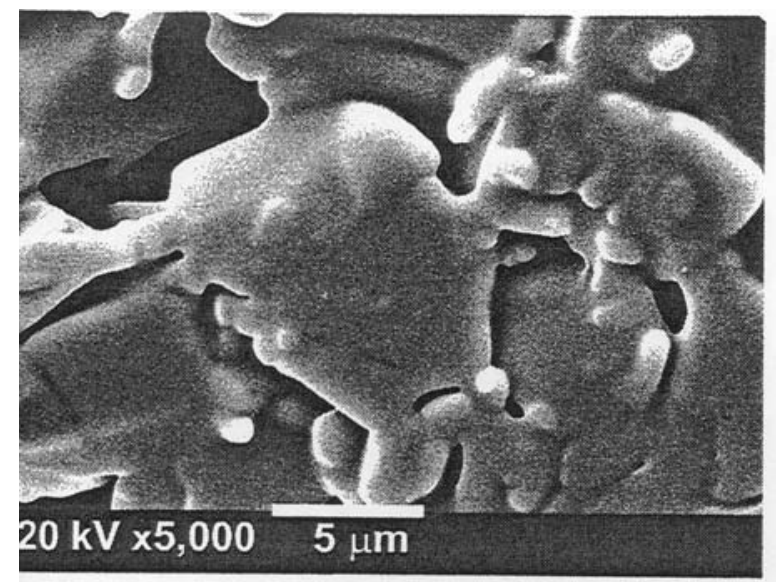

Figura 41 - Efeito da sinterização do vidro telurito moído com grãos cujo tamanho é inferior a $62 \mu \mathrm{m}$ [2].

\subsubsection{Referências}

[1] Gorvenia, C. R. E. Fibras Ópticas de Vidros Teluritos Dopados com Érbio e Túlio para Amplificadores Ópticos de Grande Largura de Banda. 2004. Tese (Doutorado) - Instituto de Física Gleb Wataghin, Campinas, São Paulo.

[2] Chillcce, E. F. Fibras ópticas de vidros teluritos de tungstênio para amplificação de grande largura de banda. 2005. Tese (Doutorado) - Instituto de Física Gleb Wataghin, Campinas, São Paulo.

[3] Hruby, A.; Houserova, J. Glass forming region in the Cd-Ge-As ternary system. Czech J. Phys. v. 22, p. 1187-1192, 1972.

\subsection{Equipamento experimental de absorção óptica (AO)}

Um equipamento de absorção óptica é basicamente composto de várias partes como: fonte, rede de difração, porta-amostra, detectores, monocromadores, etc. Na figura 42 está representado um diagrama simplificado dos principais componentes do espectrofotômetro Cary 500.

Foi utilizado neste trabalho um espectrômetro Varian, modelo Cary 500 de feixe duplo no modo de absorbância, cujos comprimentos de onda variam desde 200 
até 3000 nm do Laboratório de Cristais lônicos, Filmes Finos e Datação - LACIFID do Instituto de Física - USP.

As funções básicas da dupla de monocromadores são: dividir a dispersão linear recíproca em duas aberturas para uma dada banda espectral e fazer com que as aberrações sejam canceladas para todos os comprimentos de onda. Existe ainda uma segunda função, no caso da utilização de líquidos com solvente submetido em um feixe e o solvente puro no outro, para medir a quantidade de concentrações de impurezas nas amostras.

Neste aparelho, utiliza-se uma lâmpada de deutério na região do UV e uma lâmpada de quartzo halogênio na região do visível e infravermelho. Quando se efetua a varredura ao longo do intervalo de comprimento de onda de $175 \mathrm{~nm}$ a 900 $\mathrm{nm}$, usa-se como detector uma célula fotomultiplicadora e para o intervalo de 900 $\mathrm{nm}$ a $2500 \mathrm{~nm}$ uma célula fotocondutora de PbS.

As medidas foram efetuadas utilizando o ar como referência, mantendo sempre as mesmas condições do aparelho quanto à geometria e a largura das fendas, posicionando as amostras sempre perpendicularmente à direção do feixe de luz incidente.

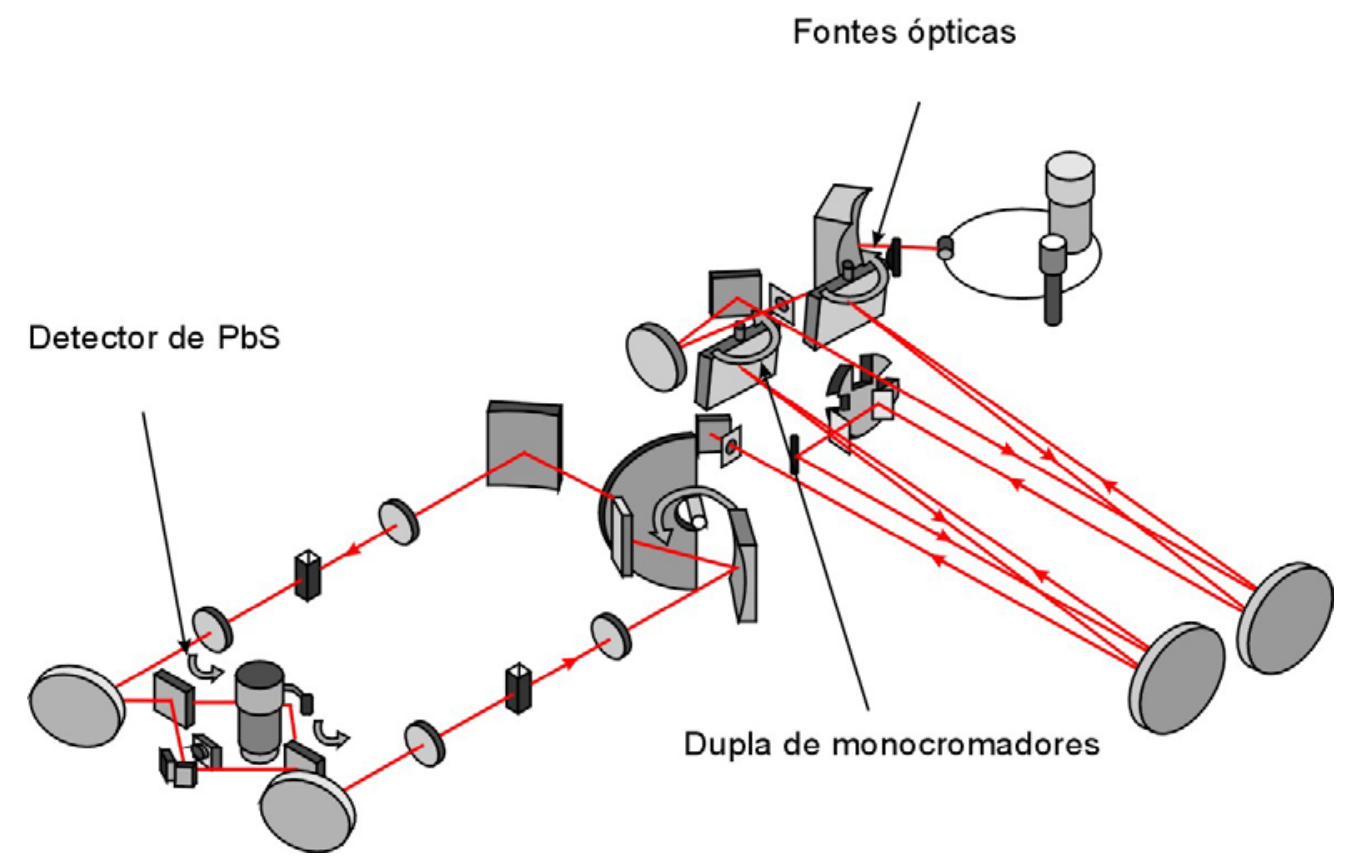

Figura 42 - Esquema simplificado de funcionamento do modelo Cary 500. 


\subsection{Microscopia eletrônica de transmissão (MET) e espectroscopia de fluorescência de raios-X por energia dispersiva (EDS)}

As medidas de microscopia eletrônica de transmissão (MET) e espectroscopia de fluorescência de raios-X por energia dispersiva (EDS) foram realizadas no Laboratório de Microscopia Eletrônica do Instituto de Física da USP utilizando um microscópio eletrônico de transmissão, modelo Philips CM 200 operado a $200 \mathrm{KV}$.

No microscópio o feixe eletrônico é gerado a partir do grampo de tungstênio do catodo que ao ser aquecido emitirá elétrons que serão acelerados devido à presença do anodo e colimadores pelo cilindro de Wehnelt. O feixe eletrônico divergente criado é focalizado sobre a amostra por meio de duas lentes condensadoras. O feixe é focalizado na posição da amostra em uma mancha pequena que pode variar de 2 a $10 \mu \mathrm{m}$ de diâmetro. Quando o feixe passa através da abertura da objetiva, é formada a primeira imagem ampliada da amostra. A lente intermediária ampliará a primeira imagem mais duas vezes. A imagem final estará visível sobre o anteparo fluorescente e será registrado na placa fotográfica.

Neste caso para a preparação das amostras foram utilizadas duas situações: na primeira a amostra foi moída e na segunda foi raspada superficialmente. $O$ próximo passo foi diluí-las em água e colocar as partículas sobrenadantes em uma microtela de carbono. As amostras moídas não apresentaram bons resultados.

As partículas metálicas espalham muito mais o feixe de elétrons do que o vidro, de forma que podem ser identificadas pelo contraste claro-escuro das micrografias. A princípio a composição do vidro poderá ser identificada pelo próprio microscópio por meio da técnica denominada espectroscopia de fluorescência de raio-X por energia dispersiva (EDS). Seu funcionamento é baseado no fato de que quando o feixe de elétrons incide sobre o material, os elétrons pertencentes às camadas mais próximas do núcleo do átomo são excitados, mudando de níveis energéticos. Ao retornarem para a posição inicial liberam a energia emitida com determinado comprimento de onda no espectro do raio-X, o qual será medido por um detector instalado na câmara de vácuo do MET. É possível distinguir os elementos constituintes da amostra devido ao fato de que elétrons que constituem um átomo possuem energias distintas. 
O diâmetro reduzido do feixe de elétrons permite uma determinação da composição de nanopartículas com tamanhos menores que $5 \mu \mathrm{m}$.

Vale ressaltar que todos os espectros de EDS apresentam um espectro devido ao cobre, isto ocorre, pois o suporte para microscopia é constituído por este material.

\subsection{Medidas de índice de refração linear (IRL)}

O feixe de laser acopla luz na amostra vítrea passando através de um prisma com um ângulo de incidência $\left(\theta_{\mathrm{i}}\right)$, respeitando a condição de casamento de fases entre o vetor de onda de propagação da luz paralelo à base do prisma $k n_{p} \operatorname{sen} \theta_{i}$ for igual ao vetor de onda de propagação $k n_{v} \operatorname{sen} \theta_{v}$. Devido à relação entre o índice de refração do prisma $\left(n_{p}\right)$ e da amostra $\left(n_{v}\right)$, a luz será refratada ou completamente refletida. O índice de refração é determinado a partir do ângulo para o qual a luz é completamente refletida (ângulo de Brewster). A figura 43 apresenta um esquema simplificado do funcionamento do aparato experimental.

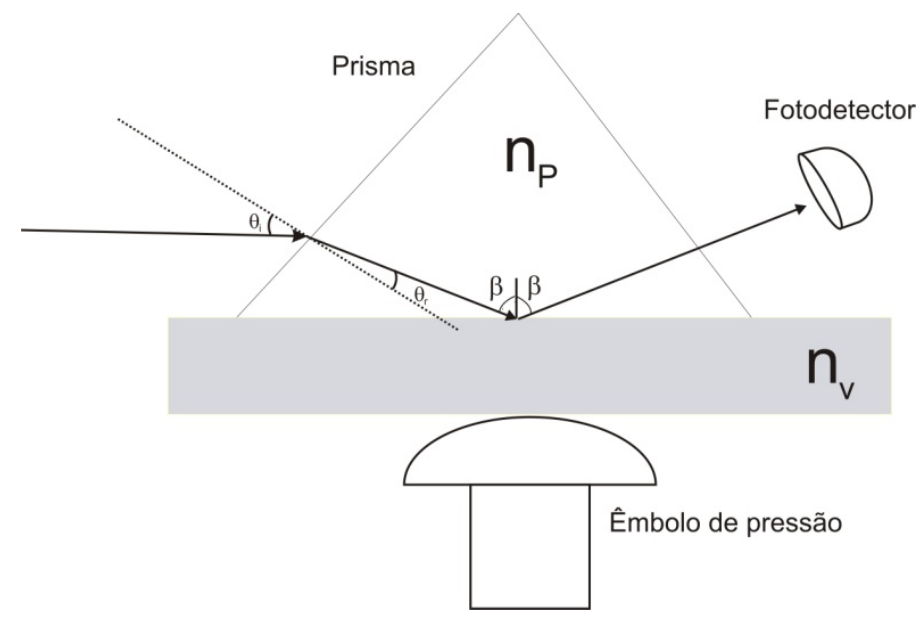

Figura 43 - Esquema simplificado de funcionamento do aparato experimental para as medidas de IRL.

Para efetuar as medidas do IRL das amostras produzidas foi utilizado o equipamento marca Prism Coupler Metricon, modelo 2010 pertencente ao Laboratório de Materiais Vítreos do Instituto Gleb Wataghin, UNICAMP (figura 44). 
Este equipamento opera com três lasers nos seguintes comprimentos de onda: 632,8; 1305,4 e $1536 \mathrm{~nm}$. Possui dois prismas que permitem medidas do índice de refração variando entre $1-2,4$, com incerteza $\pm 0,0005$, sendo o prisma 4443,1 utilizado nas medidas.

O equipamento é constituído por três partes: um módulo óptico, um microcomputador (utilizado para a aquisição dos dados) e um controlador da rotação de ângulo que faz a conexão entre a parte óptica e o microcomputador. O módulo óptico é uma caixa constituída por: lasers, um jogo de espelhos pelo qual a luz é refletida até chegar ao prisma, placas de meia onda para selecionar as polarizações TE e TM; um suporte de acoplamento que contém prisma e fotodetector e um motor para acionar o movimento giratório. O prisma está montado sobre um motor giratório que faz movimentos de rotação.

O feixe do laser incide na base do prisma que está em contato com a amostra vítrea, devido à pressão exercida pelo êmbolo de pressão (devido ao gás de nitrogênio) e reflete a luz dirigindo-a ao fotodetector. Para todas as medidas foi utilizado o modo TE de polarização.

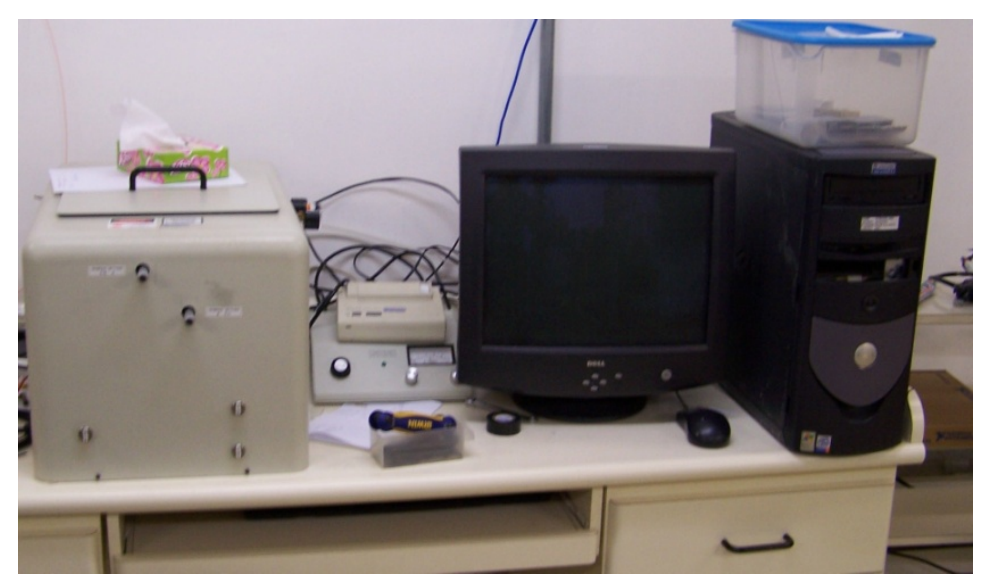

Figura 44 - Equipamento utilizado para as medidas de IRL.

\subsection{Curva Varredura Z (VZ)}

Para as medidas de VZ foi utilizado o equipamento pertencente ao Laboratório de Óptica Não Linear do Grupo de Fluidos Complexos, do Instituto de 
Física da USP, sob a responsabilidade do Prof. Dr. Antônio Martins Figueiredo Neto. $\mathrm{Na}$ figura 45 segue o esquema experimental deste equipamento.

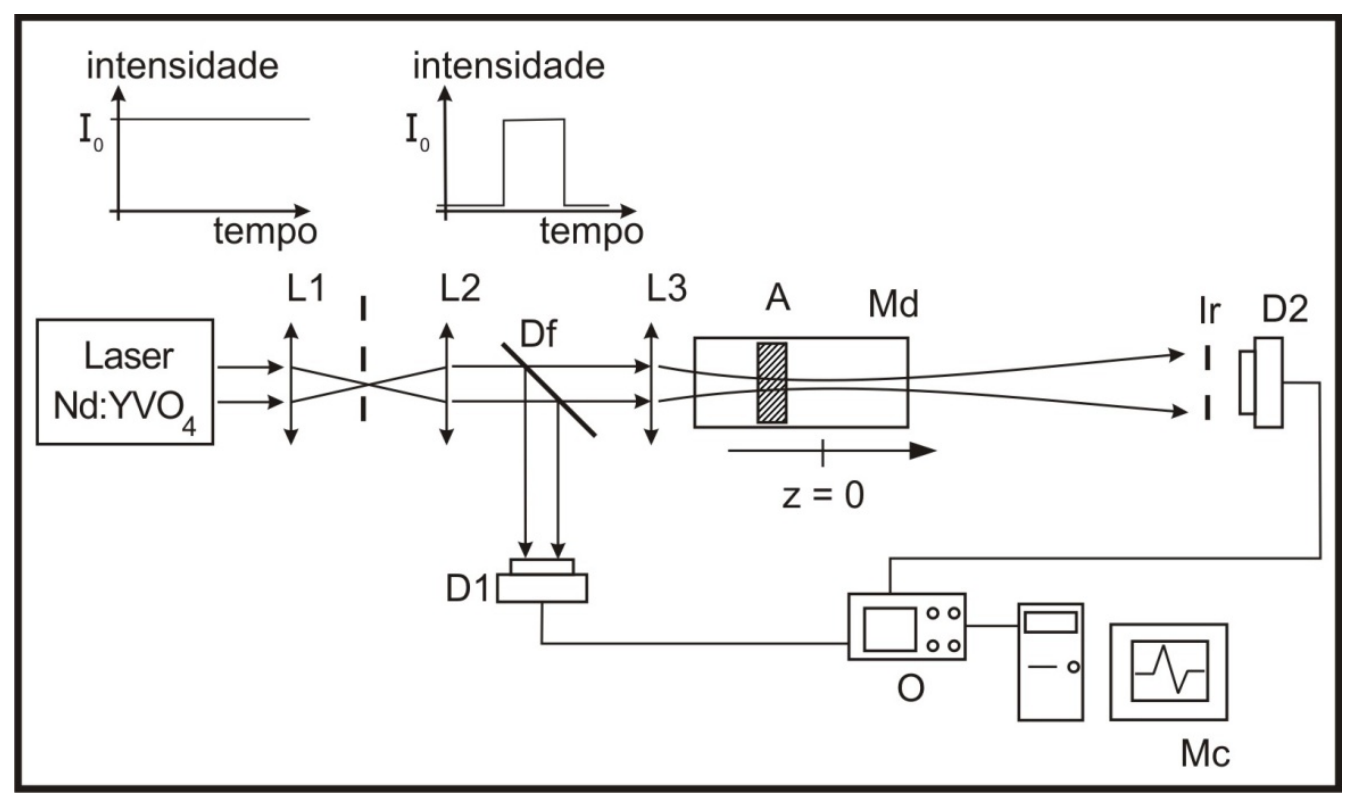

Figura 45 - Esquema de montagem da VZ na escala de milissegundos: Ch chopper; L1-L3 lentes; Df - divisor de feixe; D1 e D2 - detectores; Ir - íris; 0 osciloscópio; Mc - microcomputador; - A amostra; Md - microdeslocador [1].

Nesta montagem foram utilizados os seguintes equipamentos:

1) um laser contínuo de $\mathrm{Nd} \mathrm{YVO}_{4}$ (em 532nm), Coherent Verdi V10, com potência incidente de $(125,3 \pm 0,2) \mathrm{mW}$ e resolução temporal de $30 \mathrm{~ms}$;

2) um obturador mecânico - Ch - chopper, marca Stanford Research Systems, modelo SR540. Os pulsos possuem largura temporal $\Delta t \sim 30 \mathrm{~ms}$;

3) um conjunto de lentes;

4) dois detectores que operam entre 400 - $1100 \mathrm{~nm}$, marca Thorlabs Inc., modelo PDA55. Os detectores utilizados possuem tempo de resposta $\leq 35$ ns e área ativa de $13,7 \mathrm{~mm}^{2}$;

5) íris com $1 \mathrm{~mm}$ de diâmetro mínimo, marca Newport Co.;

6) microdeslocador Md Newport Co, modelo MTM150PP.1;

7) osciloscópio O Tektronix Inc., modelo TDS430S;

8) um microcomputador. 
Inicialmente o feixe que sai do laser passará pela lente L1 para diminuir o raio do feixe de luz e aumentar a resolução temporal do pulso, a seguir passará pelo obturador mecânico Ch e pela lente L2 para restabelecer o valor original do raio do feixe. Parte do feixe é desviada por meio do divisor de feixe Df para um detector D1 para monitorar as oscilações da intensidade do feixe de luz. A parte restante é focalizada em um ponto (chamado de $z=0$ ) por meio de uma lente convergente $L 3$ (neste experimento com distância focal de $100 \mathrm{~mm}$ ).

O feixe de luz atravessa a amostra A, passa pela abertura da íris Ir e incide sobre o detector D2. Após o sinal ser digitalizado por um osciloscópio $\mathrm{O}$ e transmitido a um microcomputador Mc para armazenamento, a amostra será deslocada por um microdeslocador Md para a medida de novos dados.

Para as medidas do $n_{2}$ térmico foram utilizadas amostras com espessura da ordem de $1 \mathrm{~mm}$. Porém, foram feitos testes anteriores para as medidas do $n_{2}$ térmico com diferentes espessuras, sendo que as amostras com espessuras menores que 0,5 mm não apresentaram resultados satisfatórios.

\subsubsection{Referências}

[1] Soga, D. Estudo de propriedades não-lineares de colóides magnéticos nas escalas de tempo de Mili e Femtossegundos. 2007. Tese (doutorado) - Instituto de Física da Universidade de São Paulo, São Paulo.

\subsection{Medidas de difração de raio-X (DRX)}

Os espectros de difração de raio-X (DRX) das amostras na forma de pó (tamanho do grão de $75 \mu \mathrm{m}$ ) foram obtidos com a utilização de um difratômetro de raio X fabricado pela Rigaku, modelo Rigaku Ultima* Plus pertencente ao Laboratório de Cristalografia do Instituto de Física da USP. Estas análises foram realizadas entre os ângulos $2 \theta$ de $10^{\circ}$ a $50^{\circ}$; com fenda de recorte de $10 \mathrm{~mm}$, fenda de espalhamento de $0,3 \mathrm{~mm}$ e a fenda de recepção de $0,6 \mathrm{~mm}$; passo de $0,05^{\circ}$; tempo de aquisição de 5s/passo e a fonte radioativa com alvo de cobre de $1,5418 \dot{A}(\mathrm{Ka})$. 


\subsection{0 - Correntes de Despolarização Termicamente Estimuladas (CDTE)}

O equipamento de medida de CDTE, pertencente ao Instituto de Física e sob a responsabilidade da Prof. Dra. Ana Regina Blak (figura 46 à esquerda) é constituído de:

1. câmara porta-amostra,

2. válvula para gás (Nitrogênio ultra-seco),

3. tubo de gás de Nitrogênio,

4. válvula de pré-vácuo,

5. bomba mecânica,

6. seletor para alto vácuo,

7. bomba turbo molecular.

A câmara porta-amostra (figura 46 à direita) é constiuída de:

a. eletrodos,

b. amostra,

c. termopar,

d. fios que conectam a tensão à amostra e possibilitam a saída para leitura de corrente.

O sistema é constituído ainda de:

1. um medidor de vácuo, modelo PO31 Micronal (mbar),

2. uma fonte de alta tensão Keithley modelo 248 - High Voltage Supply,

3. um eletrômetro programável da marca Keithley modelo 6517,

4. um controlador de temperatura Eurotherm modelo 2416,

5. um estabilizador de voltagens da TECTROL modelo 3000TVR2F/I,

6. um multímetro digital da marca HEWLLET-PACKARD modelo 3478A,

7. um microcomputador com uma placa de aquisição de dados GPIB da marca KEITHLEY, modelo IEEE-488, a aquisição e tratamento dos dados são feitos pelo software LABVIEW 8 da National Instruments.

Após introduzir a amostra no porta-amostra ligamos o sistema de vácuo e aguardamos em média 12 horas. Antes de efetuar uma medida, selecionamos o prévácuo e fechamos a válvula 4. A seguir introduzimos no sistema o Nitrogênio ultrapuro por dois motivos: 
1. para melhorar a troca de calor entre o porta-amostra e a amostra evitando a formação de gradientes de temperatura,

2. para evitar a ruptura do dielétrico do ar quando a alta tensão é aplicada.

este processo é repetido 3 vezes.

As medidas de CDTE foram realizadas polarizando as amostras nas condições descritas nas tabelas 27, 28 e 29 durante 3 minutos, a seguir a amostra é resfriada o mais rápido possível, com a ajuda do $\mathrm{N}_{2}$ líquido, até cerca de $100 \mathrm{~K}$. Este resfriamento possui um perfil de resfriamento exponencial. Em torno de $100 \mathrm{~K}$ a tensão é desligada, aguardando-se cerca de trinta minutos para permitir que toda a polarização com mobilidade suficiente relaxe. Em seguida a amostra é curto circuitada por meio do eletrômetro e a amostra é aquecida com uma taxa de $0,1 \mathrm{~K} / \mathrm{s}$, mantida inicialmente com a retirada do $\mathrm{N}_{2}$ líquido, e após aquecendo-se utilizando uma fita térmica. As medidas de CDTE foram efetuadas até a temperatura de $360 \mathrm{~K}$.
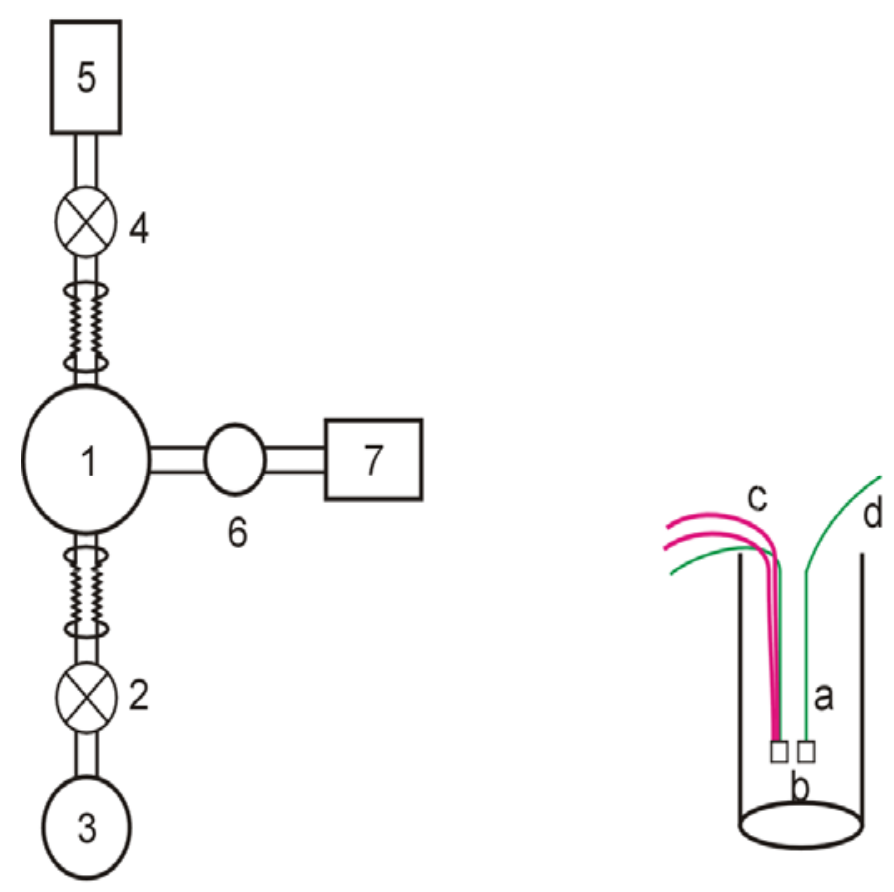

Figura 46 - Esquema experimental do equipamento de CDTE (esquerda) Representação do interior da câmara porta-amostra (direita). 
A incerteza nas medidas de CDTE é estipulada a partir de várias medidas da mesma amostra nas mesmas condições experimentais [1], assumindo uma margem de $5 \%$ de variação para os valores medidos.

\subsubsection{Referências}

[1] Parra, R. Uso da técnica de correntes de despolarização termicamente estimuladas para o controle da qualidade de filmes plásticos contendo aditivo antiestático. 1995. Dissertação (Mestrado) - Instituto de Física da Universidade de São Paulo, São Paulo.

\subsection{1 - Termoluminescência (TL)}

As curvas de TL foram obtidas utilizando-se uma leitora do tipo Daybreak 1100 Automated TL System, fabricada por Systems Inc. Daybreak Nuclear and Medical (figura 47) do Laboratório de Cristais lônicos, Filmes Finos e Datação LACIFID do Instituto de Física - USP. Este equipamento é constituído de: anodos, dinodos, fonte de alta tensão, amplificador, controlador de temperatura, computador, termopar e prancheta de aquecimento (figura 48).

O sistema funciona basicamente com duas funções: aquecimento controlado e detecção de luz. O sistema de aquecimento é constituído de uma prancheta de liga de platina, com uma área de 2,0 x 5,0 cm, alimentada por uma fonte de corrente contínua e controlada por um termopar, do tipo $\mathrm{Cr}-\mathrm{Al}$, soldado na parte central e posterior da prancheta e ligado a um controlador de temperatura que é responsável por aplicar tensão ao porta-amostra, quando necessário, para obter uma taxa de aquecimento controlada.

Quanto ao sistema de detecção de luz, os fótons emitidos a partir da amostra aquecida são detectados por uma fotomultiplicadora EMI 9235QA montada sobre uma câmara escura, cujo sinal de saída é transformado em sinal elétrico e enviado ao computador que possui o software TLAPPLIC, desenvolvido pelo fabricante, para obter as curvas TL. 


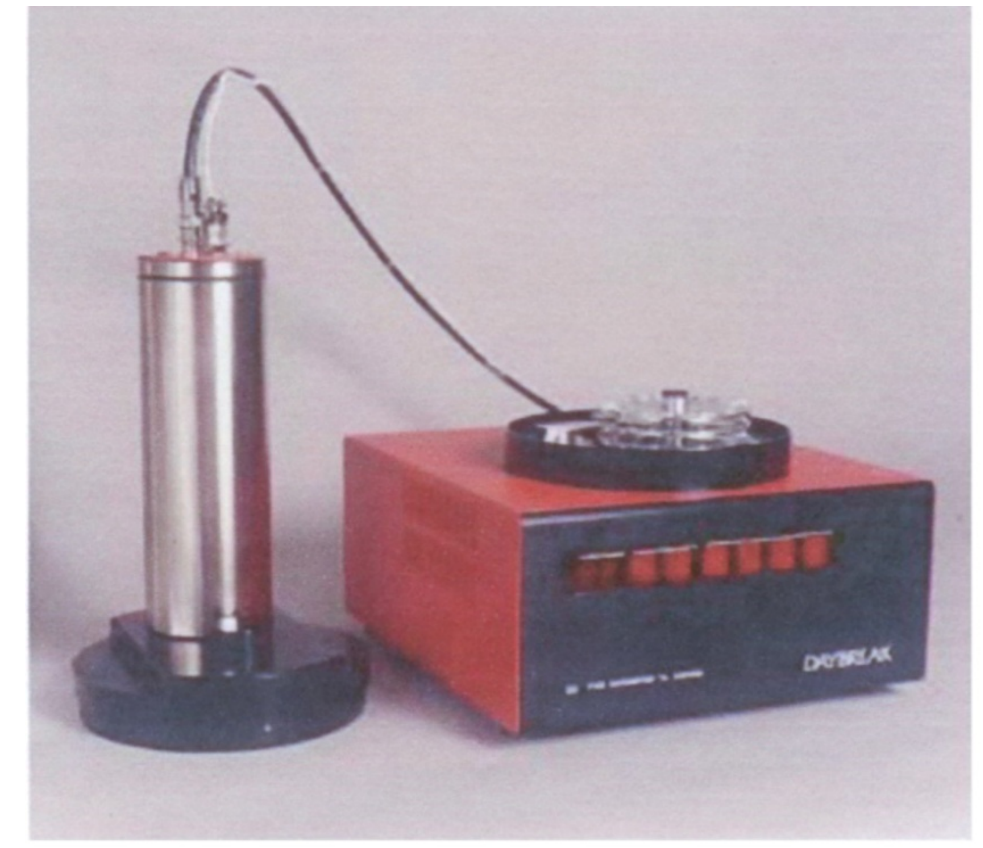

Figura 47 - Leitora do tipo Daybreak - 1100 Automated TL System [1].

Todas as leituras TL foram feitas com um pequeno fluxo de nitrogênio, com a taxa de aquecimento de $10^{\circ} \mathrm{C} / \mathrm{s}$ e com tamanho do grão entre 180 e $75 \mu \mathrm{m}$.

Durante as medidas de TL o processo de aquecimento apresenta emissão de radiação de corpo negro pela prancheta aquecida, para solucionar este problema são usados dois tipos de filtros ópticos: Corning 7-59 e Schott BG-39, que atenuam fótons com comprimento de onda na região do infravermelho próximo e registram emissões na faixa de 300 a $500 \mathrm{~nm}$. 


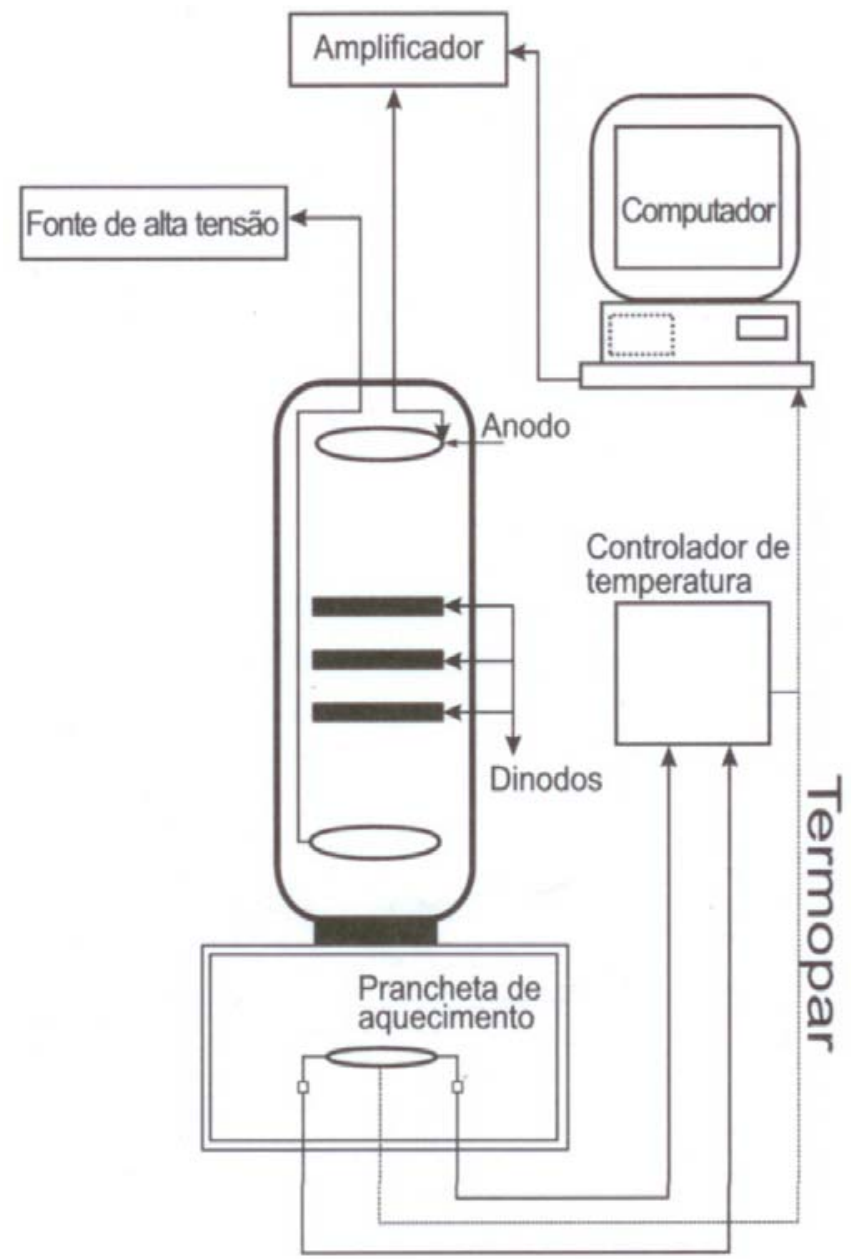

Figura 48 - Esquema de funcionamento da leitora do tipo Daybreak - 1100 Automated TL System [2].

\subsubsection{Referências}

[1] Giehl, J. M. Análises espectroscópicas em vidros aluminoboratos de bário dopados com íons de Mn. 2005. Dissertação (Mestrado) - Instituto de Física da Universidade de São Paulo, São Paulo.

[2] Sullari, H. S. L. Centros de cor, centros paramagnéticos e centros de luminescência dependentes de defeitos pontuais em zirconita. 2005. Tese (Doutorado) - Instituto de Física da Universidade de São Paulo, São Paulo.

\subsection{Radiação Gama}


Todas as amostras foram irradiadas à temperatura ambiente e envolvidas em um saco plástico transparente de $10 \mu \mathrm{m}$ de espessura, com a borda vedada com fita adesiva. As superfícies foram cobertas com placas de acrílico de $3 \mathrm{~mm}$ de espessura para manter o equilíbrio eletrônico.

As amostras foram irradiadas no Instituto de Pesquisas Nucleares (IPEN), sendo expostas a uma fonte de Cobalto ${ }^{60} \mathrm{Co}$ (panorâmica), com atividade de $1698,76 \times 10^{10} \mathrm{~Bq}$. A meia vida deste material é de 5261 anos e a fonte permite a irradiação simultânea de várias amostras, já que seu campo de irradiação é de $10 \times 10 \mathrm{~cm}^{2}$. Na tabela 12 seguem as amostras com a respectiva: dose, taxa de dose, distância e tempo de exposição.

Tabela 12 - Dose de radiação gama aplicada nas amostras.

\begin{tabular}{|l|l|l|l|l|}
\hline Amostras & Dose & Taxa de dose & Distância & $\begin{array}{l}\text { Tempo } \\
\text { exposição }\end{array}$ \\
\hline $\mathrm{A}_{3}, \mathrm{~A}_{5}$ & $100 \mathrm{~Gy}$ & $186,2 \mathrm{~Gy} / \mathrm{h}$ & $10 \mathrm{~cm}$ & 32,2 minutos \\
\hline $\mathrm{B}_{2}, \mathrm{~B}_{3}, \mathrm{~B}_{5}, \mathrm{C}_{1}$ & $1 \mathrm{kGy}$ & $186,2 \mathrm{~Gy} / \mathrm{h}$ & $10 \mathrm{~cm}$ & 322,2 minutos \\
\hline $\begin{array}{l}\mathrm{A}_{3}, \mathrm{~A}_{5}, \mathrm{~B}_{2}, \mathrm{~B}_{3}, \mathrm{~B}_{5}, \\
\mathrm{C}_{1}\end{array}$ & $5 \mathrm{kGy}$ & $0,3622 \mathrm{kGy} / \mathrm{h}$ & $5 \mathrm{~cm}$ & 13,8 horas \\
\hline $\begin{array}{l}\mathrm{A}_{3}, \mathrm{~A}_{5}, \mathrm{~B}_{2}, \mathrm{~B}_{3}, \mathrm{~B}_{5}, \\
\mathrm{C}_{1}\end{array}$ & $15 \mathrm{kGy}$ & $0,3622 \mathrm{kGy} / \mathrm{h}$ & $5 \mathrm{~cm}$ & 41,4 horas \\
\hline $\mathrm{B}_{2}, \mathrm{~B}_{3}, \mathrm{~B}_{5}, \mathrm{C}_{1}$ & $25 \mathrm{kGy}$ & $0,3622 \mathrm{kGy} / \mathrm{h}$ & $5 \mathrm{~cm}$ & 69 horas \\
\hline $\mathrm{B}_{2}, \mathrm{~B}_{3}, \mathrm{~B}_{5}, \mathrm{C}_{1}$ & $50 \mathrm{kGy}$ & $0,3622 \mathrm{kGy} / \mathrm{h}$ & $5 \mathrm{~cm}$ & 138 horas \\
\hline
\end{tabular}

\subsection{Ressonância Paramagnética Eletrônica (RPE)}

Para as medidas de RPE (figura 49) foi utilizado o espectrômetro marca Bruker EMX 032T, pertencente ao Instituto de Química, sob a responsabilidade da Prof. Dra. Shirley Schreier. O equipamento é constituído de:

1. uma fonte de microondas operando na banda $X$, com $9,799 \mathrm{GHz}$ de freqüência,

2. um eletroímã, 
3. uma cavidade retangular operando no modo $\mathrm{TE}_{102}$,

4. um estabilizador de tensão,

5. fonte de alimentação dos circuitos eletrônicos,

6. sistema de refrigeração do equipamento ("chiller") que refrigera a água do eletroímã,

7. um micro computador e um programa especifico para a aquisição de dados (Win EPR).

Para todas as medidas de RPE foram utilizados os mesmos parâmetros descritos na tabela 13 .

Tabela 13 - Parâmetros de RPE.

\begin{tabular}{|l|l|}
\hline Parâmetros & Valores \\
\hline Resolução & 2048 pontos \\
\hline Potência de microondas & $6,423 \mathrm{~mW}$ \\
\hline Ganho & $2,0 \times 10^{3}$ ou $2, \times 10^{5}$ \\
\hline Fase & 0 graus \\
\hline Harmônico & 1 \\
\hline Freqüência de modulação & $100 \mathrm{KHz}$ \\
\hline Amplitude de modulação & $5,0 \mathrm{G}$ \\
\hline Conversão & $81,920 \mathrm{~ms}$ \\
\hline Constante de tempo & $163,840 \mathrm{~ms}$ \\
\hline Tempo de varredura & $167,772 \mathrm{~s}$ \\
\hline Número de varreduras & 1 \\
\hline Campo magnético & $3200 \mathrm{G}$ \\
\hline Largura de varredura & $2000 \mathrm{G}$ \\
\hline
\end{tabular}

As amostras foram colocadas em tubo de quartzo fundido, com diâmetro interno de $3 \mathrm{~mm}$, posicionados no centro da cavidade.

Os resultados das medidas foram normalizados pela massa e as respectivas massas de cada amostra seguem na tabela 14 . 
Para evitar erros sistemáticos medimos a posição da linha do DPPH e determinamos o desvio do campo magnético por meio da comparação do valor de $\mathrm{g}$ calculado.

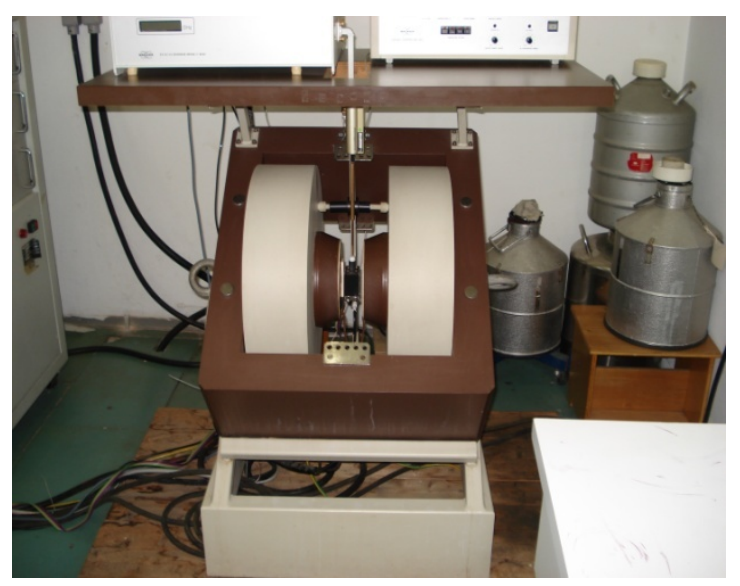

Figura 49 - Espectrômetro de RPE.

Tabela 14 - Massas das amostras medidas por RPE.

\begin{tabular}{|l|l|}
\hline Amostra & Massa (g) \\
\hline$B_{2}$ & 0,4062 \\
\hline$B_{3}$ & 0,2100 \\
\hline$B_{5}$ & 0,3395 \\
\hline$C_{1}$ & 0,3536 \\
\hline
\end{tabular}

\subsection{Medidas de densidade utilizando método baseado no princípio de} Arquimedes

As medidas de densidade foram realizadas no Laboratório de Produção de Materiais Vítreos do Centro de Pesquisas em Óptica e Fotônica (CePOF) do Instituto Gleb Wataghin da UNICAMP, com a colaboração do Prof. Dr. Luiz Carlos Barbosa.

As medidas de densidade dos materiais vítreos foram realizadas utilizando o método de Arquimedes. Para o experimento foram utilizados os seguintes materiais:

1) uma balança com precisão de $0,0001 \mathrm{~g}$; 
2) água destilada;

3) um suporte, um gancho com um copinho em uma das extremidades (contendo um furo) e uma superfície cilíndrica com a parte superior aberta, sendo todos os materiais em vidro;

4) uma pinça para manipular a amostra.

Inicialmente a amostra foi colocada sobre a balança para a determinação de sua massa $\left(\mathrm{m}_{\mathrm{a}}\right)$, a seguir a amostra foi retirada, sobre o prato da balança foi colocado um suporte de vidro e sobre a região branca da figura 50 foram fixados suportes de vidro e sobre eles um cilindro contendo água destilada. Nesta posição a balança foi zerada. Com a ajuda de uma pinça a amostra foi introduzida dentro do "copinho", descrito anteriormente, e imersa na água destilada. Nesta fase do experimento a balança registrou a massa aparente da amostra $\left(m_{a p}\right)$.

Como o sistema está em equilíbrio:

$$
m_{a} g-E_{e}=m_{a p} g,
$$

em termos da densidade, teremos:

$$
\rho_{a}=\left(\frac{m_{a}}{m_{a}-m_{a p}}\right) \rho_{l},
$$

onde $\rho_{a}$ é a densidade da amostra, $E_{e}$ é o empuxo e $\rho_{l}=1 \frac{\mathrm{g}}{\mathrm{cm}^{2}}$ é a densidade da água destilada.

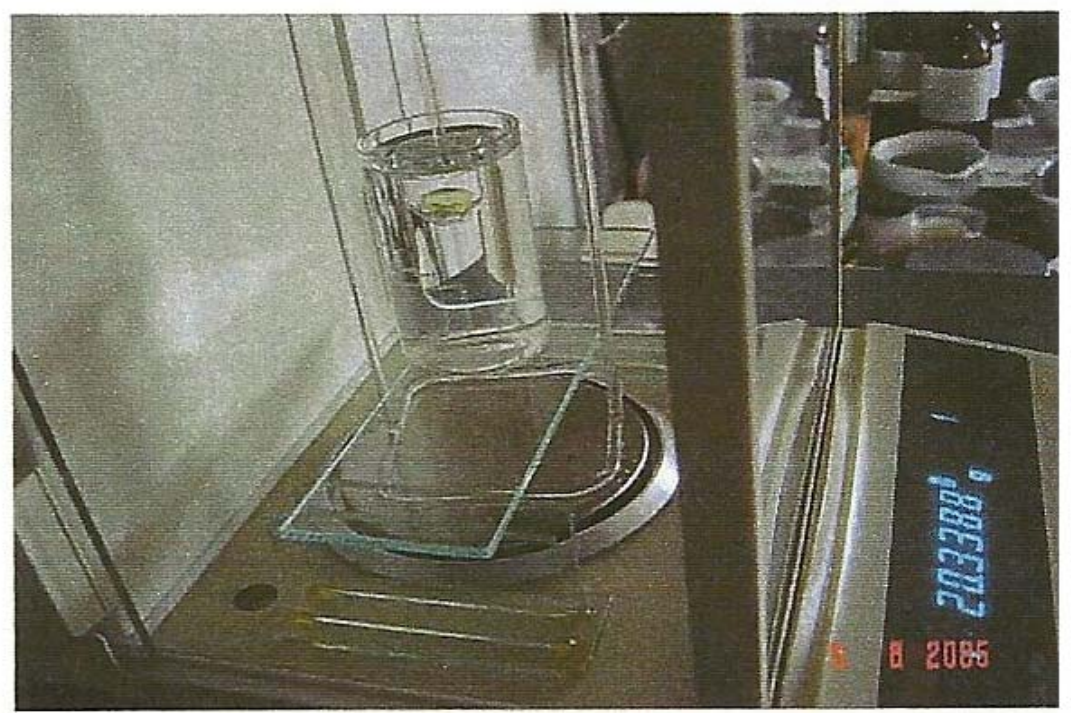

Figura 50 - Imagem real do sistema para medida da densidade usando o método baseado no princípio de Archimedes. 


\subsection{Forno para polarização eletrotérmica (FPE) (montagem e procedimento)}

O objetivo inicial do projeto de doutoramento consistia na produção de um forno para a polarização eletro térmica (FPE) e geração do harmônico de segunda ordem (GHS) nos materiais descritos na tabela 10. A construção do forno foi realizada com sucesso, apesar dos esforços não obtivemos nenhum material dobrador de freqüências com o material estudado. Vale ressaltar que não foi realizada nenhuma experiência que reproduzisse fielmente um material cuja literatura já houvesse reportado. Achamos interessante incluir neste trabalho a construção deste.

Com a finalidade de contenção de custos e aprimoramento do processo de GHS optamos em produzir um forno com uma série de cerâmicas especiais responsáveis pela isolação térmica e elétrica do sistema, estas cerâmicas foram produzidas pela empresa Engecer e projetadas pelo engenheiro elétrico Paulo Zippert.

O FPE (figura 51) foi produzido pelo engenheiro Paulo Zippert da empresa Lujoj Ltda, sob a supervisão dos físicos Júlia Maria Giehl e Walter Maigon Pontuschka, sendo constituído de:

- uma fonte de alta tensão DC com entrada de $220 \mathrm{~V}$ e com limite de saída $5,8 \mathrm{KV}$, a fonte foi projetada com um limitador de corrente de $1 \mathrm{~mA}$, para evitar possíveis acidentes e danos;

- um controlador de temperatura com uma incerteza de $\pm 5 \%$;

- um sistema de aquecimento com um limite de $500{ }^{\circ} \mathrm{C}$ por 6 horas;

- um sistema de cerâmicas responsável pela isolação térmica e elétrica;

- uma ponta de prova de alta tensão utilizada para calibrar as medidas da fonte de alta tensão (redução de 1/1000);

- um sistema de eletrodos, catodo e anodo com diâmetro de $6 \mathrm{~mm}$ cada, acoplados as cerâmicas. Na figura 52 temos a vista do eletrodo inferior e a cavidade de cerâmica no qual será colocada a amostra. Na figura 53 temos a vista do eletrodo superior. 
A amostra é colocada entre duas placas de mica de cerca de 0,15 mm, ou duas placas de Ulten de mesma espessura (figura 54).

O processo de polarização eletro térmica $(\mathrm{PE})$ consiste em esperar cerca de 50 minutos para que a temperatura pré-determinada estabilize, a seguir liga-se a alta tensão estipulada em um tempo pré-determinado (baseado na literatura [1-3]), estas condições variam conforme o material utilizado. Transcorrido o tempo prédeterminado verificamos que a corrente medida no sistema não estabilizava em torno de 0,6 $\mu \mathrm{A}$ (conforme reportado por Quintero Rojas [4]), verificamos uma instabilidade, ora aumentando, ora diminuindo de intensidade. Dando continuidade ao teste, desligamos o aquecimento do forno e ligamos um ventilador em frente ao forno para que o resfriamento ocorra mais rápido. Esperamos até o sistema atingir a temperatura de $45^{\circ} \mathrm{C}$ com a tensão aplicada para que o efeito permaneça gravado na amostra. Todas as tentativas de polarizar as amostras foram feitas sem controle de atmosfera.

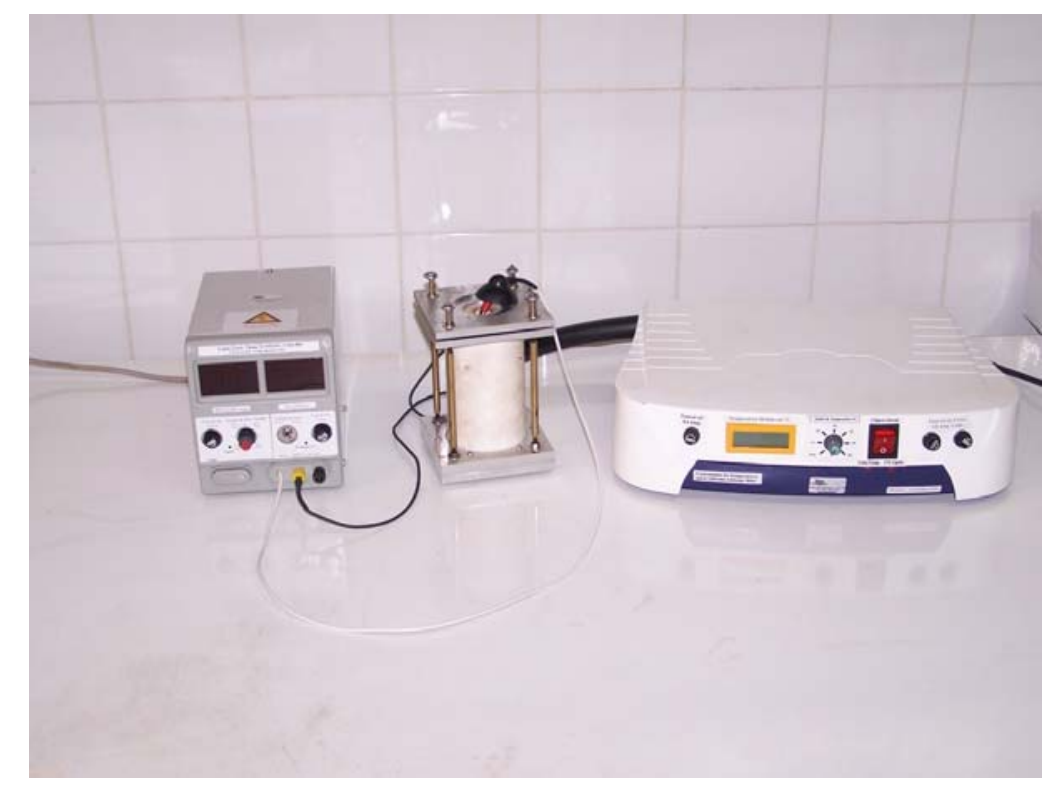

Figura 51 - Foto do forno para polarização eletrotérmica. 


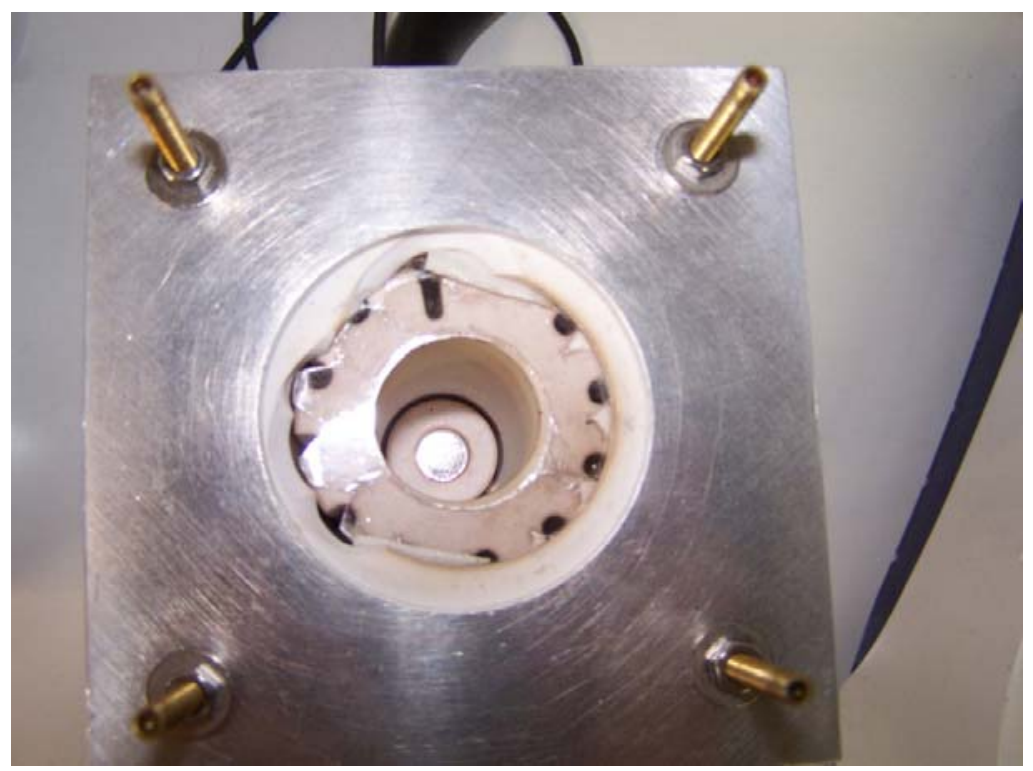

Figura 52 - Foto do forno para polarização eletrotérmica onde aparece em detalhe o eletrodo inferior e a superfície onde é colocada a amostra.

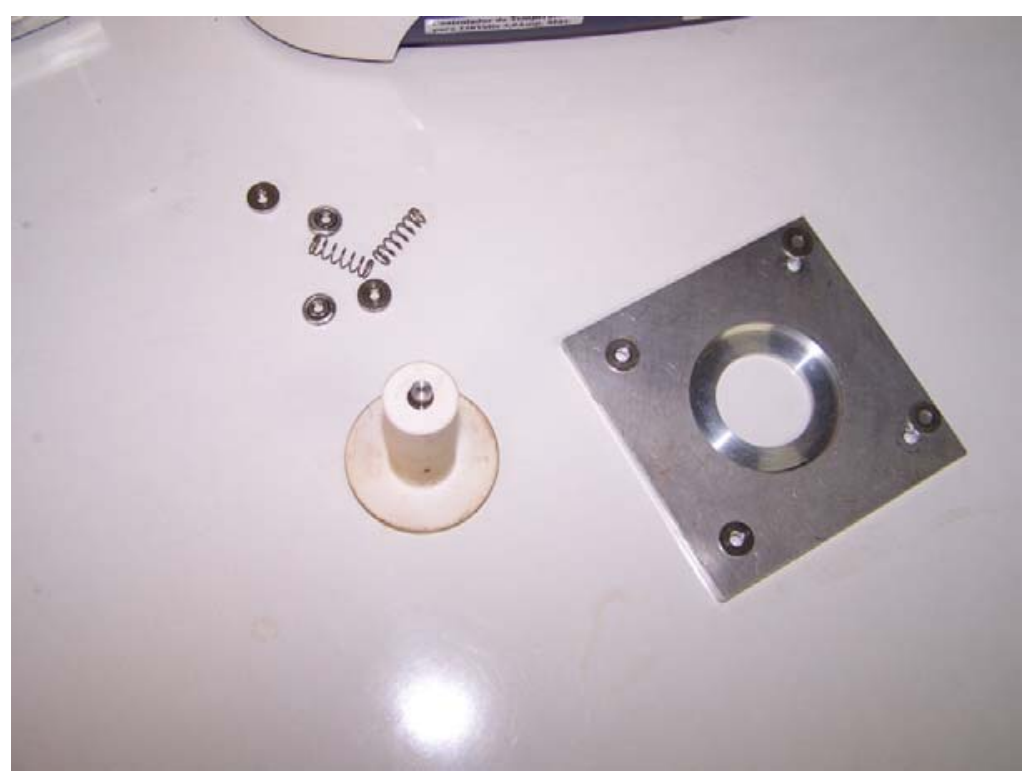

Figura 53 - Foto do eletrodo superior fora do forno. 


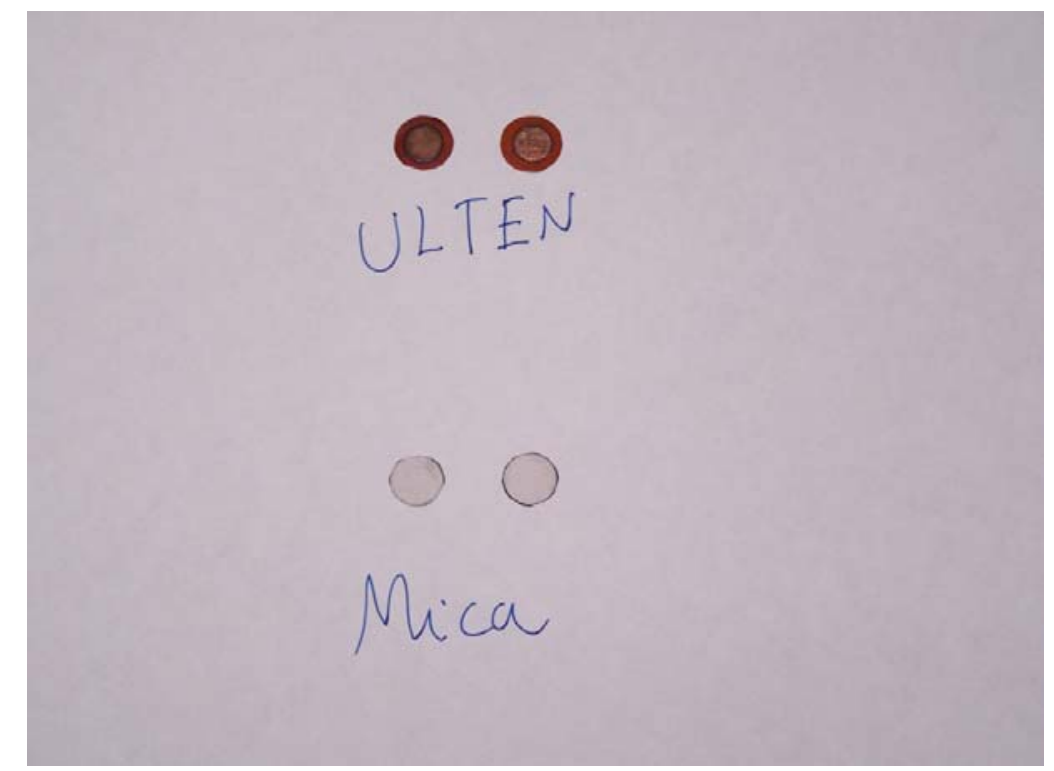

Figura 54 - Mica e Ulten utilizados.

\subsubsection{Referências}

[1] Narazaki, A.; Tanaka, K.; Hirao, K.; Soga, N. Induction and relaxation of optical second-order nonlinearity in tellurite glasses. J. Appl. Phys., v. 85, n. 4, p. 20462051, 1999.

[2] Tanaka, K.; Narazaki, A.; Hirao, K.; Soga, N. Optical second harmonic generation in poled $\mathrm{MgO}-\mathrm{ZnO}-\mathrm{TeO}_{2}$ and $\mathrm{B}_{2} \mathrm{O}_{3}-\mathrm{TeO}_{2}$ glasses. J. Non-Cryst. Solids, v. 203, p. 4954, 1996.

[3] Tanaka, K.; Narazaki, A.; Yonezaki, Y.; Hirao, K. Poling-induced structural change and second-order nonlinearity of $\mathrm{Na}^{+}$doped $\mathrm{Nb}_{2} \mathrm{O}_{5}-\mathrm{TeO}_{2}$ glass. J. Phys.: Condens. Matter., v. 12, n. 30, L513-518, 2000.

[4] Quintero Rojas, G. A. Polarização Eletrotérmica de Vidros e Fibras Ópticas. 2005. Tese (Doutorado) - Instituto de Física, Pontifícia Universidade Católica, Rio de Janeiro, Rio de Janeiro. 


\section{Capítulo 4}

\section{Resultados experimentais e discussões}

\subsubsection{Análise térmica diferencial (ATD)}

A seguir temos dois termogramas da amostra $A_{2}$, um na forma monolítica (figura 55) e outro em pó com tamanho de grão de $75 \mu \mathrm{m}$ e massa de $40 \mathrm{mg}$ (figura 56) para demonstrar o fenômeno endotérmico da sinterização das partículas de vidro, para mostrar que os dois "supostos" picos de fusão ocorrem em ambos os casos como descrito na seção 3.4.

$\mathrm{Na}$ figura 55 temos uma banda endotérmica referente à $\mathrm{T}_{\mathrm{g}}$ em $370^{\circ} \mathrm{C}$, um pico exotérmico referente a $T_{x}$ em $476^{\circ} \mathrm{C}$ e dos picos endotérmicos referente a $T_{f}$ em 673 e $743^{\circ} \mathrm{C}$.

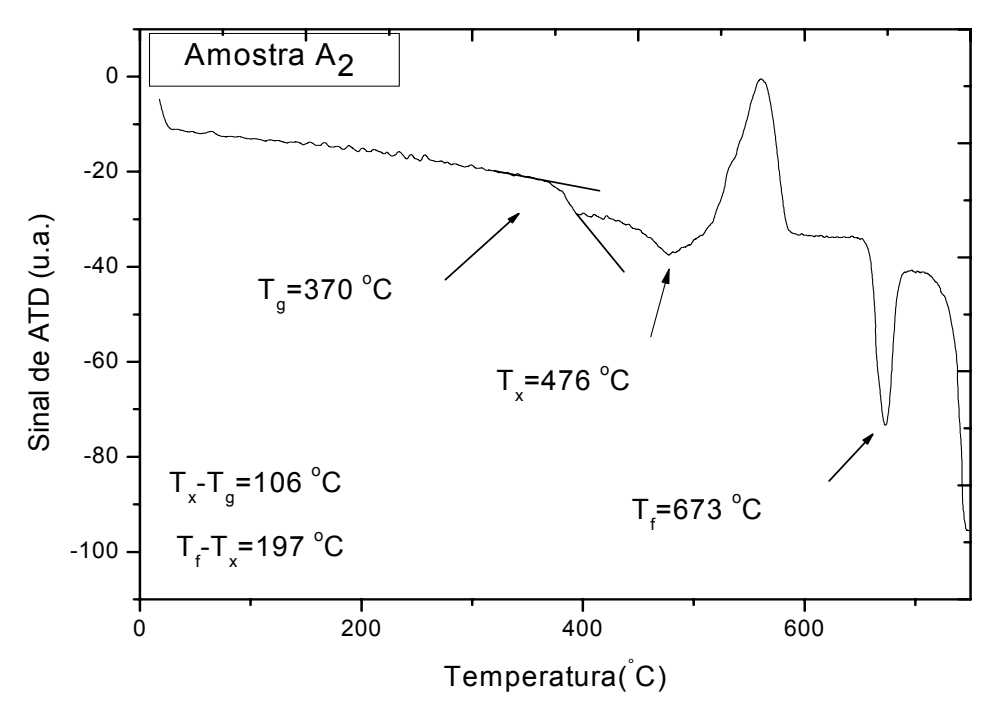

Figura 55 - Termograma ATD da amostra $A_{2}$ na forma monolítica.

$\mathrm{Na}$ tabela 15 seguem os resultados dos termogramas das medidas de $T_{g}, T_{x} e$ $T_{f}$ de todas as amostras. Para a obtenção destes resultados foram utilizadas amostras na forma de pó com tamanho de grão de $75 \mu \mathrm{m}$, massa de $40 \mathrm{mg}$ e taxa de aquecimento de $10^{\circ} \mathrm{C} / \mathrm{min}$.

De acordo com os resultados de ATD (tabela 15), os vidros com nióbio (série A) apresentaram uma $T_{g}$ mais alta. Isto indica que a adição de nióbio torna as 
ligações atômicas desses vidros mais fortes e, portanto, para que a relaxação estrutural ocorra, é necessário fornecer a esses materiais uma energia maior.

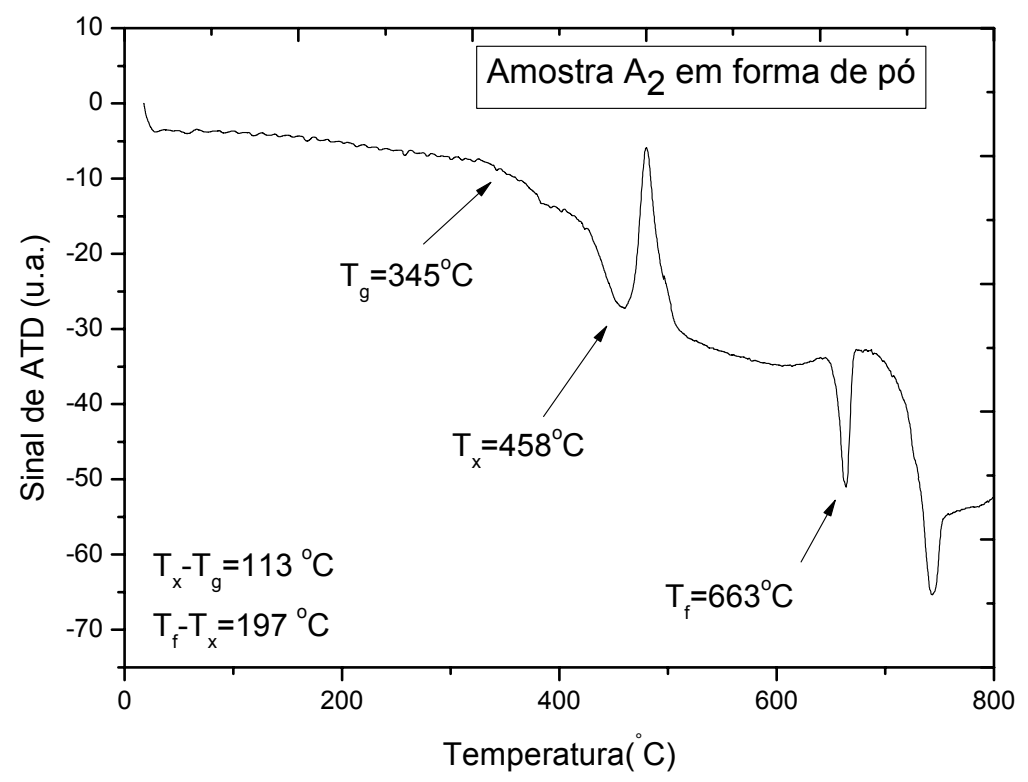

Figura 56 - Termograma ATD da amostra $A_{2}$ em pó.

Como descrito anteriormente na seção 3.4, quanto maior o $H_{r}$, menor é a tendência do vidro se cristalizar durante o resfriamento e maior a sua estabilidade térmica contra a vitrificação. Os vidros da série $A$ não demonstraram nenhum efeito da maior adição de $\mathrm{AgNO}_{3}$ na rede vítrea.

Para a série $\mathrm{B}$ com a adição de uma quantidade razoável de $\mathrm{AgNO}_{3}$ ( 5 mol\%), diminuiu significativamente a temperatura de cristalização (tabela 15) e, conseqüentemente, com a diminuição do número de Hruby temos uma facilidade maior de cristalização. Observou-se experimentalmente que parte da amostra $\mathrm{B}_{5}$ que não sofreu pressão no momento em que o vidro foi vertido apresentou-se leitosa, pois o resfriamento foi neste caso mais lento o suficiente para que ocorra a cristalização. Com a finalidade de constatar se ocorreu cristalização foi feita a medida de DRX (seção 4.6).

Ao comparar a estabilidade da amostra $B_{3}$ em relação a $C_{1}$ observa-se que a presença de $\mathrm{Zn}$ aumentou drasticamente a constante de Hruby da amostra $\mathrm{B}_{3}$. A causa provável é de que o íon $\mathrm{Zn}^{2+}$, ao ocupar uma posição de íon modificador da rede vítrea, coordenado com cerca de 6 íons vizinhos de oxigênio, tende a produzir 
uma superposição do tipo $\sigma$ entre os orbitais $d$ do íon $\mathrm{Zn}^{2+}$ e os orbitais do tipo $p$ do oxigênio, dando origem ao caráter parcialmente covalente em uma nova unidade estrutural modificadora da rede vítrea próxima à de um octaedro estabilizando, assim, a estrutura da rede contínua aleatória do vidro. Esta interpretação é consistente com a verificação de Burger e colaboradores [1] da existência da ordem de curto alcance nos vidros $\mathrm{ZnO}$ por meio da difração de nêutrons, absorção no infravermelho e espectroscopia Raman. Shimizugawa e colaboradores [2], utilizando radiação de luz síncroton, ao estudar a estrutura de vidros $\mathrm{TeO}_{2}-\mathrm{ZnO}$ com base no EXAFS do nível $k$ do $T e$, indicaram que as distâncias interatômicas nos sítios axiais entre Te e $\mathrm{O}$ decresceram de 0,208 para 0,199 nm para concentrações crescentes de $\mathrm{ZnO}$, enquanto as distâncias nos sítios equatoriais permaneceram constantes.

Tabela 15 - Resultados das medidas de análise térmica diferencial.

\begin{tabular}{|l|l|l|l|l|l|}
\hline Amostra & $\mathrm{T}_{\mathrm{g}}\left({ }^{\circ} \mathrm{C}\right)$ & $\mathrm{T}_{\mathrm{x}}\left({ }^{\circ} \mathrm{C}\right)$ & $\mathrm{T}_{\mathrm{f}}\left({ }^{\circ} \mathrm{C}\right)$ & $\mathrm{T}_{\mathrm{x}}-\mathrm{T}_{\mathrm{g}}$ & $\mathrm{H}_{\mathrm{r}}$ \\
\hline $\mathrm{A}_{2}$ & 345 & 458 & 663 & 113 & $0,55 \pm 0,02$ \\
\hline $\mathrm{A}_{3}$ & 376 & 479 & 663 & 103 & $0,56 \pm 0,02$ \\
\hline $\mathrm{A}_{4}$ & 372 & 471 & 660 & 99 & $0,52 \pm 0,02$ \\
\hline $\mathrm{A}_{5}$ & 359 & 460 & 662 & 103 & $0,51 \pm 0,02$ \\
\hline $\mathrm{B}_{2}$ & 256 & 417 & 491 & 161 & $2,18 \pm 0,02$ \\
\hline $\mathrm{B}_{3}$ & 256 & 404 & 490 & 148 & $1,72 \pm 0,02$ \\
\hline $\mathrm{B}_{5}$ & 243 & 368 & 485 & 125 & $1,07 \pm 0,02$ \\
\hline $\mathrm{C}_{1}$ & 257 & 314 & 351 & 57 & $0,61 \pm 0,02$ \\
\hline
\end{tabular}

\subsubsection{Referências}

[1] Burger, H.; Kneipp, K.; Hobert, H.; Vogel, W.; Kozhukharov, V.; Neov, S. Glass formation, properties and structure of glasses in the $\mathrm{TeO}_{2}-\mathrm{ZnO}$ system. J. NonCryst. Solids, v. 151, p. 134, 1992.

[2] Shimizugawa, Y.; Maeseto, T.; Inoue, S.; Nukui, A. Structure of $\mathrm{TeO}_{2}-\mathrm{ZnO}$ glasses by RDF and Te, Zn K EXAFS. Phys. Chem. Glasses, v. 38, n. 4, p. 201, 1997. 


\subsection{Absorção óptica (AO)}

\subsubsection{Absorção óptica $(A O)$ sem tratamento térmico posterior}

Devido à alta transparência na região do visível e do infravermelho em vidros teluritos se observa inicialmente a viabilidade para as medidas do índice de refração não linear.

O espectro do coeficiente de absorção versus o comprimento de onda para as amostras da série $A$ segue na figura 57 , da série $B$ na figura 58 e da amostra $C_{1}$ na figura 59, na região do visível e infravermelho.

$\mathrm{Na}$ figura 60 segue a determinação pelo método de Jan Tauc [1] da energia gap óptico para uma transição indireta.

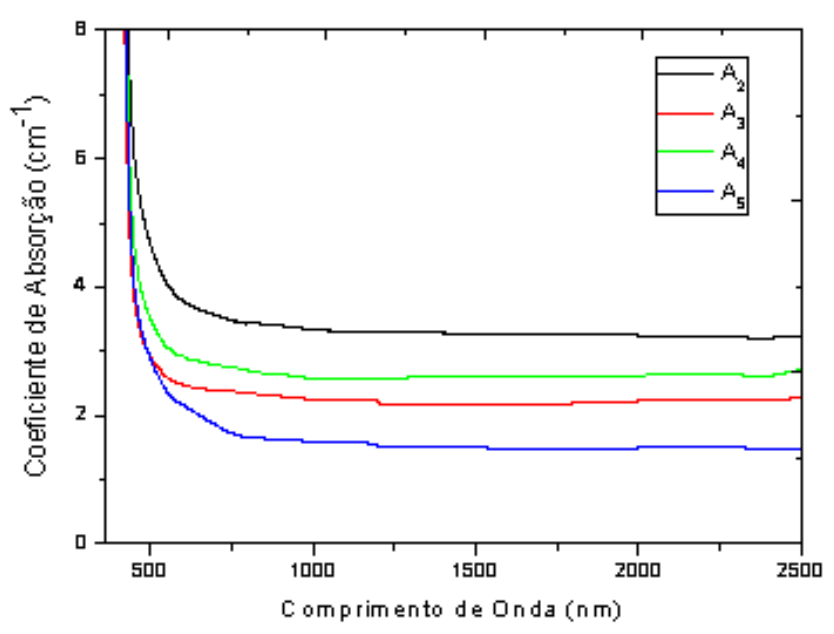

Figura 57 - Espectro do coeficiente de absorção versus comprimento de onda das amostras $A_{2}, A_{3}$, $A_{4}$ e $A_{5}$ recozidas a $320^{\circ} \mathrm{C}$. 


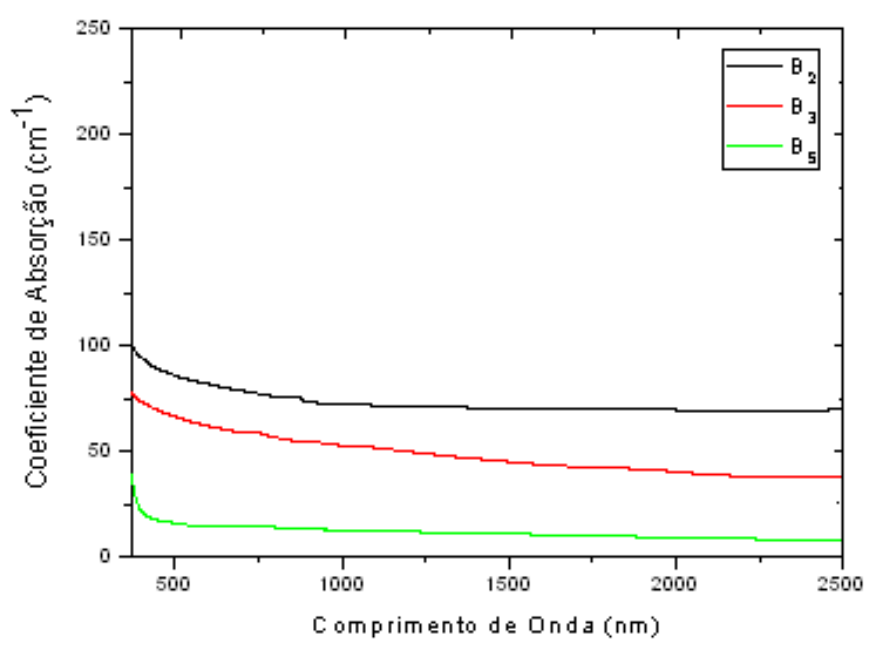

Figura 58 - Espectro do coeficiente de absorção versus comprimento de onda das amostras $B_{2}, B_{3}$ e $B_{5}$.

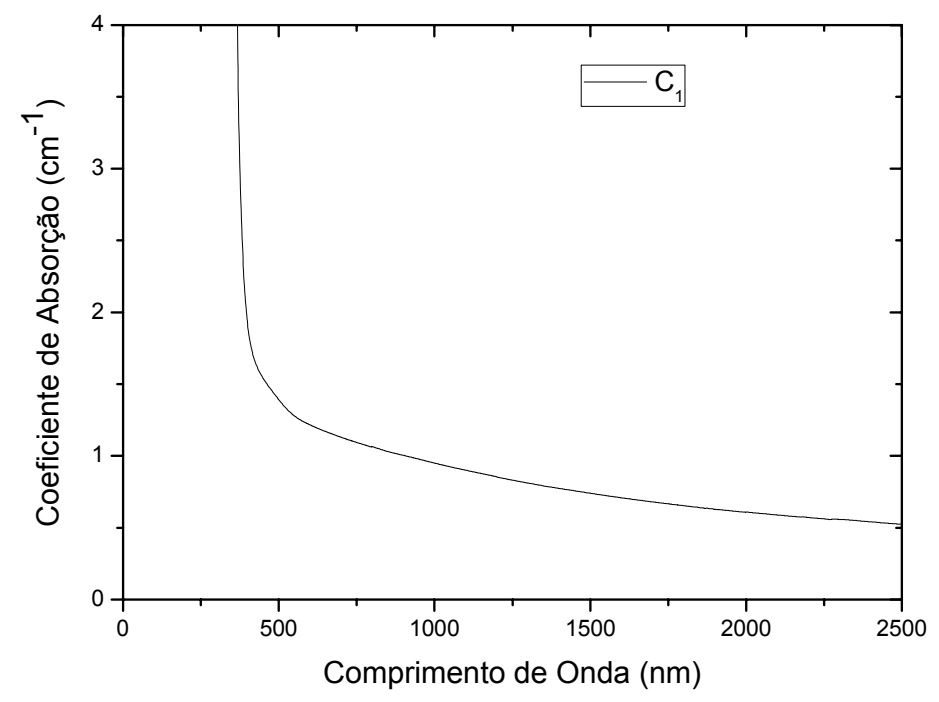

Figura 59 - Espectro do coeficiente de absorção versus comprimento de onda da amostra $C_{1}$. 


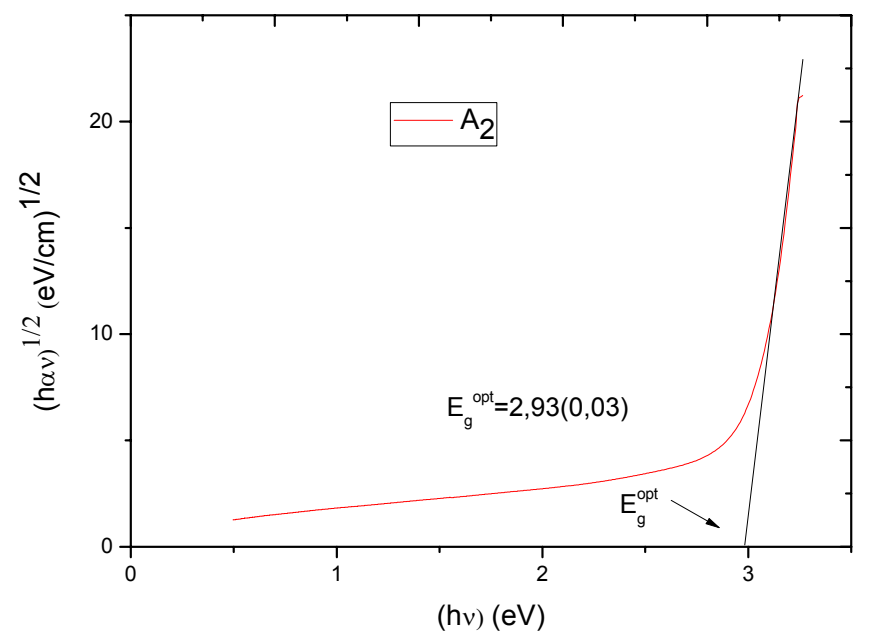

Figura 60 - Espectro $(\alpha h v)^{1 / 2}$ versus $h v$ para a determinação da energia do gap óptico para uma transição indireta permitida.

Na tabela 16 seguem os valores das energias dos $E_{g}$ de cada amostra para uma transição permitida direta e indireta. Os resultados foram obtidos de maneira análoga à da figura 60 , para uma transição permitida indireta (seção $2.3 .4 \mathrm{e}$ apêndice A.2). Os resultados sugerem que dentro do intervalo de incerteza as amostras da série A não apresentam diferenças significativas de energia do gap óptico e conferem com os resultados de Prakash e colaboradores [2] e Berthereau e colaboradores [3] para os vidros com estequiometria próxima. Já as amostras da série $B$ apresentam uma pequena diferença sugerindo que a introdução da prata provoca um diminuição da $E_{o p t}$ (amostra $B_{5}$ ) como ocorre nas amostras de Terashima et al [4] no vidro à base de $\mathrm{B}_{2} \mathrm{O}_{3}-\mathrm{Ag}_{2} \mathrm{O}$.

Prakash e colaboradores [2] encontraram a energia da cauda de Urbach $\Delta \mathrm{E}=$ $(0,174 \pm 0,001) \mathrm{eV}$ para a amostra com estequiometria $\left(10 \mathrm{Na}_{2} \mathrm{O}-\mathrm{xNb}_{2} \mathrm{O}_{5}-(90-\mathrm{x})\right.$ $\mathrm{TeO}_{2}$ ) $\mathrm{mol} \%$ e $\mathrm{x}=10$ (mais próxima de nossa estequiometria em relação à quantidade de $\mathrm{Nb}_{2} \mathrm{O}_{5}$ ). Para $\Delta \mathrm{E}$ encontrada nestes vidros sugere-se que os defeitos são mínimos. Ao contrário do que ocorre em outros vidros óxidos uma adição de $\mathrm{Nb}^{5+}$ à matriz vítrea $10 \mathrm{Na}_{2} \mathrm{O}-90 \mathrm{TeO}_{2}$ apresenta uma redução no gap óptico e nas caudas de Urbach e um aumento da densidade do vidro. $O$ cálculo das energias de Urbach para a amostra $A_{3}$ revelou uma energia menor de $\Delta E=(0,105 \pm 0,001) \mathrm{eV}$ do que a amostra de Prakash e colaboradores [2], isto ocorreu devido ao fato que a amostra 
$\mathrm{A}_{3}$ apresentou menor quantidade de $\mathrm{Na}_{2} \mathrm{O}$ (é conhecido que este elemento alcalino introduz mais defeitos a rede vítrea, devido à quebra da cadeia covalente produzindo maior quantidade de oxigênios terminais).

Nas figuras 61 e 62 segue-se uma ilustração da região $B$ na qual a reta coincide com o espectro, com o qual foram efetuados os cálculos de $\Delta \mathrm{E}$. A variação de $\Delta \mathrm{E}$ para as amostras da série $\mathrm{A}$ e $\mathrm{B}$ segue um padrão de comportamento para a primeira dopagem de prata, ou seja, temos uma energia menor do que a amostra sem dopagem. A seguir, para a série $A$, temos um crescimento não monotônico com a adição do dopante (os dados estão expostos na tabela 16).

Os resultados das energias de Urbach são válidos para regiões muito pequenas e sua variação com o aumento de prata podemos afirmar que se referem a sistemas complexos ainda não bem compreendidos, já que o esperado seria um crescimento monotônico com a adição de prata na matriz vítrea (espera-se que a prata introduza defeitos na estrutura vítrea de modo análogo aos demais elementos modificadores da rede).

Vale ressaltar que o tema das energias para a cauda de Urbach não é um assunto inteiramente explicado, havendo várias propostas teóricas apresentadas. Alguns autores como Toyozawa (1959) [5], Mahr (1963) [6], Mahan (1966) [7] e Keil (1966) [8] atribuem a participação de bandas excitônicas ao decaimento exponencial da cauda de Urbach. Outros autores como Redfield (1963) [9] e Dexter (1967) [10] atribuíram o alargamento presente da cauda de Urbach à ação do campo elétrico local conhecido como efeito Franz-Keldysh. Por último, outros autores como Dow and Hopfield (1972) [11] e Redfield (1970) [12] atribuem o citado alargamento ao campo elétrico local com a simultânea presença de uma linha excitônica.

As amostras irradiadas com raios gamma com diferentes doses não apresentaram nenhuma banda de absorção. Vidros aluminoboratos dopados com prata [13] apresentaram um centro em $296 \mathrm{~nm}$ que cresceu com o aumento da radiação, já vidros fosfatos [14] apresentaram um pico em 340 nm. 
Tabela 16 - Energias do gap óptico de cada amostra.

\begin{tabular}{|l|l|l|l|}
\hline Amostra & $\mathrm{E}_{\text {opt }}^{\mathrm{d}}(\mathrm{eV})$ & $\mathrm{E}_{\text {opt }}^{\mathrm{i}}(\mathrm{eV})$ & $\Delta \mathrm{E}(\mathrm{meV})$ \\
\hline $\mathrm{A}_{2}$ & $3,14 \pm 0,03$ & $2,93 \pm 0,03$ & $101,0 \pm 1,0$ \\
\hline $\mathrm{A}_{3}$ & $3,10 \pm 0,03$ & $2,87 \pm 0,03$ & $105,0 \pm 1,0$ \\
\hline $\mathrm{A}_{4}$ & $3,06 \pm 0,03$ & $2,85 \pm 0,03$ & $112,0 \pm 1,0$ \\
\hline $\mathrm{A}_{5}$ & $3,09 \pm 0,03$ & $2,84 \pm 0,03$ & $110,0 \pm 1,0$ \\
\hline$B_{2}$ & $3,63 \pm 0,03$ & $3,83 \pm 0,03$ & $146,0 \pm 2,0$ \\
\hline$B_{3}$ & $3,34 \pm 0,03$ & $3,59 \pm 0,03$ & $192 \pm 4$ \\
\hline$B_{5}$ & $2,40 \pm 0,03$ & $2,66 \pm 0,03$ & $330 \pm 4$ \\
\hline$C_{1}$ & $2,95 \pm 0,03$ & $2,76 \pm 0,03$ & $300 \pm 5$ \\
\hline
\end{tabular}

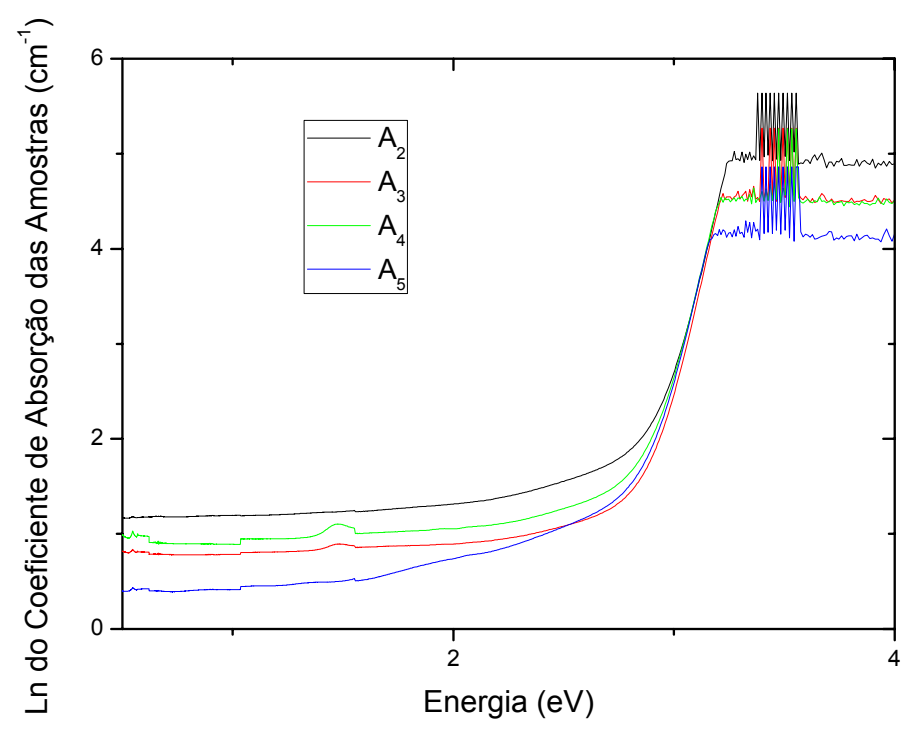

Figura 61 - Espectro do logaritmo natural do coeficiente de absorção da série de amostras $A$ em função da energia. 


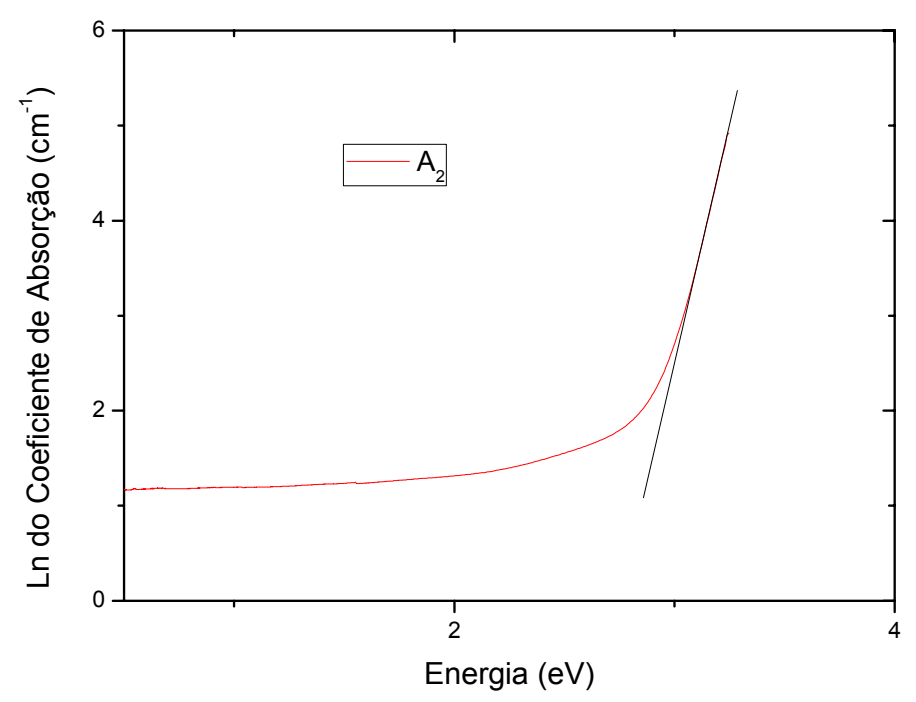

Figura 62 - Espectro do logaritmo natural do coeficiente de absorção da amostra $A_{2}$ em função da energia para ilustrar a região $B$ da margem da banda de condução.

\subsubsection{Absorção óptica (AO) das amostras sem recozimento e com posterior tratamento térmico}

Com o objetivo de investigar as condições da nossa matriz vítrea dopada com $\mathrm{AgNO}_{3}$ desenvolver a formação de nanopartículas de prata decidimos executar uma série de tratamentos térmicos.

A amostra $A_{3}$ não apresentou nenhuma diferença após o tratamento térmico (figura 63), já a amostra $A_{4}$ apresentou um maior coeficiente de extinção. Se considerarmos que o coeficiente de extinção é composto do coeficiente de absorção e do espalhamento e que o coeficiente de absorção da amostra $A_{4}$ é desprezível, podemos considerar que essa amostra, tratada termicamente, apresenta um maior espalhamento da luz para comprimentos de onda no intervalo da medida.

As amostras $B_{2}, B_{3}$ e $B_{5}$ não apresentaram nenhuma banda de absorção antes do tratamento térmico (figura 58 ).

A seguir as amostras foram tratadas termicamente em temperaturas acima da $\mathrm{Tg}$ em atmosfera ambiente. Na figura 64 (à esquerda) segue o espectro da evolução 
da banda de absorção em 446, 455 e 466 nm; atribuída à ressonância de plasmons da prata, com tratamentos térmicos de $270^{\circ} \mathrm{C}, 290^{\circ} \mathrm{C}$ e $310^{\circ} \mathrm{C}$ com duração de 2 horas, referente à amostra $B_{2}$, dopada com menor quantidade de prata $(0,5 \mathrm{~mol} \%$ de $\mathrm{AgNO}_{3}$. Podemos observar que com o aumento da temperatura de tratamento, a banda cresceu e apresentou um deslocamento para o vermelho, característico de um sistema de nanopartículas sendo depositado, com partículas aumentando em tamanho, o que concorda com os resultados da literatura [15], enquanto que a largura da banda (largura à meia altura (FWHM)) diminuiu de $(117 \pm 1) \mathrm{nm}$ para (99 $\pm 9) \mathrm{nm}$ e $(63,7 \pm 1,5) \mathrm{nm}$ tabela 17 .

Para a amostra $B_{5}$ (vide fig. 64 à direita) dopada com uma maior quantidade de prata $\left(5 \mathrm{~mol} \%\right.$ de $\mathrm{AgNO}_{3}$ ), o tratamento térmico a $270{ }^{\circ} \mathrm{C}$ e $290{ }^{\circ} \mathrm{C}$ por 2 horas produziu uma discreta redução da intensidade do pico e, portanto, do número de partículas, indicando que ocorreu ou uma dissolução ou então um agrupamento, já nesta fase do tratamento térmico. Em comparação com a amostra $B_{2}$ a banda de plasmons apresentou um desvio para o vermelho, não ocorrendo mudanças significativas entre as temperaturas de $270{ }^{\circ} \mathrm{C}$ e $290{ }^{\circ} \mathrm{C}$. Quanto a FWHM é observada uma redução na largura de banda com o aumento da temperatura de $(178 \pm 3) \mathrm{nm}$ para $(161 \pm 7) \mathrm{nm}$ (ver tabela 17).

Submetemos a amostra $\mathrm{B}_{5}$ a um polimento após termos eliminado a presença da banda de $\mathrm{AO}$ da ressonância de plasma da prata e verificamos 0 desaparecimento da banda em $480 \mathrm{~nm}$, conforme indicado na figura 65, de onde concluímos que as nanopartículas de prata se formaram sobre a superfície.

Pela localização da banda de plasmons e por meio da comparação com a literatura (seção 2.4) cogitamos que a forma das nanopartículas é esférica. Para confirmar a forma e o tamanho das nanopartículas criadas, um estudo de sua morfologia foi efetuado por microscopia eletrônica de transmissão (TEM), como será apresentado na próxima seção. 


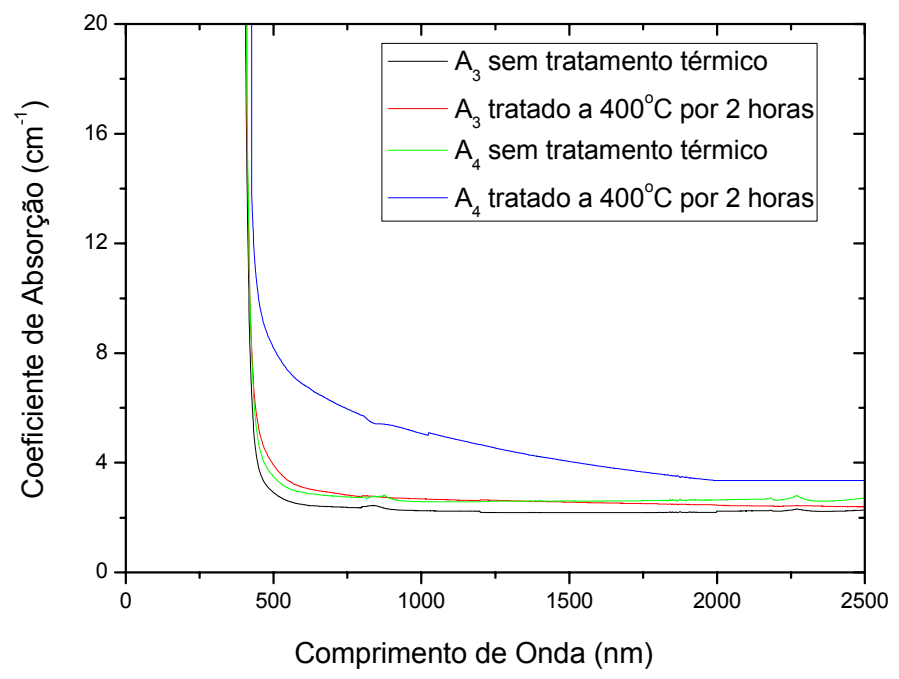

Figura 63 - Espectro do coeficiente de absorção versus comprimento de onda das amostras $A_{3}$ e $A_{4}$, ambas tratadas a $400^{\circ} \mathrm{C}$ por duas horas.

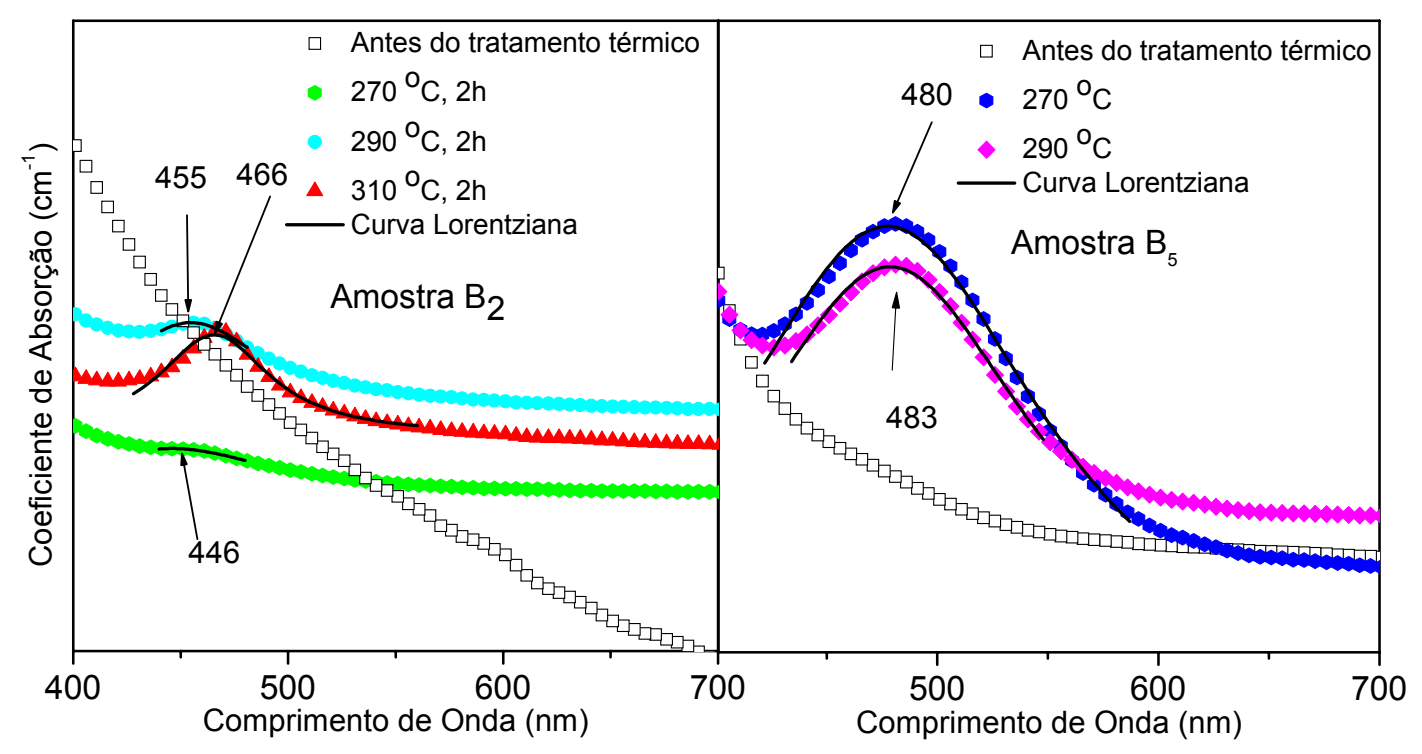

Figura 64 - Espectro do coeficiente de absorção versus comprimento de onda da amostra $B_{2}$ (esquerda) e $B_{5}$ (direita) com diferentes tratamentos térmicos. 


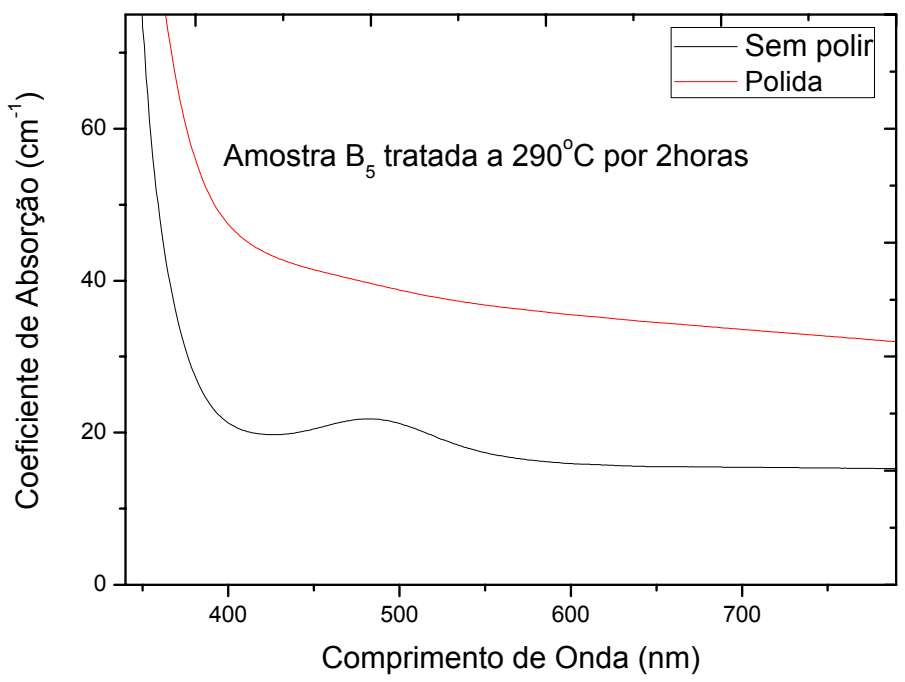

Figura 65 - Espectro do coeficiente de absorção versus comprimento de onda da amostra $B_{5}$ tratada termicamente a $290^{\circ} \mathrm{C}$ por 2 horas e após com um polimento posterior.

Tabela 17 - Valores da largura a meia altura das amostras $B_{2}$ e $B_{3}$ tratadas com diferentes temperaturas.

\begin{tabular}{|l|l|l|}
\hline Amostra & Temperatura & Largura a meia altura \\
\hline \multirow{3}{*}{$\mathrm{B}_{2}$} & $270{ }^{\circ} \mathrm{C}$ & $117 \pm 18$ \\
\cline { 2 - 3 } & $290^{\circ} \mathrm{C}$ & $98 \pm 9$ \\
\cline { 2 - 3 } & $310^{\circ} \mathrm{C}$ & $63,7 \pm 1,5$ \\
\hline $\mathrm{B}_{3}$ & $270^{\circ} \mathrm{C}$ & $178 \pm 3$ \\
\cline { 2 - 3 } & $290^{\circ} \mathrm{C}$ & $161 \pm 7$ \\
\hline
\end{tabular}

Segundo Houde-Walter e colaboradores [16, 17] a interdifusão dos cátions nos vidros é fortemente dependente da concentração de NBO's.

Considerando uma amostra tratada termicamente teremos os seguintes efeitos: 
a) a degeneração da rede vítrea mediante a quebra das ligações covalentes do NBO's e a liberação de um oxigênio, para cada ligação quebrada (figura 66a);

b) o oxigênio liberado doa um elétron à prata segundo a reação $\mathrm{Ag}^{+}+\mathrm{O}^{-2} \rightarrow$ $A g^{0}+O^{-}$(figura $\left.66 \mathrm{~b}\right)$;

c) o oxigênio $O^{-}$passa a ocupar uma posição intersticial compensando carga com a vacância de oxigênio formada durante a fusão do vidro. Após posteriores tratamentos térmicos as nanopartículas de prata metálica poderão criar um filme sobre a superfície da amostra pela aglomeração e nucleação do $A g^{0}$ (figura $66 \mathrm{c}$ );

d) o NBO cuja carga anteriormente fora compensada pelo $\mathrm{Ag}^{+}$passa a ter a sua carga compensada pela vacância de oxigênio mais próxima (figura 66 c). 
a)

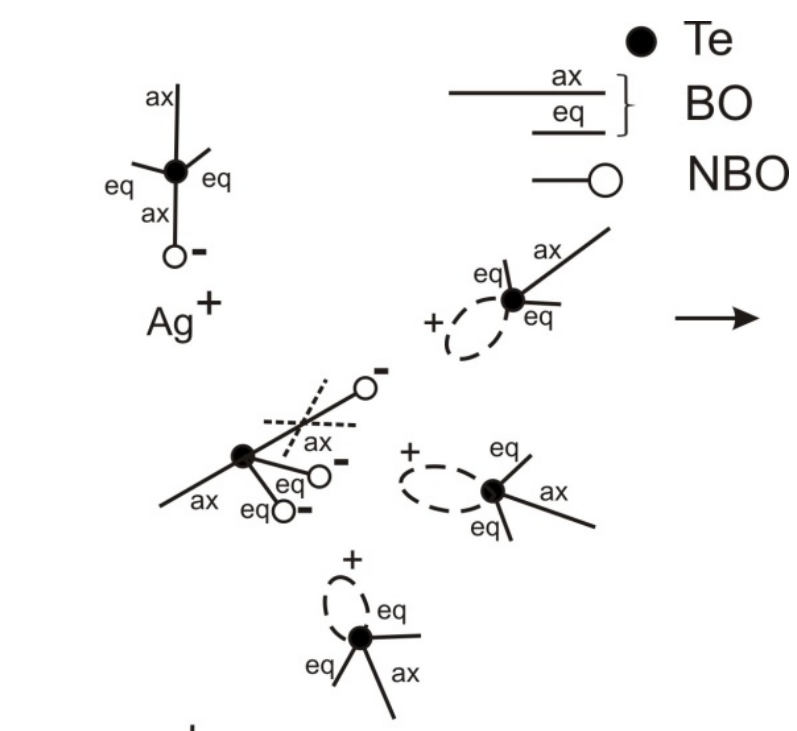

b)
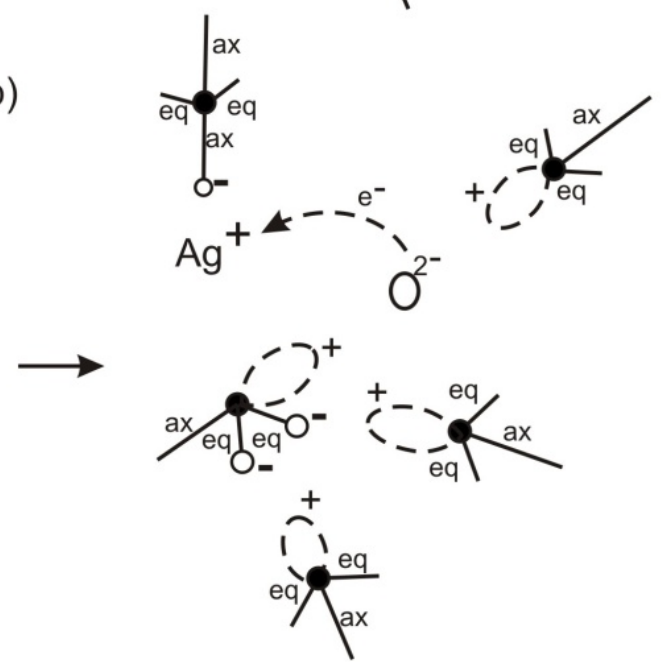

c)

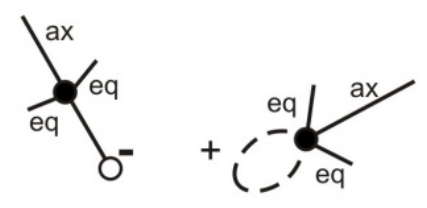

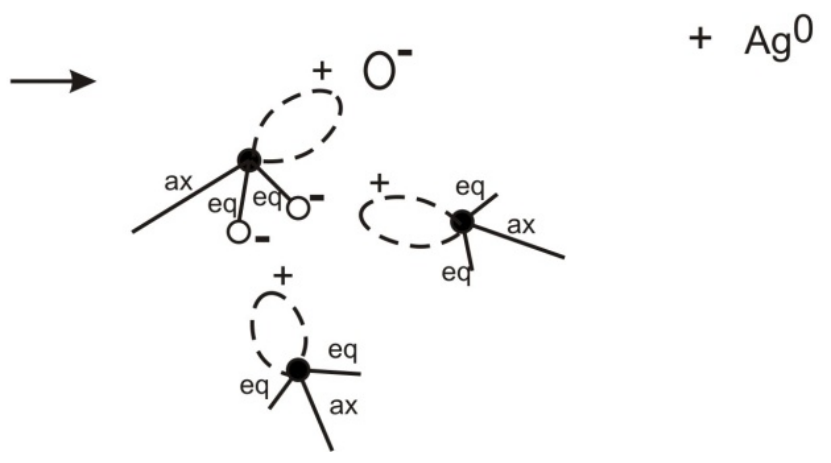

Figura 66 - Modelo para formação de nanopartículas de prata. 


\subsubsection{Referências}

[1] Tauc J. Amorphous and liquid semiconductors. New York U. K. Plenum Pres, 1974.

[2] Prakash, G. V.; Rao, D. N.; Bhatnagnar, A. K. Linear optical properties of niobiumbased tellurite glasses. Solid State Comm., v. 119, p. 39-44, 2001.

[3] Berthereau, A.; Le Luyer, Y.; Olazcuaga, R.; Le Flem, G.; Couzi, M.; Canioni, L.; Segonds, P.; Sarger, L.; Ducasse, A. Nonlinear optical properties of some tellurium (IV) oxide glasses. Mat. Res. Bul., v. 29, n. 9, p. 933-941, 1994.

[4] Terashima, K.; Kim, S. H; Yoko, T. Nonlinear optical properties of $\mathrm{B}_{2} \mathrm{O}_{3}$-based glasses: $\mathrm{M}_{2} \mathrm{O}-\mathrm{B}_{2} \mathrm{O}_{3}(\mathrm{M}=\mathrm{Li}, \mathrm{Na}, \mathrm{K}, \mathrm{Rb}, \mathrm{Cs}$, and $\mathrm{Ag})$ binary borate glasses.J. Am. Ceram. Soc., v. 78, n. 6, p. 1601-1605, 1995.

[5] Toyozawa, Y. Prog. Theor. Phys. Suppel., v. 12, p. 111, 1959.

[6] Mahr, H. Absorption Band Shape and Urbach's Rule of Localized Excitons. Phys. Rev., v. 132, p. 1880-1884, 1963.

[7] Mahan, G. D. Phonon-Broadened Optical Spectra: Urbach's Rule. Phys. Rev., v. 145, p. 602-608, 1966.

[8] Keil, T. H. Theory of the Urbach Rule.Phys. Rev., v. 144, p. 582-587, 1966.

[9] Redfield, D. Effect of Defect Fields on the Optical Absorption Edge. Phys. Rev., v. 130, p. 916-918, 1963.

[10] Dexter, D. L. Interpretation of Urbach's Rule. Phys. Ver. Lett., v. 19, p. 13831385, 1967.

[11] Dow, J. D.; Hopfield, J. J. Effective-impurity model of optical absorption edges. J. Non-cryst. Solids, v. 8-10, p. 664-669, 1972.

[12] Dow, J. D., Redfield, D. Electroabsorption in Semiconductors: The Excitonic Absorption Edge. Phys. Rev. B, v. 1, p. 3358-3371, 1970.

[13] Ghosh, A. K. Optical properties of electron and hole traps in Ag-doped aluminoborate glass. J. Phys. Chem. Solids, v. 30, p. 2385-2394, 1969.

[14] Schulman, J. H.; Shurcliff, W.; Ginther, R. J.; Attix, F. Radiophotoluminescence dosimetry system of the U. S. Navy. Nucleonics, v. 11, p. 52, 1953.

[15] Blondeau, J. Ph.; Catan, F.; Andreazza-Vignolle, C.; Sbai, N. Plasmon resonance and clustering of silver nanoclusters embedded in glass. Plasmonics, v. 3, n. 2, p. 65-71, 2008. 
[16] Houde-Walter, S. N.; Inman, J. M.; Dent, A. J.; Greaves, G. N. Sodium and silver environments and iron-exchange processes in silicate and aluminosilicate glasses. J. Phys. Chem., v. 97, p. 9330-9336, 1993.

[17] Messerschmidt, B.; Mclntyre, B. L.; Houde-Walter, S. N. Desired concentrationdependent ion exchange for micro-optic lenses. Applied Opt., v. 35, n. 28, 56705676, 1996.

\subsection{Microscopia eletrônica de transmissão (MET) e espectroscopia de fluorescência de raios-X por energia dispersiva (EDS)}

As micrografias obtidas a partir das amostras moídas não se apresentaram úteis para a identificação de nanopartículas de prata. As imagens das nanopartículas de prata que foram raspadas da superfície da amostra $B_{2}$ tratada termicamente em diferentes temperaturas e mesmo tempo de tratamento $(2 \mathrm{~h})$ consta na figura 67 . A forma aproximadamente esférica das partículas precipitadas na amostra $B_{2}$ é consistente com a banda de $\mathrm{AO}$ em $\lambda \approx 446,455$ e $466 \mathrm{~nm}$ (vide figura 64 à esquerda). As nanopartículas precipitadas na superfície da amostra $\mathrm{B}_{2}$ à temperatura de $270^{\circ} \mathrm{C}$ durante 2 horas (figura 67 à esquerda) apresentam uma forma aproximadamente esférica, com o tamanho variando de 0,5 a $8 \mathrm{~nm}$ e com diâmetro médio de $(5 \pm 1) \mathrm{nm}$. Nesta micrografia foi possível obter as nanopartículas isoladas da matriz vítrea. Entretanto, após o tratamento térmico da amostra $\mathrm{B}_{2} \mathrm{a}$ $290^{\circ} \mathrm{C}$ por 2 horas, observou-se a presença de nanopartículas superficiais bem distribuídas com diâmetro médio de $(7 \pm 1) \mathrm{nm}$, conforme mostrado na figura 67 (centro), vale ressaltar que o tamanho das partículas foi bastante disperso variando desde 2 a $19 \mathrm{~nm}$. Quando a amostra $B_{2}$ foi submetida a um tratamento térmico a $310^{\circ} \mathrm{C}$ por 2 horas (figura 67 , à direita), o tamanho médio das nanopartículas decresceu para (13 \pm 1$) \mathrm{nm}$ e variou de 4 a $26 \mathrm{~nm}$.

Na figura 68, 69 e 70 temos o espectro de EDS da amostra $B_{2}$ tratada termicamente, respectivamente, a $270^{\circ} \mathrm{C}, 290^{\circ} \mathrm{C}$ e $310^{\circ} \mathrm{C}$ durante o período de duas horas cada. O pico em CuL pertence ao porta-amostra de cobre utilizado.

$\mathrm{Na}$ figura 68 é possível observar a presença dos picos referentes às nanopartículas de prata, zinco na camada $\mathrm{K}$ e de oxigênio. Devido à pequena 
quantidade de Te é possível confirmar que as nanopartículas encontram-se praticamente isoladas da matriz vítrea. Já na figura 69 observamos uma quantidade superior de Ag e Te na camada $L$ e na figura 70 uma quantidade ainda maior de $\mathrm{Te}$ provando que o pedaço analisado possuía mais matriz vítrea.
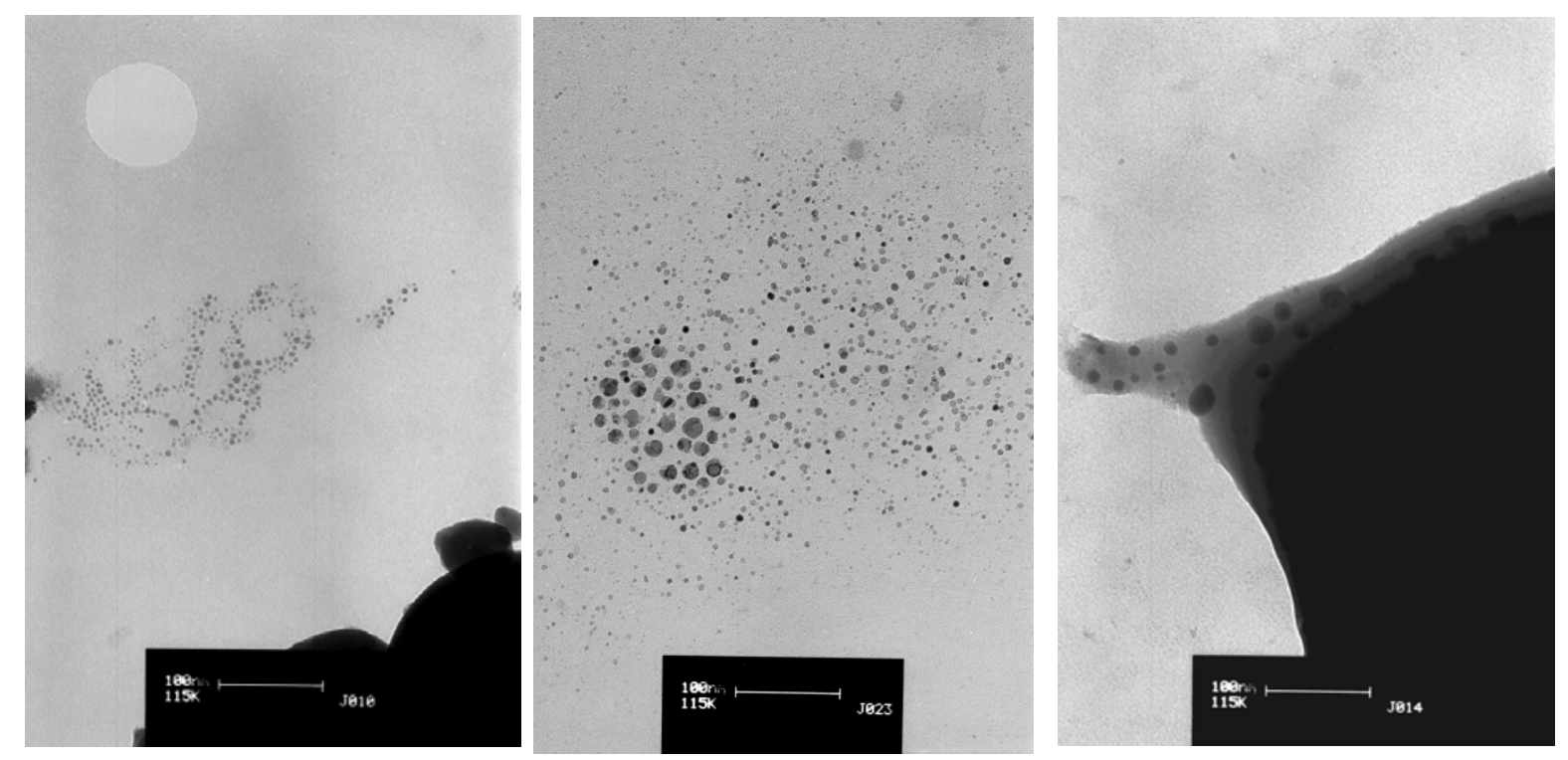

Figura 67 - Micrografias da amostra $B_{2}$ tratada a $270^{\circ} \mathrm{C}$ por duas horas (esquerda), a $290^{\circ} \mathrm{C}$ por duas horas (central) e a $310^{\circ} \mathrm{C}$ por duas horas (direita).

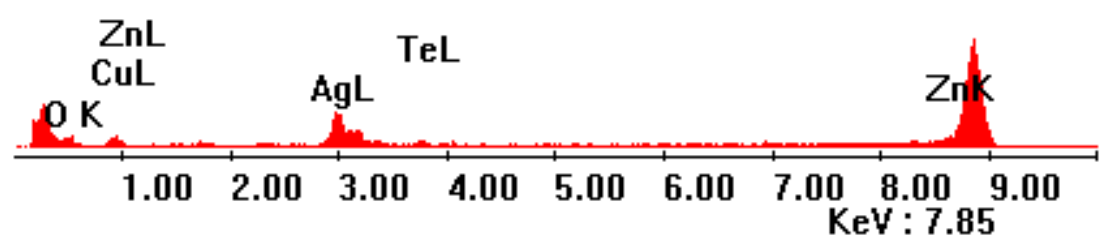

Figura 68 - Espectro de EDS da amostra $B_{2}$ tratada a $270^{\circ} \mathrm{C}$ por 2 horas. 


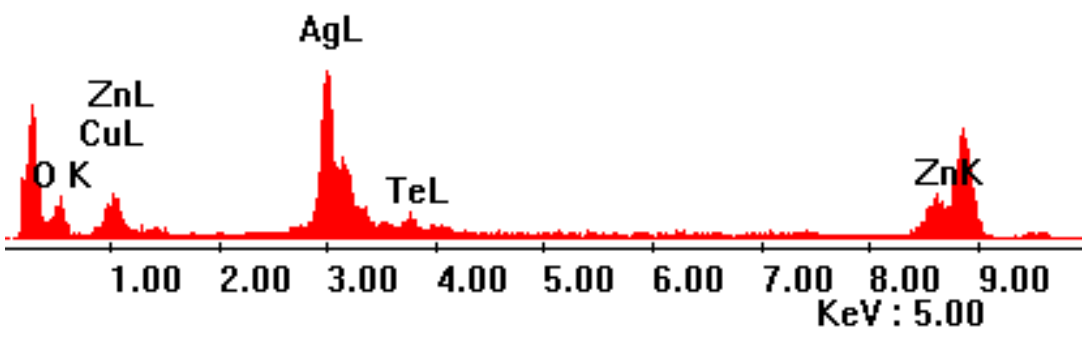

Figura 69 - Espectro de EDS da amostra $B_{2}$ tratada a $290^{\circ} \mathrm{C}$ por 2 horas.

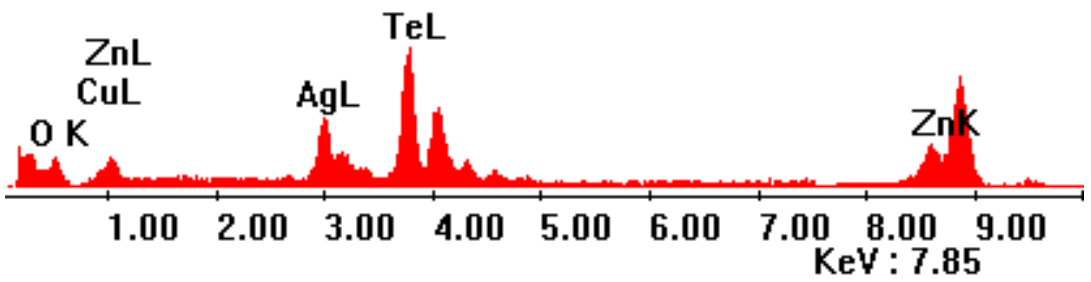

Figura 70 - Espectro de EDS da amostra $B_{2}$ tratada a $310^{\circ} \mathrm{C}$ por 2 horas.

A amostra $\mathrm{B}_{5}$, dopada com $5 \mathrm{~mol} \%$ de $\mathrm{AgNO}_{3}$, tratada termicamente a $270^{\circ} \mathrm{C}$ por 2 horas (vide figura 71 à esquerda) apresentou partículas aproximadamente esféricas, com diâmetro médio de $(9 \pm 1) \mathrm{nm}$, formando inclusive aglomerados. Após tratamento a $290^{\circ} \mathrm{C}$ por 2 horas, foram observados precipitados isolados, assim como também aglomerados, o tamanho médio das nanopartículas é de aproximadamente $(17 \pm 1) \mathrm{nm}$ (vide figura 71 à direita). Não foram encontradas partículas no interior da matriz vítrea da amostra $B_{5}$, a parte preta da micrografia representa a matriz vítrea.

Nas figuras 72 e 73 temos os espectros de EDS da amostra $B_{5}$ tratada durante duas horas nas temperaturas de $270^{\circ} \mathrm{C}$ e $290^{\circ} \mathrm{C}$. Ambos espectros revelaram a presença de $\mathrm{Zn}, \mathrm{Te}$ e as nanopartículas de prata. Como esperado a figura 73 revelou uma maior quantidade de Te, já que observamos a matriz vítrea nesta micrografia. 

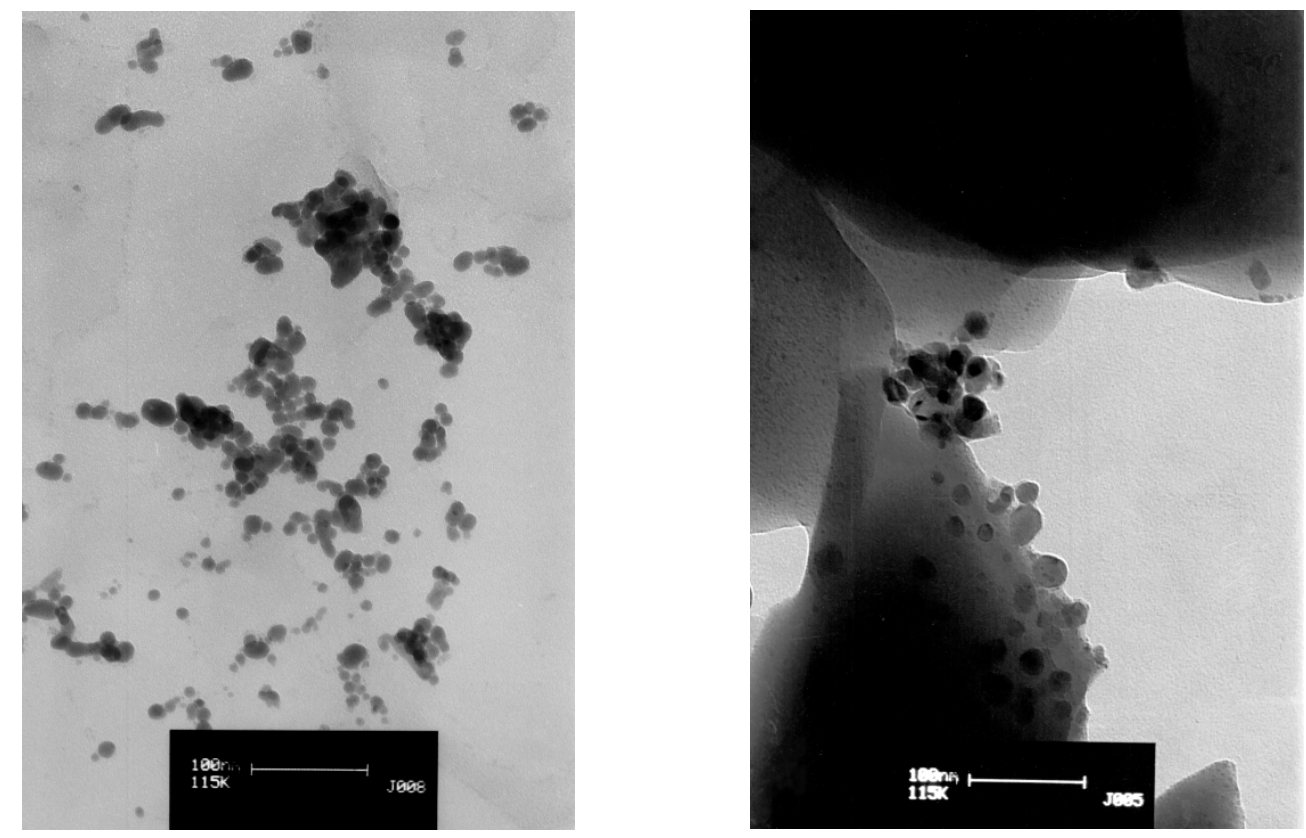

Figura 71 - Micrografias da amostra $B_{5}$ tratada a $270^{\circ} \mathrm{C}$ por duas horas (esquerda) e a $290^{\circ} \mathrm{C}$ por duas horas (direita).

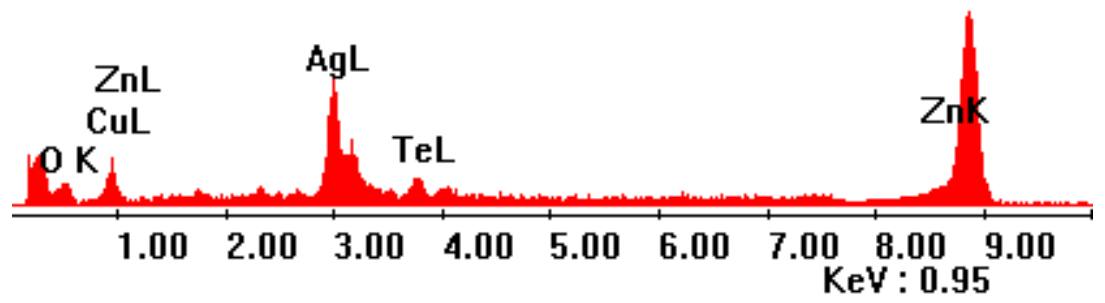

Figura 72 - Espectro de EDS da amostra $B_{5}$ tratada a $270^{\circ} \mathrm{C}$ por 2 horas.

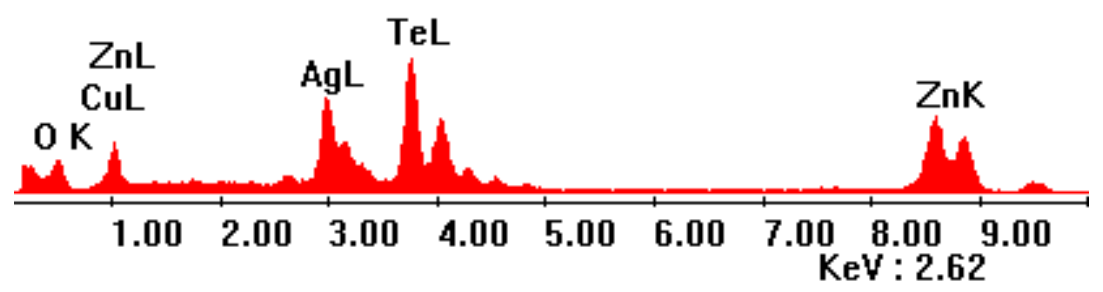

Figura 73 - Espectro de EDS da amostra $B_{5}$ tratada a $270^{\circ} \mathrm{C}$ por 2 horas. 


\section{4 Índice de refração linear (IRL) experimentais e discussões dos cálculos obtidos a partir dos resultados}

Os valores do índice de refração linear encontrados nos vidros teluritos à base de nióbio são maiores do que aos dos vidros fluoretos, silicatos e fosfatos, sendo próximos aos dos vidros calcogenetos; mas ligeiramente inferiores aos do vidro telurito puro e de outros vidros teluritos binários [1].

As medidas foram repetidas com diferentes polimentos, para comprimentos de onda entre $630 \mathrm{~nm}$ e $1540 \mathrm{~nm}$, e os resultados das amostras com melhor polimento seguem na tabela 18 e 19 em que verificamos que o índice de refração decresce com o aumento da freqüência. Este comportamento está de acordo com a teoria clássica e quântica (capítulo 2 e apêndice A.1) que nos diz que o índice de refração em relação à freqüência cresce para baixas freqüências (inferiores ao UV); próximo das freqüências de ressonância (UV), a dispersão torna-se anômala, ou seja, o índice de refração decresce com o aumento da freqüência.

Tabela 18 - Comprimento de onda versus índice de refração medido.

\begin{tabular}{|l|l|l|l|l|}
\hline$\lambda(\mathrm{nm})$ & $\mathrm{n}$ amostra $\mathrm{A}_{2}$ & $\mathrm{n}$ amostra $\mathrm{A}_{3}$ & $\mathrm{n}$ amostra $\mathrm{A}_{4}$ & $\mathrm{n}$ amostra $\mathrm{A}_{5}$ \\
\hline 632,8 & $2,1705 \pm 0,0018$ & $2,1701 \pm 0,0013$ & $2,1707 \pm 0,0005$ & $2,1732 \pm 0,0005$ \\
\hline 1305,4 & $2,1076 \pm 0,0017$ & $2,1073 \pm 0,0008$ & $2,1073 \pm 0,0005$ & $2,1103 \pm 0,0005$ \\
\hline 1536 & $2,1006 \pm 0,0015$ & $2,1003 \pm 0,0012$ & $2,1010 \pm 0,0005$ & $2,1034 \pm 0,0005$ \\
\hline
\end{tabular}

Tabela 19 - Comprimento de onda versus índice de refração medido.

\begin{tabular}{|l|l|l|l|}
\hline$\lambda(\mathrm{nm})$ & $\mathrm{n}$ amostra $\mathrm{B}_{2}$ & $\mathrm{n}$ amostra $\mathrm{B}_{3}$ & $\mathrm{n}$ amostra $\mathrm{C}_{1}$ \\
\hline 632,8 & $1,9119 \pm 0,0005$ & $1,9093 \pm 0,0005$ & $2,0461 \pm 0,0005$ \\
\hline 1305,4 & $1,8727 \pm 0,0005$ & $1,8712 \pm 0,0005$ & $1,9933 \pm 0,0005$ \\
\hline 1536 & $1,8681 \pm 0,0005$ & $1,8668 \pm 0,0005$ & $1,9874 \pm 0,0005$ \\
\hline
\end{tabular}


O índice de refração linear no comprimento de onda de $632,8 \mathrm{~nm}$ para as amostras $A_{2}, A_{3}, A_{4}$ e $A_{5}$ vale respectivamente 2,1705 $\pm 0,0018,2,1701 \pm 0,0013$, $2,1707 \pm 0,0005,2,1732 \pm 0,0005$; demonstrando que não é sensível à adição de pequenas quantidades de prata. Nasu e colaboradores [2] obteve 2,18 no mesmo comprimento de onda, para a amostra $10 \mathrm{Nb}_{2} \mathrm{O}_{5}-10 \mathrm{TiO}_{2}-80 \mathrm{TeO}_{2}$. Isto ocorre porque esse vidro apresenta maior quantidade de metais pesados, o que contribui para um aumento no índice de refração linear. Já as amostras da série $B$ apresentaram o índice de refração linear menor devido justamente à troca do elemento pesado $\left(\mathrm{Nb}_{2} \mathrm{O}_{5}\right)$ por $\mathrm{ZnO}$.

Comparando os resultados de Kim e colaboradores [3] das matrizes vítreas $\left(10 \mathrm{Nb}_{2} \mathrm{O}_{5} .90 \mathrm{TeO}_{2}\right) \mathrm{mol} \%$ e $\left(20 \mathrm{Nb}_{2} \mathrm{O}_{5} .80 \mathrm{TeO}_{2}\right) \mathrm{mol} \%$ para o comprimento de onda de $633 \mathrm{~nm}$ encontramos os índices de refração de 2,172 e 2,182, o que concorda com os valores encontrados para a série $A$.

Nas amostras da série $B$ a adição de prata evidenciou um sensível aumento do índice de refração linear (tabela 19) entre as amostras $B_{2}$ e $B_{3}$. Não foi possível medir o índice de refração da amostra $B_{5}$.

A amostra $C_{1}$ apresentou um índice de refração de 2,0461 $\pm 0,0005$ no comprimento de onda de $632,8 \mathrm{~nm}$, sendo este valor mais elevado comparado a amostra $\mathrm{B}_{3}$ para o mesmo comprimento de onda. Isto ocorreu devido a adição de $\mathrm{TeO}_{2}$ em substituição ao $\mathrm{ZnO}$.

Os índices de refração ordinário das amostras $A_{1}, A_{2}, A_{3}, A_{4}, A_{5}, B_{2}, B_{3}$ e $C_{1}$ medidos para os comprimentos de onda de 632,8, 1305,4 e $1536 \mathrm{~nm}$ diferem entre si devido à dispersão, cujo comportamento foi explicado por um número de modelos, tais como as equações de dispersão e absorção de Kramers-Krönig, modelo de Drude-Lorentz, aproximação de Cauchy e Sellmeier. Após efetuarmos os ajustes utilizando estes vários modelos verificamos que o de Sellmeier apresentou os resultados dos parâmetros mais consistentes com a literatura, como o número de Abbé $v_{\mathrm{d}}$ e o índice de refração não linear $n_{2}$, calculado a partir $v_{d}$.

A equação de Sellmeier é dada pela expressão:

$$
n(\lambda)=\left(1+\sum_{j} \frac{S_{j} \lambda^{2}}{\lambda^{2}-M_{j}}\right)^{\frac{1}{2}},
$$

em que são $\mathrm{S}$ e $\mathrm{M}$ os coeficientes de Sellmeier. 
Para estimar o valor do índice de refração em determinados comprimentos de onda não disponíveis foi utilizada a equação 4.4.1. Os resultados seguem nas tabelas 20 e 21.

Tabela 20 - Resultados do índice de refração linear calculados por meio da equação de Sellmeier.

\begin{tabular}{|l|l|l|l|l|}
\hline$\lambda(\mathrm{nm})$ & $\mathrm{n}$ amostra $\mathrm{A}_{2}$ & $\mathrm{n}$ amostra $\mathrm{A}_{3}$ & $\mathrm{n}$ amostra $\mathrm{A}_{4}$ & $\mathrm{n}$ amostra $\mathrm{A}_{5}$ \\
\hline 486,1 & $2,2370 \pm 0,0006$ & $2,2365 \pm 0,0006$ & $2,2370 \pm 0,0005$ & $2,2396 \pm 0,0006$ \\
\hline 532 & $2,2092 \pm 0,0006$ & $2,2088 \pm 0,0006$ & $2,2093 \pm 0,0005$ & $2,2119 \pm 0,0006$ \\
\hline 587,6 & $2,1851 \pm 0,0006$ & $2,1847 \pm 0,0006$ & $2,1853 \pm 0,0005$ & $2,1877 \pm 0,0006$ \\
\hline 656,3 & $2,1642 \pm 0,0006$ & $2,1638 \pm 0,0006$ & $2,1644 \pm 0,0005$ & $2,1669 \pm 0,0006$ \\
\hline 1064 & $2,1153 \pm 0,0006$ & $2,1150 \pm 0,0006$ & $2,1157 \pm 0,0005$ & $2,1181 \pm 0,0006$ \\
\hline
\end{tabular}

Tabela 21 - Resultados do índice de refração linear calculados por meio da equação de Sellmeier.

\begin{tabular}{|l|l|l|l|}
\hline$\lambda(\mathrm{nm})$ & $\mathrm{n}$ amostra $\mathrm{B}_{2}$ & $\mathrm{n}$ amostra $\mathrm{B}_{3}$ & $\mathrm{n}$ amostra $\mathrm{C}_{1}$ \\
\hline 486,1 & $1,9523 \pm 0,0006$ & $1,9485 \pm 0,0005$ & $2,1043 \pm 0,0006$ \\
\hline 532 & $1,9356 \pm 0,0006$ & $1,9323 \pm 0,0005$ & $2,0807 \pm 0,0006$ \\
\hline 587,6 & $1,9209 \pm 0,0006$ & $1,9181 \pm 0,0005$ & $2,0602 \pm 0,0006$ \\
\hline 656,3 & $1,9080 \pm 0,0006$ & $1,9056 \pm 0,0005$ & $2,0423 \pm 0,0006$ \\
\hline 1064 & $1,8775 \pm 0,0006$ & $1,8759 \pm 0,0005$ & $2,0005 \pm 0,0006$ \\
\hline
\end{tabular}

Com a finalidade de obter alguns parâmetros físicos como energia média do oscilador (equação (2.2.1.18)), energia de dispersão (equação (2.2.1.19)), constante dielétrica (equação (2.2.1.21)) e susceptibilidade linear foi realizado um ajuste linear a partir dos dados experimentais, utilizando o método de Wemple [4]. As equações com os respectivos ajustes e as grandezas seguem na tabela 22 e 23. 
Tabela 22 - Cálculo de $E_{0}$ e $E_{d}$ utilizando o método de Wemple.

\begin{tabular}{|c|c|c|c|c|c|c|}
\hline Amostra & Equação & \multicolumn{3}{|c|}{$\lambda(\mathrm{nm}), \mathrm{X}(\mathrm{eV}), \mathrm{n}_{\text {cal }}$} & $\mathrm{E}_{0}(\mathrm{eV})$ & $\mathrm{E}_{\mathrm{d}}(\mathrm{eV})$ \\
\hline \multirow{6}{*}{$\mathrm{A}_{2}$} & \multirow[t]{6}{*}{$Y=-0,0073 X+0,2974$} & $\lambda(\mathrm{nm})$ & $\mathrm{X}=\mathrm{E}^{2}$ & $\mathrm{n}_{\text {cal }}$ & \multirow[t]{6}{*}{$6,38 \pm 0,08$} & \multirow[t]{6}{*}{$21,46 \pm 0,28$} \\
\hline & & 632,8 & 3,8400 & $2,1708 \pm$ & & \\
\hline & & & & 0,0029 & & \\
\hline & & 1305,4 & 0,9023 & $2,1068 \pm$ & & \\
\hline & & & & 0,0013 & & \\
\hline & & 1536,0 & 0,6517 & $\begin{array}{l}2,1017 \pm \\
0,0013\end{array}$ & & \\
\hline \multirow[t]{6}{*}{$\mathrm{A}_{3}$} & \multirow[t]{6}{*}{$Y=-0,0072 X+0,2975$} & $\lambda(\mathrm{nm})$ & $\mathrm{X}=\mathrm{E}^{2}$ & $\mathrm{n}_{\text {cal }}$ & \multirow[t]{6}{*}{$6,43 \pm 0,09$} & \multirow[t]{6}{*}{$21,61 \pm 0,29$} \\
\hline & & 632,8 & 3,8400 & $2,1693 \pm$ & & \\
\hline & & & & 0,0027 & & \\
\hline & & 1305,4 & 0,9023 & $2,1063 \pm$ & & \\
\hline & & & & 0,0013 & & \\
\hline & & 1536,0 & 0,6517 & $\begin{array}{l}2,1012 \pm \\
0,0013\end{array}$ & & \\
\hline \multirow[t]{6}{*}{$\mathrm{A}_{4}$} & \multirow[t]{6}{*}{$Y=-0,0073 X+0,2974$} & $\lambda(\mathrm{nm})$ & $\mathrm{X}=\mathrm{E}^{2}$ & $\mathrm{n}_{\text {cal }}$ & \multirow[t]{6}{*}{$6,38 \pm 0,05$} & \multirow[t]{6}{*}{$21,46 \pm 0,18$} \\
\hline & & 632,8 & 3,8400 & $2,1708 \pm$ & & \\
\hline & & & & 0,0017 & & \\
\hline & & 1305,4 & 0,9023 & $2,1068 \pm$ & & \\
\hline & & & & 0,0008 & & \\
\hline & & 1536,0 & 0,6517 & $\begin{array}{l}2,1017 \pm \\
0,0008\end{array}$ & & \\
\hline \multirow[t]{4}{*}{$A_{5}$} & \multirow[t]{4}{*}{$Y=-0,0072 X+0,2964$} & $\lambda(\mathrm{nm})$ & $\mathrm{X}=\mathrm{E}^{2}$ & $\mathrm{n}_{\mathrm{cal}}$ & \multirow[t]{4}{*}{$6,42 \pm 0,19$} & \multirow[t]{4}{*}{$21,7 \pm 0,6$} \\
\hline & & 632,8 & 3,8400 & $\begin{array}{l}2,1727 \pm \\
0,0027\end{array}$ & & \\
\hline & & 1305,4 & 0,9023 & $\begin{array}{l}2,1094 \pm \\
0,0013\end{array}$ & & \\
\hline & & 1536,0 & 0,6517 & $\begin{array}{l}2,1043 \pm \\
0,0012\end{array}$ & & \\
\hline \multirow[t]{4}{*}{$\mathrm{B}_{2}$} & \multirow[t]{4}{*}{$Y=-0,0077 X+0,4063$} & $\lambda(\mathrm{nm})$ & $\mathrm{X}=\mathrm{E}^{2}$ & $\mathrm{n}_{\text {cal }}$ & \multirow[t]{4}{*}{$7,26 \pm 0,11$} & \multirow[t]{4}{*}{$17,88 \pm 0,27$} \\
\hline & & 632,8 & 3,8400 & $\begin{array}{l}1,9117 \pm \\
0,0019\end{array}$ & & \\
\hline & & 1305,4 & 0,9023 & $\begin{array}{l}1,8719 \pm \\
0,0010\end{array}$ & & \\
\hline & & 1536,0 & 0,6517 & $\begin{array}{l}1,8687 \pm \\
0,0009\end{array}$ & & \\
\hline
\end{tabular}




\begin{tabular}{|c|c|c|c|c|c|c|}
\hline \multirow[t]{7}{*}{$\mathrm{B}_{3}$} & \multirow[t]{7}{*}{$Y=-0,0075 X+0,407$} & $\lambda(\mathrm{nm})$ & $X=E^{2}$ & $\mathrm{n}_{\text {cal }}$ & \multirow[t]{7}{*}{$7,37 \pm 0,10$} & \multirow[t]{7}{*}{$18,10 \pm 0,26$} \\
\hline & & \multirow[t]{2}{*}{632,8} & 3,8400 & $1,9089 \pm$ & & \\
\hline & & & & 0,0017 & & \\
\hline & & \multirow[t]{2}{*}{1305,4} & 0,9023 & $1,8704 \pm$ & & \\
\hline & & & & 0,0009 & & \\
\hline & & \multirow[t]{2}{*}{1536,0} & 0,6517 & $1,8673 \pm$ & & \\
\hline & & & & 0,0008 & & \\
\hline \multirow[t]{7}{*}{$\mathrm{C}_{1}$} & \multirow[t]{7}{*}{$Y=-0,0078 X+0,3438$} & $\lambda(\mathrm{nm})$ & $X=E^{2}$ & $\mathrm{n}_{\text {cal }}$ & \multirow[t]{7}{*}{$6,64 \pm 0,09$} & \multirow[t]{7}{*}{$19,3 \pm 0,3$} \\
\hline & & 632,8 & 3,8400 & $2,0460 \pm$ & & \\
\hline & & & & 0,0009 & & \\
\hline & & \multirow[t]{2}{*}{1305,4} & 0,9023 & $1,9923 \pm$ & & \\
\hline & & & & 0,0010 & & \\
\hline & & \multirow[t]{2}{*}{1536,0} & 0,6517 & $1,9874 \pm$ & & \\
\hline & & & & 0,0008 & & \\
\hline
\end{tabular}

Kim e colaboradores [18] calculou $\mathrm{E}_{0}$ e $\mathrm{E}_{\mathrm{d}}$ para o vidro $\mathrm{TeO}_{2}$ e encontrou um valor de 6,85 eV e 23,7 eV, estes valores estão mais próximos dos vidros da série $A$, pois estes vidros apresentam menor quantidade de outros elementos presentes em sua composição. Wemple [4] reporta o valor do $\kappa_{1}$ do cristal de $\mathrm{TeO}_{2}$ como 4,87, cujo resultado é próximo dos resultados da série $A$.

Tabela 23 - Constante dielétrica e susceptibilidade linear.

\begin{tabular}{|l|c|c|}
\hline Amostra & \multicolumn{1}{|c|}{$\kappa_{1}$} & \multicolumn{1}{c|}{$\chi$} \\
\hline$A_{2}$ & $4,36 \pm 0,06$ & $0,267 \pm 0,005$ \\
\hline$A_{3}$ & $4,36 \pm 0,06$ & $0,267 \pm 0,005$ \\
\hline$A_{4}$ & $4,36 \pm 0,04$ & $0,267 \pm 0,003$ \\
\hline$A_{5}$ & $4,37 \pm 0,14$ & $0,268 \pm 0,011$ \\
\hline$B_{2}$ & $3,46 \pm 0,05$ & $0,195 \pm 0,004$ \\
\hline$B_{3}$ & $3,46 \pm 0,05$ & $0,195 \pm 0,004$ \\
\hline$C_{1}$ & $3,91 \pm 0,06$ & $0,232 \pm 0,003$ \\
\hline
\end{tabular}




\subsubsection{Referências}

[1] Prakash, G. V.; Rao, D. N.; Bhatnagnar, A. K. Linear optical properties of niobiumbased tellurite glasses. Solid State Comm., v. 119, p. 39-44, 2001.

[2] Nasu, H.; Matsuoka, J.; Kamiya K. Second - and third-order optical non-linearity of homogeneous glasses. J. J. Non-Cryst. Solids, v. 178, p. 23-30, 1994.

[3] Kim, S. H.; Yoko, T. Nonlinear optical properties of $\mathrm{TeO}_{2}$-based glasses: $\mathrm{MO}_{\mathrm{X}^{-}}$ $\mathrm{TeO}_{2}$ (M=Sc, Ti, V, Nb, Mo, Ta, and W) binary glasses. J. Am. Ceram. Soc., v. 78, n. 4, p.1061-1065, 1995.

[4] Wemple, S.H. Optical Oscillator Strengths and excitation energies in solids, liquids, and molecules. J. Chem. Phys., v. 67, p. 2151-2168, 1977.

\section{5 Índice de refração não linear experimental e calculado}

\subsection{1 Índice de refração não linear obtido por meio da técnica de Varredura Z (VZ)}

Os resultados da VZ foram obtidos em colaboração com a professora Dra. Sarah I. P. M. Do Nascimento Alves da Universidade Federal de São Paulo, campus Diadema e do professor Dr. Antonio Figueiredo Neto do Laboratório de Fluidos Complexos da Universidade de São Paulo, campus São Paulo.

Uma das formas para avaliar se o material estudado terá aplicações promissoras em fotônica, por exemplo, como para produção de fibras é necessário determinar alguns parâmetros ópticos como o índice de refração não linear. Para as

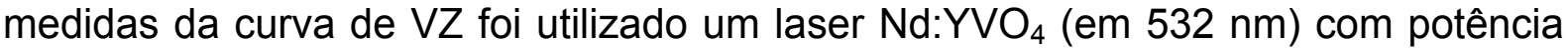
incidente de $(125,3 \pm 0,2) \mathrm{mW}$ e resolução temporal (com o uso de um chopper $\mathrm{f}=17 \mathrm{~Hz}$ ) de $30 \mathrm{~ms}$.

Por meio desta técnica foram estudadas as amostras $A_{2}, A_{3}, A_{4}$ e $A_{5} . \mathrm{Na}$ tabela 24 seguem os resultados do cálculo do $\mathrm{n}_{2}$ térmico obtidos por meio dos modelos de Sheik-Bahae sem absorção (equação 2.3.6.10) e com absorção (equação 2.3.6.15), lente térmica (equação 2.3.6.20) e lente térmica aberrante (equação 2.3.6.20). 
Nas figuras 74, 75, 76 e 77 seguem as curvas $V Z$ das amostras $A_{2}, A_{3}, A_{4}$ e $A_{5}$ com os ajustes de Sheik-Bahae sem (SBSA) e com absorção (SBCA), lente térmica (LT) e lente térmica aberrante (LTA).

Inicialmente, para a amostra $A_{2}$ (figura 74) com uma pequena adição de $\mathrm{AgNO}_{3}$ (0,5 mol\%), ocorre um aumento do vale que segue até $2 \mathrm{~mol} \%$ (figura 76), em contrapartida com a amostra $A_{5}$ com $5 \mathrm{~mol} \%$ (figura 77), o espectro tornou-se extremamente assimétrico resultando em uma curva com somente um pico, sendo o vale praticamente extinto. Para as amostras $A_{2}, A_{3}$ e $A_{4} O$ modelo de Sheik-Bahae com absorção revelou ser o melhor ajuste (figuras 74, 75 e 76), para a amostra $A_{5}$ nenhum dos modelos descritos acima ajustados concordou com os resultados experimentais. A partir destes resultados obtidos cogitamos a possibilidade da coesistência de efeitos térmicos e eletrônicos nestas medidas.

Nas figuras 74 a 78, observamos que o $n_{2}$ do vidro da série A é positivo (a amostra comporta-se como uma lente delgada convergente) e concorda com os trabalhos de Dutreilh-Colas e colaboradores [1] para o vidro $85 \mathrm{TeO}_{2} \cdot 15 \mathrm{NbO}_{2-5}$. Nas amostras da série $\mathrm{A}$, para pequenas dopagens de prata (até $2 \mathrm{~mol} \%$ de $\mathrm{AgNO}_{3}$ ), os resultados da VZ reproduzem o comportamento das amostras de Zhao et al [2], compostas por $\left(80 \mathrm{TeO}_{2}-2 \mathrm{Nb}_{2} \mathrm{O}_{5}\right)$ mol\% e $1 \%$ porcentagem peso de $\mathrm{AgCl}$, apresentando um valor menor para as amostras sem dopagem.

Na figura 78 temos o espectro da amostra $A_{5}$ ajustado pela função descrita por Lara (equação 2.3.6.21). Para este modelo foi possível somente ajustar esta amostra e na tabela 25 seguem-se os parâmetros obtidos. Este modelo não leva em conta efeitos de absorção não linear para descrever a decomposição gaussiana do feixe ou para incluir termos referentes à aberração das lentes. Entretanto, esta expressão pode ser utilizada como primeira aproximação para explicar resultados experimentais no qual não é conhecido o conceito de lente foto induzida. Outra observação interessante é de que o melhor ajuste ocorreu para $\mathrm{m} \neq \mathrm{N}$.

Em virtude dos modelos citados não se ajustarem a todos os valores experimentais propomos uma adaptação do modelo de Sumi [3].

$\mathrm{Na}$ figura 79 estão representados dois potenciais adiabáticos, inicialmente desocupados: a) o nível superior que corresponde ao fundo da $\mathrm{BC}$, para o qual foi excitado um foto-elétron, via irradiação ionizante, promovido a partir do nível 
ocupado mais elevado ou "higher occupied molecular orbital" (HOMO) da BV, pertencente a um orbital $2 \mathrm{p}$ do $\mathrm{NBO}^{-}$e b) o orbital molecular "low unoccupied molecular orbital" (LUMO) em função da coordenada $Q$ da distorção da rede em torno dos centros envolvidos no processo da ionização: $\mathrm{N} \mathrm{NBO}^{-}$e o cátion interagente $\mathrm{Ag}^{+}$.

Tabela 24 - Valores de $\mathrm{n}_{2}$ calculados a partir dos modelos de SB sem (SBSA) e com absorção (SBCA), LT e LT aberrante (LTA).

\begin{tabular}{|l|l|l|l|l|l|}
\hline Amostra & $n_{2} \operatorname{SBSA}\left(\frac{\mathrm{m}^{2}}{\mathrm{w}}\right)$ & $\mathrm{n}_{2} \operatorname{SBCA}\left(\frac{\mathrm{m}^{2}}{\mathrm{w}}\right)$ & $\beta \mathrm{SBCA}\left(\frac{\mathrm{m}}{\mathrm{w}}\right)$ & $\mathrm{n}_{2} \mathrm{LT}\left(\frac{\mathrm{m}^{2}}{\mathrm{w}}\right)$ & $\mathrm{n}_{2} \mathrm{LTA}\left(\frac{\mathrm{m}^{2}}{\mathrm{w}}\right)$ \\
\hline $\mathrm{A}_{2}$ & $6,37 \times 10^{-13}$ & $6,30 \times 10^{-13}$ & $6,26 \times 10^{-7}$ & $1,55 \times 10^{-12}$ & $1,10 \times 10^{-13}$ \\
\hline $\mathrm{A}_{3}$ & $3,11 \times 10^{-16}$ & $3,10 \times 10^{-16}$ & $8,53 \times 10^{-11}$ & $8,65 \times 10^{-16}$ & $6,00 \times 10^{-17}$ \\
\hline $\mathrm{A}_{4}$ & $4,61 \times 10^{-13}$ & $4,59 \times 10^{-13}$ & $7,44 \times 10^{-7}$ & $1,10 \times 10^{-12}$ & $9,60 \times 10^{-14}$ \\
\hline $\mathrm{A}_{5}$ & $1,11 \times 10^{-12}$ & $9,03 \times 10^{-13}$ & $4,84 \times 10^{-6}$ & $2,36 \times 10^{-12}$ & $1,28 \times 10^{-14}$ \\
\hline
\end{tabular}

Tabela 25 - Parâmetros obtidos no ajuste por Lara

\begin{tabular}{|l|l|}
\hline Grandeza & Valor obtido \\
\hline$\frac{Z_{c}}{2 F_{0 m}}$ & $0,914 \pm 0,008$ \\
\hline $\mathrm{m}$ & $0,714 \pm 0,007$ \\
\hline
\end{tabular}

Quando o elétron excitado para a BC com energia igual ou superior do ponto $R$ de encontro entre dois níveis $(Q=-\Delta p)$ estiver passando por uma relaxação vibracional, ao atingir o ponto $\mathrm{R}$, será capturado pelo orbital LUMO Ag com a energia $E_{d}+E_{f}$ disponível para ser toda fornecida ao sistema vibracional por meio da relaxação por multifônons, até atingir a base deste estado. Durante o tempo muito curto $\left(\leq 10^{-12} s\right)$ a rede vibra violentamente em torno do $\mathrm{NBO}$ e de $\mathrm{Ag}^{+}$e essa energia fornecida ao sistema vibracional, inicialmente acumulada na coordenada $Q$, é chamada "phonon kick" (pontapé de fônons). Além desta energia ser transformada em calor e também realçar várias reações, tais como o deslocamento de um átomo de sua posição, captura coerente de elétron e buraco e outros [3, 4], podendo ocasionar instabilidades locais de ordem eletrostática, vibracional e estrutural. 
Assumindo que o fenômeno desencadeado pelo "phonon kick" realçou a reação de captura coerente de elétron e buraco, assumimos que o buraco anteriormente deixado na BV pelo foto-elétron previamente excitado, é simultaneamente capturado no ponto $\mathrm{D}$, conforme ilustrado na figura 79 , dando origem a um éxciton fortemente acoplado à rede e que decai rapidamente fornecendo a sua energia à rede até que ocorra a recombinação entre o elétron e o buraco sem a emissão de um fóton, este é chamado éxciton de Frenkel porque alcança somente os primeiros vizinhos.

Lonzaga et al [5] sugeriram que, sob o efeito de irradiação, ocorrem excitações que ocasionam o aparecimento de éxcitons confinados nos canais contendo pares de elementos alcalinos e NBO's. Os NBO's em vidros alcalinos mesmo às baixas concentrações ocorrem em aglomerados [5], fato que foi confirmado por diversos autores, tendo por base estudos de dinâmica molecular, EPR, XRD e difração de nêutrons. Em vidros silicatos de sódio os NBO's permanecem localizados no topo da banda de valência, enquanto que os estados excitados vazios dos íons alcalinos encontram-se no fundo da banda de condução [6], sendo válida esta premissa devido ao fato de ambos os vidros apresentarem NBO's tão logo seja adicionado um óxido alcalino à sua estrutura.

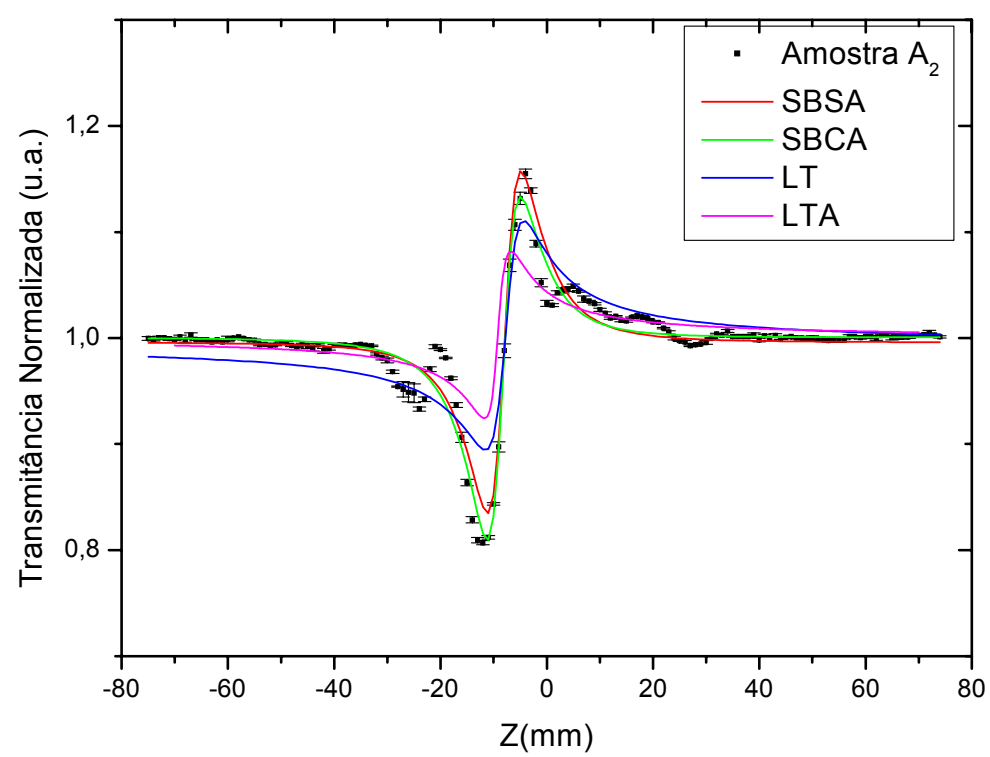

Figura 74 - Curvas VZ com ajuste por SB sem absorção, SB com absorção, LT e LT aberrante para a amostra $A_{2}$, contendo 0,5 mol\% de $\mathrm{AgNO}_{3}$. 


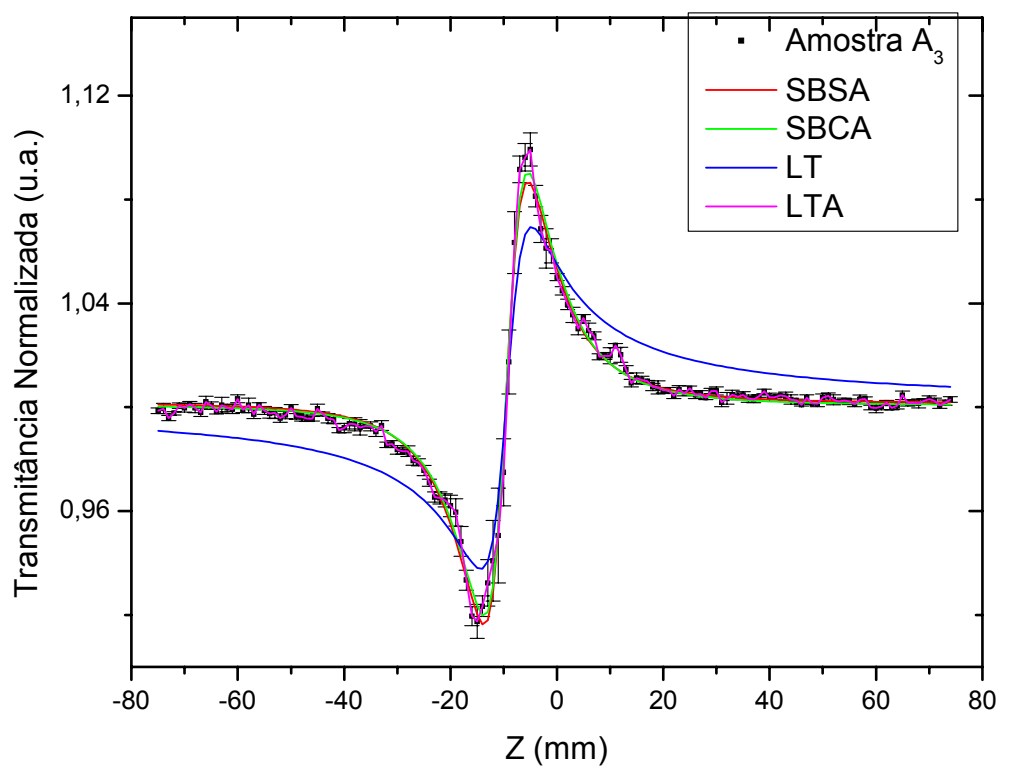

Figura 75 - Curvas VZ com ajuste por SB sem absorção, SB com absorção, $L T$ e $L T$ aberrante para a amostra $A_{3}$, isenta de prata.

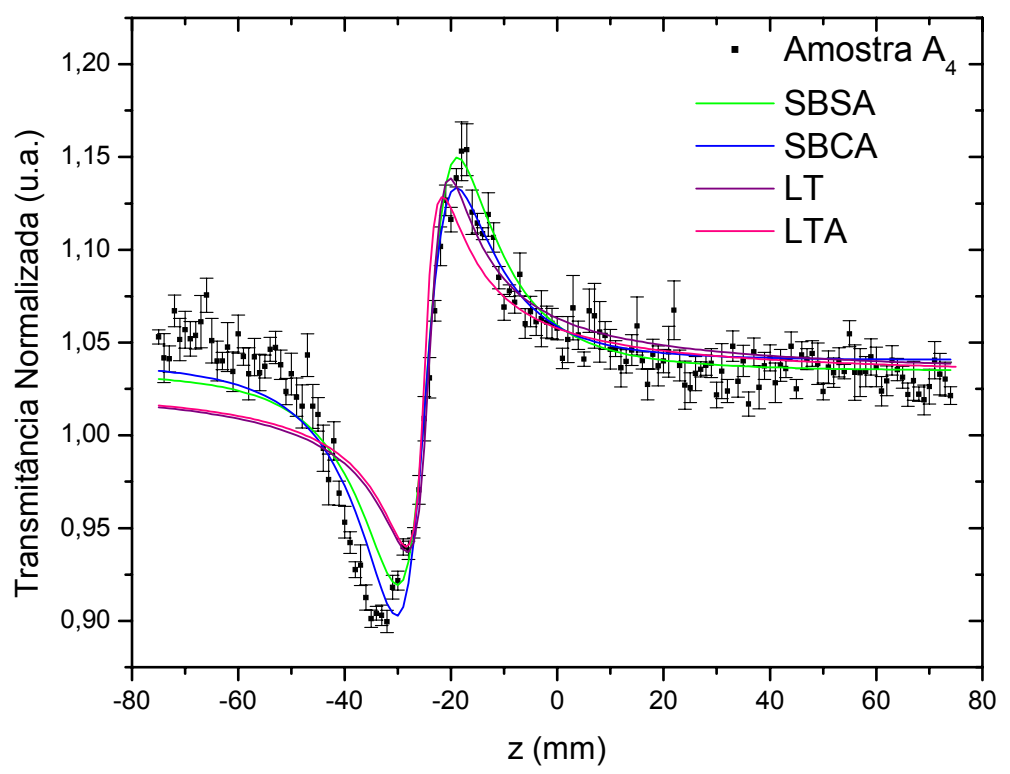

Figura 76 - Curvas VZ com ajuste por SB sem absorção, SB com absorção, $L T$ e $L T$ aberrante para a amostra $A_{4}$, contendo 2,0 mol\% de $\mathrm{AgNO}_{3}$. 


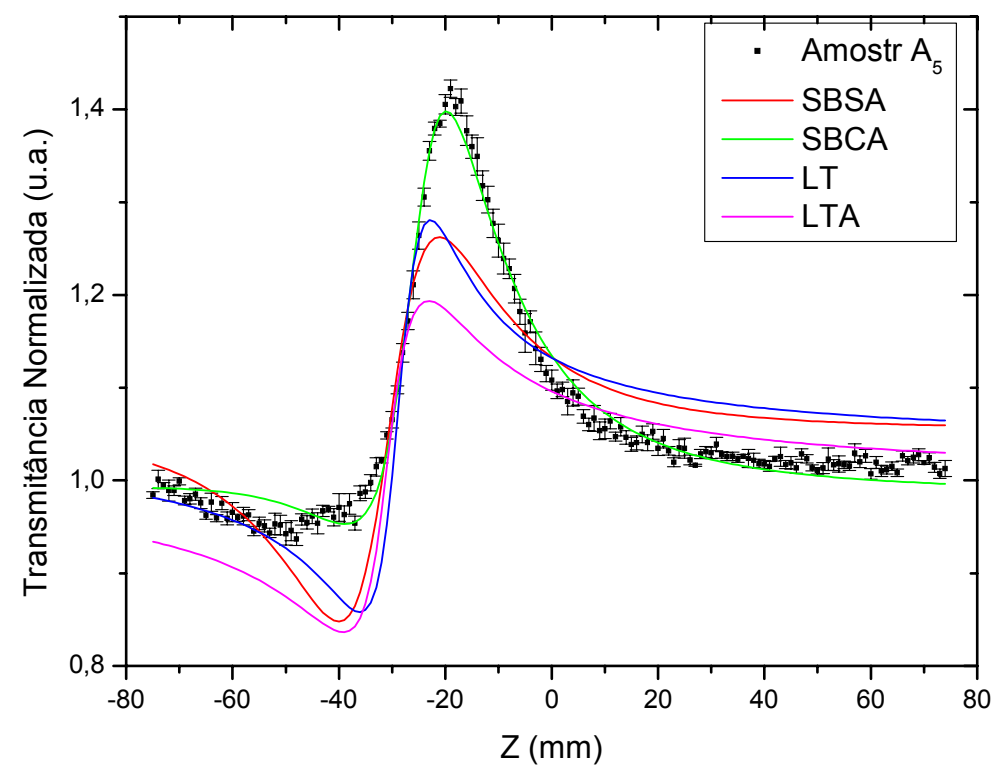

Figura 77 - Curvas VZ com ajuste por SB sem absorção, SB com absorção, $L T$ e $L T$ aberrante para a amostra $A_{5}$, contendo 5,0 mol\% de $\mathrm{AgNO}_{3}$.

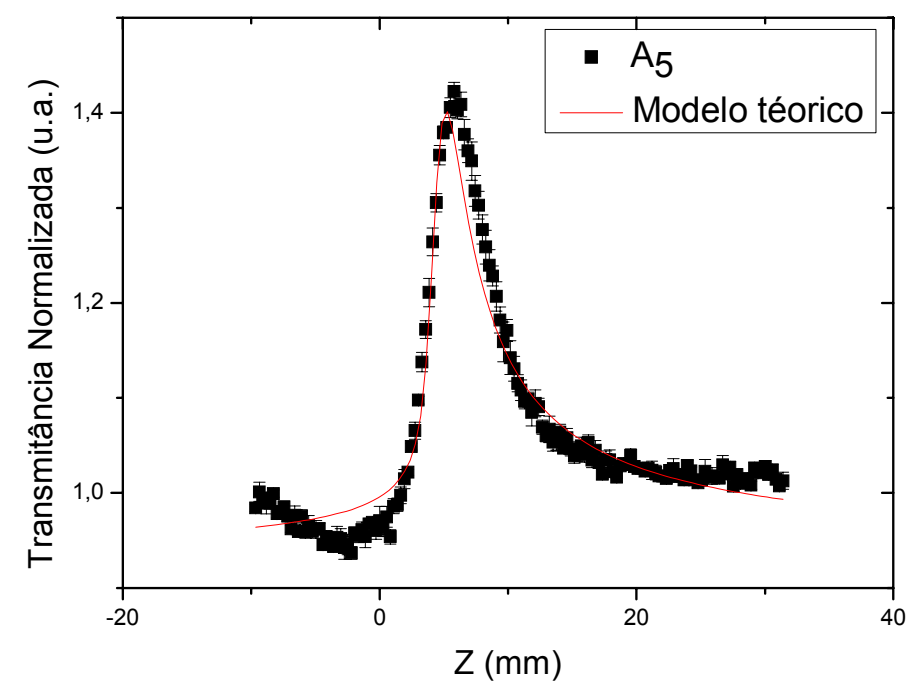

Figura 78 - Curvas VZ com ajuste pelo método de Lara para a amostra $A_{5}$, contendo $5,0 \mathrm{~mol} \%$ de $\mathrm{AgNO}_{3}$. 


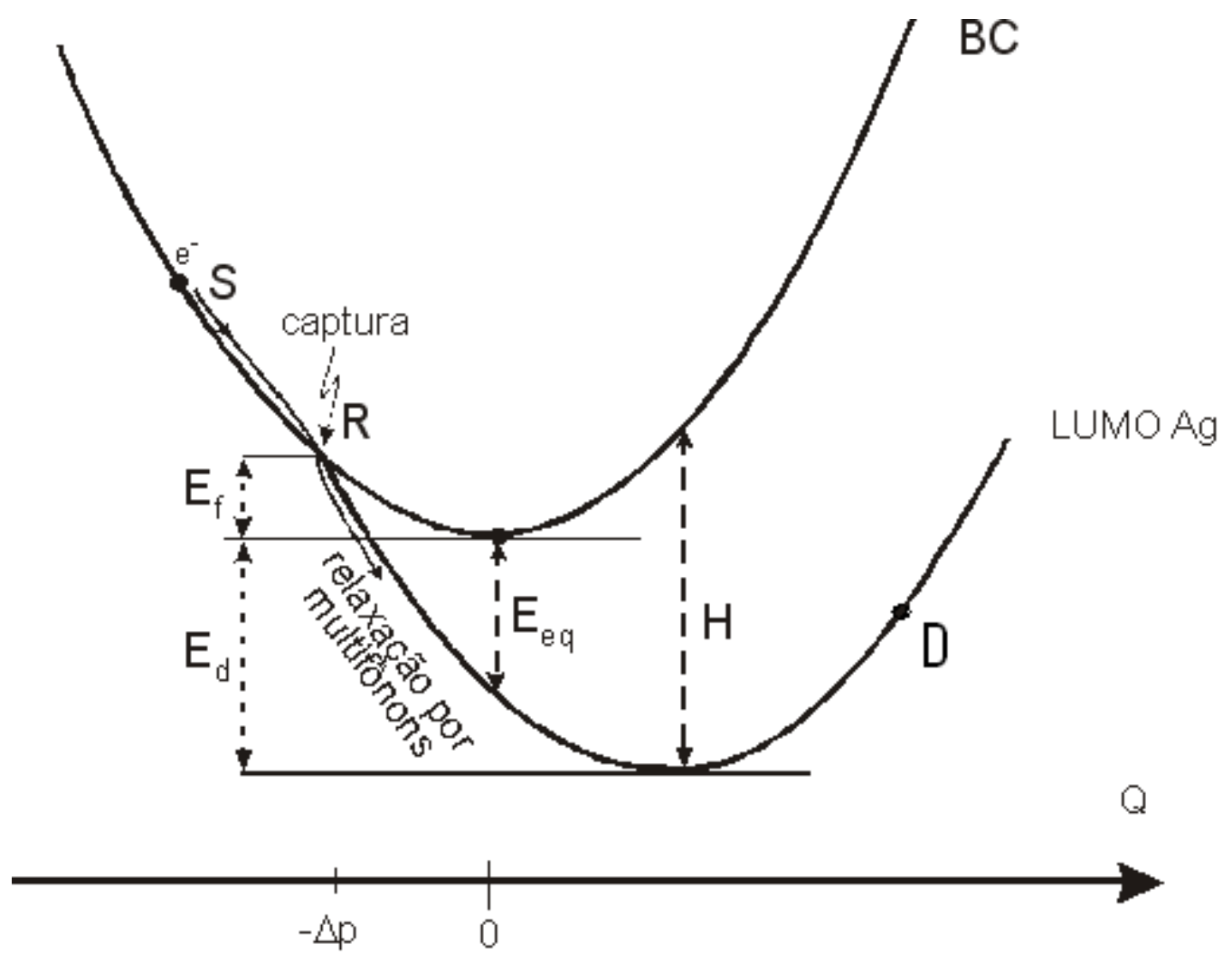

Figura 79 - Esquema que representa uma transição não-radiativa.

\subsection{2 Índice de refração não linear $\mathrm{n}_{2}$ calculado}

Com a finalidade de estimar o $\mathrm{n}_{2}$, calculamos o seu valor utilizando a expressão (2.1.4.1), (2.1.4.2) e os dados da tabela 20 e 21. Os valores seguem na tabela 26.

Adair e colaboradores [7] obtiveram os valores do $\mathrm{n}_{2}$ calculados por meio da equação 2.1.4.1 e medidos por meio da técnica de mistura de três ondas, respectivamente $\mathrm{n}_{2 \text { calc. }}=28 \times 10^{-13}$ esu e $\mathrm{n}_{2 \text { med. }}=23 \times 10^{-13}$ esu para $\circ$ vidro $\left(79 \mathrm{TeO}_{2} .20 \mathrm{Na}_{2} \mathrm{O} .1 \mathrm{Nd}_{2} \mathrm{O}_{3}\right) \mathrm{mol} \%$. Este resultado é próximo dos valores da série de amostras do tipo $B$, considerando o fato de compararmos diferentes composições.

Kim e colaboradores [8] obteve o número de Abbé de 28,5 para o vidro $\mathrm{TeO}_{2}$, que se aproxima dos valores calculados para as amostras da série B. 
Tabela 26 - Valores calculados do índice de refração não linear eletrônico $\mathrm{n}_{2}$ calculados.

\begin{tabular}{|l|l|l|}
\hline Amostra & $\begin{array}{l}\text { Número } \\
\text { de Abbé }\end{array}$ & $n_{2}\left(x 10^{-13}\right)$ esu \\
\hline$A_{2}$ & $16,29 \pm 0,19$ & $42,6 \pm 2,0$ \\
\hline$A_{3}$ & $16,30 \pm 0,19$ & $42,6 \pm 2,0$ \\
\hline$A_{4}$ & $16,33 \pm 0,16$ & $42,5 \pm 1,7$ \\
\hline$A_{5}$ & $16,35 \pm 0,19$ & $42,5 \pm 2,0$ \\
\hline$B_{2}$ & $20,78 \pm 0,40$ & $17 \pm 3$ \\
\hline$B_{3}$ & $21,38 \pm 0,35$ & $16,6 \pm 2,7$ \\
\hline$C_{1}$ & $17,13 \pm 0,23$ & $31,0 \pm 2,3$ \\
\hline
\end{tabular}

\subsubsection{Referências}

[1] Dutreilh-Colas, M.; Thomas, P.; Champarnaud-Mesjard, J. C. New $\mathrm{TeO}_{2}$ based glasses for nonlinear optical applications: study of the $\mathrm{Tl}_{2} \mathrm{O}-\mathrm{TeO}_{2}-\mathrm{Bi}_{2} \mathrm{O}_{3}, \mathrm{Tl}_{2} \mathrm{O}-$ $\mathrm{TeO}_{2}-\mathrm{PbO}$ and $\mathrm{Tl}_{2} \mathrm{O}-\mathrm{TeO}_{2}-\mathrm{Ga}_{2} \mathrm{O}_{3}$ systems. Phys. Chem. Glasses, v. 44, n. 5, p. 349-352, 2003.

[2] Zhao, Z.; Jia, T. ; Lin, J.; Wang, Z.; Sun, Z. Femtosecond non-resonant optical nonlinearity of silver chloride nanocrystal doped niobic tellurite glass. J. Phys. D Appl. Physics, v. 42, p. 1-6, 2009.

[3] Sumi, H. Nonradiative electron-hole recombination through deep centers in semiconductors. J. Lum., v. 40 \& 41, p. 76-79, 1988.

[4] Klinger, M. I. e colaboradores Soviet physics, Uspekhi, v. 28, p. 994, 1985.

[5] Lonzaga, J. B.; Avanesyan, S. M.; Langford, S. C.; Dickinson, J. T. Color center formation in soda-lime glass with femtosecond laser pulses. J. of Appl. Phys., v. 94, n. 7, p. 4332-4340, 2003.

[6] Murray, R. A.; Ching, W. Y. Electronic structure of sodium silicate glasses J. of Non-Cryst. Solids, v. 94, p. 144-159, 1987. 
[7] Kim, S. H.; Yoko, T.; Sakka, S. Linear and nonlinear optical properties of $\mathrm{TeO}_{2}$ glass. J. Am. Cerac. Soc., v. 76, n. 10, p. 2486-2490, 1993.

[8] Adair, R.; Chase, L. L.; Payne, S. A. Nonlinear refractive-index measurements of glasses using three-wave frequency mixing. J. Opt. Soc. Am. B, v. 4, n. 6, p. 875$881,1987$.

\subsection{Difração de raios-X (DRX)}

Através da figura 80 referente às amostras $A_{2}, A_{3}, A_{4}$ e $A_{5}$, sem a aplicação de tratamento térmico, observa-se que as difrações de $A_{2}, A_{3}, A_{4}$ e $A_{5}$ consistem essencialmente de estruturas amorfas, devido à ausência de picos estreitos que seriam característicos de eventuais estruturas cristalinas.

A figura 81 apresenta as amostras $B_{2}, B_{3}$ e $B_{5}$ sem recozimento e sem nenhum tratamento térmico posterior, respectivamente. Ambas apresentam um halo amorfo localizado em torno de 23 graus superposto ao halo mais intenso, centrado em 30 graus. Este resultado revelou que o semi-halo localizado à esquerda do espectro não é devido às nanopartículas de prata, já que a amostra sem nenhum dopante revelou o mesmo semi-halo. A amostra $B_{5}$ aparentemente apresenta pequenos picos sobrepostos à estrutura amorfa, não sendo possível diferenciá-los do ruído, pois apresentam a mesma intensidade.

Na figura 82 temos o DRX da amostra $C_{1}$, como nas amostras anteriores apresenta um halo amorfo localizado em torno de 22 graus superposto ao halo mais intenso, centrado em 29 graus.

$\mathrm{Na}$ figura 83 segue o espectro da amostra $B_{2}$ (sem recozimento) com um posterior tratamento térmico de 310 graus Celsius (mesma temperatura que revelou um pico nas medidas de $\mathrm{AO}$ ). Não foi observado nenhum pico de cristalização devido ao tratamento térmico. 


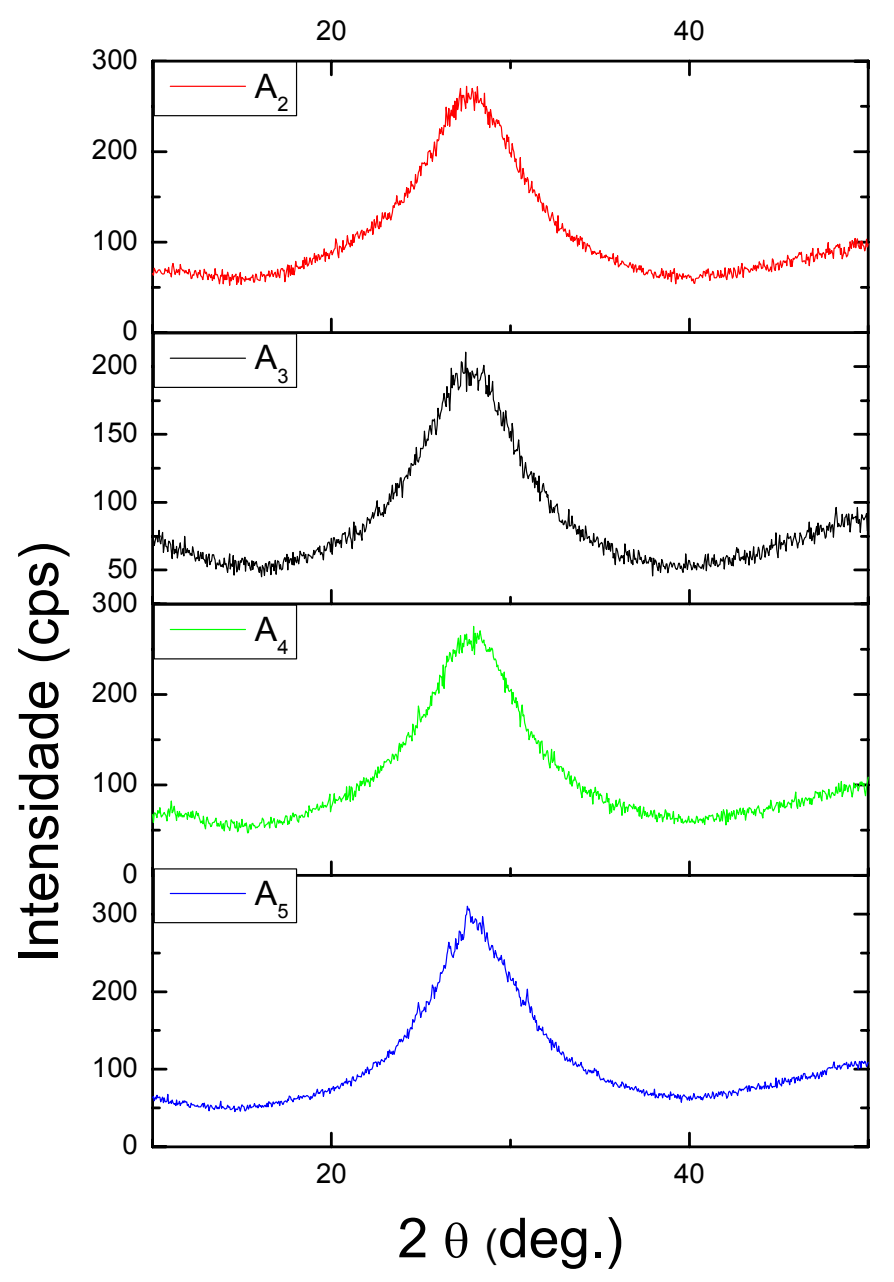

Figura 80 - Espectros de DRX das amostras dos vidros teluritos de nióbio sem tratamento térmico. 


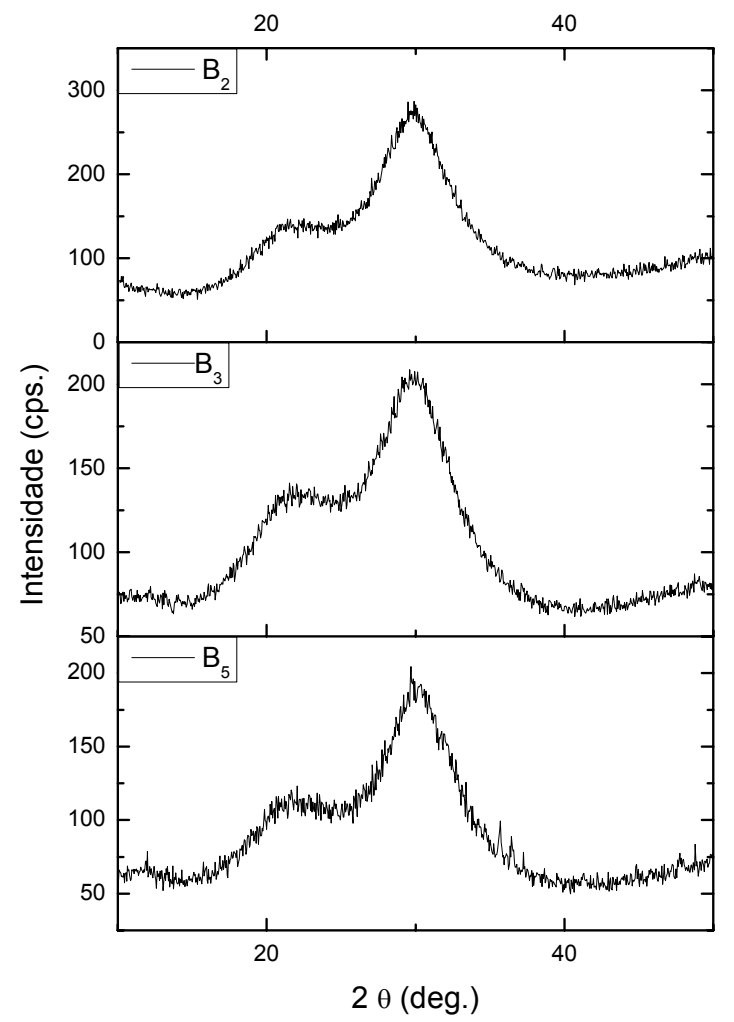

Figura 81 - Espectro de $D R X$ das amostras $B_{2}, B_{3}$ e $B_{5}$ sem tratamento térmico e sem recozimento, respectivamente.

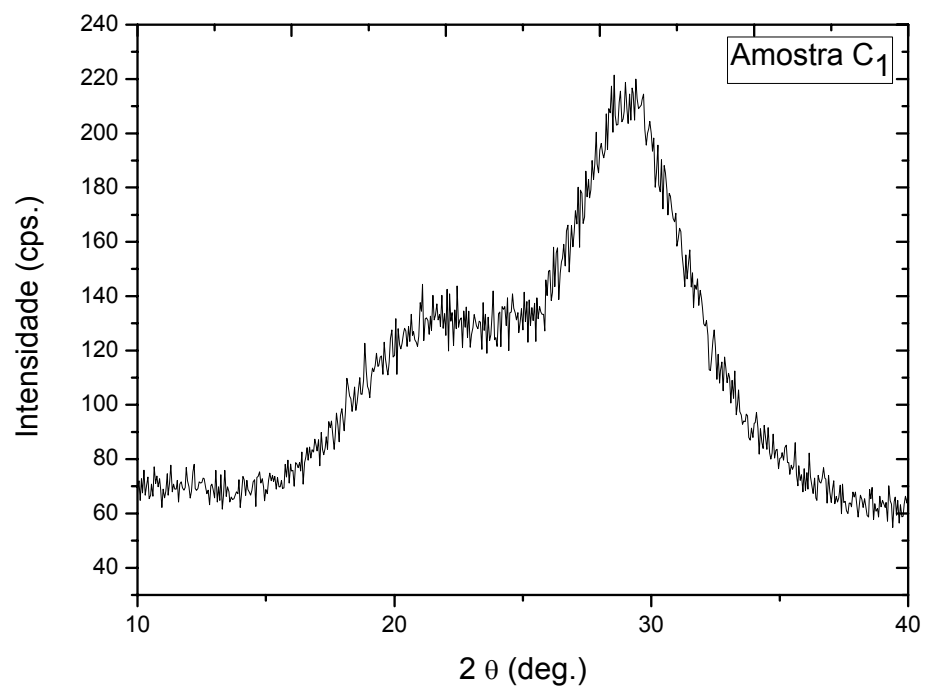

Figura 82 - Espectro de DRX das amostras $C_{1}$ sem tratamento térmico e sem recozimento. 


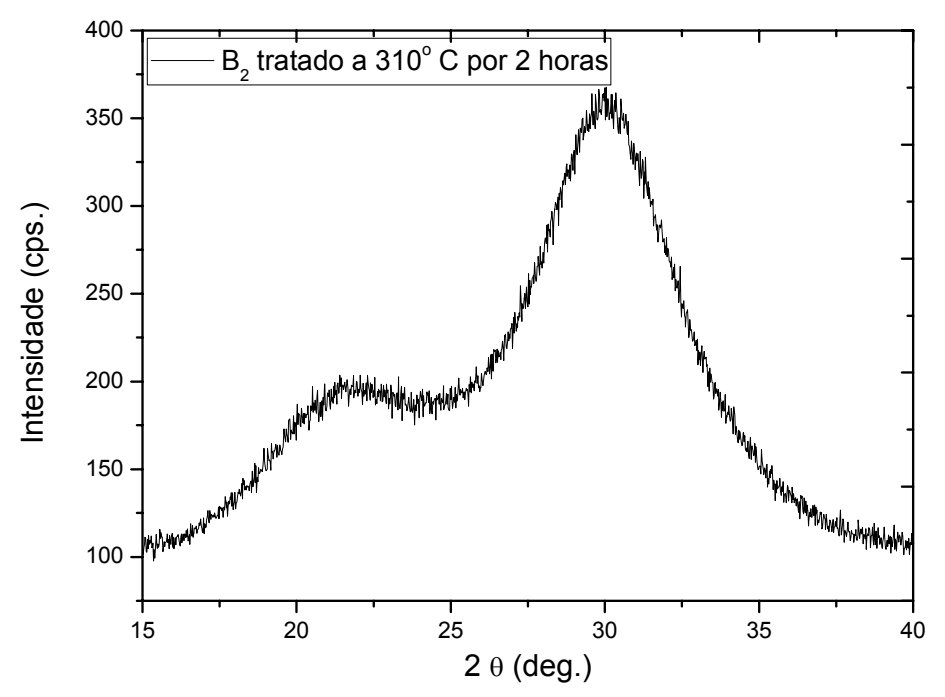

Figura 83 - Espectro de $D R X$ das amostras $B_{2}$ tratada termicamente a $310^{\circ} \mathrm{C}$ por 2 horas.

Com a finalidade de estudar o comportamento dos termogramas de ATD quanto às duas curvas de fusão resolvemos tratar termicamente a amostra $A_{3} \mathrm{em}$ diferentes temperaturas (todas tratadas durante 3 horas), a $550^{\circ} \mathrm{C}$ (antes do primeiro ponto de fusão), a $690^{\circ} \mathrm{C}$ (após o primeiro ponto de fusão) e a $750^{\circ} \mathrm{C}$ (no segundo ponto de fusão). Para as duas primeiras temperaturas verificamos que não existe mudança de fase cristalina na figura 84; o que ocorreu foi simplesmente o aumento da intensidade de alguns picos com a temperatura de tratamento térmico superior. $\mathrm{Na}$ figura 85 temos a identificação dos principais picos cristalográficos. Na figura 86 identificamos que na amostra tratada a $750^{\circ} \mathrm{C}$ houve uma diminuição acentuada de $\mathrm{TeO}_{2}$ nos picos identificados como "a", apresentando a prova experimental que o $\mathrm{TeO}_{2}$ pode ter sido volatizado.

$\mathrm{Na}$ figura 87 mostramos um exemplo prático da identificação dos picos cristalográficos, da amostra $A_{3}$, após tratamento térmico a $550^{\circ} \mathrm{C}$ : Neste exemplo identificamos os picos de: $\mathrm{Nb}_{2} \mathrm{Te}_{4} \mathrm{O}_{13}, \mathrm{TeO}_{2}$ e $\mathrm{Te}_{3} \mathrm{Nb}_{2} \mathrm{O}_{11}$. 


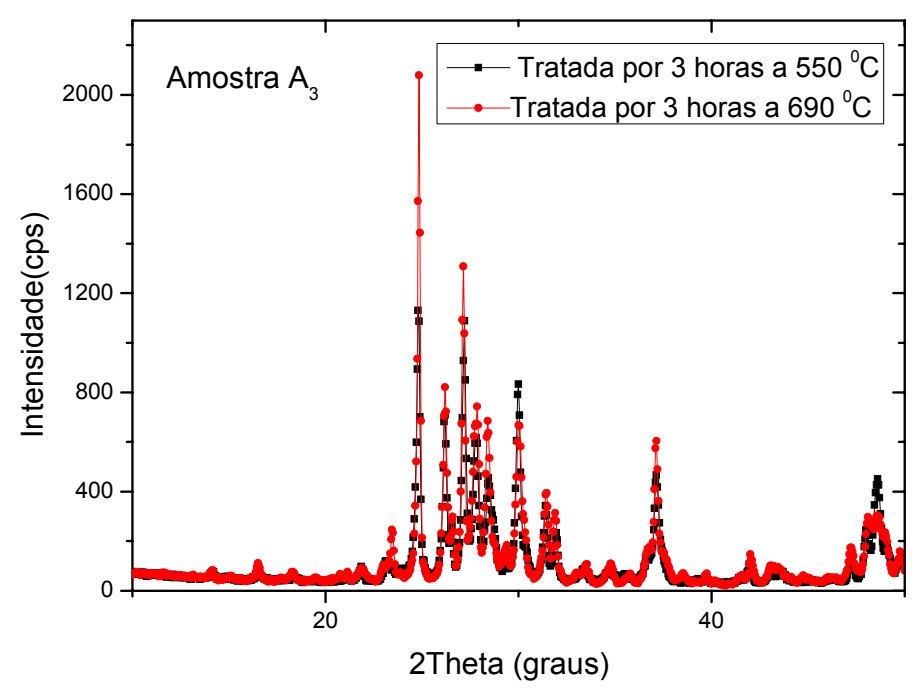

Figura 84 - Espectro de $D R X$ da amostra $A_{3}$ com diferentes tratamentos térmicos.

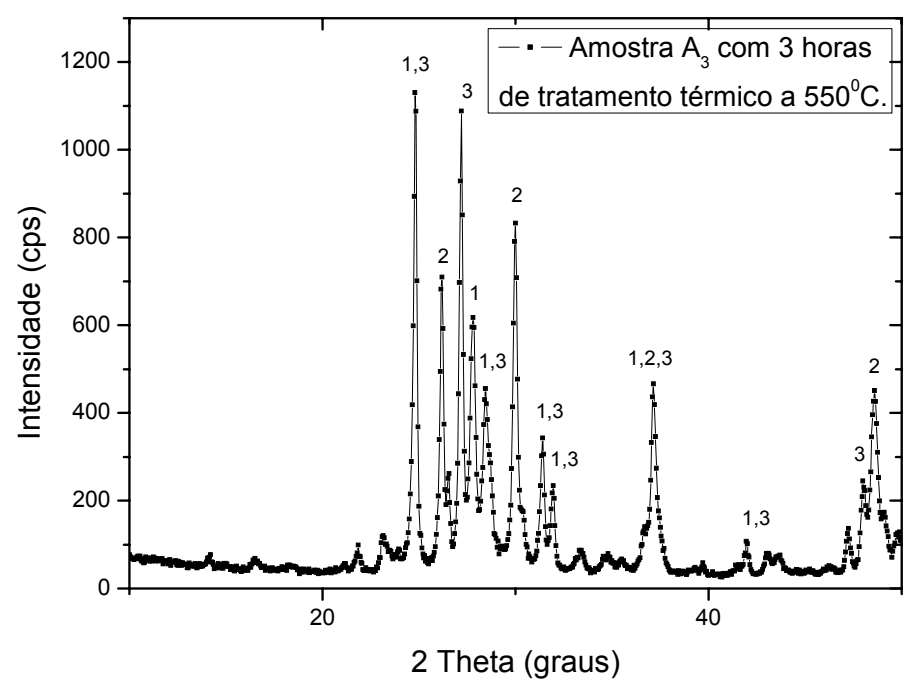

Figura 85 - Espectro de $D R X$ da amostra $A_{3}$ tratada termicamente a $550^{\circ} \mathrm{C}$ por 3 horas, com os precipitados identificados pelos índices $1=\mathrm{Nb}_{2} \mathrm{Te}_{4} \mathrm{O}_{13}, 2=\mathrm{TeO}_{2} \mathrm{e}$ $3=\mathrm{Te}_{3} \mathrm{Nb}_{2} \mathrm{O}_{11}$. 


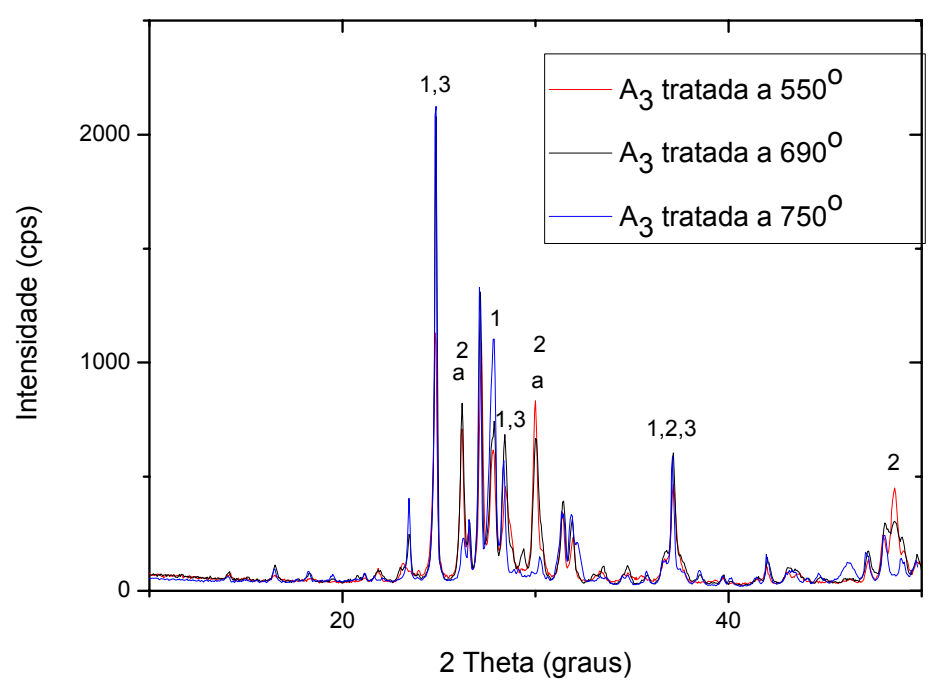

Figura 86 - Espectro de $D R X$ da amostra $A_{3}$ com diferentes tratamentos térmicos, (cada tratamento com a duração de 3 horas), com os precipitados identificados pelos índices $1=\mathrm{Nb}_{2} \mathrm{Te}_{4} \mathrm{O}_{13}, 2=T e \mathrm{O}_{2}, 3=\mathrm{Te}_{3} \mathrm{Nb}_{2} \mathrm{O}_{11}$ e a= para indicar a diminuição acentuada de $\mathrm{TeO}_{2}$.

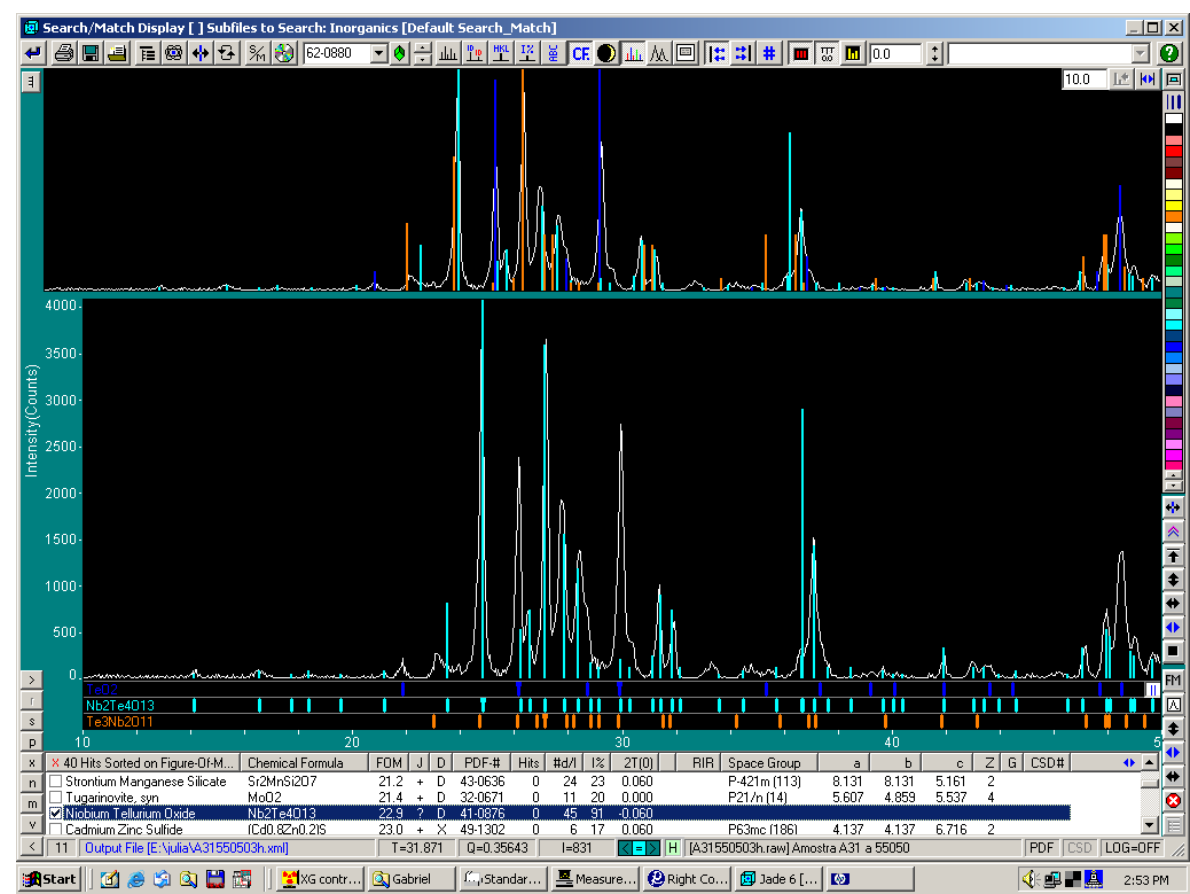

Figura 87 - Espectro de $D R X$ da amostra $A_{3}$ com tratamento térmico de 3 horas a $550^{\circ} \mathrm{C}$ e a análise da estrutura cristalina constituinte por meio do programa Jade. 


\subsection{Medidas de Correntes de Despolarização Termicamente Estimuladas (CDTE)}

Com a finalidade de compreender os mecanismos estruturais envolvidos nos processos de polarização submetemos todas as amostras à técnica de CDTE. Em todas as medidas tomou-se o cuidado de submeter a amostra a diferentes tensões, sempre localizada na mesma posição entre os eletrodos. A taxa de aquecimento e resfriamento foi mantida em aproximadamente $0,1 \mathrm{~K} / \mathrm{s}$. A espessura das amostras variou de 1 a $2 \mathrm{~mm}$.

Para cada série de amostras foi elaborada uma tabela com os parâmetros experimentais utilizados na obtenção dos resultados de CDTE, em que temos a amostra utilizada, a tensão aplicada, a temperatura medida no momento da aplicação da tensão (TAT), a temperatura no qual a tensão foi desligada (TDT), a amostra submetida à irradiação ou a algum tratamento térmico (IRR ou TT), a espessura e a figura referente aos parâmetros.

\subsubsection{Série $A$}

Os dados experimentais referentes às amostras da série $A$ seguem na tabela 27.

Tabela 27 - Parâmetros experimentais utilizados nas curvas de CDTE.

\begin{tabular}{|l|l|l|l|l|l|l|}
\hline Amostra & Tensão & TAT & TDT & IRR & Espessura (mm) & Figura \\
\hline $\mathrm{A}_{4}$ & $1000 \mathrm{~V}$ & $297 \mathrm{~K}$ & $106 \mathrm{~K}$ & Nenhum & $(1,290 \pm 0,005)$ & 88 \\
\hline
\end{tabular}




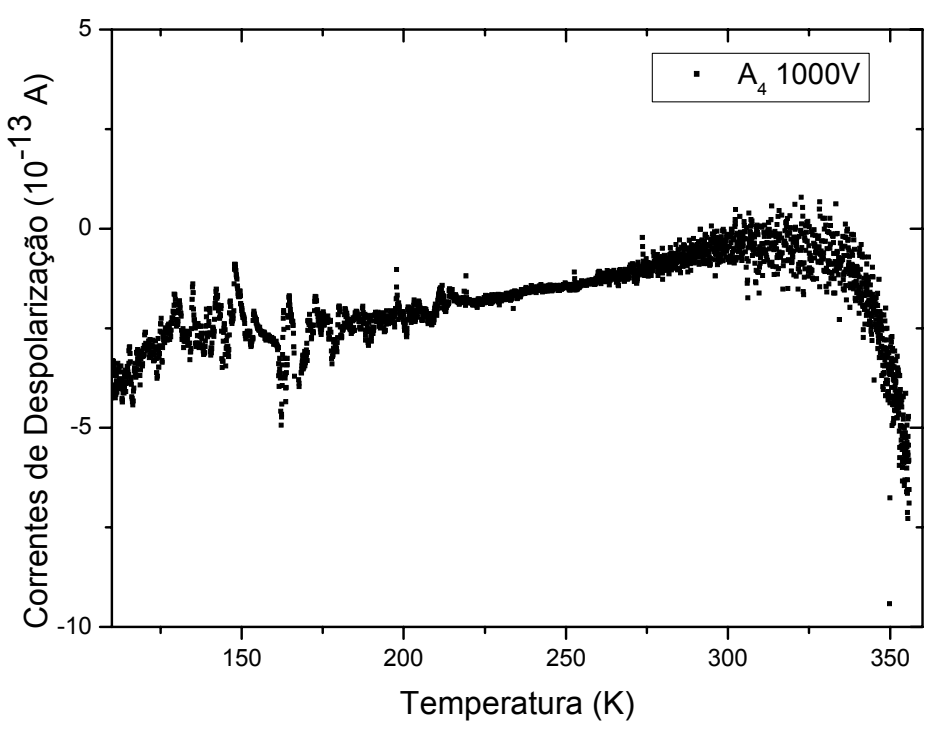

Figura 88 - Espectro de CDTE da amostra $A_{4}$.

\subsubsection{Série $B$}

Os dados experimentais referentes às amostras da série B seguem na tabela 28.

Tabela 28 - Parâmetros experimentais utilizados nas curvas de CDTE.

\begin{tabular}{|l|l|l|l|l|l|l|}
\hline Amostra & Tensão & TAT & TDT & IRR & Espessura $(\mathrm{mm})$ & Figura \\
\hline $\mathrm{B}_{2}$ & $1500 \mathrm{~V}$ & $294,6 \mathrm{~K}$ & $101,3 \mathrm{~K}$ & Nenhum & $(1,350 \pm 0,005)$ & 89 \\
& $1800 \mathrm{~V}$ & $296,1 \mathrm{~K}$ & $97,1 \mathrm{~K}$ & & & \\
& $1800 \mathrm{~V}$ nova. & $294,9 \mathrm{~K}$ & $98,1 \mathrm{~K}$ & & & \\
& $1500 \mathrm{~V}$ & $298 \mathrm{~K}$ & $102 \mathrm{~K}$ & Nenhum & $(1,660 \pm 0,005)$ & 90 \\
\hline $\mathrm{B}_{3}$ & 1500 & & &
\end{tabular}




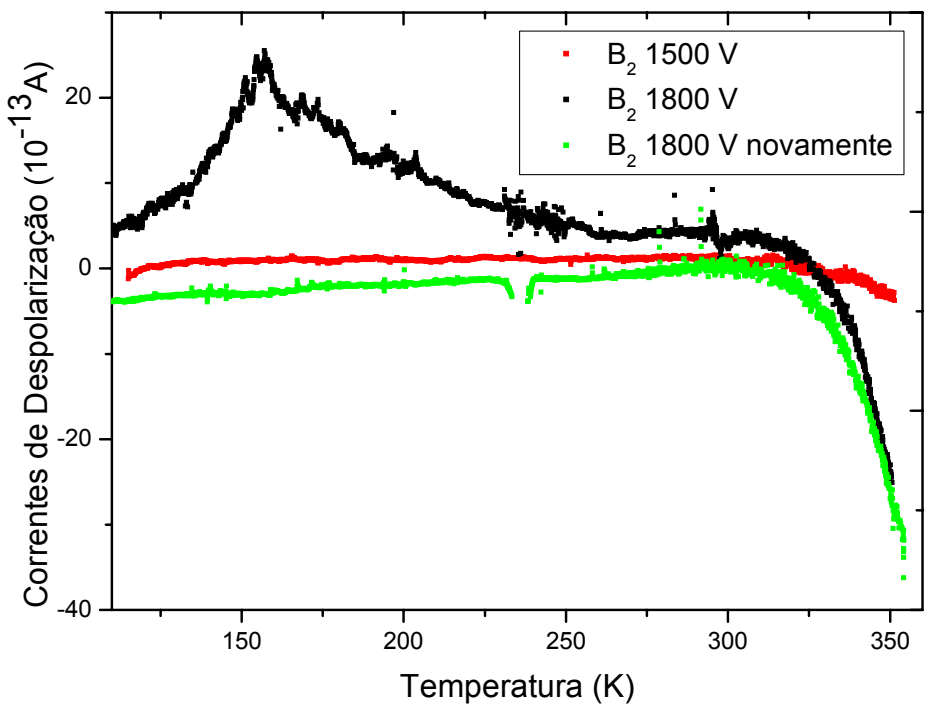

Figura 89 - Espectro de CDTE da amostra $B_{2}$.

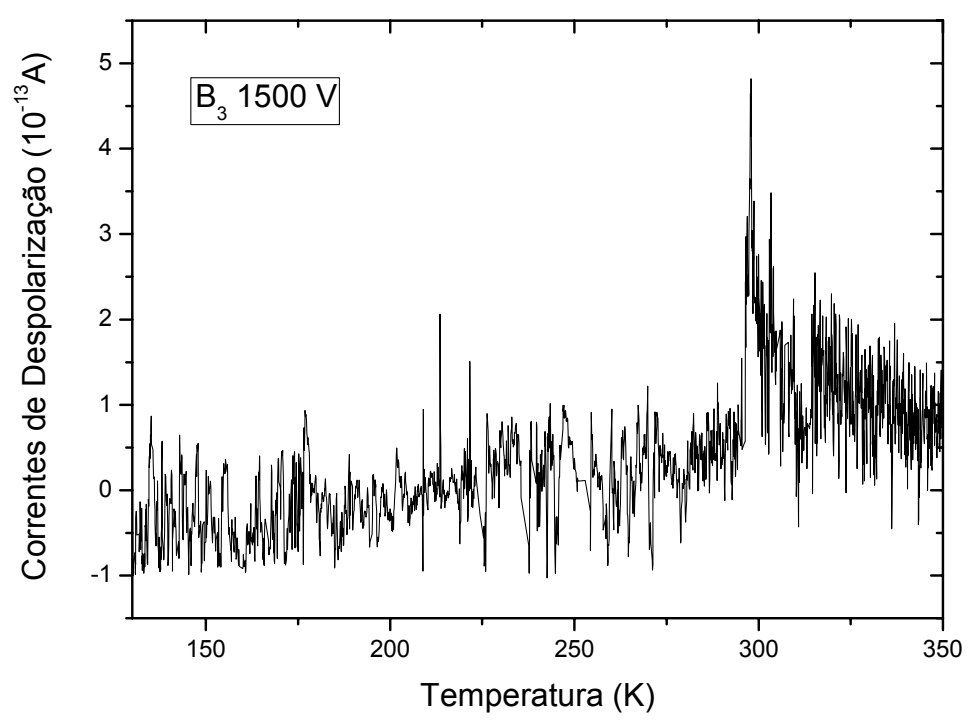

Figura 90 - Espectro de CDTE da amostra $B_{3}$.

\subsubsection{Amostra $C_{1}$}

Os dados experimentais referentes à amostra $C_{1}$ seguem na tabela 29 . 
Na figura 91 seguem os resultados para a amostra $C_{1}$. Observamos que com o aumento da tensão aplicada para o pico localizado em 302, 309 e $296 \mathrm{~K}$ (para as tensões de 1200, 1500 e 2000 V), respectivamente, ocorre um pequeno aumento de intensidade e para o pico invertido localizado em 334, 343 e $340 \mathrm{~K}$ (para as mesmas tensões descritas acima) temos um aumento considerável para as tensões maiores. Para a tensão de 1000 V não ocorreu nenhuma polarização.

Tabela 29 - Parâmetros experimentais utilizados nas curvas de CDTE.

\begin{tabular}{|l|l|l|l|l|l|l|}
\hline Amostra & Tensão (V) & TAT (K) & TDT (K) & IRR & Espessura (mm) & Figura \\
\hline $\mathrm{C}_{1}$ & 1000 & 288 & 104 & Nenhum & $(1,465 \pm 0,005)$ & 91 \\
& 1200 & 292 & 103 & & & \\
& 1500 & 297 & 105 & & & \\
& 2000 & 300,4 & 104 & & & \\
\hline $\mathrm{C}_{1}$ & $2000(\mathrm{a})$ & 300,4 & 104 & Nenhum & $(1,465 \pm 0,005)$ & 92 \\
& $2000(\mathrm{~b})$ & 295,2 & 101,5 & & & \\
\hline $\mathrm{C}_{1}$ & 1500 & 296 & 105 & Nenhum & $(1,465 \pm 0,005)$ & 94 \\
& 1500 & 300,8 & 110 & $25 \mathrm{kGy}$ & & \\
& 1500 & 297,7 & 97,3 & $50 \mathrm{kGy}$ & & \\
\hline
\end{tabular}

Um teste simples, bem utilizado, para verificar se o pico obtido é de natureza dipolar é aplicar a mesma tensão de polarização e obter o pico sempre na mesma posição. Este teste foi realizado com a amostra $C_{1}$ para a tensão de $2000 \mathrm{~V}$ (figura 92) e verificamos que não ocorreu deslocamento dos picos envolvidos. Vale lembrar que com base apenas nesses dados não podemos afirmar ainda que os picos sejam efetivamente de natureza dipolar.

A amostra $\mathrm{C}_{1}$ revelou um comportamento semelhante ao do polietileno (figura 93) investigado por T. Hashimoto e colaboradores [1]. Segundo o autor, a aparição dos dois picos de CDTE seria motivada por dois mecanismos de captura de elétrons resultante de diferentes modos de injeção de cargas: o pico positivo, devido à liberação de homo-cargas (íons ou elétrons injetados pelo eletrodo) e hetero-cargas (dipolos permanentes ou íons existentes no interior do material) que estariam 
presentes nos limites entre as regiões cristalinas e amorfas, sendo o pico negativo associado à liberação dos elétrons que foram inicialmente injetados no material e capturados na parte interna deste material. Certamente não é este o caso das amostras do presente estudo que são totalmente amorfas e, portanto, não possuem a referida interface. No presente caso atribuímos a intensidade intrínseca (do pico positivo ao pico negativo da figura 91) do CDTE aos NBO's existentes antes da irradiação.

Para complementar os estudos dos efeitos provocados na estrutura do material sob a ação dos raios gamma irradiamos a amostra com doses de 25 e 50 kGy. Inicialmente, com a dose de 25 kGy ocorreu uma diminuição da intensidade das correntes de despolarização da curva (localizada entre 300 e $360 \mathrm{~K}$ ). Com o aumento da dose pra $50 \mathrm{kGy}$ ocorreu o aparecimento de seis picos de CDTE com espaçamentos aproximadamente regulares de $50 \mathrm{~K}$, entre as temperaturas de $100 \mathrm{e}$ $300 \mathrm{~K}$ (figura 94). Para demonstrar a reprodutibilidade do processo foram feitas 3 medidas com o vidro irradiado a $50 \mathrm{kGy}$ (figura 95), o próprio processo de medida de CDTE possibilita a extinção dos efeitos da radiação.

Após o processo de medida da amostra $\mathrm{C}_{1}$ irradiada com a dose de $50 \mathrm{kGy}$ efetuamos um tratamento térmico de 2 horas a $200^{\circ} \mathrm{C}$ para eliminar os efeitos criados pela radiação verificamos que o espectro de CDTE permanece inalterado.

$O$ crescimento dos seis picos CDTE parece ocorrer às custas dos picos anteriormente existentes antes da irradiação, como confirmado pelo gráfico de correlação com o recíproco das intensidades de pico relativa, mostrada na figura 96. No entanto, após os tratamentos térmicos TT-1, TT-2 e TT-3 a redução da intensidade média dos picos induzidos por radiação em função da intensidade pp relativa (pico negativo em $330 \mathrm{~K}$ ) descreve um caminho diferente ao do crescimento durante a irradiação, de modo que a correlação entre os processos de crescimento e decaimento não é bi-unívoca. 


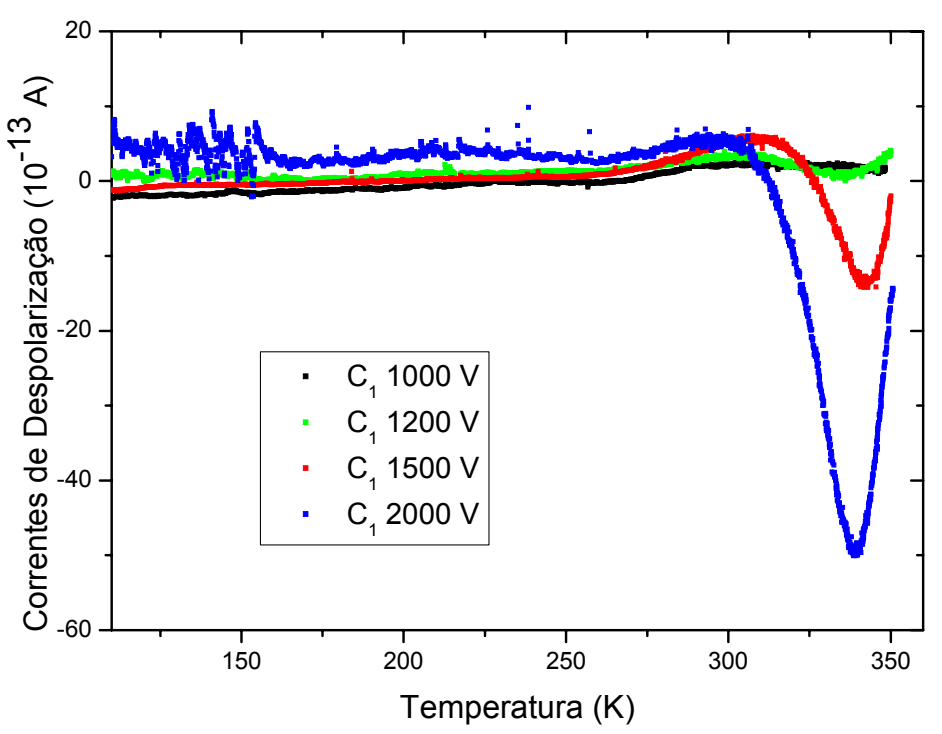

Figura 91 - Espectro de CDTE da amostra $C_{1}$.

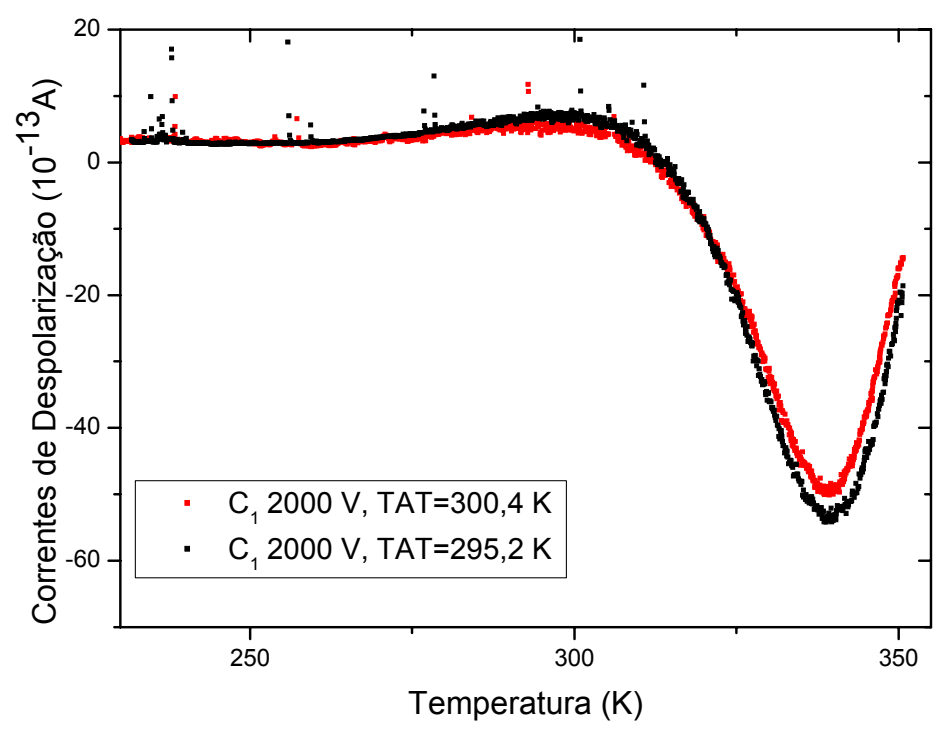

Figura 92 - Espectro de CDTE da amostra $C_{1}$ repetindo o valor da tensão com alteração da temperatura de aplicação da tensão para verificar o deslocamento do pico. 


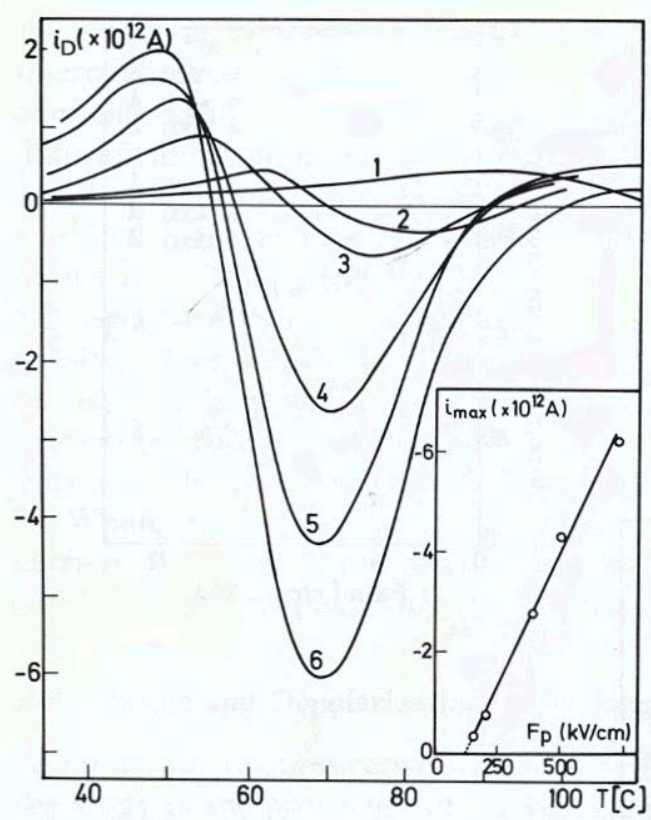

Figura 93 - Espectro de CDTE do polietileno investigado por T. Hashimoto e colaboradores [1].

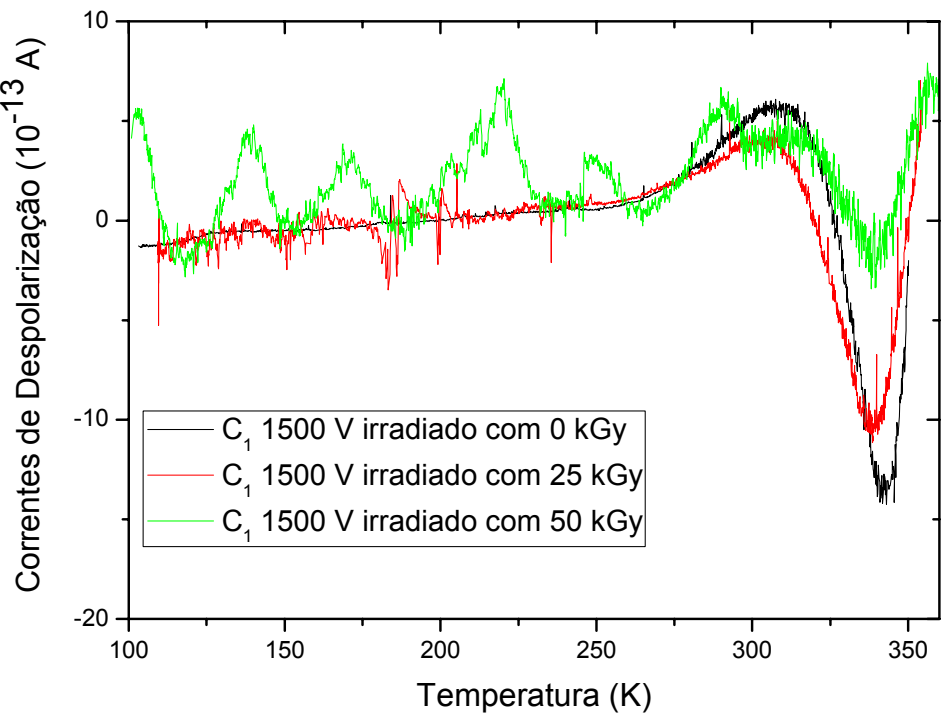

Figura 94 - Espectro de CDTE da amostra $C_{1}$ sem aplicação de radiação e com a aplicação das doses de 25 e 50 kGy. 


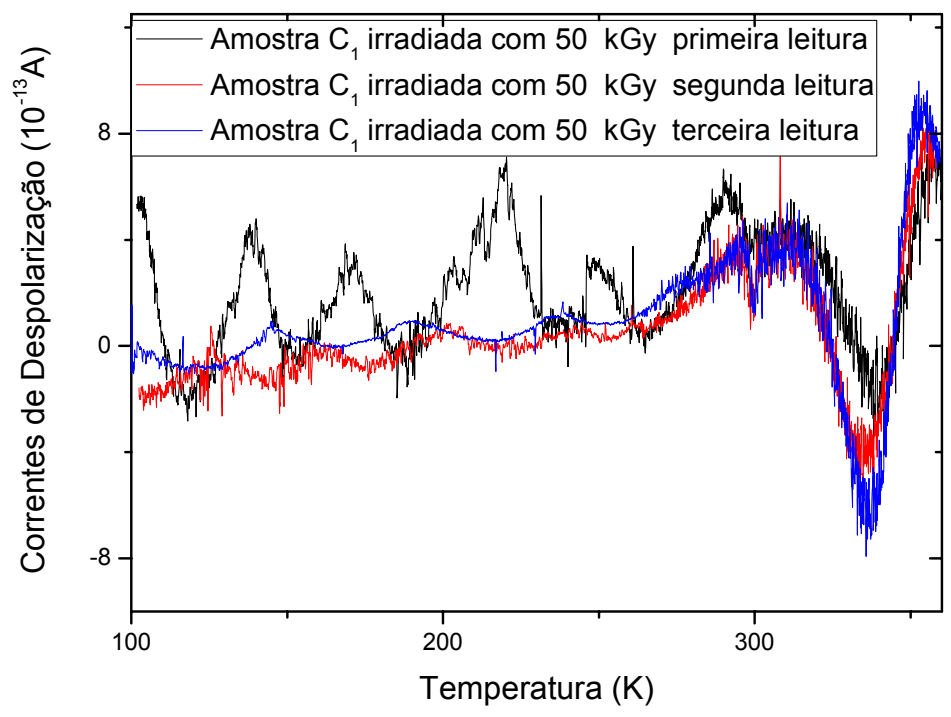

Figura 95 - Espectro de CDTE da amostra $C_{1}$ irradiada com 50 kGy.

A análise da figura 96 leva as seguintes conclusões:

1) o primeiro tratamento térmico (TT-1) eliminou aproximadamente $80 \%$ dos picos induzidos por radiação, indicando que existe um rápido decaimento térmico inicial seguido por um mais lento;

2) a correlação entre os picos induzidos por radiação e a intensidade pico a pico relativa (a intensidade pico a pico foi medida, para cada leitura, e a seguir dividida pelo maior valor para obter a intensidade pp relativa) não é bi-unívoco (quando o efeito provocado pela radiação em relação as leituras subseqüentes é interdependente e necessariamente deve retornar pelo mesmo caminho).

Uma possível explicação do fenômeno anteriormente descrito tem por base o modelo de defeitos induzidos por radiação gama ionizante e que também é radiolizante. Devido a este efeito ocorre a quebra das ligações dos NBO's segundo as possiveis reações

$\mathrm{NBO}^{-} \stackrel{\text { radiólise }}{\longrightarrow} \mathrm{V}_{o}^{+}+\mathrm{O}^{2-}$

ou

$\mathrm{NBOHC} \stackrel{\text { radiólise }}{\longrightarrow} \mathrm{V}_{\mathrm{o}}^{+}+\mathrm{O}^{-}$

produzindo vacâncias de oxigênio $V_{o}^{+}$e ânions intersticiais $O^{-}$e/ou $O^{2-}$, as custas de NBO's. Esses íns, por sua vez, sob condições favoráveis, podem 
combinar-se entre si produzindo $\mathrm{O}_{2}^{-}$ou até mesmo $\mathrm{O}_{3}^{-}$em vidros com estruturas abertas e que ficam estabilizados em sítios de compensação de carga, o que implica na produção de dipolos elétricos permanentes e que são, portanto, polarizáveis sob a ação de campo elétrico aplicado durante o procedimento usual das medidas de CDTE. Devido às características desses sítios que conferem aos íons graus de liberdade suficientes para que os dipolos possam se orientar, pelo menos parcialmente, e fornecer um pico moderado de despolarização que pudemos observar na região de temperaturas entre 100 e $300 \mathrm{~K}$. O que se observa depois é a ocorrência de um pico negativo (polarização) acentuado, cuja intensidade diminui com a dose de radiação.

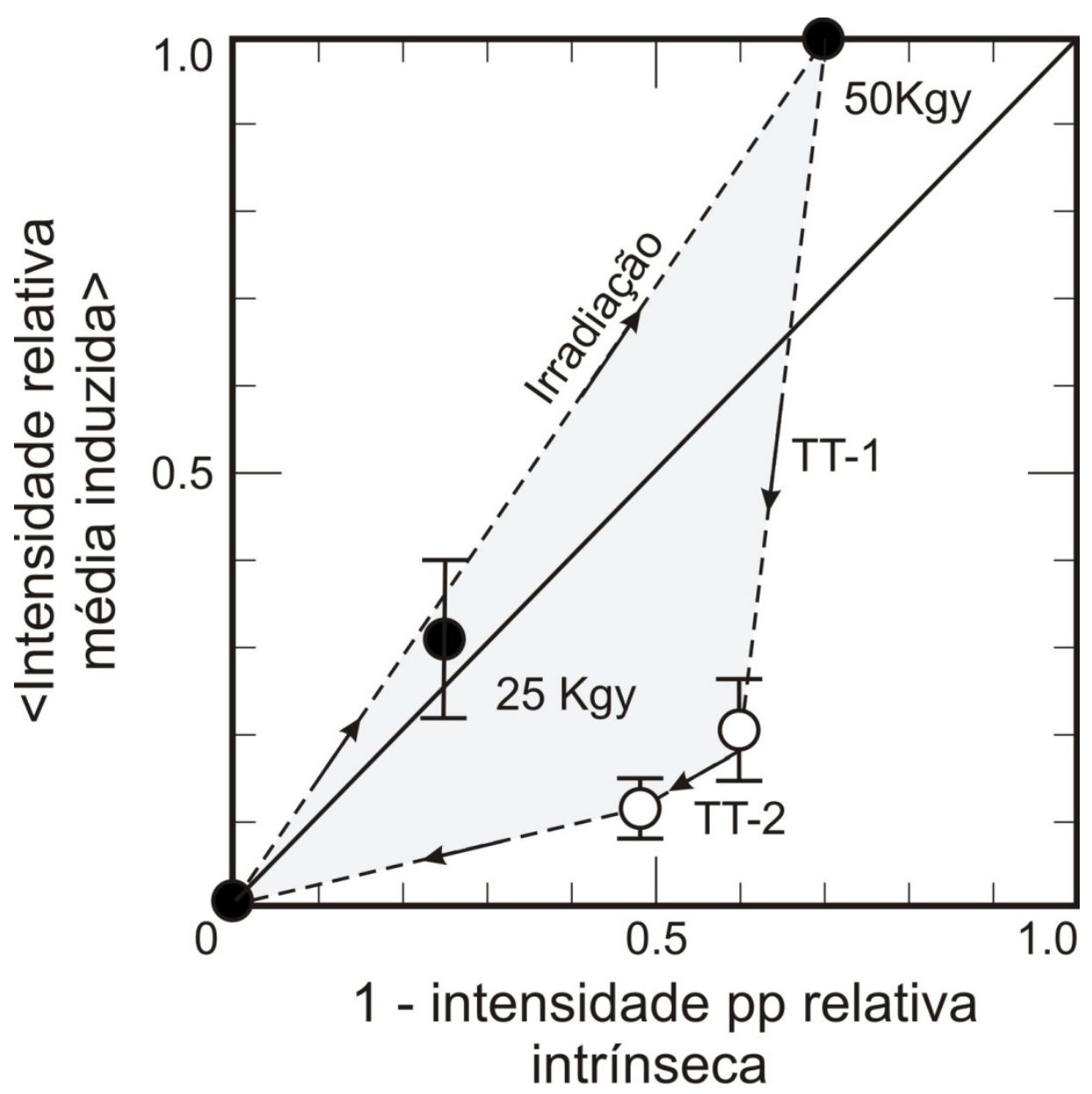

Figura 96 - Curva da correlação entre a intensidade média relativa de CDTE dos picos VS, o comportamento da intensidade pico a pico relativa intrínseca da amostra $C_{1}$ não irradiada. 
Cada leitura de CDTE, devido ao processo de aquecimento (figura 95), contribui para reverter a ação da radiação, ou seja, contribui para a reconstrução das ligações inicialmente quebradas com a produção de um excesso de ânions de oxigênio que conseqüentemente contribui para a restauração dos NBO's. Essas ligações seriam reconstruídas formando inicialmente ligações mais longas e fracas, com a gradual relaxação até a distância $\mathrm{a}_{\mathrm{x}} \sim 2,3 \AA$ ou eq $\sim 2,0 \AA$, dependendo da posição do referido NBO. Durante esta relaxação ocorrem os fenômenos responsáveis pelos picos observados por CDTE, cuja explicação detalhada ainda não é conhecida.

O fato da intensidade pico a pico relativa não ser bi-unívoco indica a participação de pelo menos mais outro centro devido aos elétrons do NBO- mais estáveis que o produto da radiólise. Este é um centro com dois elétrons emparelhados e, portanto, não paramagnético e por isso não pode ser detectado por EPR, por Giehl e colaboradores [2]. Este centro é possivelmente o TeEC.

\subsubsection{Referências}

[1] Hashimoto, T.; Shiraki, M.; Sakai T. Current reversal in the thermally stimulated current spectra of polyethylene. J. Polym. Sci., Polym. Phys., v. 13, p. 2401-2410, 1975.

[2] Giehl, J. M.; Pontuschka, W. M.; Barbosa, L. C.; Ludwig, Z. M. C. EPR of Yinduced paramagnetic centers in tellurite glasses. J. Non-Crys. Solids, v. 356, p. 1762-1767, 2010.

\subsection{Medidas de Termoluminescência (TL)}

As amostras $B_{3}, C_{1}, B_{2}$ e $B_{5}$ foram irradiadas com uma dose de $1 \mathrm{kGy}$. Os espectros de TL destas amostras foram lidos logo após a irradiação (figuras 97, 98, 99 e 100). A seguir seguem os resultados de todas as amostras (figura 101) somente do primeiro pico de TL. 
A partir dos resultados de curva isócrona (resultados discutidos na próxima seção) e da figura 101, verificamos que o processo de recombinação dos centros de defeitos é não radiativo.

$\mathrm{Na}$ tabela 30 seguem as energias de ativação obtidas por meio dos resultados experimentais pelo método da subida inicial utilizando a equação 2.5.2.1.

A tabela 31 apresenta os centros dos picos obtidos a partir do ajuste dos dados por Gaussianas de cada amostra.

$\mathrm{O}$ primeiro pico de TL é atribuído à recombinação radiativa do centro $\mathrm{TeEC}^{-}$ (cuja produção é ilustrada na figura 102) com algum centro de buraco próximo.

Quanto à causa do segundo pico propomos como mais provável a hipótese da recombinação do $\mathrm{TeOHC}$ residual com um elétron capturado por uma armadilha mais profunda, de natureza ainda não conhecida.

O terceiro pico de TL é atribuído aos fenômenos ligados ao processo de sinterização do pó.

Tabela 30 - Energia de ativação.

\begin{tabular}{|l|l|}
\hline Amostra irradiada com 1 kGy & Energia de ativação (eV) \\
\hline$B_{2}$ & $(0,90 \pm 0,02)$ \\
\hline$B_{3}$ & $(1,11 \pm 0,02)$ \\
\hline$B_{5}$ & $(1,03 \pm 0,02)$ \\
\hline$C_{1}$ & $(1,17 \pm 0,02)$ \\
\hline
\end{tabular}




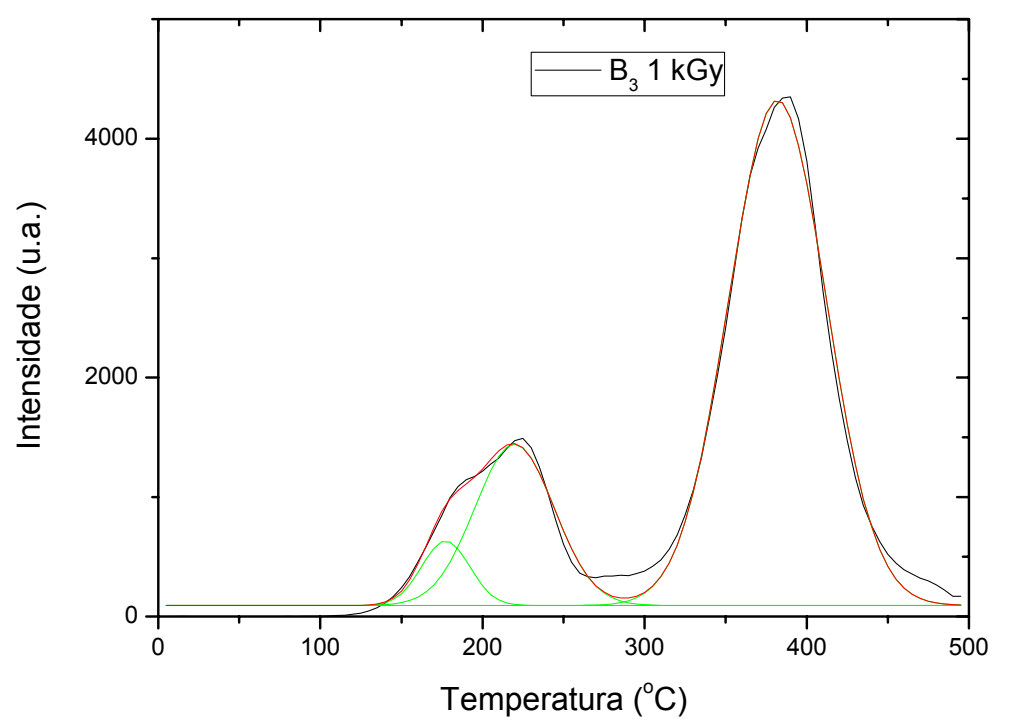

Figura 97 - Curva $T L$ da amostra $B_{3}$ irradiada com 1 kGy.

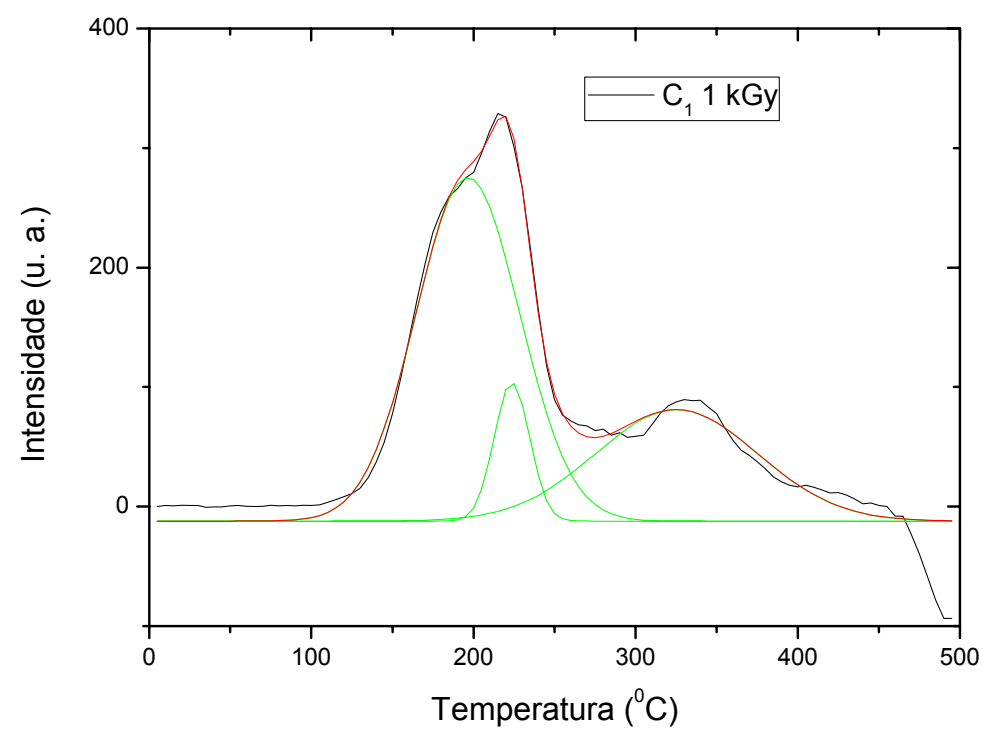

Figura 98 - Curva TL da amostra $C_{1}$ irradiada com 1 kGy. 


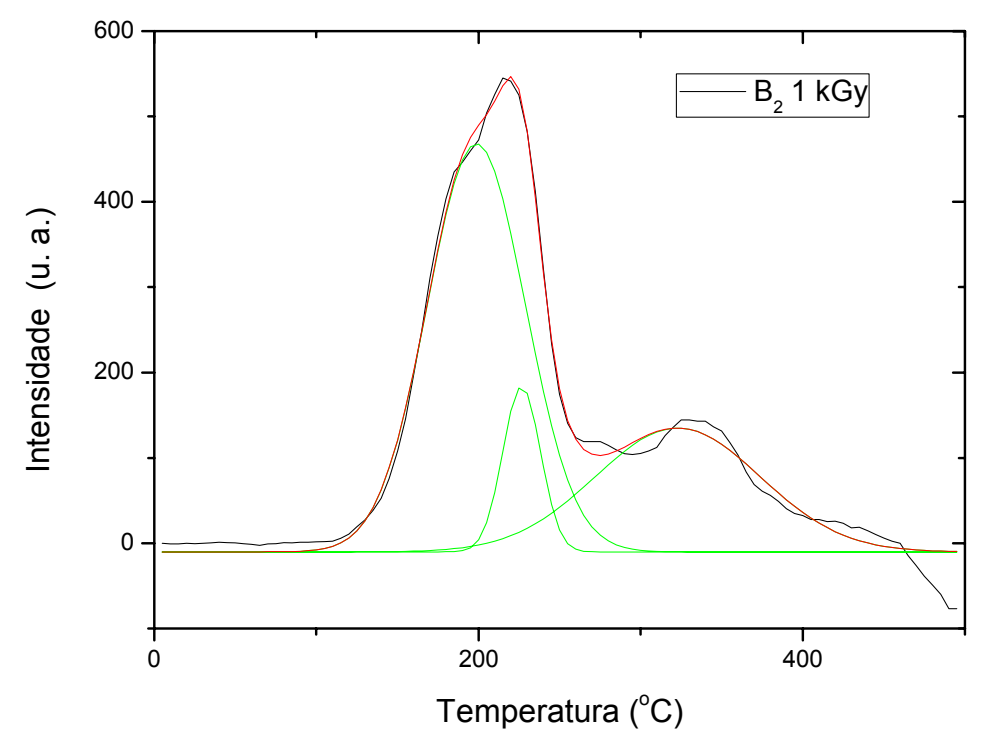

Figura 99 - Curva $T L$ da amostra $B_{2}$ irradiada com $1 \mathrm{kGy}$.

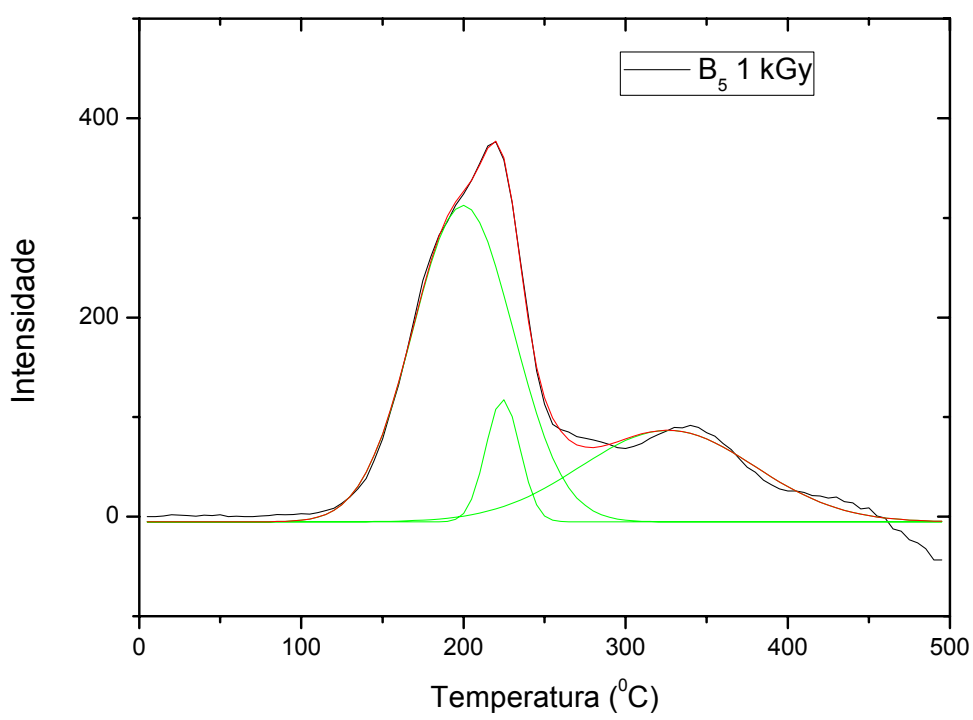

Figura 100 - Curva $T L$ da amostra $B_{5}$ irradiada com 1 kGy. 


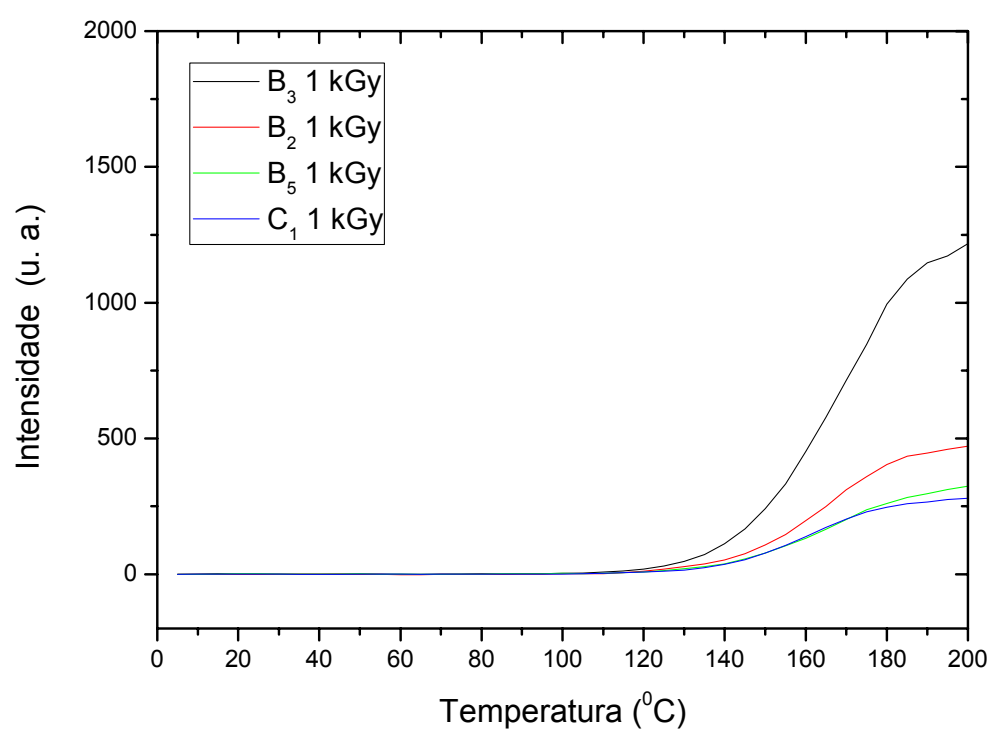

Figura 101 - Curva TL comparativa da subida inicial de todas as amostras irradiada com $1 \mathrm{kGy}$.

Tabela 31 - Centro dos picos de TL.

\begin{tabular}{|l|l|l|l|l|}
\hline Amostras & $\mathrm{B}_{2}$ & $\mathrm{~B}_{3}$ & $\mathrm{~B}_{5}$ & $\mathrm{C}_{1}$ \\
\hline $1^{\circ}$ pico $\left({ }^{\circ} \mathrm{C}\right)$ & 195 & 176 & 198 & 200 \\
\hline $2^{\circ}$ pico $\left({ }^{\circ} \mathrm{C}\right)$ & 223 & 220 & 224 & 225 \\
\hline $3^{\circ}$ pico $\left({ }^{\circ} \mathrm{C}\right)$ & 326 & 380 & 325 & 325 \\
\hline
\end{tabular}

\subsection{Medidas de ressonância paramagnética eletrônica (RPE)}

Com a finalidade de compreender a estrutura vítrea das amostras estudadas, efetuamos medidas de RPE. Todas as amostras foram irradiadas com fonte de raios $-\gamma$ (Panorâmica), à temperatura ambiente.

Para as amostras da série A não tivemos nenhuma resposta antes e após as irradiações com as doses de $100 \mathrm{~Gy}, 5 \mathrm{kGy}$ e $15 \mathrm{kGy}$. Na figura 102 segue o espectro da amostra $A_{5}$ antes e após a irradiação com $15 \mathrm{kGy}$. Prohaska e colaboradores [1] produziram uma amostra com telúrio e tungstênio e atribuíram a 
ausência da linha de RPE do vidro irradiado à natureza fortemente eletropositiva do tungstênio o que aumenta o número de oxigênios disponíveis e portanto inibe a formação dos precursores das vacâncias de oxigênios. Atribuímos a ausência do sinal de RPE nas amostras da série A, a natureza fortemente eletropositiva do nióbio, já que as amostras possuem pouca quantidade de óxido de prata e óxido de sódio.

A ressonância residual observada na figura 102 é provavelmente causada por alguns traços de centros de buracos de íons de natureza desconhecida. A semelhança dos espectros com doses de 0 kGy e 15 kGy mostra a evidência de que estas espécies paramagnéticas não são afetadas pela irradiação.

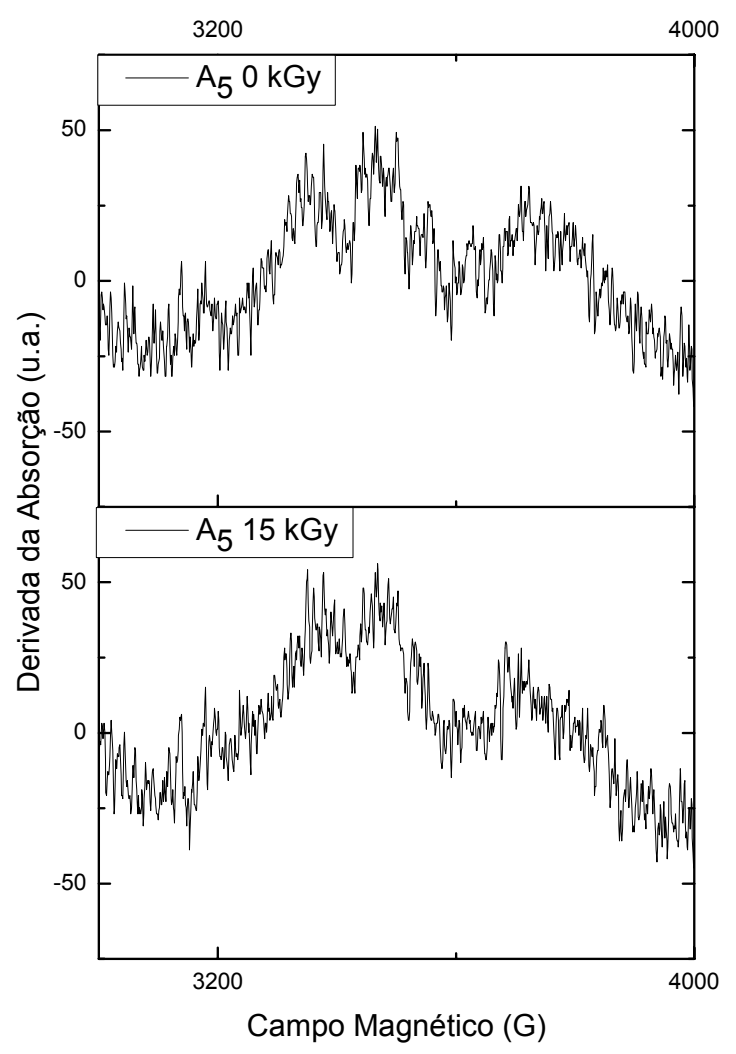

Figura 102 - Espectro de RPE da amostra $A_{5}$ irradiada com 15 kGy.

As amostras da série $B$ e a amostra $C_{1}$ foram irradiadas com doses de 1,5 15, 25 e 50 kGy. Todos os vidros destas séries apresentam três centros paramagnéticos adicionais ao $g_{0}$, são eles $g_{1}, g_{2}$ e $g_{3}$. Os centros estão exemplificados na figura 103a, na qual temos a amostra $\mathrm{B}_{3}$ a dose de $5 \mathrm{kGy}$. Na 
figura $103 \mathrm{~b}$ temos o espectro da amostra $C_{1}$ irradiado com a mesma dose e com centro $g_{0}$ bem evidente. $\Delta \mathrm{H}_{\mathrm{pp}}=(1,9 \pm 0,5) \mathrm{G}$

Nos espectros da série $B$ e da amostra $C_{1}$, após a irradiação temos: (1) uma ressonância fraca e larga $(\Delta \mathrm{H} \sim 200 \mathrm{G})$ em $\mathrm{g}_{0} \sim 2,2$ cuja natureza permanece não identificada; (2) um ombro localizado em $\mathrm{g}_{1}=2,02 \pm 0,01$, o qual ainda não foi reportado na literatura; (3) uma linha de ressonância estreita e bem resolvida em $\mathrm{g}_{2}=1,9960 \pm 0,0005$, com largura de linha $\Delta \mathrm{H}_{\mathrm{pp}}=(1,5 \pm 0,5) \mathrm{G}$ e (4) uma ressonância bem resolvida em $g_{3}=1,9700 \pm 0,0005$ e $\Delta H_{p p}=(1,9 \pm 0,5) G$, respectivamente. Após armazenamento à temperatura ambiente durante 68 dias, foi observado um decaimento mais rápido da intensidade da linha $\mathrm{g}_{2}$ (Intensidade $=$ 0,46 intensidade inicial), enquanto as linhas $g_{1}$ e $g_{3}$ apareceram mais estáveis (Intensidade $=0,56$ Intensidade inicial). Os espectros de RPE da amostra $\mathrm{B}_{3}$ do vidro telurito, imediatamente após irradiação (5 kGy) e após armazenamento por 68 dias à temperatura ambiente estão representados na figura 104.

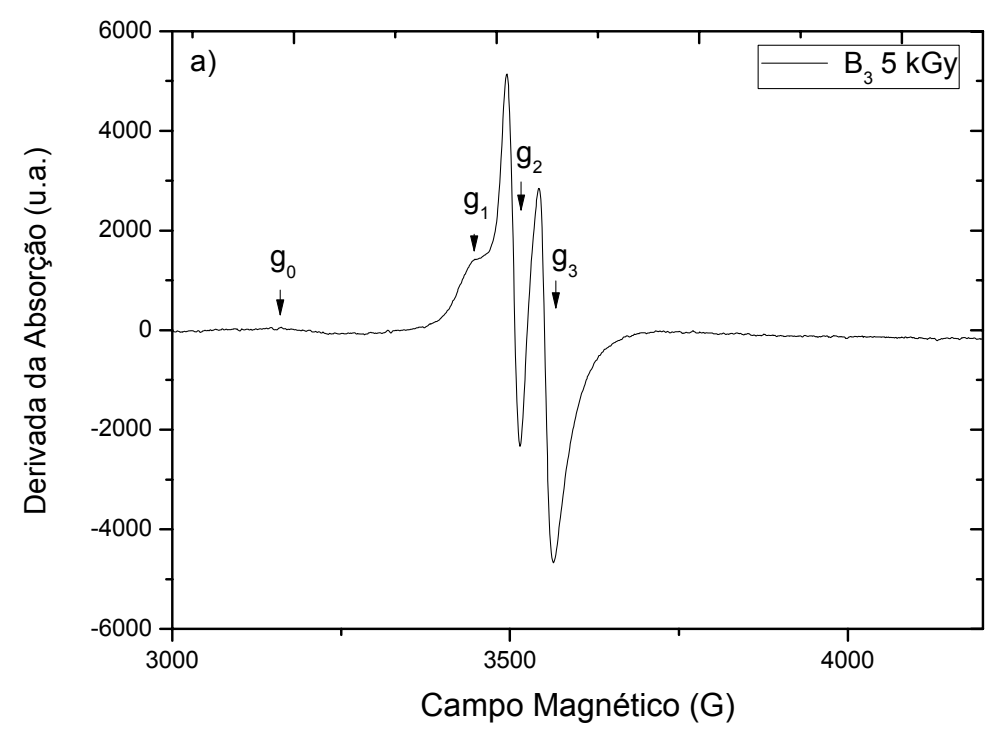




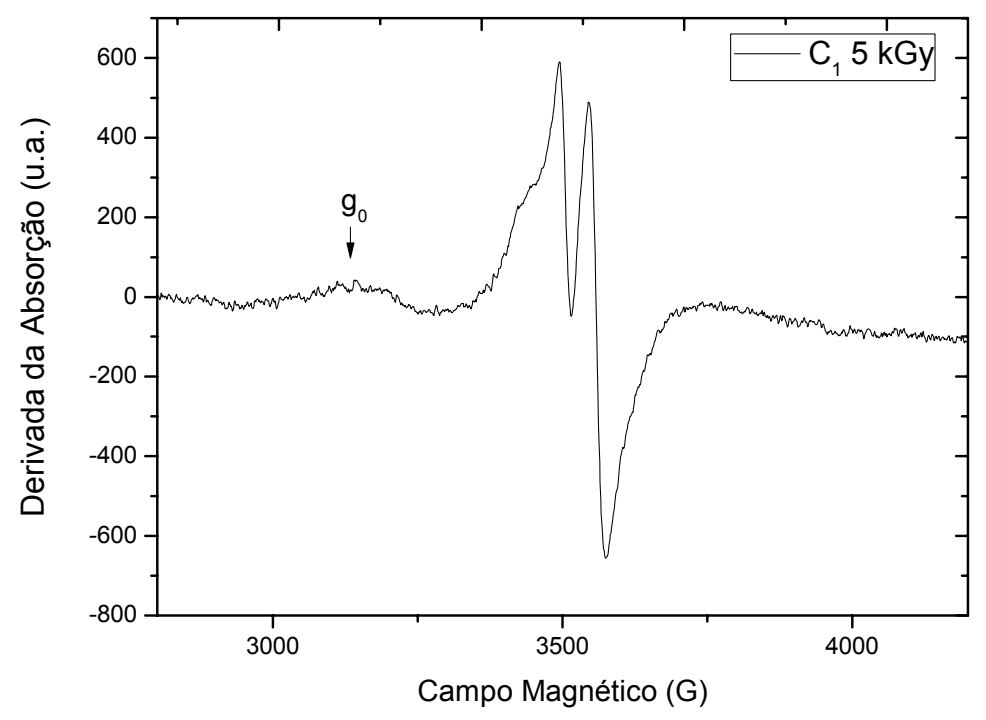

Figura 103 - Espectros das amostras dos vidros teluritos básicos das série $B$ e $C$, irradiados com raios $\gamma$, com dose de $5 \mathrm{kGy}$, à temperatura ambiente: a) $B_{3}$ e b) $C_{1}$. Resultado publicado por Giehl e colaboradores [2].

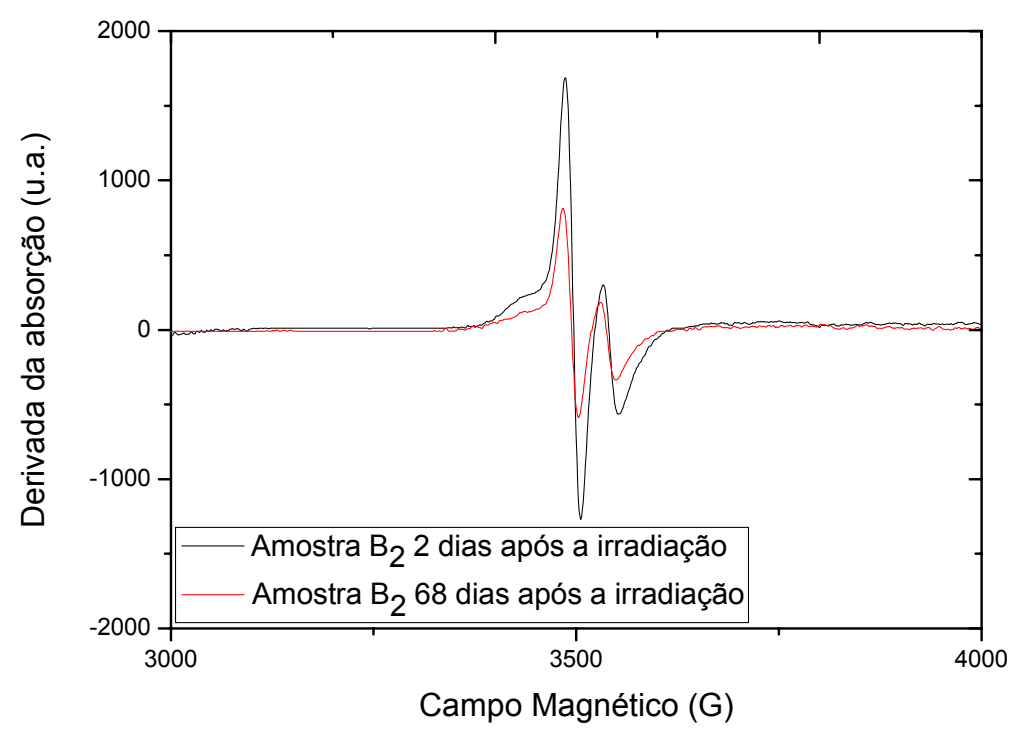

Figura 104 - Espectros de RPE da amostra $B_{3}$ do vidro telurito medido após irradiação com raios $\gamma(5 \mathrm{kGy})$ e após armazenagem por durante 68 dias à temperatura ambiente. 
O estudo da evolução das intensidades de linha das ressonâncias $g_{1}, g_{2}$ e $g_{3}$ em função da dose de irradiação foi organizado com a separação dos resultados das medidas em: não dopados e dopados com Ag, respectivamente.

\subsubsection{Vidros não dopados}

Os vidros básicos dos sistemas não dopados, tais como representados pelos espectros de RPE das amostras $B_{3}$ e $C_{1}$, irradiadas com doses de 1, 5, 15, 25 e 50 kGy (vide figuras 105 e 106) em que a quantidade de óxido modificador do vidro $B_{3}$ é mais elevada ( $15 \% \mathrm{Na}_{2} \mathrm{O} ; 25 \% \mathrm{ZnO}$ ) e $\mathrm{C}_{1}$ contém apenas $15 \%$ de $\mathrm{Na}_{2} \mathrm{O}$. Como já é bem conhecido, a mobilidade do cátion $\mathrm{Zn}^{2+}$ é pequena em comparação com $\mathrm{Na}^{+}$, de modo que a difusão de $\mathrm{Zn}^{2+}$ pode ser ignorada na presente análise. Segundo $\mathrm{C}$. $\mathrm{K}$. Kanth e colaboradores [3] quando o zinco atua como elemento modificador da rede vítrea, seu caráter covalente é comparativamente maior do que os outros cátions (para o autor chumbo), para o vidro fluoreto de zinco dopado com íons de cromo [3], e pela menor condutividade do vidro $\mathrm{ZnO}-\mathrm{ZnF}_{2}-\mathrm{B}_{2} \mathrm{O}_{3}$ dopados com íons de cobre reportados por G. N. Raju [4]. Na figura 107 observamos que para a amostra $B_{3}$ com maior quantidade de elemento modificador, a resposta $g_{1}$ cresceu monotonicamente com a dose crescente de radiação, enquanto $g_{2}$ decresceu monotonicamente com a crescente dose de radiação e enquanto $g_{3}$ cresceu supralinearmente entre 1 e 5 $\mathrm{kGy}$. Por outro lado, para a amostra $\mathrm{C}_{1}$, possuindo menor conteúdo de modificador (figura 108) todos os centros paramagnéticos decrescem entre 1 e $5 \mathrm{kGy}$, crescendo em seguida e passando por um máximo por volta de $15 \mathrm{kGy}$ e diminuindo depois, com doses de até $25 \mathrm{kGy}$.

Vale observar que as barras de erro dos gráficos das figuras 107 e 108 são da ordem de grandeza das dimensões dos pontos. 


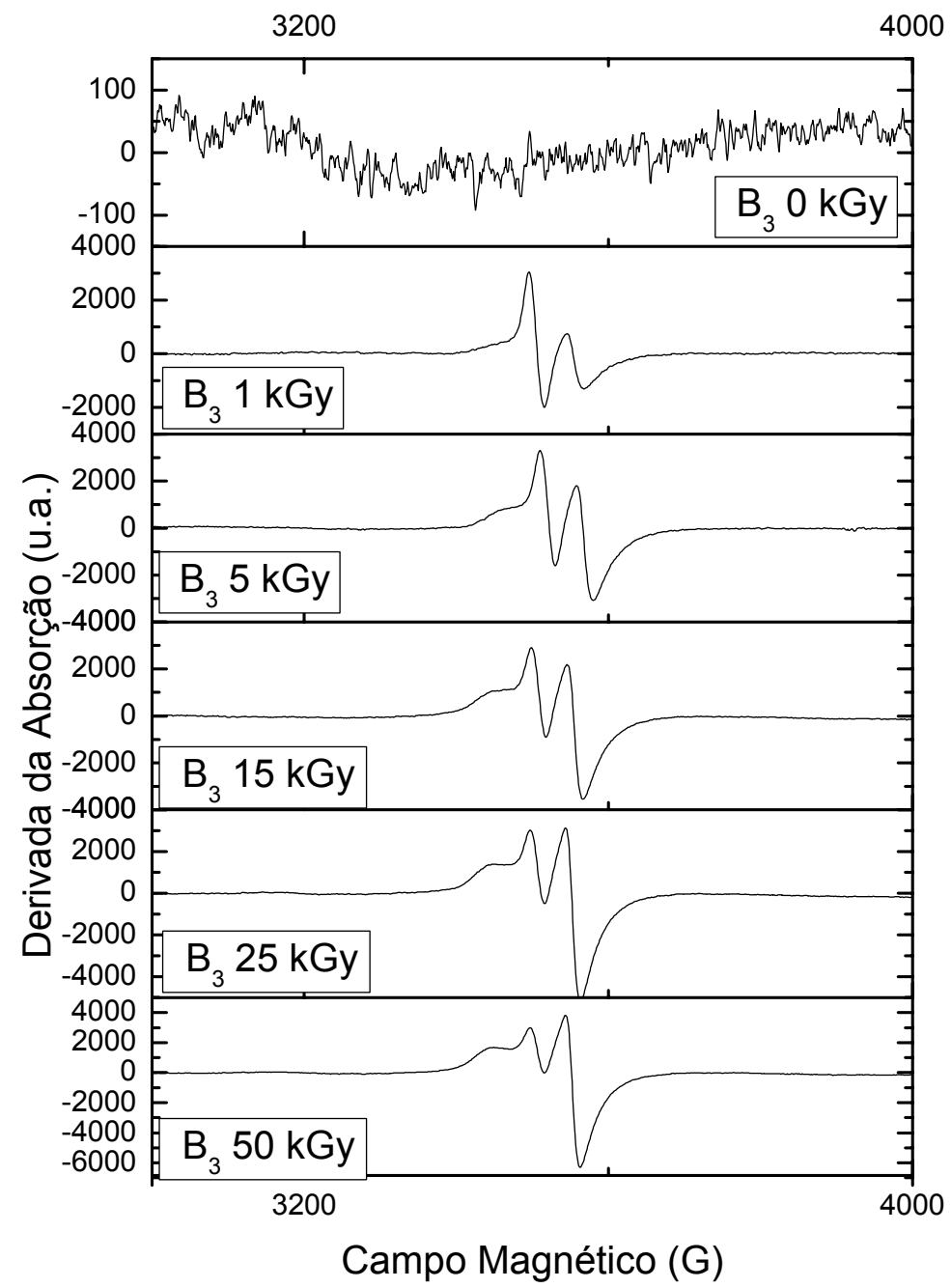

Figura 105 - Espectros de RPE da amostra $B_{3}$ irradiado com doses de 1, 5 15, 25 e 50 kGy. Resultado publicado por Giehl e colaboradores [2]. 


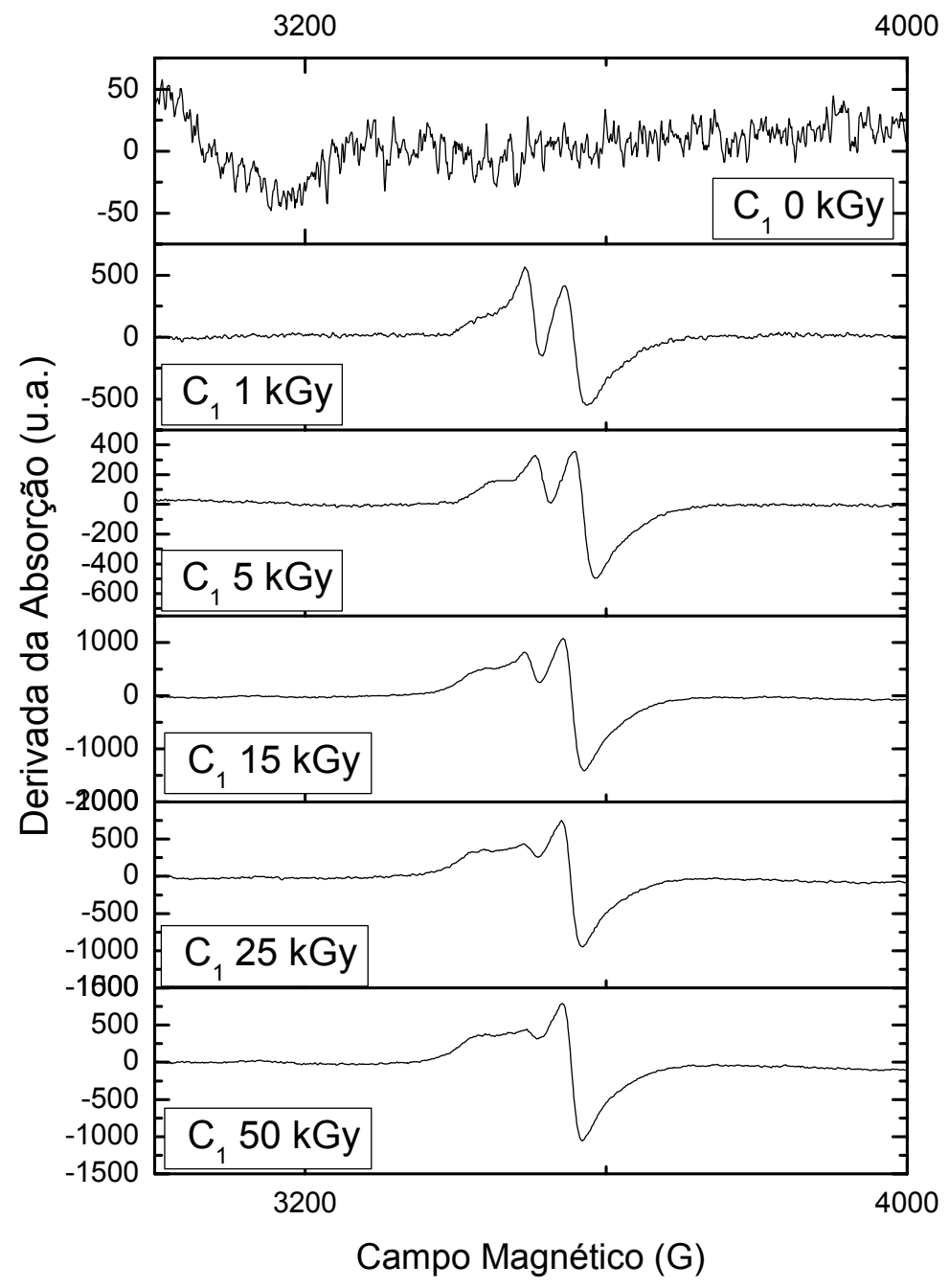

Figura 106 - Espectros de RPE da amostra $C_{1}$ irradiado com doses de 1, 5 15, 25 e 50 kGy. Resultado publicado por Giehl e colaboradores [2]. 


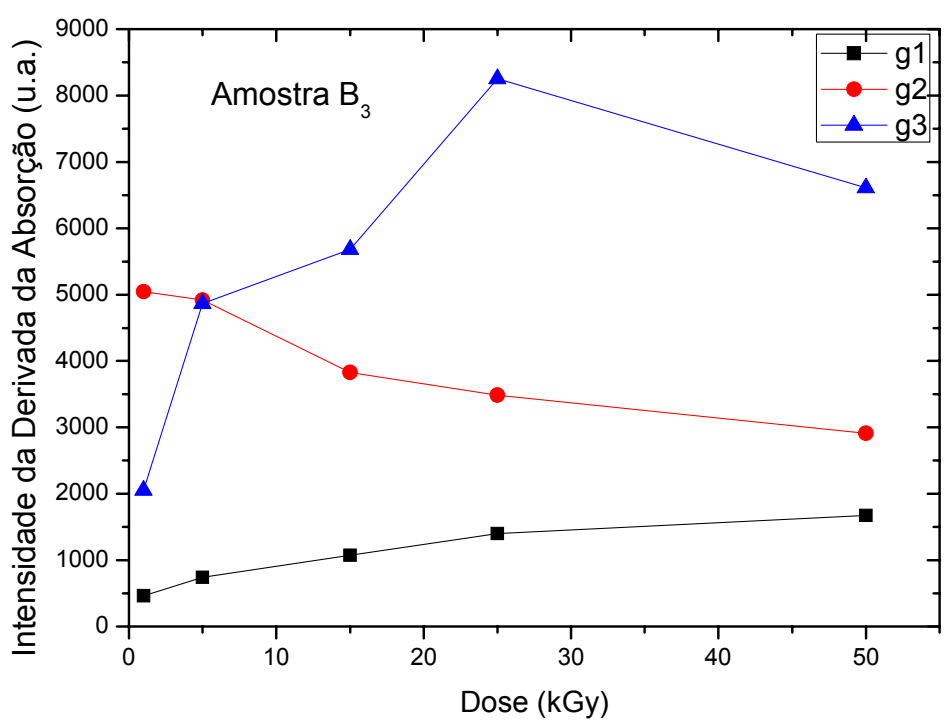

Figura 107 - Evolução das intensidades de RPE das ressonâncias $g_{1}, g_{2}$ e $g_{3}$ da amostra $B_{3}$, com a dose (kGy). Resultado publicado por Giehl e colaboradores [2].

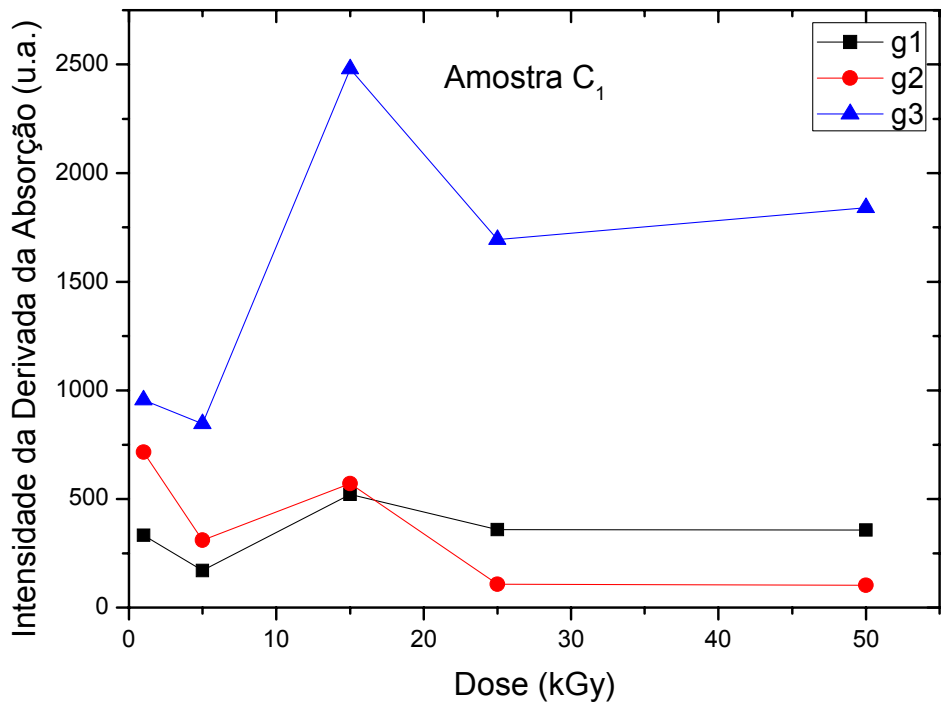

Figura 108 - Evolução das intensidades de RPE das ressonâncias $g_{1}, g_{2}$ e $g_{3}$ da amostra $C_{1}$, com a dose (kGy). Resultado publicado por Giehl e colaboradores [2]. 


\subsubsection{Vidros dopados com Ag}

$\mathrm{Na}$ figura 109 segue a derivada da absorção (u.a.) versus o campo magnético. Na figura 110 segue a evolução das intensidades de RPE da amostra $B_{2}$ dopada com $0,5 \mathrm{~mol} \%$ de prata versus a radiação. Analisando a figura 110 observamos um crescimento monotônico para as linhas $g_{1}$ e $g_{3}$ e também um aumento da inclinição em 5 kGy e a linha $g_{2}$ decresceu entre 1 e 5 kGy, aumentando depois até $15 \mathrm{kGy}$, com subseqüente diminuição causando um "fading". Com dosagem de prata maior $(5,0 \mathrm{~mol} \%)$, vide figura 111 , todas as ressonâncias decresceram entre 1 e 5 kGy, crescendo até 15 kGy e voltando a decrescer com doses mais altas até 25 kGy. Para doses mais elevadas, a ressonância $g_{3}$ cresce de novo, enquanto as intensidades de $g_{1}$ e $g_{3}$ diminuem.

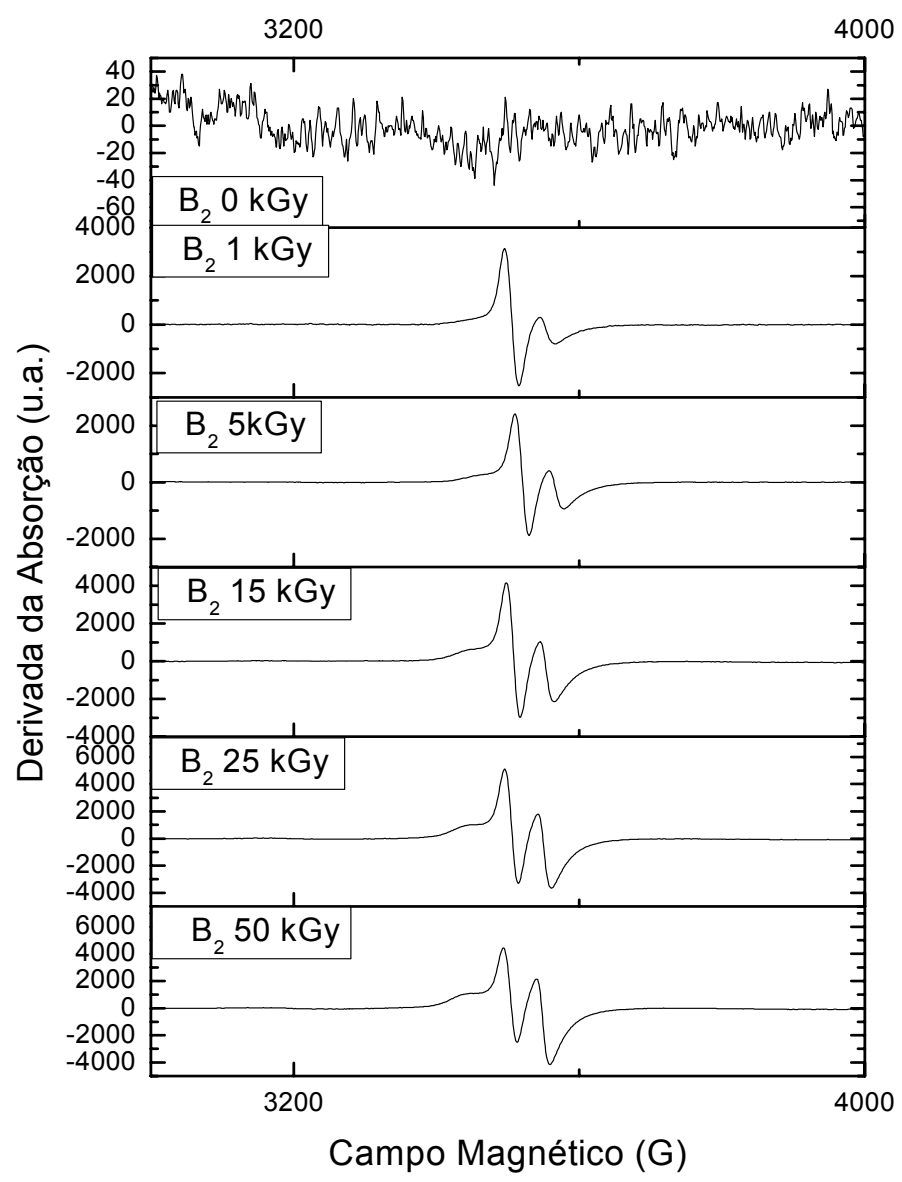

Figura 109 - Espectros de RPE da amostra $B_{2}$ irradiado com doses de 1, 5 15, 25 e 50 kGy. 


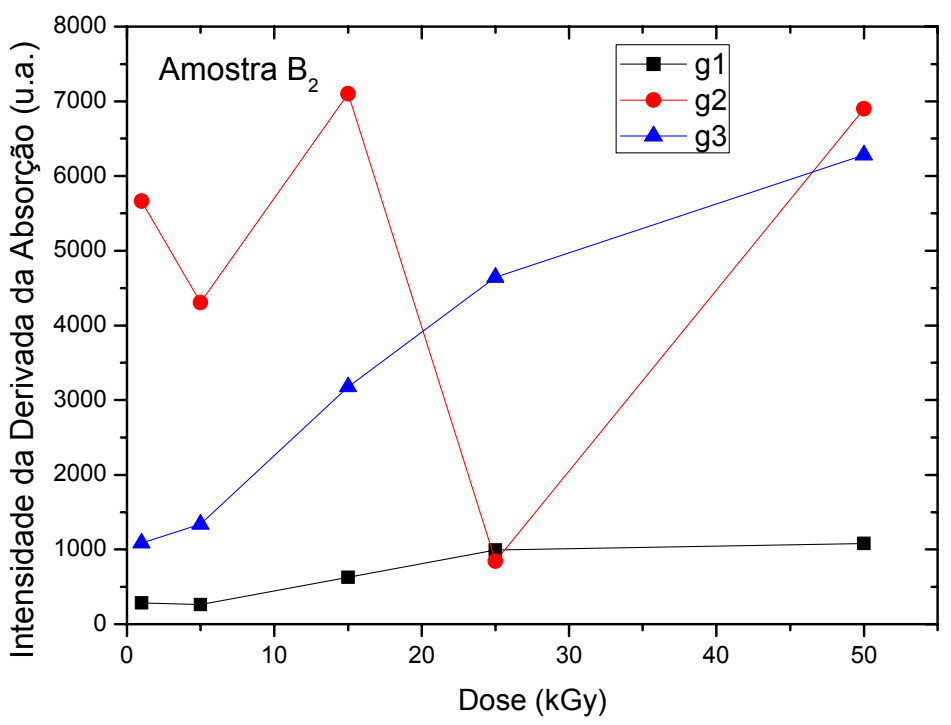

Figura 110 - Evolução das intensidades de RPE das ressonâncias $g_{1}, g_{2}$ e $g_{3}$ da amostra $B_{2}$, com a dose (kGy).

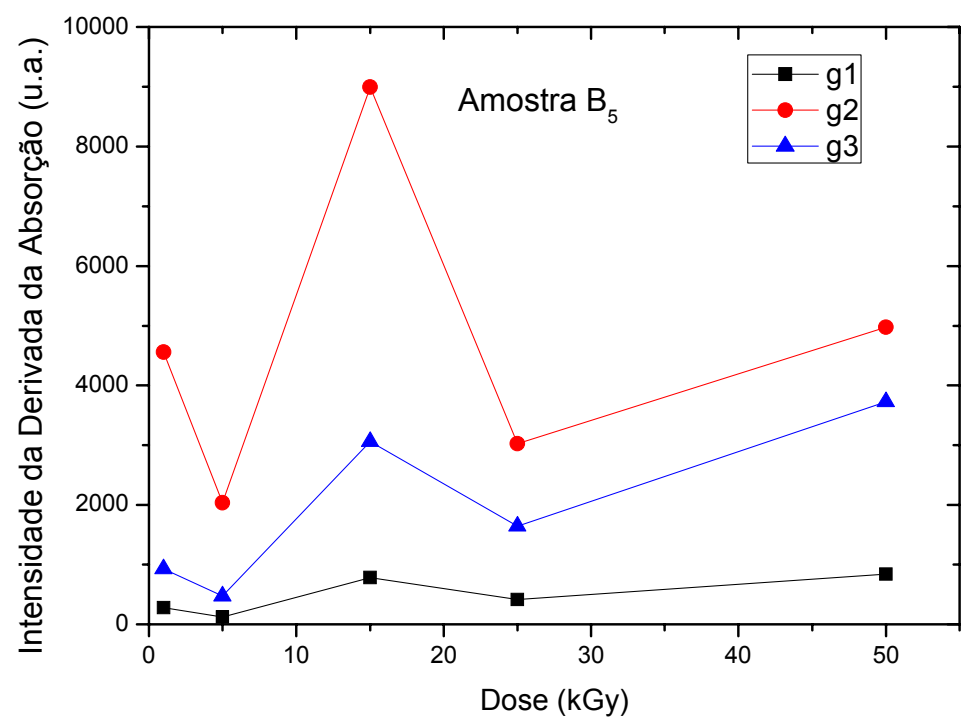

Figura 111 - Evolução das intensidades de RPE das ressonâncias $g_{1}, g_{2}$ e $g_{3}$ da amostra $B_{5}$, com a dose (kGy). 
Vale observar que as barras de erro dos gráficos das figuras 110 e 111 são da ordem de grandeza das dimensões dos pontos.

\subsubsection{Centro de buraco do oxigênio não interligante (non-bridging oxygen hole center) (NBOHC)}

A resposta paramagnética das amostras $B_{3}$ e $C_{1}$, verificada por meio da ressonância $g_{2}$ (vide figura 103) apresentou-se bastante sensível à quantidade do elemento modificador do vidro contido em sua composição química. Como é bem conhecido, a adição de óxido modificador implica, em geral, na presença de quantidades crescentes de centros de buracos de oxigênio terminal (NBOHC) na matriz vítrea. Esta linha de RPE foi observada por Prohaska [1] pela primeira vez, tendo atribuído esse resultado às armadilhas relacionadas com modificadores sem, contudo, fornecer maiores detalhes.

É bem sabido que nos vidros teluritos alcalinos, para cada carga positiva de um cátion adicionado, aparece um oxigênio não interligante (NBO) na rede vítrea [5]. Portanto, é aparente que a acima mencionada dependência da ressonância $g_{2}$ em relação às armadilhas relacionadas com os modificadores não ocorre diretamente, mas a sua intensidade de RPE é regida pela concentração de NBO's. Então, sugerimos que o defeito induzido por radiação correspondente é o centro paramagnético que consiste de um NBO ionizado, isto é, um centro NBOHC [6]. Portanto, espera-se que a intensidade da linha de RPE de um NBOHC cresça com a concentração dos óxidos modificadores. Este comportamento foi observado para a ressonância $g_{2}$ (vide figuras 107 e 108) para as amostras $\mathrm{B}_{3}(25 \% \mathrm{Zn}+15 \% \mathrm{Na}=$ $40 \%$ total) e $\mathrm{C}_{1}(15 \% \mathrm{Na})$. Nenhum sinal foi observado com as características de um possível centro de elétron alcalino (AEC), tal como o que foi observado por Griscom nos vidros boratos [7], provavelmente encoberto pelas linhas restantes dos nossos espectros de RPE dos vidros teluritos.

À medida que quantidades crescentes de um óxido alcalino $\mathrm{M}_{2} \mathrm{O}$ são introduzidos na composição do vidro, os íons de oxigênio são totalmente absorvidos pela rede vítrea covalente e a representação esquemática efetiva da figura 112a mostra que o resultado equivalente à quebra de uma ligação cria um par de 
extremidades que terminam em NBO's, cada um compensado pela carga positiva do cátion $\mathrm{M}^{+}$(vide figura 112). Na realidade, essa reação ocorre ainda na fase fundida, durante o processo de preparação do vidro. Portanto, assim como o sistema está continuamente buscando o equilíbrio termodinâmico, de acordo com a lei de ação das massas [8], as reações inversas também são prováveis de ocorrer, conforme está indicado na figura 112b, no qual a possível reconstrução da ligação foi assumida como menos provável, por simplicidade, resultando no par eletricamente carregado de um NBO- e uma vacância de oxigênio $\left(\mathrm{V}_{\mathrm{o}}^{+}\right)$e deixando uma molécula $\mathrm{M}_{2} \mathrm{O}$ que acabou, neste caso, participando como catalisador da produção de defeitos $\mathrm{V}_{\mathrm{o}}^{+}$no vidro. Essa reação pode, então, ser descrita como

$$
2 \mathrm{NBO}^{-}+2 \mathrm{M}^{+} \leftrightarrow \mathrm{NBO}^{-}+\mathrm{V}_{\mathrm{o}}^{+}+\mathrm{M}_{2} \mathrm{O}
$$

A molécula $\mathrm{M}_{2} \mathrm{O}$ pode repetir o processo até finalmente ser absorvida definitivamente pela rede vítrea, deixando em seu lugar um par de NBO's com as suas cargas respectivamente compensadas por um par de cátions $\mathrm{M}^{+}$, resultando na produção de um quadrupolo local.

Quando o par $\left(\mathrm{NBO}^{-}, \mathrm{V}_{\mathrm{o}}^{+}\right)$é exposto à ação de uma fonte de radiação ionizante, ocorre o salto de um elétron do $\mathrm{NBO}^{-}$para $\mathrm{V}_{\mathrm{O}}^{+}$produzindo um par eletricamente neutro, o $\mathrm{NBOHC}^{\circ}$ e o centro de elétron do telúrio $\left(\mathrm{TeEC}^{\circ}\right)$, vide figura 112c, indicando a reação

$$
\mathrm{NBO}^{-}+\mathrm{V}_{\mathrm{o}}^{+} \leftrightarrow \mathrm{NBOHC}^{\mathrm{o}}+\mathrm{TeEC}^{\mathrm{o}}
$$

A constante de equilíbrio $K_{1}$ desta equação é dada pelas concentrações dos centros reagentes

$$
\mathrm{k}_{1}=\left[\mathrm{NBOHC}^{\mathrm{o}}\right]\left[\mathrm{TeEC}^{\mathrm{o}}\right] /\left[\mathrm{NBO}^{-}\right]\left[\mathrm{V}_{\mathrm{o}}^{+}\right] \text {. }
$$

Uma outra reação esperada sob o efeito da irradiação é a transferência de carga dos NBO's para o par de cátions $\mathrm{M}^{+}$, produzindo o par eletricamente neutro de $\mathrm{NBOHC}^{\circ}$ e $2 \mathrm{M}^{\circ}$

$$
2 \mathrm{NBO}^{-}+2 \mathrm{M}^{+} \leftrightarrow 2 \mathrm{NBOHC}+2 \mathrm{M}^{\mathrm{o}}
$$

Cuja constante de equilíbrio $K_{2}$ é dado por

$$
\mathrm{k}_{2}=\left[\mathrm{NBOHC}^{\mathrm{o}}\right]\left[\mathrm{M}^{\mathrm{o}}\right] /\left[\mathrm{NBO}^{-}\right]\left[\mathrm{M}^{+}\right] \text {. }
$$




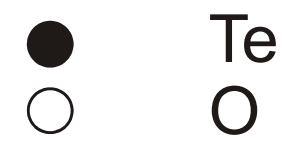

a)
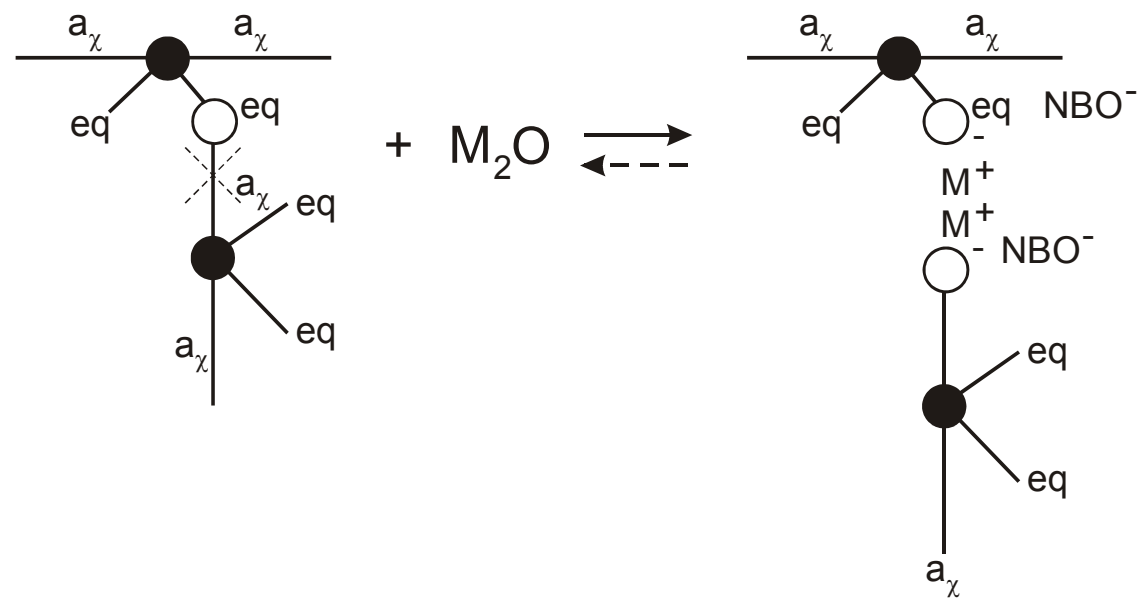

b)
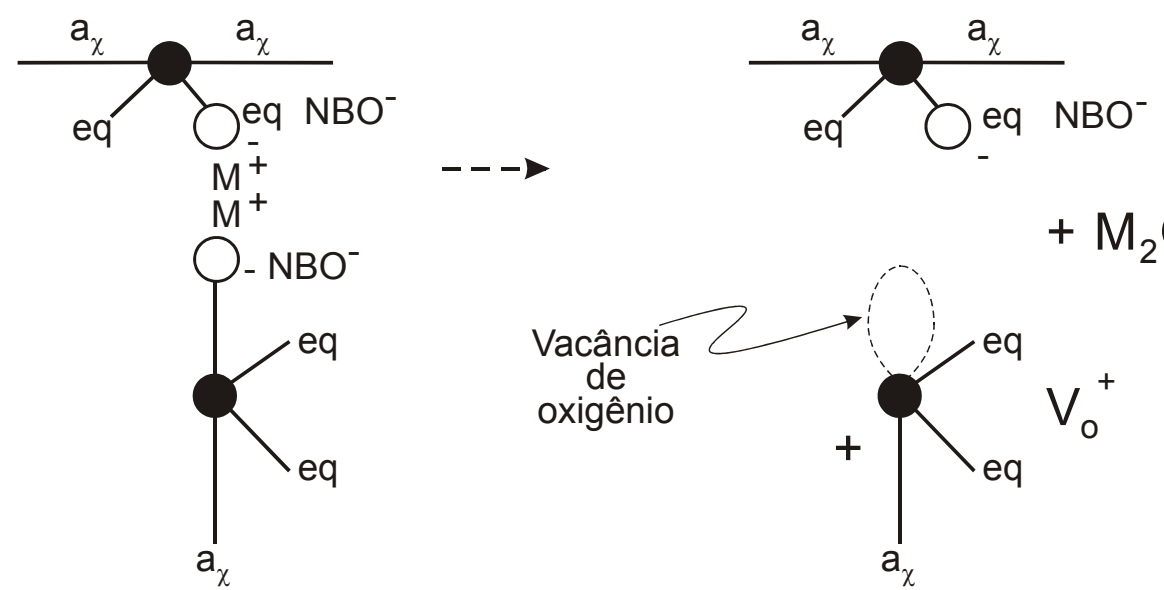

$$
+\mathrm{M}_{2} \mathrm{O}
$$

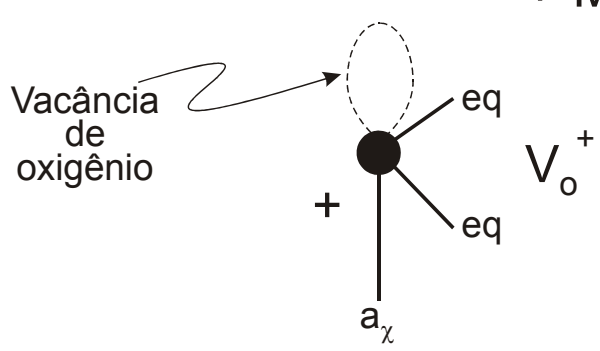

c)
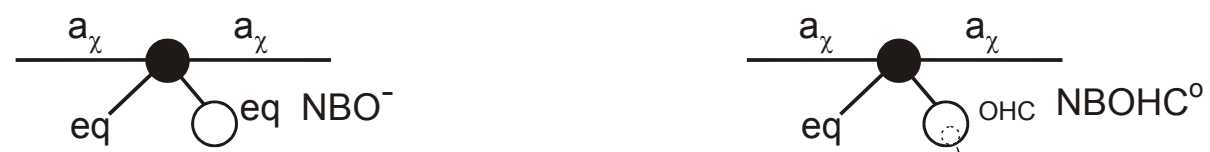

Irradiação
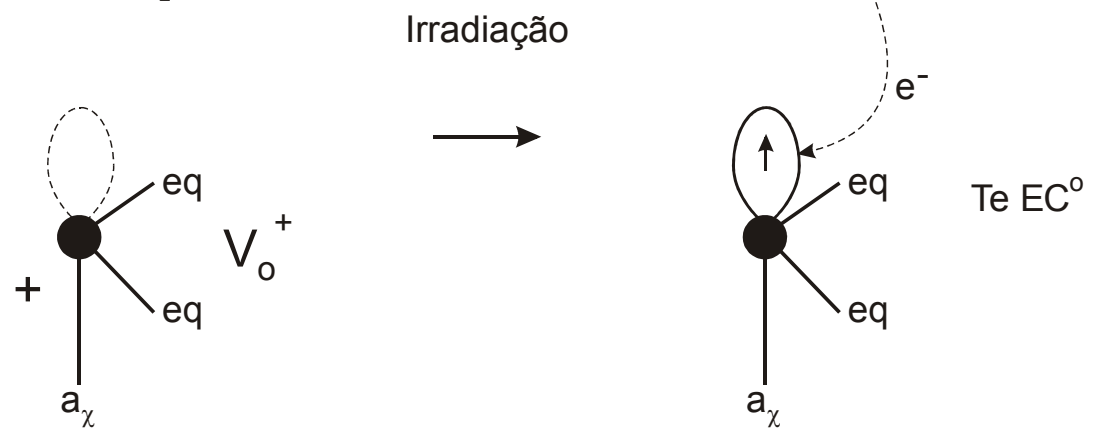

Figura 112 - Formação por meio da quebra de ligação, de um par de NBO's com as respectivas cargas compensadas pelos cátions $\mathrm{M}^{+}$; b) Reação parcial reversa, onde a molécula $\mathrm{M}_{2} \mathrm{O}$ é removida, deixando um par que se atrai mutuamente, $\mathrm{NBO}^{-}$e a vacância de oxigênio $\mathrm{V}_{\mathrm{o}}^{+}$; c) Efeito da radiação ionizante 
sobre o par $\left(N B O^{-}, \mathrm{V}_{0}^{+}\right)$, resultando o par eletricamente neutro (NBOHC, TeEC). Vale lembrar que a ligação axial é meramente ilustrativa. Resultado publicado em Giehl e colaboradores [2].

\subsubsection{Centro de elétron do telúrio (TeEC)}

A ressonância bem resolvida e estreita, identificada na figura 103 como $g_{3}$, foi observado por Prohaska [1] pela primeira vez, tendo sido atribuída a um centro de vacância de oxigênio do tipo $\mathrm{V}_{\mathrm{o}}^{+}$, este centro é bem caracterizado e relativamente estável à temperatura ambiente, como foi reportado por Prohaska e confirmado pelo presente trabalho. Os centros de elétrons da maioria dos vidros óxidos tais como, por exemplo, o centro de elétron do boro (BEC) [9], encontrado nos vidros boratos são muito sensíveis ao spin nuclear do cátion formador do vidro e, portanto, o valor de $g$ é avaliado por meio de um cálculo indireto que utiliza os dados da estrutura hiperfina que são obtidos por RPE. Os nossos resultados sobre vidros teluritos indicam um valor bem definido de $\mathrm{g}_{3}$ para o elétron capturado no orbital pendente $\mathrm{e}$ a sua maior estabilidade sugere um estado mais localizado.

$O$ nosso resultado $g_{3}=1,9700 \pm 0,0005$ é consistente com a identificação de RPE de centros de vacância de oxigênio no paratelurito cristalino irradiado com feixe de elétrons estudados por A. Watterich e colaboradores [10].

Eles efetuaram também uma análise detalhada de uma linha intensa de um centro de spin $\frac{1}{2}$ com $92,14 \%$ de isótopos nucleares do Te com spin 0 e uma análise dos restantes $7,86 \%$ spins nucleares $\frac{1}{2}$. O deslocamento médio hiperfino chegou a aproximadamente $30 \mathrm{G}$, de modo que em nossas amostras de vidro esta fraca resposta foi alargada e encoberta por outras ressonâncias superpostas.

\subsubsection{Centro de buraco de telúrio e oxigênio (TeOHC)}


O perfil que se obtém com a subtração das ressonâncias $g_{2}$ e $g_{3}$ do espectro de RPE da amostra $B_{3}$ irradiada à temperatura ambiente é mostrada na figura 113. O espectro resultante com $g_{\|}=g_{1}=2,02 \pm 0,01$ e $\Delta H_{p p}=(1,5 \pm 0,5) G$ e $\mathrm{g}_{\perp} \sim 2,0$ foi atribuído ao centro de buraco de telúrio e oxigênio ( $\mathrm{TeOHC}$ ).

A linha atribuída ao TeOHC por Prohaska e colaboradores [1] em nossa opinião deve ser um artefato, pois não se espera a presença de centros de buraco sem previa irradiação, portanto a linha com $g=2,0747 \pm 0,0005$ é provavelmente a ressonância de alguma impureza presente no vidro.

$\mathrm{O}$ mecanismo de formação do $\mathrm{TeOHC}$ se dá da seguinte forma: um elétron é emitido de um oxigênio BO sob o efeito da radiação ionizante, este elétron ou é capturado por um cátion próximo, ou por uma vacância de oxigênio para formar um centro de elétron de um álcali ou um centro de elétron do telúrio (TeEC), respectivamente, conforme mostrado na figura 114.

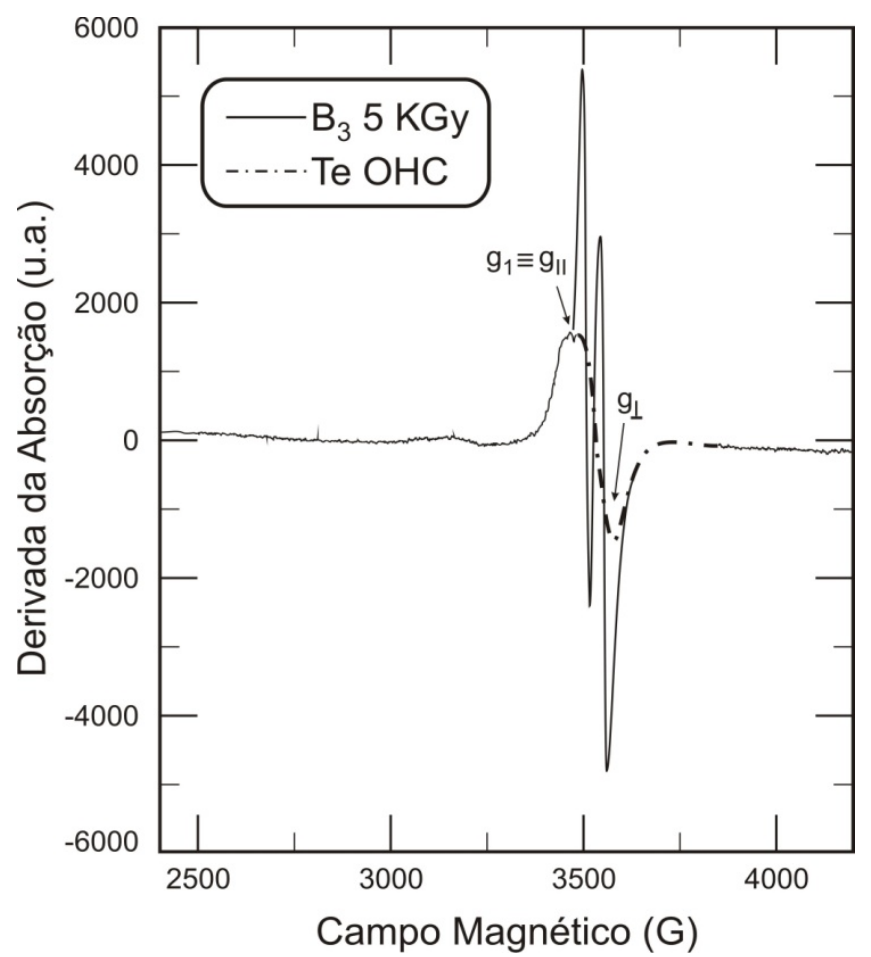

Figura 113 - Espectro de RPE da linha de TeOHC (linha pontilhada), após a subtração das ressonâncias $g_{1}$ e $g_{2}$, da amostra $B_{3}$ irrradiada com dose de $5 k G y$. Resultado publicado por Giehl e colaboradores [2]. 


\section{- Te \\ $\bigcirc \mathrm{O}$}
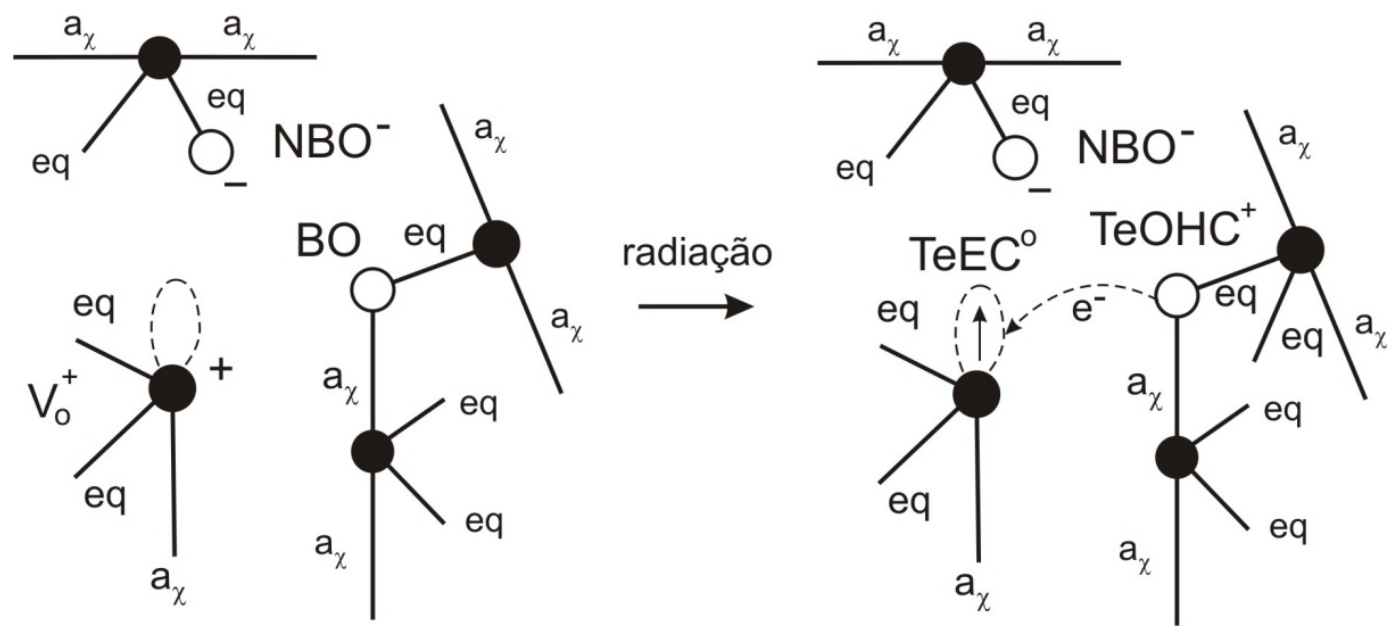

Figura 114 - Modelo de formação do TeOHC. A notação das ligações é meramente ilustrativa.

\subsubsection{Evolução das intensidades das ressonâncias $g_{1}, g_{2}$ e $g_{3} \operatorname{com}$ a dose crescente de irradiação}

Nesta seção é feita uma análise comparativa do comportamento das intensidades de RPE da amostra $B_{3}$, com alto conteúdo de elemento modificador, com $\mathrm{C}_{1}$ contendo baixo índice de elemento alcalino e ausência de $\mathrm{Zn}$, em função da dose de irradiação, conforme as representações mostradas nas figuras 107 e 108, respectivamente.

Após a irradiação com dose de $1 \mathrm{KGy}$ observou-se que na amostra $B_{3}$, contendo maior quantidade de elemento modificador, a intensidade de $g_{2}$ indica uma concentração de NBOHC de aproximadamente quatro vezes maior do que a da amostra $C_{1}$, o que é uma conseqüência da maior quantidade de NBO's precursores da amostra precedente (vide figura 112) e equações 4.9.3.1, 4.9.3.2 e 4.9.3.3) produzindo NBOHC's sob a ação da radiação ionizante. O subseqüente decréscimo de NBOHC's pode ser explicado pela radiólise expressa pela reação 4.9.3.4 e 
4.9.3.5 (vide figura 115), desde a condição de equilíbrio da reação $k_{1}>>k_{2}$ esteja satisfeita também é possível que ocorra a reação reversa 4.9.3.2 (recombinação elétron-buraco) também ocorra a irradiação e que contribui com o decréscimo de NBOHC's no intervalo de 1 kGy a $5 \mathrm{kGy}$. Observa-se claramente que para a amostra $\mathrm{C}_{1}$ (vide figura 108), no vidro com baixo índice de modificador, os NBO's e as vacâncias de oxigênio ocorrem aos pares (vide figura 112b) e sob irradiação os pares NBOHC e TeEC tendem a permanecer unidos, de modo que a probabilidade da recombinação entre elétrons e buracos permanece elevada.

Para a mostra $\mathrm{B}_{3}$, com índice mais elevado de íons modificadores, irradiada com a dose inicial (1 kGy), a produção de NBOHC's já atingiu a saturação e para as doses subseqüentes decresce devido à radiólise exercida pela radiação (figura 115). $O$ crescimento supralinear de TeEC, presente na amostra $B_{3}$ mas não em $C_{1}$, pode ser explicado como o resultado da alta quantidade de vacâncias de oxigênio criadas pela ação da radiólise, ao quebrar as ligações de um grande número de NBO's presentes nas estruturas isoladas de $\mathrm{Te}_{2} \mathrm{O}_{5}^{2-}$ e $\mathrm{TeO}_{3}^{2-}[11,5]$, presentes nos vidros teluritos possuindo alto conteúdo de modificadores e, portanto, alta concentração de NBO's.

O perfil de crescimento das ressonâncias $g_{1}, g_{2}$ e $g_{3}$ da amostra $C_{1}$, no intervalo de 5 kGy a 15 kGy, é uma conseqüência da formação de novas vacâncias de oxigênio produzidas pela radiólise das ligações de oxigênio ao longo de toda a rede vítrea, de modo que foi criada uma população adicional de novas armadilhas para elétrons e buracos produzidos pela ação ionizante da fonte de radiação. Acima de 15 kGy observa-se um simultâneo decrescimento de todas as três ressonâncias, o que é um efeito típico de recombinação de elétrons e buracos, o que se torna preponderante após o esgotamento da produção dos respectivos precursores. Para as doses mais elevadas que se seguem existe a tendência das reações do sistema entrar em equilíbrio. 

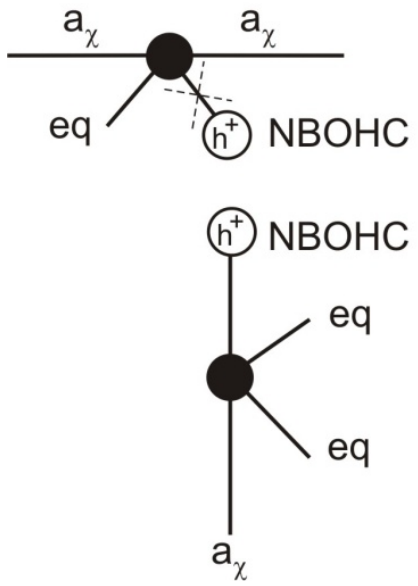

radiação
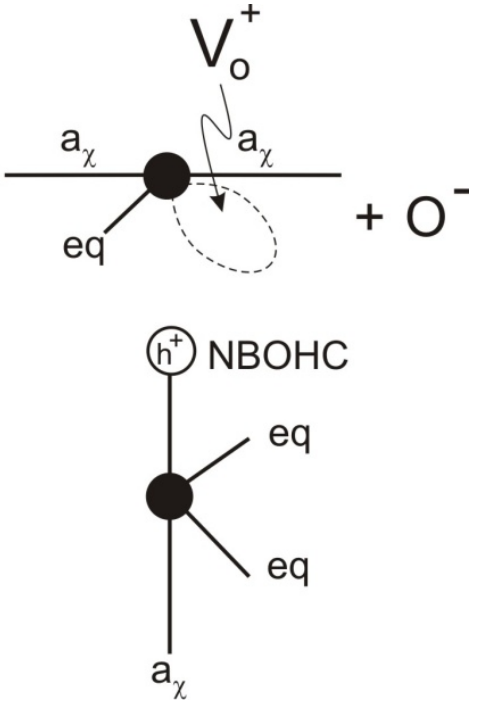

Figura 115 - Representação esquemática do processo da diminuição da intensidade da ressonância $\mathrm{g}_{2}(\mathrm{NBOHC})$, resultando em uma vacância de oxigênio e um ânion $O^{-}$. A notação das ligações é meramente ilustrativa. Resultado publicado por Giehl e colaboradores [2].

\subsubsection{Curva isócrona}

Com a finalidade de observar o comportamento do decaimento térmico das intensidades das linhas em $g_{1}, g_{2}$ e $g_{3}$ bem como o limite de temperatura no qual os centros de defeitos são extintos, construímos a curva isócrona das amostras $B_{2}, B_{3}$, $\mathrm{B}_{5}$ e $\mathrm{C}_{1}$ irradiadas com raios gama, com dose de $1 \mathrm{kG}$ e tratadas termicamente durante 10 minutos em cada temperatura. Os gráficos da intensidade relativa versus temperatura das amostras $B_{3}, C_{1}, B_{2}$ e $B_{5}$ seguem nas figuras $116,117,118$ e 119. Uma característica comum de todas as curvas é de que a ressonância em $g_{1}$ não é completamente extinta até a temperatura de $140^{\circ} \mathrm{C}$. Também nessas figuras as barras de erro experimental são da ordem do tamanho dos pontos representados.

Para as amostras $B_{3}$ e $C_{1}$ os centros em $g_{2}$ e $g_{3}$ são extintos nas temperaturas de $140^{\circ} \mathrm{C}$ e $160^{\circ} \mathrm{C}$, respectivamente.

Para as amostras $B_{2}$ e $B_{5}$ (figuras 118 e 119) os centros $g_{2}$ e $g_{3}$ são completamente extintos em $160^{\circ} \mathrm{C}$. 


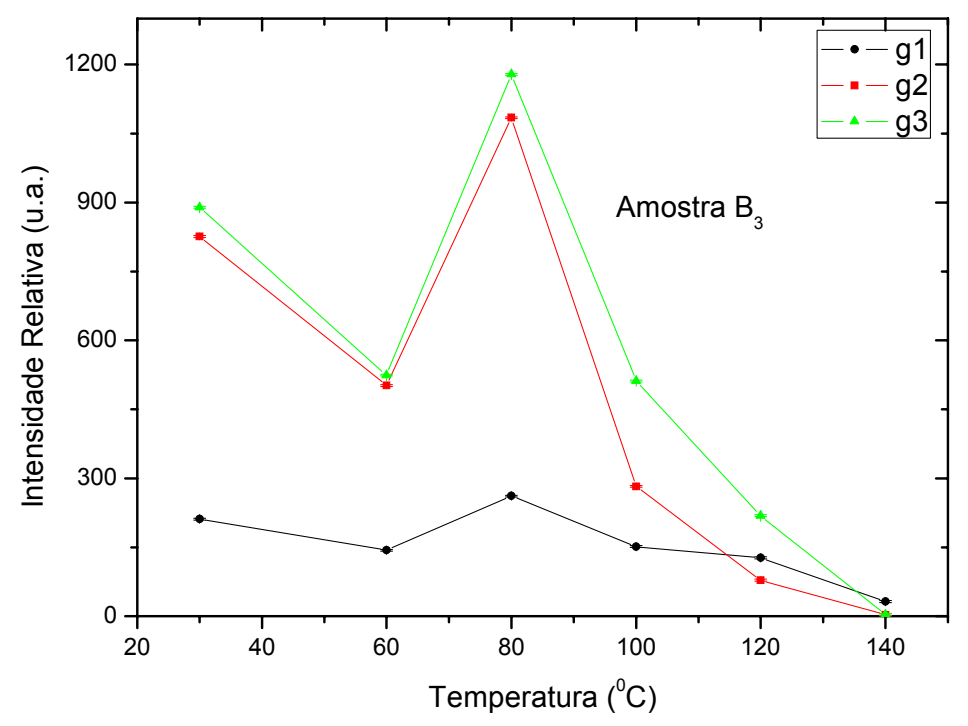

Figura 116 - Curva isócrona da amostra $B_{3}$.

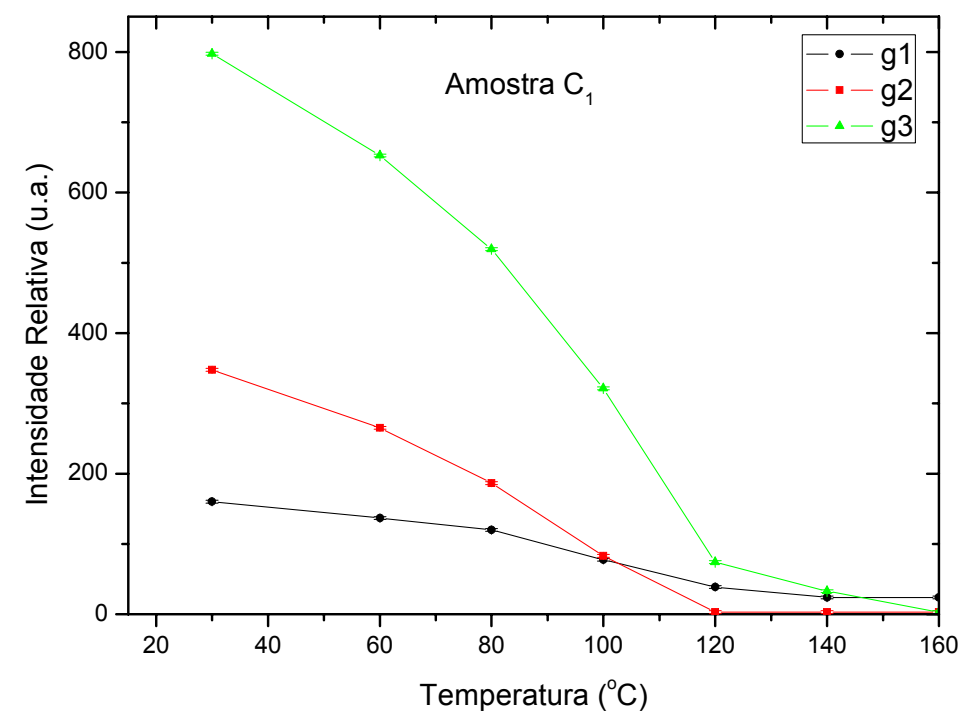

Figura 117 - Curva isócrona da amostra $C_{1}$.

Ao comparar as curvas de decaimento isócrono das intensidades de RPE $g_{1}$, $\mathrm{g}_{2}$ e $\mathrm{g}_{3}$ das amostras do vidro telurito de sódio e zinco (amostra $\mathrm{B}_{3}$ ) com a do vidro telurito de sódio, sem a presença de zinco (amostra $C_{1}$ ), mostradas nas figuras 116 e 117, respectivamente, constatamos que as três curvas da amostra $C_{1}$ decaem 
monotonicamente, o que indica simplesmente que o centro de elétron $\operatorname{TeEC}^{\circ}$ e $\mathrm{TeOHC}^{+}$previamente formados durante a irradiação, recombinam entre si até a sua mútua extinção quase completa. Devido à presença do zinco na composição química, após um decréscimo inicial não radioativo (I) entre $30 \leq \mathrm{TT} \leq 60^{\circ} \mathrm{C}$, observa-se a partir do TT a $60^{\circ} \mathrm{C}$ um crescimento de todos os três centros até atingir um máximo em $80^{\circ} \mathrm{C}$, seguido de um rápido decréscimo até o TT em $100^{\circ} \mathrm{C}$, para então as curvas retomarem o decaimento monotônico semelhante ao observado para a amostra $\mathrm{C}_{1}$.

A completa extinção de $\mathrm{NBOHC}^{\circ}$ e $\mathrm{TeEC}^{\circ}$ se estende até o TT de $140^{\circ} \mathrm{C}$ e o aparecimento da emissão $\mathrm{TL}$ ocorre apenas às temperaturas superiores a $130^{\circ} \mathrm{C}$, sendo que a maior intensidade foi observada para a amostra $B_{2}$, o que nos leva à conclusão de que existe pelo menos um centro não paramagnético (e por isso mesmo não detectado por RPE) responsável pela TL observada em uma faixa de temperaturas mais altas do que a esperada. Nessas condições, fomos levados a sugerir a hipótese abaixo para os possíveis mecanismos de transferência de carga envolvidos nos processos de irradiação e TT.

Considerando a situação altamente provável de um íon $\mathrm{Zn}^{2+}$ compensando a carga de dois NBO's adjacentes, conforme indicado na figura 120a, na vizinhança de um par $\left(\mathrm{NBO}^{-}, \mathrm{V}_{\mathrm{o}}^{+}\right)$onde a vacância de oxigênio está compensando a carga do terceiro $\mathrm{NBO}^{-}$da mesma unidade bipiramidal da estrutura do vidro telurito. Sob irradiação, dois elétrons provenientes do par de NBO's vizinhos são transferidos do zinco para formar um par de NBOHC's e $\mathrm{Zn}^{\circ}$. Durante o TT entre 30 e $60^{\circ} \mathrm{C}$, na fase I, o par de NBOC's torna-se não paramagnético por meio da transferência de um elétron de um para o outro, formando um par de valências alternada $\left(\mathrm{NBO}^{-}, \mathrm{NBOHC}^{+}\right)$, no qual o centro $\mathrm{NBOHC}^{+}$possui dois buracos. Nas fases seguintes do $\mathrm{TT}, \mathrm{o} \mathrm{Zn}^{\circ}$ transfere dois elétrons à vacância de oxigênio próxima, em duas etapas:

$$
\begin{aligned}
& \mathrm{Zn}^{0}+\mathrm{V}_{0}^{+} \stackrel{\mathrm{TT}\left(60-80^{\circ} \mathrm{C}\right)}{\longrightarrow} \mathrm{Zn}^{+}+\mathrm{TeEC}^{0} \\
& \mathrm{Zn}^{+}+\mathrm{TeEC}^{0} \stackrel{\mathrm{TT}\left(80-100^{\circ} \mathrm{C}\right)}{\longrightarrow} \mathrm{Zn}^{2+}+\mathrm{TeEC}^{-}
\end{aligned}
$$


$\mathrm{Na}$ fase (II) verifica-se o crescimento do $\mathrm{TeEC}^{0}$ que foi identificado como o centro responsável pela ressonância em $\mathrm{g}_{3}$.

Já na fase III, à medida que o $\operatorname{TeEC}^{\circ}$ pasa a receber o segundo elétron, o orbital da vacância de oxigênio passa a ter um par de elétrons com spins emparelhados, de modo que o sinal de EPR de $g_{3}$ passa a decrescer. $O$ centro $\mathrm{TeEC}^{-}$é, conseqüentemente, mais estável e sobrevive até a faixa de temperaturas $\geq 130^{\circ} \mathrm{C}$ onde se observa a emissão TL. Como a composição química da amostra $\mathrm{B}_{3}$ também contém $\mathrm{Na}^{+}$compensando carga com $\mathrm{NBO}^{-}$o decaimento térmico correspondente ao $\mathrm{TT}$ para $30 \leq \mathrm{TT} \leq 60^{\circ} \mathrm{C}$ e $100 \leq \mathrm{TT} \leq 140^{\circ} \mathrm{C}$ pode ser explicado pela reação:

$$
\mathrm{NBOHC}^{0}+\mathrm{TeEC}^{-} \rightarrow \mathrm{NBO}^{-}+\mathrm{V}_{0}^{+} \text {. }
$$

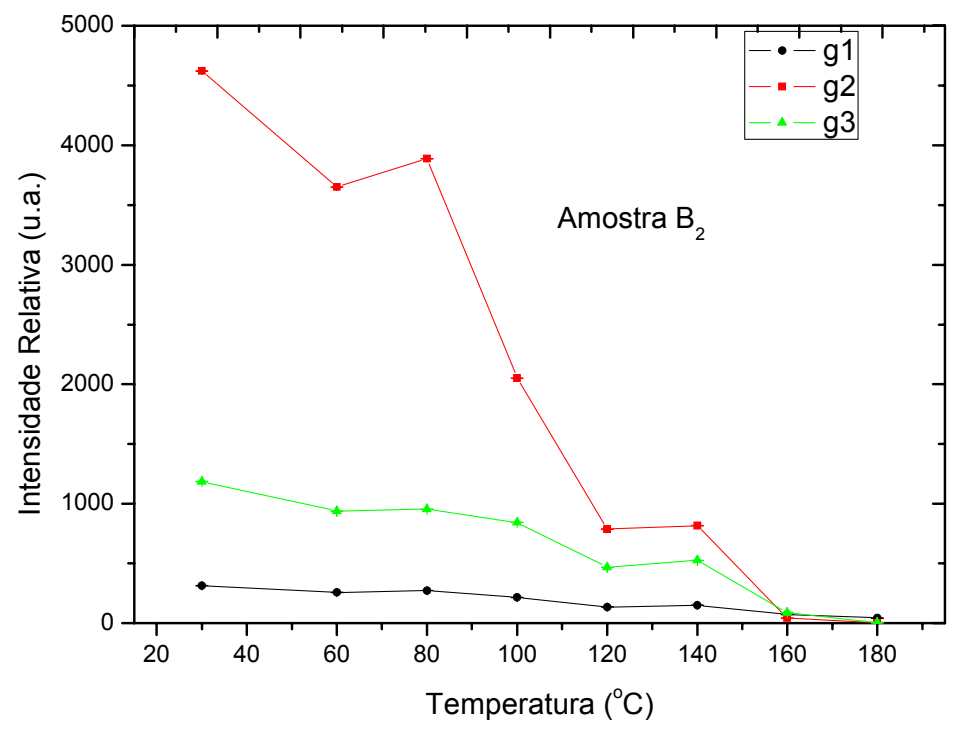

Figura 118 - Curva isócrona da amostra $B_{2}$. 


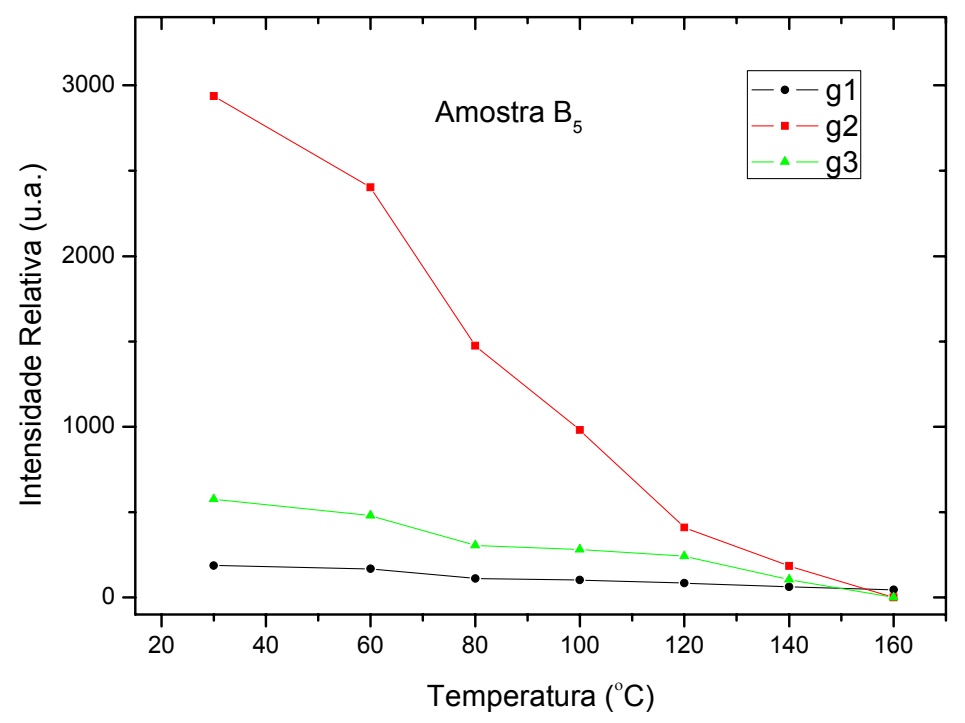

Figura 119 - Curva isócrona da amostra $B_{5}$.

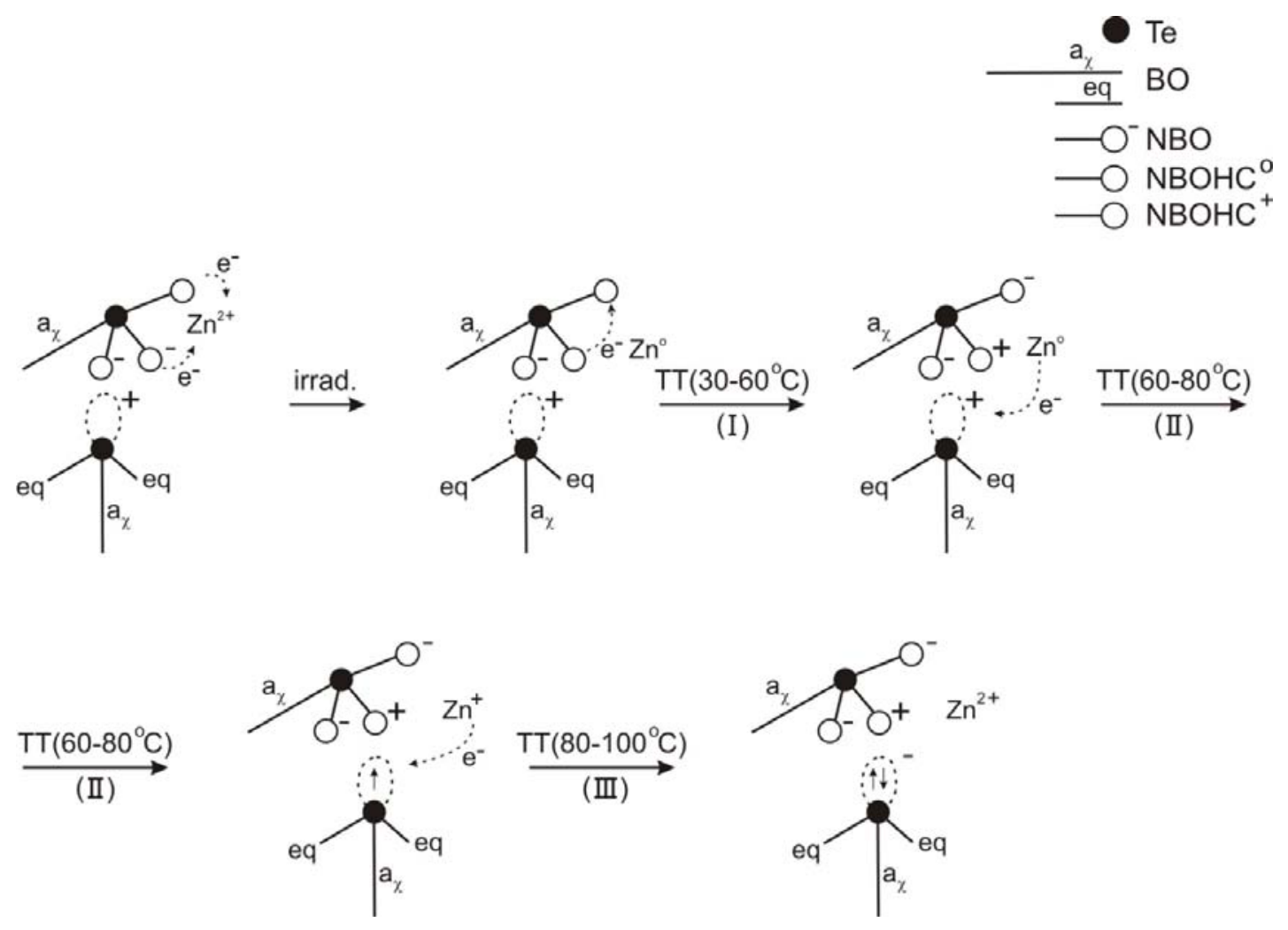

Figura 120 - Mecanismo de formação do TeEC. A notação das ligações é meramente ilustrativa. 


\subsubsection{Referências}

[1] Prohaska, J. D.; Wang, J. S.; Bartram, R. H. Eletron spin resonance observations of excimer-laser-induced paramagnetic centers in tellurite glasses. Appl. Phys. Lett., v. 67, n. 13, p. 1841-1843, 1995.

[2] Giehl, J. M.; Pontuschka, W. M.; Barbosa, L. C.; Ludwig, Z. M. C. EPR of Yinduced paramagnetic centers in tellurite glasses. J. Non-Crys. Solids, v. 356, p. 1762-1767, 2010.

[3] Kanth, C. L.; Raghavaiah, B. V.; Appa Rao, B.; Veeraiah, N. Spectroscopic investigations on $\mathrm{ZnF}_{2}-\mathrm{MO}-\mathrm{TeO}_{2}(\mathrm{MO}=\mathrm{ZNO}, \mathrm{CdO}$ and $\mathrm{PbO})$ glasses doped with chromium ions. J. Quant. Spectrosc. Radiat. Trans., v. 90, p. 97-113, 2005.

[4] Naga Raju, G.; Srinivasa Reddy, M.; Sudhakar, K. S. V.; Veeraiah, N. Spectroscopic properties of copper ions in $\mathrm{ZnO}^{-} \mathrm{ZnF}_{2}-\mathrm{B}_{2} \mathrm{O}_{3}$ glasses. Opt. Mat., v. 29, p. 1467-1474, 2007.

[5] Sekiya, T.; Mochida, N.; Ohtsuka, A.; Tonokawa, M. Raman Spectra of $\mathrm{MO}_{1 / 2}-$ $\mathrm{TeO}_{2}(\mathrm{M}=\mathrm{Li}, \mathrm{Na}, \mathrm{K}, \mathrm{Rb}, \mathrm{Cs}$, and Ti) glasses. J. Non-Cryst. Solids, v. 144, p. 128-145, 1992.

[6] Stapelbroek, M.; Griscom, D. L.; Friebele, E. J.; Sigel,Jr., G. H. Oxygenassociated trapped-hole centers in high-purity fused silicas. J. Non-Cryst. Solids, v. 32, p. 313, 1979.

[7] Griscom, D. L. E.S.R. studies of radiation damage and structure in oxide glasses not containing transition group ions: A contemporary overview with illustrations from the alkali borate system. J. Non-Cryst. Solids, v. 13, p. 251, 1973/74.

[8] Sienko, M.; Plane, R. "Chemistry", McGraw-Hill Book Company, Inc., p.253, 1961.

[9] Griscom, D. L. ESR Studies of an Intrinsic Trapped-Electron Center in X-Irradiated Alkali Borate Glasses. J. Chem. Phys., v. 55, p. 1113, 1971.

[10] Waterich, A.; Bartram, R. H.; Gilliam, O, R.; Kappers, L. A.; Edwards, G. J.; Földvári, I.; Voszka, R. ESR identification of radiation-induced oxygen vacancy centers in paratellurite. Phys. Rev. B, v. 32 n. 4, p. 2533, 1985.

[11] Neov, S.; Kozhukharov, V.; Gerasimova, I.; Krezhov, K.; Sidzhimov, B. A model for structural recombination in tellurite glasses. J. Phys. C: Solid State Phys., v. 12, p. 2475, 1979. 


\subsection{Medidas de densidade dos vidros}

$\mathrm{Na}$ tabela 32 seguem os resultados das medidas de densidade realizadas pelo método de Arquimedes para as amostras da série $A$ e $B$ e para a amostra $C_{1}$.

$\mathrm{A}$ amostra $\mathrm{A}_{3}$ apresenta um resultado próximo ao de Prakash e colaboradores [1] para o vidro $\left(10 \mathrm{Na}_{2} \mathrm{O}-10 \mathrm{Nb}_{2} \mathrm{O}_{5}-80 \mathrm{TeO}_{2}\right)$ vide tabela 1 , considerando as diferenças estequiométricas entre as duas amostras.

Os valores das densidades e dos índices de refração linear crescem com o aumento da concentração de $\mathrm{AgNO}_{3}$ para as amostras da série $\mathrm{B}$. É fácil verificar que este aumento mantém o volume molar do vidro praticamente constante e, portanto, não ocorre qualquer mudança estrutural significativa nos vidros dopados com prata.

Tabela 32 - Resultados das medidas de densidade.

\begin{tabular}{|l|l|}
\hline Amostra & Densidade $\frac{\mathrm{g}}{\mathrm{cm}^{3}}$ \\
\hline $\mathrm{A}_{2}$ & $5,4604 \pm 0,0005$ \\
\hline $\mathrm{A}_{3}$ & $5,2960 \pm 0,0005$ \\
\hline $\mathrm{A}_{4}$ & $5,3580 \pm 0,0005$ \\
\hline $\mathrm{A}_{5}$ & $5,3224 \pm 0,0005$ \\
\hline $\mathrm{B}_{2}$ & $4,9960 \pm 0,0007$ \\
\hline $\mathrm{B}_{3}$ & $4,8840 \pm 0,0007$ \\
\hline $\mathrm{B}_{5}$ & $5,1200 \pm 0,0007$ \\
\hline $\mathrm{C}_{1}$ & $4,9770 \pm 0,0005$ \\
\hline
\end{tabular}

\subsubsection{Referências}

[1] Prakash, G. V.; Rao, D. N.; Bhatnagnar, A. K. Linear optical properties of niobiumbased tellurite glasses. Solid State Comm., v. 119, p. 39-44, 2001. 


\section{Capítulo 5}

\section{Sumário e conclusões}

\subsection{Sumário dos resultados de absorção óptica (AO) das amostras dopadas com prata, com posterior tratamento térmico e microscopia eletrônica de transmissão (TEM)}

As amostras da série A não apresentaram a precipitação de nanopartículas de prata. A partir do modelo proposto na seção 4.2.2 propomos que a precipitação da prata metálica se dá por meio da degeneração da rede vítrea mediante a quebra das ligações covalentes do NBO's e a liberação de um oxigênio.

As amostras da série $\mathrm{B}$ dopadas com $\mathrm{AgNO}_{3}$ apresentaram a precipitação de nanopartículas de prata. Para a amostra $\mathrm{B}_{2}$, dopada com $0,5 \mathrm{~mol} \%$ de $\mathrm{AgNO}_{3}$, a banda de plasmons esta centrada em 446, 455 e $466 \mathrm{~nm}$ para os tratamentos térmicos de $270^{\circ} \mathrm{C}, 290^{\circ} \mathrm{C}$ e $310^{\circ} \mathrm{C}$ com duração de 2 horas. Podemos observar que com o aumento da temperatura de tratamento, a banda cresceu e apresentou um deslocamento para o vermelho, característico de um sistema de nanopartículas sendo depositado, com partículas aumentando em tamanho de $(5 \pm 1) \mathrm{nm},(7 \pm 1)$ $\mathrm{nm}$ e $(13 \pm 1) \mathrm{nm}$; respectivamente.

Para a amostra $\mathrm{B}_{5}$ dopada com $0,5 \mathrm{~mol} \%$ de $\mathrm{AgNO}_{3}$, o tratamento térmico a $270^{\circ} \mathrm{C}$ e $290^{\circ} \mathrm{C}$ por 2 horas produziu uma discreta redução da intensidade do pico e, portanto, do número de partículas, indicando que ocorreu ou uma dissolução ou então um agrupamento, já nesta fase do tratamento térmico.

Provamos que a precipitação das nanopartículas de prata foi superficial e mesmo para aquelas que estão mergulhadas na matriz vítrea localizam-se na região superficial.

A amostra $\mathrm{B}_{5}$, dopada com $5 \mathrm{~mol} \%$ de $\mathrm{AgNO}_{3}$, tratada termicamente a $270^{\circ} \mathrm{C}$ por 2 horas apresentou partículas aproximadamente esféricas, com diâmetro médio de $(9 \pm 1) \mathrm{nm}$, formando inclusive aglomerados. Após tratamento a $290^{\circ} \mathrm{C}$ por 2 horas, foram observados precipitados isolados, assim como também aglomerados, o tamanho médio das nanopartículas é de aproximadamente $(17 \pm 1) \mathrm{nm}$. Não foram encontradas partículas no interior da matriz vítrea da amostra $B_{5}$. 


\subsection{Sumários dos resultados ópticos}

Os valores do índice de refração linear das amostras da série A concordam com a literatura.

Nas amostras da série B a adição de prata evidenciou um sensível aumento do índice de refração linear entre as amostras $B_{2}$ e $B_{3}$.

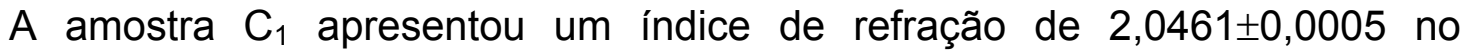
comprimento de onda de $632,8 \mathrm{~nm}$, sendo este valor mais elevado comparado a amostra $\mathrm{B}_{3}$ para o mesmo comprimento de onda. Isto ocorreu devido a adição de $\mathrm{ZnO}$ em substituição a determinada parte de $\mathrm{TeO}_{2}$.

Os resultados das energias dos gaps ópticos sugerem que dentro do intervalo de incerteza as amostras da série A não apresentam diferenças significativas e conferem com a literatura para os vidros com estequiometria próxima. Já as amostras da série $B$ apresentam uma pequena diferença sugerindo que a introdução da prata provoca uma diminuição da $\mathrm{E}_{\mathrm{g}}\left(\right.$ amostra $\left.\mathrm{B}_{5}\right)$.

$\mathrm{O} \mathrm{n}_{2}$ das amostras da série $A$ é positivo e concorda com a literatura. Inicialmente, para a amostra $A_{2}$ com uma pequena adição de $\operatorname{AgNO}_{3}(0,5 \mathrm{~mol} \%)$, ocorre um aumento do vale que segue até $2 \mathrm{~mol} \%$, em contrapartida com a amostra $A_{5}$ com $5 \mathrm{~mol} \%$, o espectro tornou-se extremamente assimétrico resultando em uma curva com somente um pico, sendo o vale praticamente extinto. Para as amostras $A_{2}, A_{3}$ e $A_{4}$ o modelo de Sheik-Bahae com absorção revelou ser o melhor ajuste, para a amostra $A_{5}$ nenhum dos modelos descritos acima ajustados concordou com os resultados experimentais. A partir destes resultados obtidos cogitamos a possibilidade da coexistência de efeitos térmicos e eletrônicos nestas medidas. Em virtude dos modelos citados não se ajustarem a todos os valores experimentais propomos uma adaptação do modelo de Sumi para explicar a assimetria da curva VZ com a adição de prata.

\subsection{Sumário dos resultados de CDTE}


No presente caso atribuímos a intensidade intrínseca (pico a pico) do CDTE aos NBO's existentes antes da irradiação.

Conclui-se que sob o efeito da irradiação $\gamma$ da amostra $C_{1}$, os seis picos de CDTE cresceram com a dose, à custa dos NBO's radiolizados, mas um outro centro de defeito (provavelmente o $\mathrm{TeEC}^{-}$) não detectado foi também produzido, pois as etapas que se seguiram de tratamento térmico (decorrentes das leituras de CDTE subseqüentes TT-1, TT-2 e TT-3) não foram biunívocas com a recuperação do pico intrínseco.

\subsection{Sumário dos resultados de TL}

A partir dos resultados de TL obtidos concluímos que o processo de recombinação dos centros de defeitos é não radiativo.

O primeiro pico de TL é atribuído possivelmente à recombinação radiativa do centro TeEC- ${ }^{-}$com algum centro de buraco próximo.

Quanto à causa do segundo pico propomos como mais provável a hipótese da recombinação do $\mathrm{TeOHC}$ residual com um elétron capturado por uma armadilha mais profunda, de natureza ainda não conhecida.

O terceiro pico de TL é atribuído aos fenômenos ligados ao processo de sinterização do pó.

\subsection{Sumário dos resultados de RPE}

Quatro respostas paramagnéticas foram detectadas e interpretadas nos vidros teluritos irradiados:

a. Um "ombro" de largura $(\Delta \mathrm{H} \sim 200 \mathrm{G})$ foi localizado em $\mathrm{g} \sim 2,0$, cuja natureza permanece não identificada;

b. Um "ombro" em $\mathrm{g}_{\|}=\mathrm{g}_{1}=2,02 \pm 0,01 \mathrm{com}$ largura $\left(\Delta H_{p p}=1,5 \pm\right.$ 0,5) $G$ com uma "asa" superposta com $g_{2}$ e $g_{3}$ com valor estimado de $\mathrm{g}_{\perp} \sim 2,0$, atribuído ao TeOHC; 
c. Uma linha estreita em $\mathrm{g}_{2}=1,9960 \pm 0,0005$ com largura $\left(\Delta \mathrm{H}_{\mathrm{pp}}=\right.$ $1,5 \pm 0,5) G$ atribuída ao centro $\mathrm{NBOHC}$;

d. Outra linha estreita $g_{3}=1,9700 \pm 0,0005$ com $\left(\Delta H_{p p}=1,9 \pm\right.$ $0,5) G$ devido ao TeEC, respectivamente;

Os vidros teluritos de nióbio irradiados com radiação gamma não apresentam sinal de RPE, indicando a sua excelente resistência à radiação.

$\mathrm{O}$ estudo da evolução das intensidades das ressonâncias em $\mathrm{g}_{1}, \mathrm{~g}_{2} \mathrm{e} \mathrm{g}_{3}$ apresentam boa concordância com o modelo de TeOHC, NBOHC e TeEC proposto neste trabalho.

Nossos resultados de crescimento inicial da intensidade com a radiação e posterior decréscimo indicam uma forte relação entre a concentração de NBOHC e os NBO's nos vidros. Sugerimos que esse processo de decréscimo é devido à quebra das ligações covalentes de NBOHC (e também do NBO) sob a ação da radiólise oriunda da irradiação de alta energia dos raios gamma produzindo um dipolo local $\left[\mathrm{V}_{\mathrm{O}}^{+}, \mathrm{O}^{-}\right]$, o qual também pode recombinar por meio da reação reversa, desde que as concentrações dos defeitos reagentes e a magnitude da constante de equilíbrio sejam favoráveis.

\subsection{Conclusões finais}

Este trabalho buscou a melhor compreensão dos fenômenos físicos e estruturais envolvendo a dinâmica da criação de defeitos intrínsecos durante a fase líquida da preparação de vidros teluritos, bem como a irradiação com raios gama. Foram elaborados modelos para explicar os resultados complementares obtidos utilizando diversas técnicas experimentais. Uma vez identificados os centros detectados por RPE, tornou-se possível interpretar os resultados provenientes das demais técnicas experimentais. Assim, pudemos concluir que com o uso de TL que as recombinações entre os centros já definidos anteriormente são não-radiativas e que os centros radiativos envolvidos em TL não podem ser estas, com exceção do $\mathrm{TeOHC}^{+}$, que não apresentou uma extinção total até a região de $130^{\circ} \mathrm{C}$, onde começa a TL. 
A presença do $1^{\circ}$ pico de TL pode ser explicada com a proposta do modelo do mecanismo de formação do TeEC' (figura 120), no qual foi postulado o aparecimento do centro com 2 elétrons, onde foi considerada a participação do cátion $Z^{2+}$. Já o $3^{\circ}$ pico foi atribuído à ocorrência da sinterização do pó vítreo, à temperatura de $340^{\circ} \mathrm{C}$ e que coincide com uma queda endotérmica em ATD.

Como o elemento formador do vidro telurito é pesado, espera-se que o mesmo apresente fenômenos não lineares, de grande interesse em fotônica. Assim, recorremos à técnica de VZ para proceder as medidas de $\mathrm{n}_{2}$. Para isso, foram necessárias as medidas dos índices de refração linear em três comprimentos de onda.

Como as propriedades físicas não lineares dependem da polarização de dipolos contidos no vidro, foi realizado um estudo com o auxílio da técnica de CDTE, a qual revelou-se sensível à presença dos NBO's no vidro.

A presença de nanopartículas metálicas tem se revelado favorável à produção de vidros que possam favorecer a geração do $2^{\circ}$ harmônico sob a influência da luz laser. Assim, foram produzidas amostras dopadas com prata e que foram submetidas a diversos tratamentos térmicos, com a obtenção da precipitação de nanopartículas, detectadas pela banda de $\mathrm{AO}$ em $\sim 540 \mathrm{~nm}$ e os resultados comparados com a observação direta por TEM.

A precipitação de nanopartículas de prata ocorreu na superfície da amostra e o mecanismo das reações foi explicado com a proposição do $4^{\circ}$ modelo, representado na figura 66, onde um oxigênio de um NBO foi liberado sob a forma do ânion $\mathrm{O}^{2-}$, cujo excesso de elétrons reduziu os íons $\mathrm{Ag}^{+}$dissolvidos no vidro dopado.

\section{Projetos futuros}

1. Novas tentativas de polarizar as amostras termicamente através do forno já construído e por meio da adaptação do equipamento de medidas de despolarização termicamente estimulada para altas temperaturas;

2. Produção de um filme com base nas amostras da série $B$ para a produção de nanopartículas controladas; 
3. Incorporação de terras raras as amostras da série $B$ juntamente com a incorporação de $\mathrm{Ag}_{2} \mathrm{O}$ e $\mathrm{AgNO}_{3}$;

4. Medidas de lente térmica das amostras da série $A$;

5. Medidas de VZ da série $B$.

\section{Anexo 1 - Uma breve revisão, do ponto de vista da eletrodinâmica clássica do comportamento do índice de refração real e complexo}

Quando uma carga é acelerada pela força externa $\vec{F}_{\text {ext }}$, ela perde energia devido à emissão de radiação eletromagnética. A radiação emitida gera um campo de radiação representado por uma força reativa $\overrightarrow{\mathrm{F}}_{\mathrm{r}}$ que descreve a reação do campo de radiação sobre a partícula.

Pela terceira lei de Newton temos:

$$
\mathrm{ma}=\overrightarrow{\mathrm{F}}_{\mathrm{r}}+\overrightarrow{\mathrm{F}}_{\mathrm{ext}}
$$

no qual $\overrightarrow{\mathrm{F}}_{\text {ext }}$ uma força externa.

Considerando que a potência $P$ é dada pela fórmula de Larmor:

$$
\mathrm{P}=\frac{2 \mathrm{e}^{2} \mathrm{a}^{2}}{3 \mathrm{c}^{3}}=\frac{2 \mathrm{e}^{2} \dot{\mathrm{v}}^{2}}{3 \mathrm{c}^{3}}=\overrightarrow{\mathrm{F}}_{\mathrm{r}} \cdot \overrightarrow{\mathrm{v}}
$$

onde " $\mathrm{v"}$ a velocidade da partícula.

Integrando a potência de reação em pequeno intervalo de tempo e considerando que o movimento é periódico, temos:

$$
\int_{t_{1}}^{t_{2}} \vec{F} \cdot \vec{v} d t=-\frac{2 e^{2}}{3 c^{3}} \int_{t_{1}}^{t_{2}} \vec{v} \cdot \vec{v} d t
$$

Desprezando o primeiro termo da integração por partes, chegamos à expressão:

$$
\int_{t_{1}}^{t_{2}}\left(\vec{F}_{r}-\frac{2 e^{2}}{3 c^{3}} \ddot{\vec{v}}\right) \cdot \vec{v} d t=0
$$

donde podemos avaliar a força da reação:

$$
\overrightarrow{\mathrm{F}}_{\mathrm{r}}=\frac{2 \mathrm{e}^{2}}{3 \mathrm{c}^{3}} \ddot{\overrightarrow{\mathrm{v}}} .
$$


Considerando ser fisicamente aceitável a hipótese que $\left|\vec{F}_{\mathrm{r}}\right| \ll\left|\overrightarrow{\mathrm{F}}_{\text {ext }}\right|$ e introduzindo o tempo característico:

$$
\tau_{c}=\frac{2 \mathrm{e}^{2}}{3 \mathrm{mc}^{3}}
$$

podemos reescrever a equação (A.1.1) sob a forma:

$$
\mathrm{m}\left(\dot{\overrightarrow{\mathrm{v}}}-\tau_{c} \ddot{\overrightarrow{\mathrm{v}}}\right)=\overrightarrow{\mathrm{F}}_{\text {ext }}
$$

Considerando um elétron ligado por uma força harmônica

$$
\overrightarrow{\mathrm{F}}=-\mathrm{k}_{\mathrm{m}} \overrightarrow{\mathrm{r}}
$$

em que $\omega_{0}=\sqrt{\frac{\mathrm{k}_{\mathrm{m}}}{\mathrm{m}}}$

$\omega_{0}$ é a freqüência de ressonância e $\mathrm{k}_{\mathrm{m}}$ coeficiente de restituição, substituindo a equação (A.1.9) e (A.1.8) na equação (A.1.7), utilizando a aproximação $\dddot{\vec{r}} \cong-\omega_{0}{ }^{2} \dot{\vec{r}}$, temos:

$$
\ddot{\vec{r}}+\dot{\vec{r}}+\omega_{0}^{2} \vec{r}=0
$$

onde $\gamma \equiv \tau_{c} \omega_{0}{ }^{2}$.

Agora vamos considerar que este elétron ligado harmonicamente é forçado a oscilar sob a ação da componente elétrica da onda eletromagnética externa. A teoria de espalhamento e dispersão de luz baseia-se nesta consideração.

Vamos supor que a velocidade do elétron é não-relativística e desta forma desprezar o efeito do campo magnético da radiação incidente, para o tratamento das freqüências óticas.

A força que age sobre um elétron é:

$$
\vec{F}=-e \vec{E}
$$

onde $\vec{E}=\vec{E}_{0} e^{-i \omega t}$

A equação do movimento de um elétron ligado num campo elétrico é:

$$
\ddot{\vec{r}}-\tau_{c} \dddot{\vec{r}}+\omega_{0}{ }^{2} \vec{r}=-\frac{e}{m} \vec{E}_{0} e^{-i \omega t}
$$

Utilizando a aproximação $\dddot{\vec{r}}=-\omega^{2} \dot{\vec{r}}$ na equação (A.1.14), temos:

$$
\ddot{\vec{r}}+\tau_{c} \omega^{2} \dot{\vec{r}}+\omega_{0}{ }^{2} \vec{r}=-\frac{e}{m} \vec{E}_{0} e^{-i \omega t}
$$


Para levar em conta outros processos dissipativos, além da reação da radiação, incluiremos o termo resistivo $\Gamma^{\prime} \dot{\vec{r}}$, onde:

$$
\Gamma=\Gamma^{\prime}+\tau_{c} \omega^{2}
$$

na equação (A.1.15):

$$
\ddot{\vec{r}}+\Gamma \dot{\vec{r}}+\omega_{0}^{2} \vec{r}=-\frac{e}{m} \vec{E}_{0} e^{-i \omega t}
$$

Isolando $\vec{r}$ temos:

$$
\vec{r}=-\frac{e}{m} \frac{E_{0} e^{-i \omega t}}{\left(\omega_{0}{ }^{2}-\omega^{2}-i \omega \Gamma\right)}
$$

Para obter a parte real e imaginária do índice de refração e analisar seu comportamento em relação à freqüência, para o caso simplificado de meios rarefeitos, vamos estudar o problema da dispersão de ondas eletromagnéticas.

Considerando que a onda incida sobre $\mathrm{N}$ elétrons por unidade de volume, cada um deles irá espalhar uma onda plana incidente de acordo com a seção de choque para o espalhamento por um elétron ligado, dado pela equação:

$$
\sigma_{e}=\frac{8 \pi}{3} r_{0}^{2} \frac{\omega^{2}}{\left(\omega^{2}-\omega_{0}^{2}\right)^{2}+\Gamma^{2} \omega^{2}} .
$$

Esta radiação espalhada, em geral, irá se combinar com o campo externo modificando a velocidade efetiva da onda. Para resolver este problema é possível obter o efeito de vários centros espalhadores pela superposição das ondas individuais. Para o estudo da dispersão é mais conveniente tratar a re-irradiação como sendo um efeito coletivo da polarização elétrica do material.

A polarização induzida de um dado material relaciona-se com o deslocamento de elétrons por:

$$
\vec{P}=-N e \vec{r},
$$

onde o índice de refração $\mathrm{n}$, para $\mu=1$ é:

$$
n=\sqrt{\varepsilon} \text {. }
$$

Sendo $\varepsilon=\frac{4 \pi P}{E}+1$.

Substituindo a equação (A.1.22) na equação (A.1.21), temos:

$$
n=\left(1+\frac{4 \pi P}{E}\right)^{\frac{1}{2}} \text {. }
$$


Utilizando o Binômio de Newton para a equação (A.1.23) e mantendo apenas os dois primeiros termos da expansão binomial, temos:

$$
n=\left(1+\frac{2 \pi P}{E}\right)
$$

Considerando meios rarefeitos, onde $\mathrm{n}$ não difere da unidade e substituindo as equações (A.1.20) e (A.1.18) na equação (A.1.24), temos aproximadamente:

$$
n \cong 1+\frac{2 \pi N e^{2}}{m} \frac{1}{\omega_{0}{ }^{2}-\omega^{2}-i \Gamma \omega} .
$$

A parte real $(\operatorname{Re}(n))$ e a imaginária $(\operatorname{Im}(n))$ são, portanto, iguais a:

$$
\begin{array}{r}
\operatorname{Re}(n)=1+\frac{2 \pi N e^{2}}{m}\left[\frac{\left(\omega_{0}{ }^{2}-\omega^{2}\right)}{\left(\omega_{0}{ }^{2}-\omega^{2}\right)^{2}+\Gamma^{2} \omega^{2}}\right] \\
\text { e } \quad \operatorname{Im}(n)=\frac{2 \pi N e^{2}}{m}\left[\frac{\Gamma \omega}{\left(\omega_{0}{ }^{2}-\omega^{2}\right)^{2}+\Gamma^{2} \omega^{2}}\right] .
\end{array}
$$

\section{Anexo 2 - Absorção óptica do fundo da banda de condução}

\section{A.2.1 Transições diretas}

De acordo com o teorema de Van Hove, a expressão da densidade de estados $N(E)$ na proximidade do fundo da banda de condução é dada por [1]

$$
\begin{aligned}
& N(E)=\frac{\left(2 m^{*}\right)^{\frac{3}{2}} \sqrt{E}}{2 \pi^{2} \hbar^{3}}=C_{0} \sqrt{E}, \\
& E=h v-E_{g} \\
& C_{0}=\frac{\left(2 m^{*}\right)^{\frac{3}{2}}}{2 \pi^{2} h^{3}}
\end{aligned}
$$

onde E é a energia medida a partir do topo da banda de valência e $\mathrm{m}^{*}$ a massa reduzida do elétron.

A equação A.2.1.1 é válida para os estados estendidos da banda de condução, onde a energia absorvida é maior ou igual a uma energia crítica que vamos designar como região I ( $\mathrm{h} v \geq \mathrm{E}_{\mathrm{cr}}$ ), onde a absorção óptica, proporcional a $\mathrm{N}(\mathrm{E})$, é dada por 


$$
\alpha_{\mathrm{I}}=\mathrm{C}\left(\mathrm{h} v-\mathrm{E}_{\mathrm{g}}\right)^{\frac{1}{2}}
$$

Para os vidros e outras substâncias sólidas não cristalinas, aparece uma cauda exponencial, conhecida como a cauda de Urbach, que domina a região II de estados localizados com energia menor do que $E_{r}$, onde a absorção óptica é descrita pela equação

$$
\alpha_{\mathrm{II}}=\mathrm{A}^{\frac{\mathrm{h} v}{\Delta \mathrm{E}}}
$$

em que A é uma constante e $\Delta E$ é a energia de Urbach.

Esta equação também é expressa em função da temperatura sob a forma

$$
\alpha_{\mathrm{II}}=\alpha_{\mathrm{g}} \mathrm{e}^{-\frac{\gamma^{\prime}\left(\mathrm{E}_{\mathrm{g}}-\mathrm{h} v\right)}{\mathrm{KT}}}, \quad\left(\mathrm{h} v \leq \mathrm{E}_{\mathrm{cr}}\right)
$$

em que $\alpha_{\mathrm{g}}$ é a absorção óptica no limite entre as regiões I e II, k é a constante de Boltzmann e

$$
\gamma^{\prime}=\frac{\mathrm{kT}}{\Delta \mathrm{E}}
$$

Assumindo que o coeficiente de absorção óptica é uma função contínua e lisa no limite entre as regiões I e II, valem as propriedades

$$
\alpha_{\mathrm{I}}(\mathrm{h} v)=\alpha_{\mathrm{II}}(\mathrm{h} v)
$$

e

$$
\frac{\mathrm{d}}{\mathrm{d}(\mathrm{h} v)} \alpha_{\mathrm{I}}(\mathrm{h} v)=\frac{\mathrm{d}}{\mathrm{d}(\mathrm{h} v)} \alpha_{\mathrm{II}}(\mathrm{h} v), \quad\left(\mathrm{h} v=\mathrm{E}_{\mathrm{cr}}\right) .
$$

Efetuando as operações algébricas, obtemos:

$$
h v_{\mathrm{cr}}=\frac{\mathrm{KT}}{2 \sigma}+\mathrm{E}_{\mathrm{g}},
$$

em que $\sigma=\gamma^{\prime} \mathrm{C}$

e $v_{\text {cr }}$ é a freqüência crítica, de onde foram calculadas as relações abaixo

$$
\begin{aligned}
\mathrm{C} & =\frac{\alpha_{\mathrm{g}}}{\sqrt{\mathrm{e}}} \sqrt{\frac{2 \sigma}{\mathrm{KT}}} \\
\mathrm{e} \quad \gamma^{\prime} & =\frac{\sqrt{\mathrm{e}}}{\alpha_{\mathrm{g}}} \sqrt{\frac{\sigma \mathrm{KT}}{2}}, \quad\left(\mathrm{~h} v=\mathrm{E}_{\mathrm{cr}}\right) .
\end{aligned}
$$

Assim, a equação A.2.1.4 pode ser escrita como 


$$
\alpha_{\mathrm{I}}=\frac{\alpha_{\mathrm{g}}}{\sqrt{\mathrm{e}}} \sqrt{\frac{2 \sigma}{\mathrm{KT}}}\left(\mathrm{h} \nu-\mathrm{E}_{\mathrm{g}}\right)^{\frac{1}{2}}, \quad\left(\mathrm{~h} \nu \geq \mathrm{E}_{\mathrm{cr}}\right)
$$

e a expressão A.2.1.6 pode ser, analogamente,

$$
\alpha_{\mathrm{II}}=\alpha_{\mathrm{g}} \exp \left\{-\frac{\sqrt{\mathrm{e}}}{\alpha_{\mathrm{g}}} \sqrt{\frac{\sigma}{2 \mathrm{KT}}}\left(\mathrm{E}_{\mathrm{g}}-\mathrm{h} v\right)\right\} \quad\left(\mathrm{h} v \leq \mathrm{E}_{\mathrm{cr}}\right) .
$$

Substituindo $\mathrm{h} v=\mathrm{E}_{\mathrm{g}}+1$ na expressão A.2.1.4 temos:

$$
\alpha_{\left(E_{g}+1\right)}=C \text {. }
$$

Assim, podemos expressar o comportamento da absorção óptica sob a forma:

$$
\text { Região I: } \quad \alpha_{\mathrm{I}}(\mathrm{h} v)=\alpha_{\left(\mathrm{E}_{\mathrm{g}}+1\right)}\left(\mathrm{h} v-\mathrm{E}_{\mathrm{g}}\right)^{\frac{1}{2}}, \quad\left(\mathrm{~h} v \geq \mathrm{E}_{\mathrm{cr}}\right)
$$

$$
\text { Região II: } \quad \alpha_{\mathrm{II}}(\mathrm{h} v)=\alpha_{\left(\mathrm{E}_{\mathrm{g}}\right)} \mathrm{e}^{-\frac{\gamma^{\prime}(\mathrm{Eg}-\mathrm{h} v)}{\mathrm{KT}}}, \quad\left(\mathrm{h} v \leq \mathrm{E}_{\mathrm{cr}}\right)
$$

$$
\text { ou } \quad \alpha_{\text {II }}(h v)=A e^{\frac{h v}{\Delta E}}
$$

em que

$$
A=\alpha_{\left(E_{g}\right)} e^{-\frac{\gamma^{\prime} E_{g}}{K T}} .
$$

Este resultado é válido para o caso particular no qual as transições da banda de valência para a região I são diretas. Vamos discutir a seguir, o caso mais geral em que o expoente de $\alpha_{\mathrm{I}}$, igual a $\frac{1}{2}$ é substituído por um valor $\mathrm{n} \neq \frac{1}{2}$.

\section{A.2.1 Referências}

[1] Ziman, J. M. Principles of the theory of solids. Cambridge at the University Press, Cambridge, 1964.

\section{A.2.2 Transições indiretas}

Vamos, agora, considerar o caso mais geral em que a absorção óptica na região I é expressa por

$$
\alpha_{\mathrm{I}}(\mathrm{h} v)=\mathrm{C}\left(\mathrm{h} v-\mathrm{E}_{\mathrm{g}}\right)^{\mathrm{n}}, \quad\left(\mathrm{h} v \geq \mathrm{E}_{\mathrm{cr}}\right)
$$

e completar o sistema com a equação A.2.1.6. Aplicando a condição de continuidade de $\alpha_{\mathrm{I}}, \alpha_{\mathrm{II}}$ e das respectivas derivadas em $\mathrm{E}=\mathrm{E}_{\mathrm{cr}}$, obtemos 


$$
\begin{aligned}
\mathrm{E}_{\mathrm{cr}} & =\mathrm{E}_{\mathrm{g}}+\mathrm{n} \Delta \mathrm{E} \\
\mathrm{e} \quad \frac{\alpha_{\mathrm{g}}}{\mathrm{C}} & =\left(\frac{\mathrm{n} \Delta \mathrm{E}}{\mathrm{e}}\right)^{\mathrm{n}} .
\end{aligned}
$$

Sendo C uma constante a determinar, temos o sistema

$$
\begin{aligned}
\alpha_{\mathrm{I}}(\mathrm{h} v) & =\mathrm{C}\left(\mathrm{h} v-\mathrm{E}_{\mathrm{g}}\right)^{\mathrm{n}}, & & \left(\mathrm{h} v \geq \mathrm{E}_{\mathrm{cr}}\right) \\
\text { e } \quad \alpha_{\mathrm{II}}(\mathrm{h} v) & =\mathrm{C}\left(\frac{\mathrm{n} \Delta \mathrm{E}}{\mathrm{e}}\right)^{\mathrm{n}} \mathrm{e}^{\frac{1}{\Delta \mathrm{E}}\left(\mathrm{h} v-\mathrm{E}_{\mathrm{g}}\right),} & & \left(\mathrm{h} v \leq \mathrm{E}_{\mathrm{cr}}\right) \\
\text { em que } \alpha_{\mathrm{E}_{\mathrm{cr}}} & =\mathrm{C}\left(\frac{\mathrm{n} \Delta \mathrm{E}}{\mathrm{e}}\right)^{\mathrm{n}}, & &
\end{aligned}
$$

de modo que obtemos, finalmente,

$$
\begin{array}{ll}
\alpha_{I}(h v)=\frac{\alpha_{E_{c r}}}{\left(\frac{n \Delta E}{e}\right)^{n}}\left(h v-E_{g}\right)^{n}, & \left(h v \geq E_{c r}\right) \\
\alpha_{I I}(h v)=\alpha_{E_{c r}} e^{-\frac{1}{\Delta E}\left(E_{c r}-h v\right)}, & \left(h v \leq E_{c r}\right) .
\end{array}
$$

\section{Anexo 3 - Relações entre $n_{2}$ e $\chi^{(3)}$ em diferentes unidades}

A relação numérica entre a susceptibilidade $\chi^{(3)}$ e $\mathrm{n}_{2}$ depende de diversos fatores: a) se $\mathrm{n}_{2}$ é definido em termos do quadrado da amplitude do campo elétrico ou intensidade; b) se um fator $\frac{1}{2}$ é incluído ou não nas definições de amplitude de campo e ainda mais um outro fator $\frac{1}{2}$ na definição de $\mathrm{n}_{2}$; c) se o fator $\mathrm{T}$ é incorporado na definição da susceptibilidade e d) qual sistema de unidades está sendo utilizado. Então existem pelo menos $2^{5}$ relações que podem ser utilizadas, causando uma fonte contínua de discrepância e de confusão. Algumas relações são dadas por Gibbs [1].

A definição do $\mathrm{n}_{2}$ em unidades SI é:

$$
\mathrm{n}_{\mathrm{t}}(\omega)=\mathrm{n}(\omega)+\delta \mathrm{n}_{\mathrm{t}}(\omega)=\mathrm{n}_{0}(\omega)+\mathrm{n}_{2}(\omega)\left|\mathrm{E}_{\mathrm{c}}\right|^{2},
$$

no qual o campo elétrico é dado por:

$$
\overrightarrow{E_{c}}=\frac{1}{2}\left[E \mathbf{e} \mathrm{e}^{-\mathrm{i} \omega \mathrm{t}}+\mathrm{E}^{*} \mathbf{e}^{*} \mathrm{e}^{\mathrm{i} \omega \mathrm{t}}\right] .
$$


A polarização total em $\omega$ é de amplitude $P$, dada por:

$$
\overleftrightarrow{\mathrm{P}}_{\omega}(\mathrm{t}) \simeq \overleftrightarrow{\mathrm{P}}_{\omega}^{(1)}(\mathrm{t})+\overleftrightarrow{\mathrm{P}}_{\omega}^{(3)}(\mathrm{t})=
$$

$\varepsilon_{0}\left[\overleftrightarrow{\chi}^{(1)}(-\omega ; \omega)+\frac{3}{4} \overleftrightarrow{\chi}^{(3)}(-\omega ; \omega,-\omega, \omega)\left|\overrightarrow{\mathrm{E}}_{\omega}(\mathrm{t}) \overrightarrow{\mathrm{E}}_{\omega}^{*}(\mathrm{t})\right|\right] \overrightarrow{\mathrm{E}}_{\omega}(\mathrm{t})$

em que o fator $\mathrm{T}(-\omega ; \omega,-\omega, \omega)=\frac{3}{4}$. A expressão que relaciona $\mathrm{n}_{2}$ e $\chi^{(3)}$ em unidades SI é dada por:

$$
\mathrm{n}_{2}=\frac{3 \operatorname{Re} \chi^{(3)}(-\omega ; \omega,-\omega, \omega)}{8 \mathrm{n}_{0}}
$$

em que a unidade de $n_{2}$ é a mesma de $\chi^{(3)}$ dada em $\frac{m^{2}}{V^{2}}$. Assim como $n_{t}(\omega)$ e $\mathrm{n}(\omega), \delta \mathrm{n}_{\mathrm{t}}(\omega)$ é adimensional, de modo que as dimensões de $\mathrm{n}_{2}(\omega)$ e $\left|\mathrm{E}_{\mathrm{c}}\right|^{2}$ são complementares, isto é, $\left[\mathrm{E}_{\mathrm{c}}{ }^{2}\right]=\left[\frac{\mathrm{V}^{2}}{\mathrm{~m}^{2}}\right]$ e $\left[\mathrm{n}_{2}(\omega)\right]=\left[\frac{\mathrm{m}^{2}}{\mathrm{~V}^{2}}\right]$. De acordo com a equação (A.3.4) segue-se a dimensão de $\chi^{(3)}$ é a mesma de $\mathrm{n}_{2}$, ou seja, $\left[\chi^{(3)}\right]=\left[\frac{\mathrm{m}^{2}}{\mathrm{~V}^{2}}\right]$.

Segue-se uma definição alternativa do coeficiente de refração não linear, em unidades $\mathrm{SI}$, em termos da intensidade $\mathrm{I}_{\omega}$ :

$$
\mathrm{n}_{\mathrm{t}}=\mathrm{n}+\mathrm{n}_{2}^{\mathrm{I}} \mathrm{I}_{\omega}
$$

e

$$
\mathrm{I}_{\omega}=\frac{1}{2} \varepsilon_{0} \mathrm{cn}|\overrightarrow{\mathrm{E}}|^{2}
$$

substituindo a equação (A.3.7) na equação (A.3.6) e comparando com a equação (A.3.1), temos:

$$
\mathrm{n}_{2}\left(\frac{\mathrm{m}^{2}}{\mathrm{~V}^{2}}\right)=\frac{{ }^{\mathrm{n}}\left(\frac{\mathrm{m}^{2}}{\mathrm{~W}}\right) \varepsilon_{0} \mathrm{cn}}{2} .
$$

Como exemplo, calcularemos a transformação de unidades SI para unidades esu da amostra $A_{3}$ (através de SBSA), substituindo os respectivos dados na equação (A.1.8):

$$
\mathrm{n}_{2}=\frac{3,11 \times 10^{-16} \frac{\mathrm{m}^{2}}{\mathrm{Nm} \cdot \mathrm{s}^{-1}} 3 \times 10^{8} \frac{\mathrm{m}}{\mathrm{s}} \quad 2,20888,85 \times 10^{-12} \frac{\mathrm{C}^{2}}{\mathrm{Nm}^{2}}}{2}
$$

sabendo que $\mathrm{C}=\frac{\mathrm{J}}{\mathrm{V}} \mathrm{e} \mathrm{J}=\mathrm{Nm}$, temos: 


$$
\mathrm{n}_{2}=9,12 \times 10^{-19} \frac{\mathrm{m}^{2}}{\mathrm{v}^{2}}
$$

Para concretizar a transformação de unidades é necessário lembrar que esu $=\frac{\mathrm{cm}^{2}}{\text { Stat } \mathrm{V}^{2}}$ e que 1 Stat $\mathrm{V} \cong 300 \mathrm{~V}$, de forma que (A.3.10) será expressa sob a forma

$$
\mathrm{n}_{2}=8,21 \times 10^{-10} \frac{\mathrm{cm}^{2}}{\text { Stat }^{2}}
$$

A expressão geral que deve ser utilizada nesta transformação é dada pela equação:

$$
\mathrm{n}_{2}(\mathrm{esu})=\frac{{ }^{\mathrm{n}}\left(\frac{\mathrm{m}^{2}}{\mathrm{w}}\right) \mathrm{n}}{8,4 \times 10^{-7}}
$$

A polarização, o índice de refração linear e a constante dielétrica são dadas respectivamente, pelas equações abaixo, em unidades esu:

$$
\begin{aligned}
& \overrightarrow{\mathrm{P}}=\frac{(\varepsilon-1) \overrightarrow{\mathrm{E}}}{4 \pi}, \\
& \mathrm{n}=\sqrt{1+4 \pi \operatorname{Re} \chi_{\mathrm{esu}}^{(3)}(-\omega ; \omega)} \\
& \varepsilon=1+\left.4 \pi\left|\chi_{\mathrm{esu}}^{(1)}(-\omega ; \omega)+\frac{3}{4} \chi_{\mathrm{esu}}^{(3)}(-\omega ; \omega,-\omega, \omega)\right| \mathrm{E}\right|^{2} \mid .
\end{aligned}
$$

A expressão geral que relaciona o $\mathrm{n}_{2}$ e o $\chi^{(3)}$ em unidades esu é dada pela expressão:

$$
\mathrm{n}_{2}(\mathrm{esu})=\frac{3 \pi \operatorname{Re} \chi_{\operatorname{esu}}^{(3)}(-\omega ; \omega,-\omega, \omega)}{2 \mathrm{n}} .
$$

A relação entre os coeficientes de diferentes unidades $\mathrm{n}_{2}^{\mathrm{I}}\left(\frac{\mathrm{m}^{2}}{\mathrm{~W}}\right)$ e $\chi_{e s u}^{(3)}$ é:

$$
\mathrm{n}_{2}^{\mathrm{I}}\left(\frac{\mathrm{m}^{2}}{\mathrm{~W}}\right)=\frac{3,9 \times 10^{-6} \operatorname{Re}_{\mathrm{esu}}^{(3)}(-\omega ; \omega,-\omega, \omega)}{\mathrm{n}^{2}}
$$

$$
\text { ou } \quad \mathrm{n}_{2}(\mathrm{esu})=1,195 \times 10^{6} \cdot \mathrm{n} \mathrm{n}_{2}^{\mathrm{I}}\left(\frac{\mathrm{m}^{2}}{\mathrm{~W}}\right) \text {. }
$$

Alguns autores [2], [3] utilizam a expressão (A.3.19)

$$
\mathrm{n}_{\mathrm{t}}=\mathrm{n}+\mathrm{n}_{2}\langle\overrightarrow{\mathrm{E}} \cdot \overrightarrow{\mathrm{E}}\rangle=\mathrm{n}+\frac{1}{2} \mathrm{n}_{2}|\overrightarrow{\mathrm{E}}|^{2}
$$

ao invés da expressão (A.1.1) e a expressão: 


$$
\mathrm{n}_{\mathrm{t}}=\mathrm{n}+\mathrm{n}_{2}(\mathrm{esu})|\overrightarrow{\mathrm{E}}|^{2},
$$

introduzindo um fator adicional 2 em todos os sistemas de unidades.

\section{A.3.1 Referências}

[1] Gibbs, H. M. Optical Bistability: Controlling Light with Light. Orlando: Academic Press, 1985.

[2] Sheik-Bahae, M.; Said, A. A.; Wei, T. H.; Van Stryland, E. W. Sensitive measurement of optical nonlinearities using a single beam. J. Quantum Electron., v. 26, p. 760-769, 1990.

[3] Vogel, E. M.; Weber, M. J.; Krol, D. M. Nonlinear optical phenomena in glass. Phys. Chem. Of Glasses, v. 32, p. 231-254, 1991.

\section{Anexo 4 Artigos publicados}

Giehl, J.M. ; Pontuschka, W.M. ; Barbosa, L.C. ; Ludwig, Z.M.C. . EPR of Y-induced paramagnetic centers in tellurite glasses. Journal of Non-Crystalline Solids, v. 356, p. 1762-1767, 2010.

Giehl, J. M.; Pontuschka, W. M.; Barbosa, L. C.; Blak, A. R.; Navarro, M.; Da Costa, Z. M. Study of sodium tellurite glass using the thermally stimulated depolarization current technique (TSDC). Journal of Non-Crystalline Solids, v. 357, p. 1582-1586, 2011. 